\title{
ÍNDICE PARA SELEÇÃO DE LINHAGENS ENDOGÂMICAS DE MILHO (Zea mays L.) VISANDO POPULAÇÕES SINTÉTICAS BASEADO EM MARCADORES GENÉTICOS
}

\section{GLAUCE CRISTINA RICARDO RUMIN}

Engenheira Agrônoma

Orientador: Prof. Dr. ROLAND VENCOVSKY

\begin{abstract}
Dissertação apresentada à Escola Superior de Agricultura "Luiz de Queiroz", Universidade de São Paulo, para obtenção do título de Mestre em Agronomia, Área de Concentração: Genética e Melhoramento de Plantas.
\end{abstract}

PIRACICABA

Estado de São Paulo - Brasil

Março - 2000 


\section{ERRATA}

GLAUCE CRISTINA RICARDO RUMIN. Índice para a seleção de linhagens endogâmicas de milho (Zea mays L.) visando populações sintéticas baseado em marcadores genéticos

\begin{tabular}{|c|c|c|c|c|}
\hline p. & item & linha & onde se lê & leia-se \\
\hline 20 & 2.3 .1 & décima primeira & ... populações segregantes. & $\begin{array}{l}\text {... populações segregantes } \\
\text { quaisquer. }\end{array}$ \\
\hline 22 & 2.3 .1 & vigésima & Jansen et al. (1994) & Jansen et al. (1995) \\
\hline 29 & 3.2 .1 & décima & das & $\mathrm{da}$ \\
\hline 30 & 3.2 .1 .2 & vigésima & indivíduos homozigóticos & locos homozigóticos \\
\hline 31 & 3.2.1.2 & primeira & indivíduos homozigóticos & locos homozigóticos \\
\hline 31 & 3.2 .1 .2 & quarta e quinta & $\begin{array}{l}\ldots A_{1} \text { e } A_{2} \text {, e adotando a convenção } \\
A_{1} \text { para o alelo associados a genes } \\
\text { que aumentam o valor da } \\
\text { característica, o desvio genotípico... }\end{array}$ & $\ldots \mathrm{A}_{1}$ e $\mathrm{A}_{2}$, o desvio genotípico... \\
\hline 31 & 3.2 .1 .2 & décima oitava & $6,7,8,9,10,11,12,13,14$ e 15 & $5,6,7,8,9,10,11,12,13$ e 14 \\
\hline 32 & 3.2 .1 .2 & segunda & tabela 16 & tabela 15 \\
\hline 33 & 3.2 .1 .3 & quarta & $\ldots$ respectivamente. O segundo $\ldots$ & $\begin{array}{l}\text {.. respectivamente. Essa seleção } \\
\text { inicial por cromossomo foi } \\
\text { necessária devido à presença de } \\
\text { um número maior de variáveis } x \\
\text { que y, ou seja, de um número } \\
\text { maior de marcas do que de } \\
\text { progênies. O segundo ... }\end{array}$ \\
\hline 33 & 3.2 .1 .3 & décima terceira & $X_{i}$ & $\mathrm{x}_{\mathrm{i}}$ \\
\hline 33 & 3.2 .1 .3 & décima nona & $X_{\mathrm{ij}}$ & $\mathrm{x}_{\mathrm{ij}}$ \\
\hline 33 & 3.2 .1 .3 & vigésima & $X_{\mathrm{ij}}$ & $\mathrm{x}_{\mathrm{ij}}$ \\
\hline 34 & 3.2.1.3 & segunda & homozigótica nesse loco & Heterozigótica nesse loco \\
\hline 45 & 4.1 & oitava & $5,19 * *$ & $3,57 * *$ \\
\hline 47 & 4.2 & segunda e quinta & sondas & marcas \\
\hline 47 & 4.3 & décima & sondas & Marcas \\
\hline 47 & 4.3 & décima quinta & valor genotípico & efeito genotípico \\
\hline 48 & 4.3 & $\begin{array}{l}\text { terceira e décima } \\
\text { nona }\end{array}$ & valor genotípico & efeito genotípico \\
\hline 49 & 4.3 & terceira & valor genotípico & efeito genotípico \\
\hline 50 & 4.3 & terceira & valor genotípico & efeito genotípico \\
\hline 50 & 4.3 & vigésima quinta & sonda & marca \\
\hline 50 & 4.3 & $\begin{array}{l}\text { vigésima sexta e } \\
\text { trigésima } \\
\text { primeira }\end{array}$ & sondas & marcas \\
\hline 51 & 4.3 & $\begin{array}{l}\text { segunda, terceira, } \\
\text { quarta e sexta }\end{array}$ & sondas & marcas \\
\hline 51 & 4.4 & vigésima quarta & $8.228,7$ & $9.228,7$ \\
\hline 52 & 4.5 .1 & décima quinta & ... o comportamento ... & ... função do comportamento ... \\
\hline 53 & 4.5.1 & primeira & $X_{j}$ & $\mathrm{x}_{\mathrm{j}}$ \\
\hline 56 & 4.5 .3 & quinta & sondas & marcas \\
\hline 80 & 4.6 & vigésima primeira & 323,45 & 232,45 \\
\hline 81 & 4.6 & primeira & sondas & marcas \\
\hline 82 & 4.6 & décima primeira & 0,90 & 0,09 \\
\hline 83 & 4.6 & primeira & linhagens), ... & 68 linhagens), ... \\
\hline
\end{tabular}


Dados Internacionais de Catalogaçāo na Publicaçāo (CIP) DIVISĀO DE BIBLIOTECA E DOCUMENTAÇĀO - Campus "Luiz de Oueiroz"/USP

\author{
Rumin, Glauce Cristina Ricardo \\ Índice para seleção de linhagens endogâmicas de milho (Zea mays $L$.) visando \\ populações sintéticas baseado em marcadores genéticos / Glauce Cristina Ricardo \\ Rumin. - - Piracicaba, 2000. \\ $201 \mathrm{p}$. \\ Dissertação (mestrado) - - Escola Superior de Agricultura Luiz de Queiroz, 2000. \\ Bibliografia. \\ 1. Cruzamento vegetal 2. Diversidade genética 3. Endogamia 4. Linhagem vegetal \\ 5. Marcador genético 6. Milho 7. População de planta I. Título
}

CDD 633.15

"Permitida a cópia total ou parcial deste documento, desde que citada a fonte - $\mathrm{O}$ autor" 
Dedico este trabalho ao Prof. Dr. Roland Vencovsky, pela dedicação demonstrada para que atingíssemos os objetivos traçados inicialmente, bem como pelas inúmeras demonstrações de amizade e consideração. Mais que um orientador, o professor Vencovsky foi sempre um companheiro de trabalho. 


\section{AGRADECIMENTOS}

Ao Prof. Dr. Roland Vencovsky, pela orientação eficiente que muito contribuiu para o meu amadurecimento profissional ao longo desses anos de convivência.

Ao Dr. Fernando Ajudarte Neto, Gerente de Pesquisas e Desenvolvimento da E.B.S. Empresa Brasileira de Sementes Ltda / Grupo Zeneca, pela oportunidade de realizar este trabalho e também pelo apoio no decorrer do curso.

Aos professores e funcionários do Departamento de Genética da ESALQ.

Aos amigos do Curso de Pós-Graduação, em especial a Alexandre S. G. Coelho e Heider D. Silva que colaboraram na elaboração deste trabalho, a Fernando S. T. Miranda, companheiro de trabalhos e de estudos e também aos colegas da Zeneca Sementes que ajudaram na correção dos originais com suas sugestões.

Ao CNPQ, pelo auxilio financeiro. 


\section{SUMÁRIO}

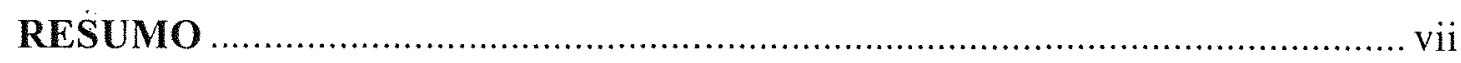

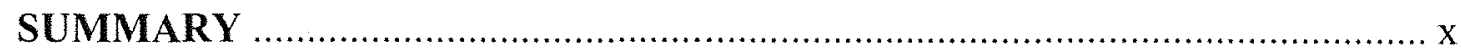

1. INTRODUÇÃ

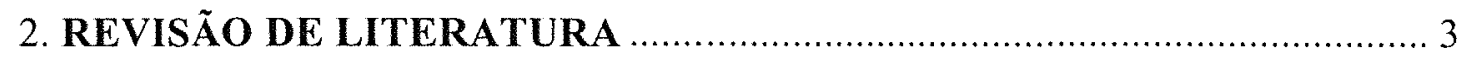

2.1.Quantificação da diversidade genética .............................................................. 3

2.2.Predição do desempenho de híbridos simples...................................................... 7

2.3.Seleção assistida por marcadores moleculares................................................... 12

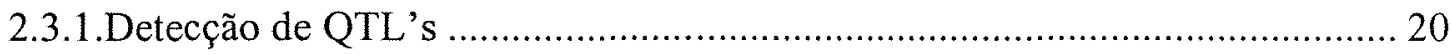

3. MATERIAL E MÉTODOS …………… 28

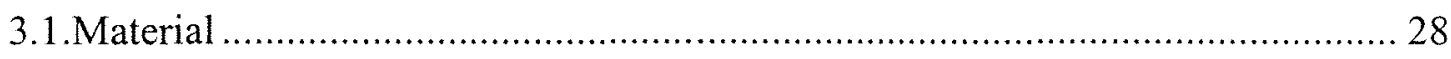

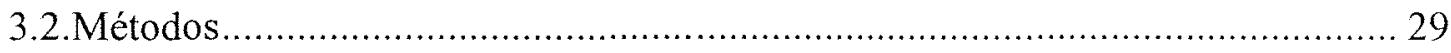

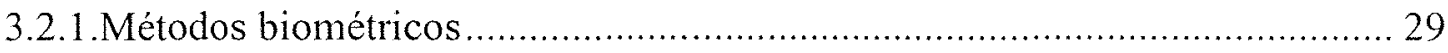

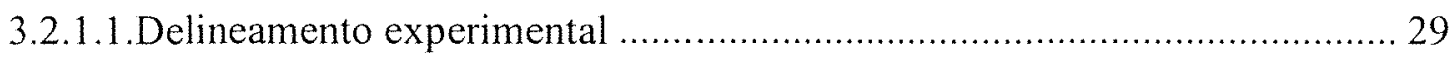

3.2.1.2. Determinação dos alelos favoráveis associados às marcas ......................... 30

3.2.1.3.Deteç̧ão das marcas com efeitos significativos ........................................ 32

3.2.1.4.Determinação da variância genética atribuída aos marcadores.................... 34

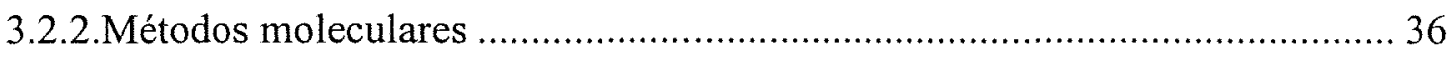

3.2.2.1.Genotipagem das plantas-mãe das linhagens ......................................... 36

3.2.2.2.Distribuição das marcas pelo genoma ........................................................ 37

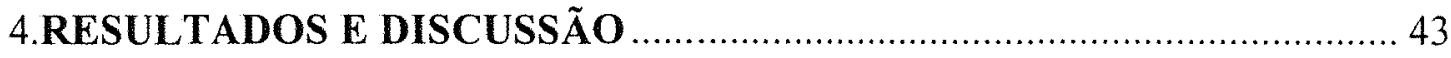

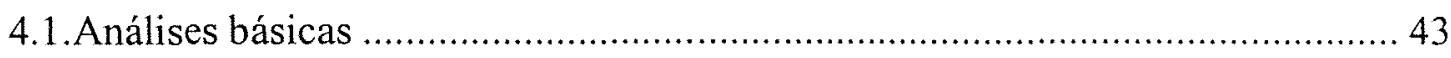

4.2.Cobertura do genoma pelas marcas utilizadas ............................................... 46

4.3.Deteç̧ão das marcas de efeito significativo .................................................. 47 
4.4. Cálculo de $\hat{p}$ para as marcas escolhidas.....................................................51

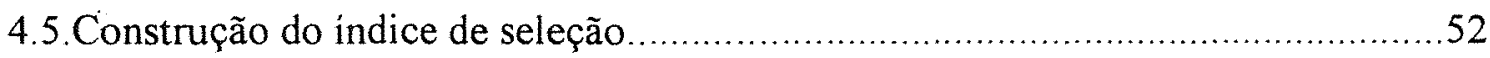

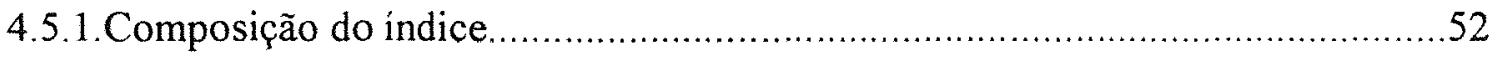

4.5.2. Tabela dialélica e seleção de linhagens.............................................54

4.5.3. Critérios de avaliação dos sintéticos.................................................55

4.6.Aplicação do índice de seleção.......................................................56

5. CONCLUSÕES

REFERÊNCIAS BIBLIOGRÁFICAS . .

APENDICE 


\section{ÍNDICE PARA SELEÇÃO DE LINHAGENS ENDOGÂMICAS DE MILHO (Zea Mays L.) VISANDO POPULAÇÕES SINTÉTICAS BASEADO EM MARCADORES GENÉTICOS}

Autora: GLAUCE CRISTINA RICARDO RUMIN

Orientador: Prof. Dr. ROLAND VENCOVSKY

\section{RESUMO}

O objetivo deste trabalho foi propor e aplicar um índice de seleção de linhagens visando a geração de sintéticos de milho, baseado em valores de produtividade de grãos e em dados de genotipagem de marcadores RFLP.

Como material básico utilizou-se uma população $F_{2}$ proveniente do cruzamento entre duas linhagens homozigóticas do grupo ISSS, integrantes do programa de melhoramento da Empresa Garst Seeds. Dessa população obtiveram-se 68 linhagens $\mathrm{S}_{2}$, sem controle genealógico, cujas plantas-mãe foram genotipadas considerando 157 locos RFLP. Amostras de DNA foram coletadas de plântulas no estágio de duas folhas. A distância média entre os locos marcadores foi de $15,30 \mathrm{cM}$. As linhagens foram submetidas a topcross, sendo o genitor masculino uma linhagem homozigótica do grupo heterótico Lancaster. As progênies assim resultantes foram avaliadas em experimentos de blocos incompletos com oito tratamentos comuns (híbridos simples), com duas repetições e instalados em quatro locais em lowa, Slater, EUA, no ano de 1996. A densidade de semeadura foi de 59.304 plantas/ha. Os dados de produtividade de grãos em $\mathrm{kg} / \mathrm{ha}$ foram submetidos a análises de variância que também forneceram as médias ajustadas das progênies em cada local e na média dos locais. Essas médias serviram de base para os cálculos posteriores. Para descartar os locos marcadores não associados a 
QTL's do caráter estudado utilizou-se processo de regressão múltipla (stepwise) em cada cromossomo separadamente, tomando-se os níveis de probabilidade $P<0,10$ e $P<0,15$ para entrada e permanência dos locos marcadores respectivamente no grupo dos considerados associados. O conjunto todo desses locos considerados foi posteriormente tomado para compor o modelo de regressão linear múltipla, cujos coeficientes de regressão parcial $\left(b_{j}\right)$ foram estimados por quadrados mínimos. Estimou-se também a proporção $(p)$ da variância genética entre progênies explicada pelos marcadores selecionados e o correspondente coeficiente de determinação $\mathrm{R}^{2}$.

Os experimentos foram de boa precisão detectando-se significância dos efeitos de progênie por local (exceto em um deles) e na média sobre os locais, bem como a significância da interação progênies x locais. Dos 157 locos identificaram-se 18 significativamente associados na média dos locais, explicando $74,7 \%$ da variação genética entre progênies. Por local os marcadores explicaram de $23,9 \%$ a $100 \%$ da variação genética entre progênies.

O indice de seleção proposto, relativamente ao par de linhagens $i$ e $i^{\prime}$, é do tipo $\quad I_{i i^{\prime}}=L_{i i^{\prime}}+D_{i i^{\prime}}$, sendo $L_{i i^{\prime}}$ função do comportamento per se das linhagens e $D_{i i^{\prime}}$ medida da complementaridade genética entre o par. $L_{i i^{\prime}}$ e $D_{i i^{\prime}}$ são estimáveis a partir dos coeficientes $b_{j}$ e da constituição genotípica das linhagens. Os 2278 valores de $I_{i i^{\prime}}$ foram organizados em tabela dialélica tomando-se a média $\vec{I}_{i}$. para identificar as linhagens candidatas a compor o sintético. Para fins de comparação, sintéticos também foram organizados com base apenas nas médias das progênies topcross. Evitaram-se sintéticos contendo freqüências nulas $(q=0)$ de marcadores ligados a alelos favoráveis de QTL's. A constituição dos sintéticos considerados ideais variou de um local para outro, havendo no entanto determinadas linhagens superiores comuns a todos eles. $\mathrm{O}$ tamanho desses sintéticos foi de 13,7,5,7 e 10 linhagens selecionadas para os locais 1 , 2, 3, 4 e para a média dos locais respectivamente. $O$ uso do indice elevou a freqüência 
dos alelos RFLP's associados a alelos favoráveis de QTL's nos sintéticos selecionados $(\bar{q})$ em comparação com o sintético selecionado pelas médias topcross. O mesmo podese dizer com relação ao efeito genotípico médio $(\bar{b})$ referente a cada sintético.

Linhagens com freqüência elevada de marcas associadas a Q'TL's favoráveis foram detectadas por ambos os métodos. Considerando as 15 melhores linhagens segundo os dois critérios, oito delas eram coincidentes e com relação às 10 melhores a coincidência foi de seis linhagens. As linhagens muito boas apresentaram, além de excelente valor per se, alta capacidade de combinação com a maioria das outras, sendo portanto detectadas por ambos os métodos. Nas linhagens logo abaixo das superiores a coincidencia deixou de existir devido à exploração da complementaridade, que o indice detecta e o topcross não. Tanto o índice como os topcrosses foram eficientes em elevar os valores de $\bar{q}$ nos sintéticos considerados ideais, quando comparados com o sintético amplo (68 linhagens). Porém, o índice levou à produção de sintéticos com valores de $\bar{q}$ maiores que os obtidos pelo critério do toperesss, o que é uma indicaçâo da importância da complementação genética na elevação da freqüência dos alelos favoráveis nos sintéticos. A utilização de um índice como o proposto só é viável se, de início, for utilizado um número suficientemente grande de locos marcadores para a cobertura adequada do genoma. 


\title{
INDEX FOR SELECTION OF INBRED LINES AIMED AT MAYZE SYNTHETIC POPULATIONS BASED ON GENETIC MARKERS
}

\author{
Author: GLAUCE CRISTINA RICARDO RUMIN
}

Adviser: Prof: Dr. ROLAND VENCOVSKY

\section{SUMMARY}

The purpose of this work was to propose and apply an index based on data of grain yield and RFLP markers, for selecting inbred lines aimed at generating synthetic maize populations.

As material, an $\mathrm{F}_{2}$ segregating population derived from a cross between two ISSS inbred lines was used. These lines are part of the Garst Seeds Co. breeding programme. From that population, $68 \mathrm{~S}_{2}$ lines were extracted and topcrossed with a Lancaster homozygous line as pollen parent. Seed parents were genotyped for 157 RFLP markers and DNA samples were extracted from plants at the two leaves stage. The average distance between marker loci was $15.30 \mathrm{cM}$. The topcross progenies were evaluated through incomplete block design experiments containing eight commercial hybrids as common entries and two replications. The experiments were set up in four locations in Iowa, USA, in 1996, with 59.304 plants/ha. Adjusted topcross progeny means, obtained from the analyses of variance of yield data $(\mathrm{kg} / \mathrm{ha})$, were used for subsequent calculations. Marker loci significantly associated with yield QTL's were identified through stepwise regressions analyses, for each chromosome separately. These markers were subsequently taken as elements of a multiple linear regression model, for estimation of the partial regression coefficients $\left(b_{j}\right)$, the proportion $(p)$ of the genetic variance among progenies explained by the markers and the $\mathrm{R}^{2}$ coefficient. 
Precision of experiments was very good (low CV's). Significance was found for progeny effects (in three locations) and progenies x locations effects. For the means over locations, 18 marker loci were found significantly associated with yield QTL's, which explained $74,7 \%$ of the genetic variance among progenies. Within locations this percentage ranged from $23,9 \%$ to $100 \%$.

For pair of lines $i$ and $i^{\prime}$, the proposed index is given by $I_{i i^{\prime}}=L_{i i^{\prime}}+D_{i i^{\prime}}$ were $L_{i i^{\prime}}$ relates to the performance of lines per se and $D_{i i^{\prime}}$ is a measure of genetic complementarity between the lines. Both quantities are estimable on the bases of the $b_{j}$ coefficients and the marker loci genotypes of the lines. The $2278 I_{i i^{\prime}}$ values were organised in a diallel table and the marginal means $\bar{l}_{i}$, taken as criterion for selection of the lines as candidates for the synthetic population. For comparison, lines were also selected simply on the basis of the topcross means. Synthetics were descarted, whenever, for any given marker locus, a zero frequency $(q=0)$ of marker alleles associated with favourable QTL alleles was found. The number of selected lines for the synthetic considered ideal, varied among locations. The numbers $13,7,5,7$ and 10 lines were found for locations $1,2,3,4$ and for the average over locations, respectively. The index was found more efficient than the topcross criterion for increasing the frequency of marker alleles associated with favourable QTL alleles $(\bar{q})$. The same could also be said for the mean genotypic effect $\bar{b}$, averaged over marker loci. Superior lines carrying a higher number of QTL alleles were identified through both criteria. Considering the best 15 lines, eight coincided for both methods. With 10 superior lines the coincidence was of $60 \%$. These lines are expected to have a superior performance per se, in addition to high general combining ability. Such a coincidence was not found for lines ranking immediately below the superior ones, in which case the index is expected to be a better criterion, as it includes a measure of genetic complementarity of a given line with all others $\left(\bar{D}_{i}\right.$. ). This is not accomplished by the topcross mean criterion. Another positive aspect of the index is that a homologue of a diallel table can be constructed without actually obtaining all pairs of crosses between lines. It is clear that such 
an index is expected to be efficient only if a sufficiently large number of marker loci is used, in order to achieve an adequate coverage of the genome. 


\section{INTRODUÇÃO}

A sintese de populações é uma etapa importante num programa de melhoramento de híbridos de milho. Em geral estas populações devem apresentar alta freqüência de alelos favoráveis para servirem como fontes de extração de genótipos superiores.

Um grande desafio imposto ao melhorista é a construção de sintéticos. Exigese eficiência e grande precisão dos experimentos de campo quando se avaliam linhagens quanto ao comportamento per se e em cruzamentos com testadores específicos. Linhagens endogâmicas, além disso, devem ser complementares em sua estrutura genética, de forma a maximizar a probabilidade de se obter linhagens mais próximas do genótipo ideal após a recombinação. Porém, uma dificuldade inerente à seleção é a ausência de inferências diretas sobre a estrutura genética das linhagens, o que pode diminuir a eficiência da seleção. No caso da sintese de novas populações, essa informação é importante porque diz respeito à complementaridade do material a ser recombinado, aumentando-se a chance de se elevar a frequiência dos alelos favoráveis no produto final.

Índices de seleção são ferramentas adequadas ao melhoramento de populações, devido à abordagem multivariada que considera um conjunto de características. Assim, mesmo que não se maximize a eficiência da seleção de uma característica isoladamente, atinge-se um valor genético superior para a população como um todo, quando se considera o conjunto de características componentes do índice. Mais 
recentemente os índices passaram a ter importância maior devido ao crescente emprego de marcadores genéticos como auxiliares na seleção.

Esse trabalho teve por objetivos:

a) propor um indice de seleção de linhagens endogâmicas de milho visando a formação de sintéticos, nele incluindo informações oriundas de experimentos a campo bem com dados de genotipagem das plantas-mãe das linhagens por marcadores RFLP;

b) orientar na escolha dos melhores sintéticos, aplicando o índice com dados obtidos em quatro locais distintos e com a média dos dados sobre os locais;

c) comparar a seleção de linhagens baseada no índice com a seleção convencional. 


\section{REVISÃO DE LITERATURA}

Um grande desafio num programa de melhoramento de plantas é a avaliação dos genótipos e a confiabilidade dos dados experimentais, principalmente para características de herança complexa, como a produtividade de grãos. Godshalk et al. (1990) afirmam que o objetivo principal de muitos programas de melhoramento é o de otimizar a eficiência da seleção das características de herança quantitativa. Assim, esforços têm sido feitos para integrar algumas técnicas de biologia molecular aos procedimentos convencionais de melhoramento de plantas, uma vez que diversos estudos demonstraram a sua aplicabilidade e eficiência na avaliação dessas características.

Os marcadores moleculares podem servir como ferramenta útil em vários aspectos do melhoramento de plantas, tais como a descrição de variedades, a construção de mapas genéticos, a medida das distâncias genéticas entre as linhagens e o próprio processo de seleção. A seguir, serão abordados pontos relativos ao uso de marcadores moleculares na medida das distâncias genéticas e no processo de seleção assistida por marcadores, com ênfase no milho.

\section{1. Quantificação da diversidade genética}

Devido à impossibilidade de predição do comportamento dos hibridos por meio do valor per se das linhagens, é necessário avaliar os seus cruzamentos, onerando os custos dos programas de melhoramento. No caso da produtividade de grãos em milho, 
os fortes efeitos da dominância no controle genético desse caráter são a causa da baixa correlação entre o valor das linhagens e o dos respectivos híbridos (Hallauer \& Miranda Filho, 1981).

Conhecer a base genética do material disponivel auxilia na definição de estratégias num programa de melhoramento. A utilidade dos marcadores moleculares para o conhecimento das relações genéticas entre linhagens e populações têm sido apontada por vários pesquisadores. Os estudos de Lee et al. (1989) concluem que os marcadores RFLP são uma alternativa potencial aos testes de campo, quando se deseja organizar linhagens de milho em grupos heteróticos distintos.

A medida da distância genética entre genótipos pode ser feita de diversas formas. Interessados em desenvolver métodos para calcular a similaridade genética, tanto entre linhagens endogâmicas como entre híbridos de milho, Smith \& Smith (1992) compararam quatro métodos diferentes. Os autores utilizaram a distância modificada de Rogers baseada em 21 locos de isoenzimas, a distância genética medida por 38 sondas de RFLP's, o coeficiente de parentesco de Malécot baseado nos dados de pedigri e a distância genética de Troyer obtida a partir da depressão por endogamia determinada pela produtividade de grãos. Concluíram que a distância de Troyer e a distância baseada no padrão de bandas de RFLP's são adequadas para se determinar a distância genética entre híbridos de milho, e os resultados obtidos concordaram com as relações de pedigri já conhecidas. Esses dois métodos podem ser úteis na determinação da similaridade entre híbridos comerciais vendidos aos agricultores, e também podem ajudar a encontrar possíveis violações aos direitos de propriedade intelectual. Os RFLP's apresentam como vantagens adicionais o fato de serem de obtenção mais rápida e de custo inferior quando comparados a testes de campo, além de não sofrerem influência dos efeitos ambientais. 
Trabalhando com 57 linhagens endogâmicas de milho pertencentes a grupos heteróticos flint e dent de ciclo precoce, Messmer et al. (1992) testaram a utilidade dos RFLP's para detectar a diversidade entre as linhagens e separá-las em grupos heteróticos distintos. Para tal, as linhagens foram genotipadas e 188 sondas foram utilizadas. Aproximadamente metade das sondas detectaram polimorfismo nos dois grupos, e $25 \%$ das combinações foram específicas para cada grupo. Assim, os autores concluíram ser possível limitar os RFLP's a um menor número de sondas com maior poder discriminatório entre as linhagens de diferentes grupos heteróticos.

Mumm \& Dudley (1994) classificaram 148 linhagens endogâmicas de milho através de análise de agrupamento baseada em RFLP's, e as associações encontradas entre as linhagens foi de forma geral coincidente com a informação do pedigri. As linhagens foram dirigidas para os grupos heteróticos predominantes, e posteriormente classificadas em subconjuntos dentro de cada grupo heterótico. Assim, este método pode ser útil em orientar e reduzir os testes de campo com linhagens de resposta heterótica desconhecida. Os autores advertem que, apesar de as 46 combinações sonda-enzima terem sido suficientes para classificar as linhagens, esse número de marcadores pode estar no limite mínimo exigido para a distinção entre elas.

Mumm et al. (1994) continuaram o estudo anteriormente conduzido por Mumm \& Dudley em 1994, classificando 148 linhagens endogâmicas de milho através de análise de agrupamento baseada em RFLP's. Foram aplicados quatro diferentes métodos de classificação, dois deles baseados no coeficiente de similaridade de Gower e outros dois baseados na fórmula de similaridade genética de Nei e Li. As linhagens foram agrupadas de forma semelhante pelos diferentes métodos, e estas informações coincidem com as fornecidas pelos dados de pedigri, sugerindo que há um agrupamento natural entre as linhagens estudadas. 
Trabalhando com milho doce, Gerdes \& Tracy (1994) apontaram a utilidade das técnicas moleculares, especialmente os RFLP's, no julgamento correto das relações genéticas entre as linhagens endogâmicas na ausência de informação de pedigri. Baseados nos dados de RFLP e de pedigri, a maior parte das linhagens endogâmicas de milho doce estudadas puderam ser separadas em dois grandes grupos heteróticos, facilitando a definição de ações dentro de um programa de melhoramento.

Lorenzen et al. (1995) destacam a utilidade dos RFLP's na análise de pedigri de soja. Foram identificados 97 locos RFLP's que se mostraram mais adequados para a cobertura do genoma de soja que os marcadores citados em estudos anteriores.

Hahn et al. (1995) estudaram 57 linhagens endogâmicas elite de milho pertencentes aos grupos heteróticos flint e dent. Os objetivos do trabalho foram: (1) investigar a proporção de variação explicada por marcadores RAPD nestes materiais, (2) examinar a utilidade dos RAPD's em dirigir linhagens para grupos heteróticos distintos e (3) comparar as medidas de similaridade genética por RAPD, coeficiente de parentesco de Malécot e similaridade genética por RFLP. Os autores concluíram que os RAPD's, em número limitado no estudo, foram menos adequados para estimar o parentesco entre linhagens endogâmicas de milho que os RFLP's, que propiciaram boa cobertura do genoma. Citam, ainda, que os marcadores RAPD apresentam menor custo quando comparados com os RFLP's, mas que essa vantagem econômica dos RAPD's sobre os RFLP's diminui de forma gradativa, à medida que o número de indivíduos analisados aumenta. Portanto os autores concluiram que os RFLP's foram o melhor sistema de marcadores para elucidar relações genéticas entre linhagens de milho. 


\section{2. Predição do desempenho de híbridos simples}

Para avaliar o desempenho de hibridos gerados a partir de linhagens endogâmicas, muito trabalho é necessário na condução de cruzamentos específicos, consumindo tempo e recursos financeiros. A redução do número de cruzamentos necessários facilitaria o trabalho do melhorista, além de economizar recursos do programa de melhoramento. Assim, vários estudos foram conduzidos com o objetivo de verificar correlações entre os genótipos dos pais, fornecidos pelos marcadores moleculares, e o comportamento de seus híbridos em testes de campo.

Godshalk et al. (1990), ao avaliar linhagens endogâmicas de milho e o desempenho de seus híbridos simples, sugerem que os RFLP's são eficientes em posicionar linhagens em grupos heteróticos distintos, não encontrando, entretanto, nenhuma relação entre a distância genética das linhagens e o desempenho de seus hibridos. Os autores também encontraram diferenças genéticas significativas entre as linhagens que pertenciam a um mesmo grupo heterótico. Apesar dessa variação dentro de grupos, os autores concluiram, pelo padrão geral de dispersão das linhagens, que os RFLP's são ferramentas úteis para a identificação de combinações superiores de linhagens endogâmicas oriundas de diferentes grupos heteróticos.

Investigando as relações entre as linhagens, a predição da heterose e a performance de seus híbridos simples, Melchinger et al. (1990) trabalharam com linhagens endogâmicas de milho e concluiram que os RFLP's podem ser usados para examinar as relações de parentesco entre as linhagens, inclusive atribuindo linhagens de origem desconhecida a grupos heteróticos adequados. Porém, os resultados também sugeriram que as medidas de distâncias genéticas baseadas em RFLP's têm uso limitado para a predição heterótica de híbridos simples, não podendo ser utilizadas para esse fim no caso de híbridos obtidos pelo cruzamento de linhagens não aparentadas. 
Dudley et al. (1991), trabalhando com linhagens endogâmicas de milho, avaliaram RFLP's e isoenzimas quanto à eficiência desses marcadores para (1) predizer o potencial de produtividade dos híbridos, (2) separar linhagens em grupos heteróticos distintos e (3) determinar quais das linhagens componentes de um híbrido simples estão mais próximas de uma linhagem doadora no caso de retrocruzamentos. Os autores utilizaram a distância modificada de Rogers como medida de diversidade genética entre as linhagens, e observaram que, apesar de a análise de agrupamento baseada nessa distância confirmar as informações de pedigri, esteve em desacordo com o agrupamento baseado na produtividade. Portanto, não foi possivel inferir o comportamento dos hibridos pela distância genética entre as linhagens que os compõem, pois a correlação entre essas informações foi baixa. Porém, ao se atribuir um valor ao híbrido (baseado nos valores genotípicos mais altos associados aos locos marcadores) detectaram correlações positivas $(r=0,78)$ entre o valor atribuído ao híbrido e a produtividade de grãos. Dos 10 híbridos analisados, os seis mais produtivos também apresentaram um alto valor atribuído ao híbrido.

Quanto maior o número de marcadores utilizados, maior o valor preditivo sobre o desempenho de hibridos. Bernardo (1992) destaca que, para que os marcadores possam ser usados como preditores de desempenho de híbridos, certas condições devem ser respeitadas, tais como: (1) o caráter a ser selecionado deve apresentar efeitos de dominância pronunciados, (2) os grupos heteróticos dos genitores devem ser complementares e as freqüências alélicas nos locos negativamente correlacionadas, (3) a característica em questão deve apresentar herdabilidade alta (4) a freqüência alélica média entre os genitores deve variar dentro de um limite estreito (5) pelo menos $30 \%$ a $50 \%$ dos QTL's devem estar ligados aos marcadores e (6) não apresentar mais do $20 \%$ a $30 \%$ dos marcadores dispersos ao acaso ou não apresentando ligação com os QTL's.

Messmer et al. (1993) analisaram 29 linhagens de milho de origem européia, sendo 18 do grupo flint e 11 do grupo dent. Os autores compararam informações de 
pedigri geradas pelo coeficiente de Malécot com os dados de similaridade genética oriundos de RFLP's dentro dos grupos. Encontraram correlação altamente significativa $(\mathrm{P}<0,01)$ entre as duas medidas, com valores de 0,71 para o grupo flint e 0,80 para 0 grupo dent. Defendem a utilização de RFLP's para identificação de linhagens e grupos heteróticos e afirmam que, havendo uma boa cobertura do genoma pelos marcadores, e número de sondas superior a 100, a medida de similaridade genética dada por RFLP's é significativamente mais precisa que o coeficiente de Malécot para aferir parentesco entre as linhagens.

Stuber (1994) aborda a importância da heterose e a necessidade de se desenvolver métodos confiáveis para identificar populações ou linhagens com fatores genéticos desejados, identificar e mapear esses fatores em linhagens e populações divergentes, realizar a introgressão desses fatores em linhagens elite e predizer o comportamento de hibridos sem a necessidade de testar todas as combinações possiveis. Apesar de os dados de marcadores moleculares, em geral, serem concordantes com os dados de pedigri quando se observa a formação de grupos heteróticos entre as linhagens, a predição do comportamento de híbridos só tem sido possível entre linhagens pertencentes a um mesmo grupo heterótico.

Informações precisas sobre a base genética das populações e linhagens são importantes para se determinar as estratégias de melhoramento e de conservação de germoplasma. Para Dubreuil et al. (1996) a ordenação precisa de linhagens endogâmicas em grupos heteróticos é um pré-requisito para a utilização eficiente do germoplasma. $\mathrm{O}$ exame dos dados de pedigri, das comparações fenotípicas, e da capacidade de combinação com vários testadores são as formas tradicionais de se utilizar a informação sobre o germoplasma. Porém, esses descritores apresentam limitações. A informação sobre o pedigri não leva em conta o efeito causado pela seleção, e os delineamentos topcross envolvendo vários testadores e várias características agronômicas são muito caros e despendem muito tempo na sua condução. Os RFLP's têm se mostrado eficientes 
na identificação de linhagens endogâmicas ou híbridos de milho altamente aparentados, mas têm falhado em predizer a heterose da produtividade de grãos nos cruzamentos entre linhagens não aparentadas. Os resultados encontrados neste estudo, consistentes com relação aos trabalhos anteriores, indicam que as classificações baseadas em marcadores são úteis, tanto na escolha de combinações de linhagens a serem avaliadas em experimentos com híbridos como na escolha de genitores em programas de melhoramento.

Lanza et al. (1997) apontaram o uso de marcadores RAPD para (1) avaliar a divergência genética entre linhagens endogàmicas de milho, (2) dirigí-las para grupos heteróticos adequados e (3) correlacionar o desempenho do cruzamento com a divergência genética das linhagens genitoras. Os autores verificaram correlações diretas e positivas entre as distâncias baseadas em RAPD's e a produtividade de grãos nos híbridos usando linhagens de germoplasma tropical. Para obter essas correlações, foi considerado o padrão de agrupamento dos dendogramas e essas informações ajudaram a estabelecer grupos heteróticos. Os resultados mostraram que as distâncias baseadas em RAPD's foram eficientes em estabelecer grupos consistentes, e podem ser usadas para auxiliar a escolha dos cruzamentos a serem realizados entre linhagens de milho tropical oriundas de população de base ampla, reduzindo dessa forma o número necessário de cruzamentos a serem produzidos.

Kozumplik et al. (1996) utilizaram marcadores como isoenzimas, RFLP's e SSR's com o objetivo de detectar QTL's responsáveis pela produtividade de grãos, altura de planta e dispersão de pólen em germoplasma exótico de milho, além de determinar a relação entre o grau de heterozigosidade dos alelos marcadores e o nível de produtividade de grãos. Os estudos foram conduzidos em duas populações geradas a partir de variedades croatas de polinização aberta. Em cada população, 169 famílias $\mathrm{F}_{3}$ foram avaliadas em dois ambientes, e as 20 familias mais produtivas bem como as 20 famílias menos produtivas de cada uma das populações originais foram utilizadas para a 
deteç̧ão dos QTL's. Não foram encontrados QTL's em comum nas duas populações estudadas. As 20 familias mais produtivas apresentaram grau de heterozigosidade maior quando comparadas com as 20 familias menos produtivas em ambas as populações.

Como a genotipagem dos pais por si só não é capaz de determinar o desempenho dos híbridos simples, os dados dos marcadores moleculares têm sido associados a novas metodologias de análise de forma a obter correlações entre genitores e o comportamento da descendência. O método conhecido como BLUP (melhor preditor linear não viesado) têm sido utilizado com o objetivo de predizer o comportamento dos híbridos com base nas linhagens genitoras, e resultados favoráveis têm sido encontrados por vários pesquisadores. Bernardo (1994) utilizou o procedimento BLUP para avaliar o desempenho de híbridos simples quanto à produtividade de grãos em milho, baseando-se nos dados de RFLP das linhagens genitoras e na produtividade de grãos de um conjunto aparentado de cruzamentos. O objetivo do trabalho foi avaliar e mostrar a utilidade do método BLUP na predição do desempenho dos híbridos simples, e também testar o método quanto à mensuração da relação genética. Foram calculadas as correlações entre os valores preditos e observados de produtividade de grãos, e essas correlações variaram de 0,654 a 0,800 . Os valores das correlações foram mais altos quando a variância genética dominante estava incluída no modelo e também quando os coeficientes de parentesco foram oriundos dos RFLP's no lugar dos dados de pedigri. As correlações permaneceram estáveis através de valores de variância genética diferentes e arbitrários aos quais foram submetidas. Os resultados encontrados sugerem que, quando se usa $o$ método BLUP, a produtividade de grãos de híbridos simples de milho pode ser efetivamente predita baseando-se nos dados de RFLP dos genitores e na produtividade de grãos de um conjunto parcial de híbridos simples. 


\section{3. Seleção assistida por marcadores moleculares}

Com o advento dos marcadores moleculares, a possibilidade de seu uso no processo de seleção de plantas sugeria algumas vantagens que não poderiam ser obtidas com os métodos convencionais. Uma das vantagens previstas foi a diminuição do tempo necessário de seleção, pelo enfoque direto nas regiões de interesse. A vantagem da seleção dirigida teria ainda maior importância em se tratando de características com baixa herdabilidade. No caso dos retrocruzamentos, além da diminuição do tempo e do monitoramento dos segmentos alvo, a seleção assistida por marcadores ainda possibilitaria o controle da entrada de segmentos não desejáveis. Assim, muitos estudos foram conduzidos para verificar a eficiência da seleção assistida por marcadores moleculares quando comparada com os métodos de seleção convencional. Os resultados encontrados mostraram que a superioridade de um método em relação ao outro depende da situação avaliada.

No intuito de demonstrar a utilidade dos marcadores, Lande \& Thompson (1990) compararam a seleção assistida por marcadores com métodos tradicionais de seleção fenotípica, através de indices de seleção com o objetivo de maximizar a taxa de ganho genético em caracteres quantitativos. Os autores também incluiram no estudo as limitações estatísticas na eficiência da seleção assistida por marcadores, incluindo o poder de detecção de associações entre os locos marcadores e os QTL's, assim como os erros de amostragem na estimativa dos coeficientes de ponderação do índice de seleção. Concluíram que a eficiência da seleção artificial pode ser aumentada substancialmente com o uso de marcadores moleculares.

Trabalhando com programas de introgressão, Hospital et al. (1992) mostraram a importância dos marcadores moleculares, tão mais úteis quanto mais conhecida for sua posição de mapeamento. Os autores demonstraram que a seleção 
assistida por marcadores pode levar a um ganho de tempo de duas gerações, quando comparada às condições normalmente utilizadas, e abordam ainda os efeitos do tempo e da intensidade de seleção, tamanho da população e posição dos marcadores. Afirmam que a seleção deve ser feita o mais cedo possível e a intensidade de seleção ser maior se os marcadores se encontrarem muito próximos do gene a ser incorporado, sem se prestar atenção aos cromossomos não portadores. Os autores destacam três pontos importantes na busca de uma estratégia ótima de seleção num programa de introgressão:

1) Para o cromossomo portador do segmento a ser incorporado, a resposta à seleção é função tanto da distância entre os marcadores e o gene, quanto da proporção dos indivíduos selecionados;

2) Após se proceder à seleção, focalizando a atenção nos cromossomos portadores dos segmentos a serem incorporados, ainda é possível selecionar visando os cromossomos não portadores. Porém, o sucesso dessa segunda etapa depende da intensidade de seleção praticada na fase inicial;

3) Comparando o uso da seleção assistida nos diferentes ciclos seletivos, a seleção será mais eficiente se praticada nos ciclos finais.

Stuber (1994) utilizou retrocruzamentos em milho para fazer a introgressão de segmentos especificos associados a características de herança complexa, como por exemplo a produtividade de grãos. O estudo demonstrou que o sucesso da introgressão foi facilitado pelo uso de marcadores moleculares.

Beavis et al. (1994) conduziram um estudo em milho para verificar se regiões do genoma poderiam ser identificadas numa amostra pequena, embora típica, de topcrosses e de progênies $F_{2: 4}$, oriundas do cruzamento entre as linhagens B14 x MO17. Foram identificadas regiões importantes para 24 características agronômicas, usando mapeamento por intervalo e estimativas simultâneas de modelos de QTL's múltiplos. O número médio de QTL's identificados foi de cerca de três a cinco por caráter. A maioria 
dos QTL's identificados foram os mesmos para os caracteres correlacionados. Verificaram que QTL's relacionados à produtividade de grãos não se encontravam nas mesmas regiões relatadas em estudos anteriores sobre o cruzamento entre B14 x MO17. Isso pode ser devido a fatores, tais como: (1) origem das linhagens genitoras, (2) tipo de progênie, (3) diferentes efeitos de interação genótipos x ambientes e (4) utilização de amostras pequenas e diferentes. Os resultados indicam que a amostragem das progênies é a mais provável explicação para as diferenças encontradas, e deve ser cuidadosamente levada em conta em estudos de detecção de QTL's.

Leon et al. (1995) trabalhando com girassol, utilizaram RFLP's com o objetivo de identificar marcadores ligados a QTL's afetando a quantidade de óleo na semente, a porcentagem de óleo no endosperma e a proporção do endosperma em relação à semente. Os autores concluíram que o uso de RFLP's pode identificar os retrocruzamentos com as constituições alélicas desejadas, e dirigir a seleção nestas regiões e combinações de QTL's. Afirmam, ainda, que os RFLP's podem ser úteis em incrementar os componentes relativos à porcentagem de óleo na semente sem afetar outras características. Os QTL's caracterizados por ligações desfavoráveis ou efeitos pleiotrópicos podem ser monitorados mais cuidadosamente na seleção dos retrocruzamentos.

Com o objetivo de colaborar no uso adequado de germoplasma exótico em programas de melhoramento de milho temperado, Ragot et al. (1995) utilizaram isoenzimas e RFLP's para identificar QTL's e monitorar a introgressão dos segmentos favoráveis em germoplasma temperado. Foram detectados QTL's afetando a produtividade de grãos e o número de espigas por plantas, e a estabilidade dos QTL's através dos ambientes foi alta. Os QTL's de efeito significativo encontrados no material exótico puderam então ser utilizados no germoplasma temperado através de retrocruzamentos. Segundo os autores, a vantagem de se monitorar retrocruzamentos com marcadores moleculares é a possibilidade de inserção controlada de fragmentos 
exóticos no germoplasma adaptado, diminuindo-se o risco da introdução simultânea de características indesejáveis.

$\mathrm{O}$ uso de marcadores com o objetivo de aumentar a eficiência dos retrocruzamentos também foi citado por Openshaw et al. (1994). A seleção auxiliada por marcadores para o genitor recorrente pode aumentar significativamente a eficiência dos programas de retrocruzamento, por permitir ao melhorista selecionar plantas que apresentem maior proporção do genoma do genitor recorrente, e selecionar os indivíduos com conversões melhores e mais próximas do alelo a ser incorporado. Em termos práticos, isso significa aumentar a probabilidade de se obter conversões desejadas e diminuir o tempo necessário para se alcançar essas conversões. No planejamento de um programa de retrocruzamentos assistido por marcadores, deve-se considerar a economia de tempo com o auxílio dos marcadores, o número de marcadores necessários, e o número de genótipos a avaliar. Através de simulação de dados, os autores verificaram que os métodos de retrocruzamento que incluiam o uso de marcadores foram todos mais eficientes quando comparados ao método tradicional.

Para Selig et al. (1999) a transferência de germoplasma oriundo de linhagens de milho exóticas para linhagens americanas apresentou alguns resultados positivos. Porém, essa transferência pode ser otimizada com o uso de marcadores moleculares, através da introgressão de segmentos específicos associados aos efeitos desejados, evitando a transferência simultânea de segmentos cromossômicos não relacionados ao caráter. O uso dos marcadores moleculares auxiliou na superação de problemas que ocorreram no passado, como a introgressão de grandes porções cromossômicas do germoplasma exótico não associadas ao caráter desejado.

Através de simulação, Edwards \& Page (1994) comparam as respostas obtidas com a seleção assistida por marcadores e a seleção recorrente convencional para espécies alógamas anuais. Foram utilizados 25 QTL's em seis modelos diferentes, três 
para a seleção assistida por marcadores e três para a seleção convencional. Os modelos envolvendo seleção assistida apresentaram diferentes taxas de recombinação entre marcadores e QTL's, com valores variando de 5\%, 10\% e 20\% de recombinação em cada um dos modelos. No caso da seleção convencional, o que diferenciou os modelos foi a herdabilidade do caráter, variando de $0,10,0,20$ e 0,40 para cada caso. A resposta inicial com seleção assistida foi mais rápida que a seleção convencional em todos os modelos. Porém, essa vantagem não se manteve no caso de perda do desequilíbrio de ligação entre marcador e QTL (20\% de recombinação). Mesmo no caso de baixa herdabilidade $\left(\mathrm{h}^{2}=0,10\right)$ a seleção convencional superou a seleção assistida ao longo dos ciclos, reforçando que a eficiência da seleção assistida por marcadores está relacionada à existência de desequilibrio de ligação. A seleção assistida também é afetada pela distância existente entre os marcadores e os QTL's e, se os marcadores estiverem muito próximos ao QTL, a seleção assistida é notavelmente superior à seleção convencional. O grande beneficio da seleção assistida foi acelerar a resposta à seleção nos modelos utilizados nesse estudo. Os autores supõe que os marcadores não são afetados pelo ambiente, tornando possível a condução dos experimentos e da seleção em estufas. Assim, enquanto a seleção convencional exigiu dois anos por ciclo, a seleção assistida necessitou de meio ano por ciclo de seleção

A diminuição no desequilíbrio de ligação com o passar dos ciclos é um fato que prejudica a seleção recorrente assistida por marcadores. Bearzoti (1997) trabalhou com seleção recorrente assistida por marcadores em espécies autógamas através de simulações, e verificou que esse tipo de seleção foi pouco eficiente por mais de um ciclo seletivo. Considerando apenas um ciclo seletivo, a seleção assistida por marcadores foi eficiente, e o tamanho das subpopulações utilizadas constituiu-se em importante fator afetando a eficiência por seleção assistida no primeiro ciclo seletivo, demandando algumas centenas de progênies para que a eficiência da seleção assistida em relação à convencional seja obtida 
Bubeck et al. (1993) trabalharam com três populações de milho com o objetivo de identificar QTL's e o tipo de ação gênica para resistência ao fungo Cercospora, em familias segregantes oriundas de cruzamentos simples, utilizando RFLP's. Os autores também procuraram determinar a consistência dos QTL's em relação a ambientes e populações. Os QTL's foram identificados baseando-se na média dos danos causados pelo fungo para cada população nos três ambientes, e também para cada ambiente envolvendo a média das três populações. Foi identificada uma região no cromossomo 2, associada à resistência ao fungo, nas três populações, e encontrou-se ação gênica aditiva para aproximadamente todos os marcadores associados com a resistência.

Num trabalho de seleção recorrente em milho, Edwards \& Johnson (1994) compararam a seleção assistida por RFLP's com a seleção fenotípica convencional e observaram que, para caracteristicas de herdabilidade baixa, como é o caso da produção de grãos, a seleção assistida conduz a progressos superiores em relação à seleção convencional. Porém, o inverso ocorre para características com alta herdabilidade, no caso a qualidade de grãos. Há também o problema de correlações negativas entre as características, em que a seleção assistida melhorou um caráter em prejuizo de outro. Os autores ainda ressaltam que as respostas à seleção auxiliada por RFLP para as duas populações estudadas foram diferentes, produzindo resultados satisfatórios na população A e resultados insatisfatórios na $B$, concluindo então que a eficiência da seleção dependerá da população utilizada.

Goldman et al. (1994) trabalharam na identificação de associações RFLPQTL relacionadas com o teor de óleo e o peso de sementes em milho, num cruzamento específico entre duas populações divergentes. As plantas utilizadas no cruzamento citado foram oriundas do cruzamento de duas populações de alto e baixo teor de proteina, que passaram por 76 ciclos de seleção divergente para concentração de óleo e para peso de sementes. As populações resultantes dessa seleção forneceram as plantas para o 
cruzamento utilizado neste estudo. Os autores verificaram que agrupamentos de dois ou mais locos marcadores na mesma região cromossômica estavam significativamente associados com a concentração de óleo em quatro diferentes regiões, e outras quatro regiões para peso de sementes. As regiões encontradas para o teor de óleo confirmam dados publicados por outros pesquisadores. Assim, pela deteç̧ão de poucos agrupamentos de locos associados com regiões genômicas controlando a concentração de óleo, os autores concluiram que o uso de RFLP's na seleção assistida por marcadores é viável para o desenvolvimento de germoplasma de milho com alto teor de óleo.

Stromberg et al. (1994) compararam os ganhos obtidos com a seleção assistida por marcadores com os alcançados pelo melhoramento convencional num programa de melhoramento de milho. O resultado alcançado com a seleção assistida por marcadores não apresentou diferenças significativas em relação ao melhoramento convencional nesse estudo, e uma das possíveis razões para este fato foi a baixa cobertura do genoma pelos 32 marcadores utilizados. Quatro dos 20 braços cromossômicos não apresentavam nenhum marcador, e cinco braços cromossômicos tinham apenas um marcador. Com a melhor cobertura dos cromossomos, associações loco-característica significativas poderiam ter sido detectadas, e ligações mais próximas estabelecidas, o que poderia levar a um aumento de ligações loco-característica-alelo no conjunto de dados utilizado.

Berke \& Rocheford (1995) conduziram um estudo em milho com o intuito de determinar o número e a localização cromossômica dos QTL's controladores do florescimento masculino, da altura de planta e de espiga, do peso de sementes e da concentração de proteina, óleo e amido nas sementes. As análises de variância detectaram associações significativas $(P<0,05)$ entre os vários locos RFLP's $\mathrm{e}$ as caracteristicas fenotípicas. O número de marcadores encontrados foi de $16,18,14,27,16,31$ e 28 , para o florescimento masculino, altura de plantas, altura de espigas, peso de sementes, concentração de proteínas, concentração de óleo e concentração de amido 
respectivamente. As regiões onde os QTL's foram detectados coincidem com dados existentes na literatura. Os autores ainda observaram que, para uma mesma característica, a direção da dominância e o tipo de ação gênica presente nos locos variaram nas diferentes regiões genômicas, exceto para a concentração de proteína, onde a dominância e a sobredominância estavam sempre associados ao baixo teor de proteína.

A incorporação de genes de resistência qualitativa é uma importante estratégia de controle da helminthosporiose do milho. Ogliari (1999) comparou um par de linhagens quase isogênicas que diferiam entre si pela presença de um gene de resistência a E. turcicum, chamado de HtP. Foram identificados dois marcadores microssatélites ligados a esse loco, e testes envolvendo a inoculação de cinco isolados brasileiros de E. turcicum sobre conjunto de linhagens isogênicas portadoras de diferentes genes de resistência a helminthosporiose, permitiram verificar que o gene HtP é um novo gene ou uma forma alélica alternativa do já descrito gene $\mathrm{Ht}_{1}$. O gene $\mathrm{HtP}$ confere resistência às raças portadoras de amplo espectro de virulência (123 e $23 r$ ) e, portanto, a autora recomendou sua introgressão em cultivares híbridas e variedades comerciais de milho nacionais.

Outra forma de obter ganhos genéticos com o auxílio de marcadores moleculares seria orientando os cruzamentos para que se formassem populações de desempenho superior. Assim, Bernardo (1999) definiu o acasalamento assistido por marcadores (MAM) como o cruzamento de indivíduos que apresentam marcadores genotípicos semelhantes. O autor utilizou simulação para: (1) comparar a resposta a seleção associada com MAM, cruzamentos baseados no fenótipo (PAM), e cruzamentos ao acaso (RM), e (2) determinar quando MAM é útil em programas de melhoramento. A simulação foi feita para 200 individuos, em cruzamento entre duas linhagens, em 25 gerações de seleção. Foram utilizados 100 marcadores codominantes distribuídos ao acaso pelos 10 cromossomos do milho. $O$ autor verificou que a perda da heterozigosidade dos QTL's foi maior em MAM que em PAM ou RM. Para esquemas de 
melhoramento de longo prazo, RM mostrou-se mais promissor que os outros métodos. $\mathrm{O}$ procedimento MAM só foi útil no melhoramento de curto prazo, especialmente em condições de herdabilidade e pressão de seleção baixas.

\section{3. 1. Detecção de QTL's}

Para que a seleção assistida por marcadores seja eficiente, é necessário um mapa de ligação altamente saturado por marcadores. É preciso inicialmente identificar associações entre marcadores e QTL's, e posteriormente usar essas informações para desenvolver linhagens e populações superiores (Dudley, 1993).

Duas maneiras tradicionais de identificar e mapear QTL's são as seguintes: métodos baseados em cruzamentos entre linhagens que diferem entre si para a característica de interesse e métodos baseados em populações segregantes. $O$ delineamento experimental mais eficiente para localizar QTL's envolve cruzamentos entre linhagens que apresentem alelos fixados de forma alternada tanto nos QTL's quanto nos locos marcadores, devido ao máximo desequilibrio de ligação entre os locos. Geralmente, populações endogâmicas divergentes são cruzadas para produzir a geração $F_{1}$, que é então retrocruzada para um dos pais ou ambos, ou então cruzada entre si para produzir a geração $F_{2}$. Em espécies que toleram endogamia, obtêm-se linhagens endogâmicas recombinantes a partir da autofecundação de individuos da geração $F_{2}$ (Falconer, \& Mackay, 1996).

Deve-se considerar, também, o número de QTL's que afetam a característica. Para Dudley (1993) quando a característica é controlada por um grande número de QTL's, sendo alguns de pequeno efeito, a probabilidade de se identificar marcadores ligados a todos os QTL's é baixa. Em plantas, associações marcador - QTL podem ser descobertas usando-se linhagens autofecuntadas oriundas de populações $F_{2}$ ou de 
retrocruzamentos, avaliadas em experimentos com repetições conduzidos em diferentes ambientes, o que permite aumentar a precisão da estimativa da associações marcador QTL. Com um grande número de marcadores ligados aos QTL's, é preciso selecionar aqueles que serão usados na seleção assistida. No caso da seleção de uma única característica, deve-se escolher os locos que serão usados e combinar essas informações.

Ajmone-Marsan et al. (1996) discutiram os efeitos de tamanho pequeno de amostras e a inconsistência ao longo dos ambientes na detecção dos QTL's em milho. Para estimar os efeitos do tamanho da população na detecção dos QTL's, os autores analisaram uma pequena amostra de progênies segregantes, derivadas do cruzamento entre duas linhagens, que foi comparada com uma amostra maior, oriunda do mesmo cruzamento, já estudada anteriormente para a deteç̧ão de QTL's. O estudo mostrou a confirmação de QTL's detectados nas duas amostras, a despeito do tamanho pequeno de uma delas. Poderia ser dito que o tamanho da amostra tem pouca influência na detecção dos efeitos dos QTL's, mas os autores não descartam a possibilidade de terem tido sorte na escolha da amostra pequena. Assim, advertem que a extrapolação desses resultados para outras populações deve ser vista com precaução, mas afirmam que os QTL's detectados para a produtividade de grãos foram consistentes ao longo dos ambientes, independentemente do tamanho de amostra utilizado, sendo então de utilidade no melhoramento assistido por marcadores.

Outro ponto importante é o tamanho da população utilizada nos estudos de deteç̧ão de QTL's. Segundo Moreau et al. (1999) o poder de detecção de associações entre marcadores e QTL's e seus efeitos são de dificil estimação quando se trabalha com populações pequenas. Estes resultados implicam na necessidade da avaliação de numerosos indivíduos pelos marcadores moleculares. Os autores citaram Knapp \& Bridges (1990), que mostraram aumento do poder de resolução no mapeamento de QTL's com um maior número de linhagens avaliadas por experimento. Ainda, devido aos efeitos da interação genótipos $\mathrm{x}$ ambientes, os fenótipos precisam ser avaliados em 
diferentes locais, mesmo que seja apenas uma repetição por local. Todos esses elementos sugerem que pode ser de maior valor avaliar as linhagens em um maior número de locais em experimentos sem repetições do que usar repetições em um menor número de locais. Os autores propõem um método em que os valores genéticos são divididos em duas partes, uma explicada pelos marcadores e outra parte não explicada. Essas duas partes foram identificadas no mesmo passo, sendo que a heterogeneidade espacial foi levada em consideração em experimentos sem repetições, conduzidos em onze locais diferentes. Essa abordagem é importante quando se deseja detectar o valor genético de indivíduos em cada experimento. Se o interesse for selecionar indivíduos para adaptação geral, cada experimento pode ser interpretado como uma repetição. Quando muitos experimentos são utilizados, o interesse em se considerar a heterogeneidade espacial diminui ao se aumentar o número de locais. Porém, considerar a heterogeneidade espacial aumenta a precisão dos valores genotipicos, o que permite usar menos experimentos para se atingir o mesmo ganho genético. Os autores enfatizam que, quando os genótipos são testados em um número pequeno de locais, considerar a heterogeneidade espacial diminui o risco de se chegar a ganhos genéticos insignificantes, caso os ambientes sejam muito heterogêneos.

A interação genótipos $\mathrm{x}$ ambientes, de grande importância para a maioria dos caracteres quantitativos, só pode ser abordada analisando separadamente os dados coletados em vários ambientes. Jansen et al. (1994) demonstram uma abordagem analitica, chamada multiple QTL mapping ou MQM, que adapta tanto o mapeamento de múltiplos QTL's quanto a interação genótipos $\mathrm{x}$ ambientes. $\mathrm{O}$ estudo aponta as vantagens do MQM quando comparado com mapeamento por intervalos ou IM, na deteç̧ão e mapeamento de múltiplos genes envolvidos na expressão de caracteres quantitativos, especialmente tratando-se de dados oriundos de vários ambientes. O procedimento de MQM apresenta dois estágios, sendo que no primeiro de identificação dos marcadores importantes e da interação marcadores $\mathrm{x}$ ambientes foi obtida pelo método de regressão múltipla backward, aplicado em todos os marcadores e ambientes. No segundo estágio, a 
probabilidade de um suposto QTL foi acessada de cada localização no mapa, como em IM, mas os marcadores pré selecionados foram usados como co-fatores, exceto para os marcadores flanqueadores do intervalo em estudo. Com o método MQM os autores encontraram evidência de 12 QTL's, quatro deles apresentando interação QTL's x ambientes.

Schön et al. (1994) mapearam e caracterizaram QTL's relacionados ao desempenho de dois topcrosses em milho, e discutiram a eficiência destes QTL's através dos diferentes ambientes e testadores. Os objetivos do trabalho foram: (1) estimar o número de QTL's com efeitos genéticos significativos envolvidos na expressão da característica, (2) determinar a magnitude de seus efeitos genéticos, (3) determinar a consistência dos QTL's para um dado testador através dos ambientes e (4) julgar a consistência dos QTL's através dos testadores. As características avaliadas foram o conteúdo de proteina, o peso das sementes e a altura das plantas. Os autores encontraram boa concordância dos QTL's detectados através dos ambientes nos dois topcrosses envolvidos. Quanto aos testadores, verificaram resultados altamente consistentes para o peso de sementes e a altura de plantas, o que não ocorreu para o conteúdo de proteína.

Lee et al. (1996) avaliaram uma população de soja por marcadores RFLP com o objetivo de: (1) identificar QTL's relacionados à altura da planta, tombamento e ciclo e (2) examinar a consistência da detecção dos QTL's em diferentes ambientes. Pela análise de variância, 11 marcadores relacionados à altura de planta e oito relacionados ao tombamento explicaram a maior parte da variabilidade genética dessas características em análises combinadas dos locais. Dos 11 marcadores relacionados à altura da planta e dos oito relacionados ao tombamento, apenas dois para altura de planta e um para o tombamento foram detectados em todos os locais, indicando a inconsistência dos QTL's através dos ambientes. Para o ciclo reprodutivo, os QTL's encontrados nos diferentes ambientes foram coincidentes. Dos cinco marcadores que explicavam a caracteristica no conjunto dos très locais, quatro estavam presentes em todos os locais. Os resultados 
desse trabalho indicaram que o nivel de consistência dos QTL's através dos ambientes é dependente da característica avaliada.

Segundo Veldboom \& Lee (1996) estudos sobre o mapeamento de QTL's conduzidos em diferentes ambientes podem levar à identificação de genes associados a condições de estresse, além de ajudar na compreensão de alguns tipos de interação genótipos $\mathrm{x}$ ambientes. Assim, conduziram um trabalho com o objetivo de investigar a ocorrência de QTL's relacionados ao florescimento e à altura das plantas em dois ambientes distintos e verificar a relação genética entre os QTL's e as características correlacionadas. Os resultados obtidos sugerem que os QTL's detectados tanto em condições de estresse como na ausência de estresse apresentam efeitos relativamente consistentes em relação à contribuição dos genitores e a localização no genoma. Tanto para a produtividade de grãos quanto para as características morfológicas, cerca de $50 \%$ dos QTL's foram detectados nos dois ambientes. Os QTL's de efeito pronunciado num ambiente nem sempre foram detectados no outro ambiente, o que indica que a magnitude do efeito de um QTL não significa necessariamente sua consistência ao longo dos ambientes.

Para que as associações marcador - QTL sejam úteis no melhoramento de plantas, elas precisam ser consistentes ao longo das populações dentro de um grupo heterótico e ao longo das linhagens de diferente background genético usadas como testadores (Kerns et al., 1999). Os autores afirmam que a identificação de QTL's é afetada por fatores como: 1) geração avaliada, 2) magnitude das diferenças entre os alelos, 3) precisão dos dados e 4) número de individuos na população usada no mapeamento. Quanto maior o efeito e quanto menor o desvio padrão do erro, maior é a probabilidade de deteç̧ão dos QTL's (Dudley, 1992, citado pelos autores). Os efeitos dos alelos considerados como favoráveis nesse estudo eram relativos a características agronômicas de milho, e foram testados quanto à sua significância no nivel de $\mathrm{P}<0,05$. Os autores concluíram que, dentro dos topcrosses, a deteç̧ão de QTL's significativos é 
função da variância genética gerada pelo cruzamento e da interação com os alelos dos testadores no QTL. Os resultados dos topcrosses apoiaram esta conclusão, pois o cruzamento oriundo do testador ISSS identificou mais marcadores significativos, mais regiões com associações marcador-QTL significativas e mais variação na análise de regressão múltipla do que o cruzamento com o testador Lancaster.

Ma \& Sorrells (1995) utilizaram RFLP's para estudar a restauração da fertilidade conferida pelos genes $R f$ em linhagens de trigo R113 e Primepi. Os autores concluíram que RFLP's são uma forma sensivel de se identificar genes relacionados com a restauração da fertilidade, por não apresentarem os efeitos de confusão dos aneuplóides, que complica a análise dos monossômicos. Também não necessitam da classificação dos dados fenotípicos, geralmente arbitrários, o que previne da deteç̧ão de genes de efeito pequeno. Numa população grande, com boa cobertura do genoma pelos marcadores moleculares e o uso de repetições para os dados fenotípicos, pode-se obter informações completas e precisas sobre esses genes.

Há várias formas de se testar a significância relacionada a locos marcadores, e uma delas é a aplicação de um teste estatístico como o teste $t$, por exemplo, em cada loco. A desvantagem dessa abordagem está em não considerar os efeitos de sobreposição das sondas. Assim, sondas similares, marcando um mesmo segmento ou boa parte dele, podem ser identificadas como significativas simultaneamente, sem considerar que se trata da mesma região cromossômica. Outro ponto negativo das comparações independentes é o aparecimento de falsos positivos, ou a probabilidade de um loco ser detectado como significativo por acaso, que está associado com o nivel de significância utilizado. Assim, métodos de abordagem múltipla dos locos são mais recomendados para a seleção das sondas.

Para Falconer \& Mackay (1996) detectar QTL's ligados a um único marcador através da frequência de recombinação entre marcador e QTL pode levar a 
valores genotipicos subestimados. A confusão das estimativas dos efeitos aditivos e de dominância de um QTL ligado a um único marcador pode ser resolvida quando se consideram pares de marcadores ligados ao QTL, o que é chamado de mapeamento por intervalo ou interval mapping. Esse método é comumente citado nos trabalhos de diversos autores, além de ser utilizado em aplicativos próprios para o mapeamento de QTL's.

Matioli $^{1}$ afirma que o método de verossimilhança é mais adequado à identificação de marcadores associados a QTL's do que testes independentes, pois utiliza informações de todos os locos em conjunto, aumentando o poder de análise. Porém o autor destaca que a eficiência do método depende do tamanho da amostra, da quantidade de marcadores e da sua distribuição ao longo do genoma.

Outra forma de se conseguir uma abordagem múltipla dos locos é através de análise de regressão. Moreau et al. (1999) cita o uso do procedimento stepwise na seleção de marcadores de efeito significativo. Como os autores trabalharam com experimentos em vários ambientes, aplicaram o procedimento stepwise em cada local separadamente, e os marcadores selecionados nesta primeira etapa foram submetidos simultaneamente a uma nova regressão stepwise para avaliação do conjunto. Os marcadores retidos no nivel de significância de $5 \%$ foram os escolhidos para participar do modelo e explicar a característica. Também Kerns et al. (1999) utilizaram o procedimento stepwise na deteç̧ão de marcadores relacionados com a expressão de várias características agronômicas de milho. Os autores trabalharam com os limites $\mathrm{P}<0,10$ para entrada e permanência no modelo, e o coeficiente $R^{2}$ da regressão foi utilizado como medida da variação explicada pelos marcadores.

\footnotetext{
${ }^{1}$ MATIOLI. S. R. (Instituto de Ciências Biológicas, Universidade de São Paulo. SP). Anotações de curso, 1999.
} 
$\mathrm{Na}$ seleção das sondas, o nivel de significância estatística utilizado pelos autores varia conforme o trabalho e conforme a característica. Assim, Godshalk et al. (1990) utilizaram diferentes níveis de significância para as características avaliadas, sendo $0,01 \%$ de probabilidade para a umidade do grão, acamamento e altura de espiga, e $1 \%$ de probabilidade para a produtividade de grãos. Dentre as sondas utilizadas, 12 estavam associadas à produtividade de grãos, 16 controlavam a umidade dos grãos, 14 associadas à altura de espiga e finalmente 32 sondas associadas ao acamamento.

Quando se tem um grande número de locos marcadores, e um teste de significância estatística é aplicado em cada loco, certos efeitos declarados como significativos podem não o ser, o que é chamado de falsos positivos ou erro Tipo I. Assim, ao se usar o nivel de significância 0,05 numa amostra com 100 marcadores, onde para cada marcador foi realizado um teste, cinco testes dentre os 100 poderão se mostrar significativos sem que haja associação real entre o loco marcador e o QTL. Como o número de marcadores utilizados geralmente é grande, um número apreciável de erros Tipo I é esperado. Lander \& Botstein (1989, citados por Dudley, 1993) sugerem o uso do nivel de significância equivalente a 0,001 com o intuito de reduzir o número de falsos positivos. Porém, ao se diminuir a probabilidade de ocorrência de erro Tipo I, aumentase a probabilidade de aparecimento de erro Tipo II, que é a aceitação da hipótese de nulidade sendo ela falsa. Assim, autores como Bubeck et al. (1993) preferem usar o nível 0,05 de probabilidade.

Estudando caracteres agronômicos em abóboras, Kennard \& Havey (1995) admitem que falsos positivos podem ocorrer no nível de significância $\mathrm{P}<0,05$, e sugerem que se confirme a detecção QTL's encontrados em gerações posteriores, como retrocruzamentos. Na seleção e descarte de QTL's significativos, os autores compararam o uso do programa Mapmaker com o procedimento de regressão múltipla backward. Ambos os métodos levaram a resultados semelhantes, sendo que o programa Mapmaker detectou associações mais significativas (maior poder de resolução). 


\section{MATERIAL E MÉTODOS}

Os dados utilizados neste estudo foram gerados pelo departamento de pesquisa e desenvolvimento da empresa Garst Seeds, componente do grupo Zeneca, com base em Slater, Iowa, EUA, no ano agrícola de 1996.

\section{1. Material}

Inicialmente, foi produzido um sintético através do cruzamento de duas linhagens endogâmicas pertencentes ao grupo ISSS, gerando os individuos da geração $F_{1}$, que foram cruzados para originar a geração $F_{2}$. Da geração $F_{2}$ obtida deste cruzamento, extraíram-se plantas que foram autofecundadas gerando as progênies $S_{1}$. Essas progênies $S_{1}$ foram autofecundadas sem controle genealógico e geraram as 68 progênies $S_{2}$ utilizadas neste estudo.

As progennies $S_{2}$ foram avaliadas em topcrosses representando o genitor feminino. Como testador, ou genitor masculino, utilizou-se uma linhagem endogâmica pertencente ao grupo heterótico Lancaster. Os experimentos ainda continham hibridos simples comercias da empresa Garst Seeds como testemunhas ou tratamentos comuns. 
Cada genitor feminino dos topcrosses foi genotipado por RFLP's, e para isso amostras de DNA foram coletadas das plântulas de milho no estágio de duas folhas.

\section{2. Métodos}

A metodologia adotada pode ser separada em biométrica e molecular, conforme segue.

\section{2. 1. Métodos biométricos}

Neste trabalho, foram utilizados experimentos conduzidos em diferentes ambientes para a avaliação da produtividade de grãos das progênies. Os resultados coletados nos experimentos foram usados na obtenção das médias ajustadas das progênies, na deteç̧ão das marcas significativas bem como na determinação das variância genética atribuída aos marcadores.

\section{2. 1. 1. Delineamento experimental}

No ano agrícola de 1996, as 68 progênies em topcrosses foram avaliadas em quatro locais diferentes, que se concentraram no estado de Iowa, EUA, na região caracterizada como Corn Belt americano.

O delineamento experimental utilizado foi em blocos incompletos com testemunhas comuns, como sugerido por Gomes (1990), por possibilitar a comparação entre progênies presentes nos diferentes blocos. Cada bloco conteve tratamentos regulares (cruzamentos entre as progênies $\mathrm{S}_{2}$ e o testador) e tratamentos comuns ou testemunhas (hibridos simples comerciais da empresa Garst Seeds). Cada experimento 
contou com duas repetições e três blocos incompletos com oito testemunhas cada um. O número de progênies presentes nos blocos foi de 30,20 e 18, para os blocos um, dois e três, respectivamente. As testemunhas, presentes em todos os blocos, possibilitaram o ajuste das médias das progênies.

A característica medida nos experimentos e utilizada neste trabalho foi a produtividade de grãos, mensurada em $\mathrm{kg} / \mathrm{ha}$. Outras características agronômicas foram medidas, mas estas serão consideradas em trabalhos posteriores. A densidade de plantio utilizada foi de 24.000 plantas por acre, o que corresponde a 59.304 plantas por hectare, de acordo com os padrões da empresa Garst Seeds.

As análises de variância, segundo o delineamento em blocos incompletos, foram executadas com o programa SAS (SAS Institute, 1999), com os valores de produtividade de grãos coletados em cada um dos quatro locais. Dessa forma foram obtidas as médias ajustadas das progênies para cada local e para a análise conjunta. Estas médias foram utilizadas posteriormente nos procedimentos de análise genética.

\section{2. 1. 2. Determinação dos alelos favoráveis associados às} marcas

Os alelos favoráveis associados às marcas foram identificados em cada loco marcador separadamente, considerando todas as progênies avaliadas. Inicialmente foi preciso definir a média de produtividade de grãos, em $\mathrm{kg} / \mathrm{ha}$, das progênies que apresentavam o mesmo genótipo. Apenas os individuos homozigóticos foram considerados nestes cálculos, feitos com os dados da genotipagem e com as médias ajustadas das progênies. Como os experimentos foram instalados em quatro locais diferentes, as médias dos homozigotos foram calculadas para cada local e também para a análise conjunta. 
Definida a média em $\mathrm{kg} / \mathrm{ha}$ dos individuos homozigóticos para as marcas RFLP, passou-se à identificação dos homozigotos favoráveis. Para isso, foi feito um contraste entre as médias dos homozigotos, conforme a definição de Falconer \& Mackay (1996). Considerando o loco A, com dois alelos marcadores $A_{1}$ e $A_{2}$, e adotando a convenção $A_{1}$ para o alelo associado a genes que aumentam o valor da característica, $o$ desvio genotípico é representado por:

$$
" a "=\frac{\left(\bar{Y}_{A_{1} A_{1}}-\bar{Y}_{A_{2} \cdot A_{2}}\right)}{2}
$$

sendo,

" $a$ " = desvio genotípico para o loco marcador em questão,

$\bar{Y}_{A_{1}-A_{1}}=$ média dos individuos com o genótipo marcador $\mathrm{A}_{1} \mathrm{~A}_{1}, \mathrm{e}$

$\bar{Y}_{\ell_{2} A_{2}}=$ média dos indivíduos com o genótipo marcador $\mathrm{A}_{2} \mathrm{~A}_{2}$.

Quando o homozigoto contrastado apresentou um valor " $a$ " positivo, foi considerado favorável. Em caso de valor " $a$ " negativo, o homozigoto foi classificado como desfavorável. Uma vez definidos quais eram os homozigotos favoráveis e desfavoráveis, os locos foram codificados para as análises de regressão posteriores. Ao homozigoto favorável atribuiu-se o valor 1 , e o homozigoto desfavorável recebeu o valor -1. Quando o genótipo apresentava apenas uma cópia do alelo favorável recebeu o valor 0 . Nas tabelas $6,7,8,9,10,11,12,13,14$ e 15 do apêndice podem ser observados os dados referentes à codificação dos genótipos das plantas-mãe das linhagens, para as 
sondas utilizadas nos cromossomos $1,2,3,4,5,6,7,8,9$ e 10 , respectivamente. A tabela 16 do apêndice mostra os dados referentes às sondas 154 a 157.

O cálculo dos valores genotípicos, conforme demonstrado acima, só seria possível em locos contendo apenas dois alelos, o que ocorreu na maioria das 157 sondas utilizadas. Nestes locos, considerou-se alelo favorável aquele cujo homozigoto apresentava um valor " $a$ " positivo. Porém, cerca de 30\% dos locos apresentavam alelos múltiplos, havendo desta forma mais de duas classes de homozigotos. Neste caso, o homozigoto que apresentou um valor maior em $\mathrm{kg} /$ ha foi considerado como favorável, e recebeu o valor 1. Quando apenas uma cópia de seus alelos estava presente num indivíduo, este foi considerado heterozigoto para o alelo favorável e recebeu o valor 0 . Os individuos que não apresentaram nenhuma cópia do alelo favorável receberam valor -1 .

Esse procedimento foi realizado para todos os 157 locos marcadores utilizados neste estudo, e repetido para cada um dos quatro locais e para a análise conjunta. Com a codificação loco a loco das progênies e as médias ajustadas de produtividade de grãos, foram feitas as análises de regressão para a determinação das sondas significativas e dos valores genotípicos associados às sondas, como será visto no próximo item.

\section{2. 1. Detecção das marcas com efeitos significativos}

Após a definição dos alelos favoráveis associados às marcas e a codificação das progênies em cada loco, foi possivel identificar quais marcadores apresentavam efeito significativo para a caracteristica produtividade de grãos, através de análises de regressão executadas pelo programa SAS (SAS Institute, 1999), conforme segue. 
Primeiramente, as marcas foram submetidas ao procedimento de regressão múltipla stepwise para cada cromossomo separadamente, que identificou as marcas significativas dentro dos níveis de significância $\mathrm{P}<0,10$ e $\mathrm{P}<0,15$, para entrada e permanência no grupo, respectivamente. $O$ segundo passo foi executar uma análise de regressão múltipla reunindo todos os cromossomos, com as marcas selecionadas pelo stepwise; aquelas que apresentaram efeitos significativos neste modelo foram utilizadas nos cálculos posteriores. A análise de regressão múltipla forneceu os coeficientes parciais de regressão $b_{j}$ e o coeficiente de determinação $\mathrm{R}^{2}$, utilizado como medida da proporção da soma de quadrados entre topcrosses explicada pelos marcadores utilizados. A deteç̧ão das marcas significativas foi feita nos quatro locais separadamente e na análise conjunta.

Na regressão múltipla foi empregado o modelo linear usual, ou seja,

$$
Y_{i}=\mu+b_{1} X_{i 1}+b_{2} X_{i 2}+\ldots+b_{j} X_{i j}+\ldots+b_{m} X_{i m}+\bar{d}_{i .}, \text { em que }
$$

$Y_{i}$ é a média ajustada da produtividade de grãos da progênie (topcross) $i(i=1,2, \ldots, n)$.

$\mu$ é o intercepto.

$b_{j}$ é o efeito genotípico associado ao loco marcador $j(j=1,2, \ldots, m)$, cuja participação no modelo foi decidida anteriormente pelo processo stepwise de regressão, aplicado por cromossomo, conforme já exposto.

$X_{i j}$ é uma variável matemática indicativa do estado genotípico da progênie $i$, no loco marcador $j$, valendo 1,0 ou -1 . Como já mencionado, $X_{i j}$ valerá 1 se a progênie for homozigótica na marca $j$ e tiver QTL's favoráveis associados a essa condição; será -1 
para os homozigotos com QTL's desfavoráveis associados e será 0 se a progênie for homozigótica nesse loco marcador $j$.

$\bar{d}_{i}$. é um desvio em relação ao modelo e engloba o erro experimental médio ocorrido na observação $Y_{i}$ bem como qualquer insuficiência paramétrica do modelo.

Observa-se, nesse modelo, que os coeficientes $b_{j}$ são equivalentes a efeitos aditivos, ou seja, efeitos aditivos associados às marcas. No caso, por exemplo, de um só QTL $(Q ; q)$ ligado à marca $M\left(M_{1}, M_{2}\right)$ em que os efeitos genotípicos são dados por:

$Q Q: \mu+a ; Q q: \mu+d ; \quad q q: \mu-a$, e a fração de recombinação entre $Q$ e $M$ é $c$, tem-se que $b=a(1-2 c)$, se as freqüências alélicas forem 0,5 . Percebe-se que, nestas condições, há correspondência entre $b$ e o desvio genotípico" $a$ ", mostrado anteriormente.

\section{2. 1. 4. Determinação da variância genética atribuída aos}

\section{marcadores}

Para quantificar a proporção da variação explicada pelos marcadores moleculares, calculou-se o valor $p$ para cada um dos locais, conforme proposto por Bearzoti e Vencovsky (1998). A composição do $\hat{p}$ pode ser vista a seguir.

$$
\hat{p}=\frac{\hat{\sigma}_{m}^{2}}{\hat{\sigma}_{g}^{2}}=\frac{\hat{\sigma}_{m}^{2}}{\hat{\sigma}_{m}^{2}+\hat{\sigma}_{h}^{2}}
$$

em que, 
$p=$ proporção da variância genética explicada pelos marcadores;

$\wedge 2$

$\sigma_{g}=$ variância genética entre as progênies;

$\wedge^{2}$

$\sigma_{m}=$ variância genética explicada pelos marcadores;

$\hat{\sigma}_{h}^{2}=$ variância genética não explicada pelos marcadores;

Na tabela 1 são apresentadas as esperanças dos quadrados médios utilizadas no cálculo de $p$ para cada local. O coeficiente de determinação calculado corresponde a $R^{2}=S Q_{\text {regressáo }} / S Q_{\text {total entre progènies }}$

Tabela 1: Esquema da análise de variância e esperanças dos quadrados médios. Análise por local.

\begin{tabular}{ccc}
\hline FV & GL & E(QM) \\
\hline progênies & $(\mathrm{t}-1)$ & $\sigma^{2}+r\left(\sigma_{h}^{2}+\sigma_{m}^{2}\right)$
\end{tabular}

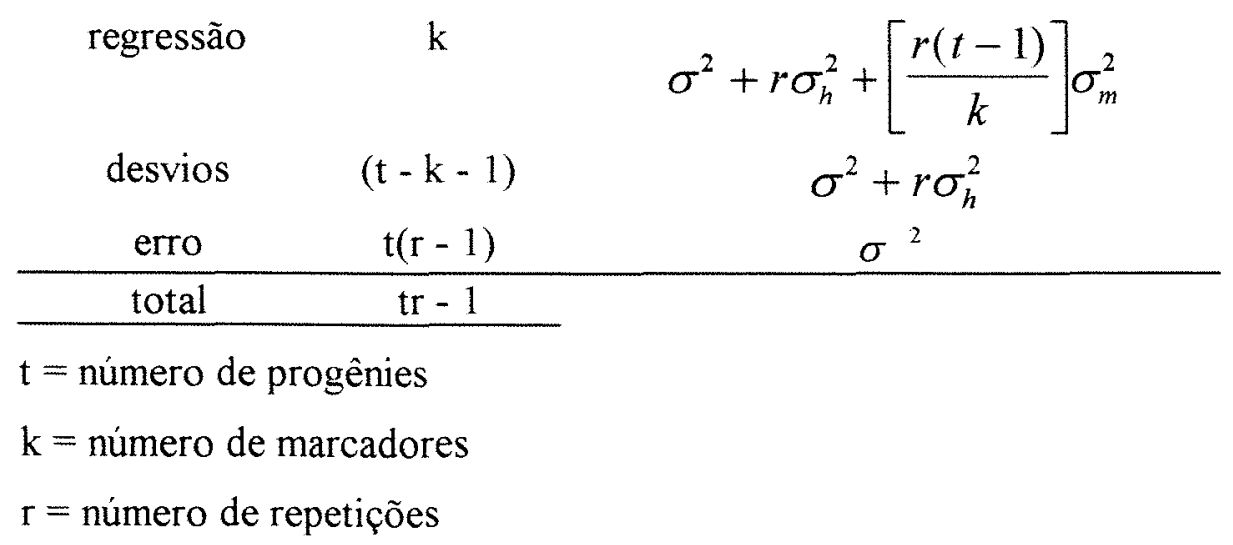


Para realizar a análise conjunta sobre locais, isolando-se os efeitos de regressão (marcas) e desvios, foi feita uma adaptação proposta por Silva ${ }^{1}$ do método de análise mostrado por Bearzoti \& Vencovsky (1998), tratando-se de pesquisa ainda em desenvolvimento.

\section{2. 2. Métodos moleculares}

Para maior clareza, os métodos moleculares foram subdivididos em dois itens, conforme dado a seguir.

\section{2. 2. Genotipagem das plantas-mãe das linhagens}

Os procedimentos de laboratório foram realizados pelo departamento de pesquisas e desenvolvimento da empresa Garst Seeds, com base em Slater, Iowa, EUA, utilizando o protocolo GENTRA, patenteado pela empresa. Esse protocolo permite a obtenção de mini-DNA preps a partir de plântulas de milho no estágio de duas folhas, oferecendo ao laboratório uma capacidade de obtenção de 800-1000 amostras de plantas individuais por dia.

A genotipagem de RFLP's foi realizada para cada genitor feminino dos topcrosses. Para a combinação sonda - enzima, usaram-se as enzimas de restrição Eco RI e Hind III. As análises de eletroforese foram realizadas em gel de agarose a $1 \%$, em instrumentação Pharmacya, a $85 \mathrm{~V}$ por duas horas, e os southern blots feitos imediatamente a seguir, em equipamento Pharmacya, transferindo-se o DNA para membranas Huhond-N As sondas foram preparadas com marcação radioativa $\left(\mathrm{P}_{32}\right)$. A tixação do DNA nas membranas, pré-hibridação, hibridação com as sondas marcadas e

${ }^{1}$ SILVA, H. D. (Universidade Federal de Uberlândia. MG). Variância genética explicada por marcadores moleculares em análises conjuntas. (Em elaboração) 
revelação foram realizadas segundo os procedimentos propostos em Current Protocols in Molecular Biology (Harvard Medical School, 1994). A genotipagem foi realizada manualmente, atribuindo-se códigos de letras ao polimorfismo de RFLP's detectado. Os dados foram então transferidos a uma base de dados para que se executassem os cálculos relativos à análise genética.

\section{2. 2. 2. Distribuição das marcas pelo genoma}

Neste trabalho foram utilizadas 157 marcas RFLP, distribuídas pelos dez cromossomos do milho. O número de marcadores utilizados por cromossomo, bem como o número de regiões cromossômicas investigadas podem ser observados na tabela 2. A coluna referente à média em centiMorgans foi calculada dividindo-se o comprimento do cromossomo, em $c M$, pelo número de intervalos produzidos pelas sondas no mesmo cromossomo, considerando-se suas extremidades. Notam-se cinco sondas extras, que detectaram polimorfismo, mas cujo o grupo de ligação não havia sido determinado.

Tabela 2: Número de sondas RFLP utilizadas por cromossomo e número de intervalos abrangidos do genoma de milho.

\begin{tabular}{cccc}
\hline Cromossomos & Número de sondas & Número de intervalos & Média $(\mathrm{cl})$ \\
\hline 1 & 22 & 17 & 16,70 \\
2 & 15 & 13 & 15,68 \\
3 & 22 & 16 & 11,31 \\
4 & 16 & 7 & 28,61 \\
5 & 21 & 19 & 11,57 \\
6 & 13 & 12 & 13,26 \\
7 & 11 & 11 & 16,32 \\
8 & 10 & 9 & 19,03 \\
9 & 17 & 13 & 11,12 \\
10 & 6 & 7 & 20,04 \\
Extras & + & - & - \\
\hline
\end{tabular}

Média $(c M)$ : valor obtido através da divisão do comprimento do cromossomo (em $c M$ ) pelo número de intervalos produzidos pelas marcas utilizadas no mesmo cromossomo.

Nas tabelas 3 a 12 pode ser observada a distribuição das 152 sondas utilizadas nos dez cromossomos do milho, bem como a distância em $c M$ entre os 
marcadores. Os cinco segmentos extras que não correspondiam a nenhum dos cromossomos, representados pelas sondas 154 a 157 , não foram apresentados nas tabelas.

Tabela 3: Distribuição das marcas RFLP e distância em $c M$ entre elas no cromossomo 1 do milho.

\begin{tabular}{|c|c|c|c|}
\hline Regiões cobertas & Sondas utilizadas & Distância entre marcas & Distância acumulada \\
\hline início & & 0 & 0 \\
\hline 1 & S1 & 46.5 & 46,5 \\
\hline 2 & S2 / S3 & 24,0 & 70,5 \\
\hline 3 & S4 & 37.6 & 108,1 \\
\hline 4 & \$5 & 8.5 & 117,0 \\
\hline 5 & S6 / S7 & 5.2 & 122,2 \\
\hline 6 & S8 & 3.6 & 125,8 \\
\hline 7 & $\mathrm{~S} 9 / \mathrm{S} 10$ & 35.9 & 161.7 \\
\hline 8 & S11 & 15.2 & 176,9 \\
\hline 9 & $\mathrm{~S} 12$ & 0.6 & 177.5 \\
\hline 10 & $\mathrm{~S} 13 / \mathrm{S} 14 / \mathrm{S} 15$ & 4.6 & 182,1 \\
\hline 11 & $\mathrm{~S} 16 / \mathrm{S} 17$ & 1,2 & 183.3 \\
\hline 12 & S18 & 39.9 & 223.2 \\
\hline 13 & S19 & 3.7 & 226,9 \\
\hline 14 & S20 & 3.8 & 230.7 \\
\hline 15 & S21 & 5,5 & 236.2 \\
\hline 16 & S22 & 30.5 & 266.7 \\
\hline fim & & 17.2 & 283.9 \\
\hline
\end{tabular}

Tabela 4: Distribuição das marcas RFLP e distância em $c M$ entre elas no cromossomo 2 do milho.

\begin{tabular}{cccc}
\hline Regiões cobertas & Sondas utilizadas & Distäncia entre marcas & Distância acumulada \\
\hline inicio & & 0 & 0 \\
1 & S23/S24 & 23.3 & 23.3 \\
2 & S25 & 24.3 & 47.6 \\
3 & S26 & 15.1 & 62,7 \\
4 & S27 & 2.7 & 65.4 \\
5 & S28 & 1.3 & 66,7 \\
6 & S30/S31 & 16.3 & 83.0 \\
7 & S29 & 13.4 & 96.4 \\
8 & S32 & 2.9 & 99.3 \\
9 & S33/S34 & 3.2 & 102.5 \\
10 & S35 & 8.7 & 111.2 \\
11 & S36 & 10.7 & 121,9 \\
12 & S37 & 27.7 & 149.6 \\
fim & & 54.3 & 203.9 \\
\hline
\end{tabular}


Tabela 5: Distribuição das marcas RFLP e distância em $c M$ entre elas no cromossomo 3 do milho.

\begin{tabular}{cccc}
\hline Regiôes cobertas & Sondas utilizadas & Distância entre marcas & Distância acumulada \\
\hline início & & 0 & 0 \\
1 & $\mathrm{~S} 38$ & 4,7 & 4,7 \\
2 & $\mathrm{~S} 39$ & 14.9 & 19,6 \\
3 & $\mathrm{~S} 40$ & 27,0 & 46,6 \\
4 & $\mathrm{~S} 41$ & 11,0 & 57,6 \\
5 & $\mathrm{~S} 42 / \mathrm{S} 43 / \mathrm{S} 44 /$ & 1,8 & 59,4 \\
& $\mathrm{~S} 45 / \mathrm{S} 46$ & & \\
6 & $\mathrm{~S} 47$ & 6.6 & 66,0 \\
7 & $\mathrm{~S} 48$ & 0,6 & 66,6 \\
8 & $\mathrm{~S} 50$ & 11,8 & 78,4 \\
9 & $\mathrm{~S} 49$ & 7,3 & 85,7 \\
10 & $\mathrm{~S} 51$ & 18,7 & 104,4 \\
11 & $\mathrm{~S} 52$ & 28,2 & 132,6 \\
12 & $\mathrm{~S} 53$ & 12,1 & 144,7 \\
13 & $\mathrm{~S} 54$ & 3.7 & 148,4 \\
14 & $\mathrm{~S} 55 / \mathrm{S} 56 / \mathrm{S} 57$ & 21,0 & 169,4 \\
15 & $\mathrm{~S} 58 / \mathrm{S} 59$ & 4.1 & 173,5 \\
fim & & 7,4 & 180.9 \\
\hline
\end{tabular}

Tabela 6: Distribuição das marcas RFLP e distância em $c M$ entre elas no cromossomo 4 do milho.

\begin{tabular}{|c|c|c|c|}
\hline Regiões cobertas & Sondas utilizadas & Distância entre marcas & Distância acumulada \\
\hline início & & 0 & 0 \\
\hline 1 & $\begin{array}{c}\text { S60 / S61 / S62 / } \\
\text { S63 }\end{array}$ & 48.9 & 48,9 \\
\hline 2 & $\begin{array}{c}\mathrm{S} 64 / \mathrm{S} 65 / \mathrm{S} 66 / \\
\mathrm{S} 67\end{array}$ & 49,2 & 98,1 \\
\hline 3 & $\begin{array}{c}\mathrm{S} 68 \text { / S69 / S70 / } \\
\text { S71 }\end{array}$ & 22.3 & 120,4 \\
\hline 4 & S72 & 35.7 & 156,1 \\
\hline 5 & $\mathrm{~S} 73 / \mathrm{S} 74$ & 4.2 & 161,1 \\
\hline 6 & S75 & 34.4 & 195.5 \\
\hline fim & & 4.8 & 200,3 \\
\hline
\end{tabular}


Tabela 7: Distribuição das marcas RFLP e distância em $c M$ entre elas no cromossomo 5 do milho.

\begin{tabular}{cccc}
\hline Regiães cobertas & Sondas utilizadas & Distância entre marcas & Distância acumulada \\
\hline início & & 0 & 0 \\
1 & $\mathrm{~S} 76$ & 12.4 & 12,4 \\
2 & $\mathrm{~S} 77$ & 39,6 & 52,0 \\
3 & $\mathrm{~S} 78$ & 2.9 & 54,9 \\
4 & $\mathrm{~S} 79$ & 30,7 & 85,6 \\
5 & $\mathrm{~S} 80$ & 4.1 & 89,7 \\
6 & $\mathrm{~S} 81 / \mathrm{S} 82$ & 7.1 & 96,8 \\
7 & $\mathrm{~S} 83$ & 6.4 & 103,2 \\
8 & $\mathrm{~S} 84$ & 11,3 & 114,5 \\
9 & $\mathrm{~S} 85 / \mathrm{S} 86$ & 7,0 & 121,5 \\
10 & $\mathrm{~S} 87$ & 10.0 & 131,5 \\
11 & $\mathrm{~S} 88$ & 9.2 & 140,7 \\
12 & $\mathrm{~S} 89$ & 6.2 & 146,9 \\
13 & $\mathrm{~S} 90$ & 4.2 & 151,1 \\
14 & $\mathrm{~S} 91$ & 1,8 & 152,9 \\
15 & $\mathrm{~S} 92$ & 18,7 & 171,6 \\
16 & $\mathrm{~S} 93 / \mathrm{S} 94$ & 12.3 & 183,9 \\
17 & $\mathrm{~S} 95$ & 13,3 & 197,2 \\
18 & $\mathrm{~S} 96$ & 7,7 & 204,9 \\
fim & & 14.9 & 219,8 \\
\hline
\end{tabular}

Tabela 8: Distribuição das marcas RFLP e distância em $c M$ entre elas no cromossomo 6 do milho.

\begin{tabular}{cccc}
\hline Regiões cobertas & Sondas utilizadas & Distância entre marcas & Distância acumulada \\
\hline inicio & & 0 & 0 \\
1 & S97 & 6,9 & 6,9 \\
2 & S98 & 20.1 & 27,0 \\
3 & S99 & 12,7 & 39,7 \\
4 & S100 & 16,9 & 56,6 \\
5 & S101/S102 & 2,5 & 59,1 \\
6 & S103/S104 & 29,3 & 88,4 \\
7 & S105 & 4,2 & 92,6 \\
8 & S106 & 18,7 & 11,3 \\
9 & S107 & 18.1 & 129,4 \\
10 & S108 & 12,7 & 142,1 \\
11 & S109 & 4,9 & 147,0 \\
fim & & 12.1 & 159,1 \\
\hline
\end{tabular}


Tabela 9: Distribuição das marcas RFLP e distância em $c M$ entre elas no cromossomo 7 do milho.

\begin{tabular}{cccc}
\hline Regióes cobertas & Sondas utilizadas & Distância entre marcas & Distância acumulada \\
\hline início & & 0 & 0 \\
1 & S110 & 49.1 & 49,1 \\
2 & S111 & 13,0 & 62,1 \\
3 & S112 & 10,5 & 72,6 \\
4 & S113/S114 & 16.2 & 88,8 \\
5 & S115 & 9,5 & 98,3 \\
6 & S116 & 2,6 & 100,9 \\
7 & S117 & 9.7 & 110,6 \\
8 & S118 & 10,5 & 121,1 \\
9 & S119 & 36,2 & 157,3 \\
10 & S120 & 12.0 & 169,3 \\
fim & & 10.2 & 179,5 \\
\hline
\end{tabular}

Tabela 10: Distribuição das marcas RFLP e distância em cM entre elas no cromossomo 8 do milho.

\begin{tabular}{cccc}
\hline Regiões cobertas & Sondas utilizadas & Distância entre marcas & Distância acumulada \\
\hline inicio & & 0 & 0 \\
1 & S121 & 0 & 0 \\
2 & $\mathrm{~S} 122$ & 36,1 & 36,1 \\
3 & $\mathrm{~S} 123$ & 21,9 & 58,0 \\
4 & $\mathrm{~S} 124$ & 5.4 & 63,4 \\
5 & $\mathrm{~S} 125$ & 40.9 & 105,9 \\
6 & $\mathrm{~S} 126$ & 33,7 & 139,6 \\
7 & $\mathrm{~S} 127 / \mathrm{S} 128$ & 22.3 & 161,9 \\
8 & $\mathrm{~S} 129 / \mathrm{S} 130$ & 5.4 & 167,3 \\
fim & & 4.0 & 171.3 \\
\hline
\end{tabular}


Tabela 11: Distribuição das marcas RFLP e distância em cM entre elas no cromossomo 9 do milho.

\begin{tabular}{cccc}
\hline Regiões cobertas & Sondas uilizadas & Distância entre marcas & Distância acumulada \\
\hline inicio & & 0 & 0 \\
1 & S131 & 16.4 & 16,4 \\
2 & S132/S133 & 11.5 & 27,9 \\
3 & S134 & 7,3 & 35,2 \\
4 & S135 & 8.7 & 43,9 \\
5 & S136/S137 & 11.4 & 55,3 \\
6 & S138 & 9,0 & 64,3 \\
7 & S139/S140 & 4.0 & 68,3 \\
8 & S141 & 8.4 & 76,7 \\
9 & S142 & 14.7 & 91,4 \\
10 & S143 & 2.5 & 93,9 \\
11 & S144 & 16.0 & 109,9 \\
12 & S145/S146/S147 & 1,3 & 111.2 \\
fim & & 33.4 & 144.6 \\
\hline
\end{tabular}

Tabela 12: Distribuição das marcas RFLP e distância em cM entre elas no cromossomo 10 do milho.

\begin{tabular}{cccc}
\hline Regiões cobertas & Sondas uilizadas & Distância entre marcas & Distância acumulada \\
\hline início & & 0 & 0 \\
1 & S147 & 55.3 & 55,3 \\
2 & S148 & 19.8 & 75,1 \\
3 & $\mathrm{~S} 149$ & 9.4 & 84,5 \\
4 & $\mathrm{~S} 150$ & 9.1 & 93.6 \\
5 & $\mathrm{~S} 151$ & 3.5 & 97,1 \\
6 & $\mathrm{~S} 152$ & 29.0 & 126,1 \\
fim & & 14.2 & 140.3 \\
\hline
\end{tabular}




\section{RESULTADOS E DISCUSSÃO}

\section{1. Análises básicas}

As médias ajustadas das progênies obtidas para cada local e para o conjunto dos locais podem ser vistas na tabela 4 do apêndice. A análise da variância para cada um dos locais pode ser observada nas tabelas $13,14,15$ e 16 . A tabela 17 apresenta a análise da variância para o conjunto dos locais.

Tabela 13: Análise da variância da produtividade de grãos (kg/ha). Topcrosses e testemunhas de milho. Local 1, lowa, EUA, 1996.

\begin{tabular}{cccc}
\hline FV & $G L$ & $Q M$ & $F$ \\
\hline Repetições & 1 & $187.170,78$ & 0,30 \\
Repetições/blocos & 4 & $5.273 .631,62$ & $8,53^{* *}$ \\
[tratamentos] & {$[75]$} & {$[1.191 .815,19]$} & {$\left[1,93^{* *}\right]$} \\
Progênies aj. & 67 & $1.091 .056,60$ & $1,76^{* *}$ \\
Marcas(regressão) & 14 & $1.518 .808,16$ & 1,55 \\
Desvios & 53 & $978.065,63$ & $1,58^{*}$ \\
Testemunhas & 7 & $1.714 .838,95$ & $2,77^{*}$ \\
progênies vs. testemunhas & 1 & $4.281 .474,24$ & $6,93 * *$ \\
Residuo & 101 & $618.213,69$ & \\
\hline total & 181 & & \\
CV & 7,8 & & \\
média & $10.073,5$ & & \\
\hline
\end{tabular}


Tabela 14: Análise da variância da produtividade de grãos ( $\mathrm{kg} / \mathrm{ha})$. Topcrosses e testemunhas de milho. Local 2, Iowa, EUA, 1996.

\begin{tabular}{cccc}
\hline $\boldsymbol{F V}$ & $\boldsymbol{G L}$ & $\boldsymbol{Q M}$ & $\boldsymbol{F}$ \\
\hline Repetições & 1 & $17.199,48$ & 0,02 \\
Repetiçôes/blocos & 4 & $30.357 .503,64$ & $34,10^{* *}$ \\
[tratamentos] & {$[75]$} & {$[1.967 .833,24]$} & {$\left[2,21^{* *}\right]$} \\
Progênies aj. & 67 & $1.687 .972,17$ & $1,90^{* *}$ \\
marcas (regressão) & 11 & $4.732 .470,70$ & $4,34^{* *}$ \\
Desvios & 56 & $1.089 .945,67$ & 1,22 \\
Testemunhas & 7 & $1.731 .097,05$ & 1,94 \\
progênies vs. testemunhas & 1 & $22.375 .678,19$ & $25,13^{* *}$ \\
Residuo & 88 & $890.369,62$ & \\
\hline total & 168 & & \\
CV & 10,6 & & \\
média & $8.927,8$ & & \\
\hline
\end{tabular}

Tabela 15: Análise da variância da produtividade de grãos ( $\mathrm{kg} / \mathrm{ha})$. Topcrosses e testemunhas de milho. Local 3, Iowa, EUA, 1996.

\begin{tabular}{cccc}
\hline$F V$ & $G L$ & $Q M$ & $F$ \\
\hline Repetições & 1 & $1.234 .638,51$ & 2,41 \\
Repetiçóes/blocos & 4 & $5.785 .939,31$ & $11,27^{* *}$ \\
[tratamentos] & {$[75]$} & {$[1.956 .878,68]$} & {$\left[3,81^{* *}\right]$} \\
Progênies aj. & 67 & $991.085,15$ & $1,93^{* *}$ \\
marcas (regressão) & 14 & $3.677 .208,88$ & $13,06^{* *}$ \\
Desvios & 53 & $281.543,02$ & 0,54 \\
Testemunhas & 7 & $3.809 .301,08$ & $7,42^{* *}$ \\
progênies vs. testemunhas & 1 & $53.698 .088,25$ & $104,63 * *$ \\
Residuo & 74 & $513.196,39$ & \\
\hline total & 154 & & \\
CV & 7,8 & & \\
média & $9.142,3$ & & \\
\hline
\end{tabular}


Tabela 16: Análise da variância da produtividade de grãos ( $\mathrm{kg} / \mathrm{ha})$. Topcrosses e testemunhas de milho. Local 4, Iowa, EUA, 1996.

\begin{tabular}{cccc}
\hline FV & $G L$ & $Q M$ & $F$ \\
\hline repetições & 1 & $741.391,68$ & 1,47 \\
repetições/blocos & 4 & $1.391 .311,27$ & $2,76^{*}$ \\
[tratamentos] & {$[75]$} & {$[770.620,94]$} & {$[1,53 *]$} \\
progênies aj. & 67 & $710.371,68$ & 1,41 \\
marcas (regressão) & 16 & $1.572 .093,80$ & $5,19 * *$ \\
desvios & 51 & $440.027,49$ & 0,87 \\
testemunhas & 7 & $839.008,72$ & 1,66 \\
progênies vs. testemunhas & 1 & $4.328 .606,76$ & $8,58 * *$ \\
residuo & 95 & $504.602,72$ & \\
\hline total & 175 & & \\
CV & 8,2 & & \\
média & $8.720,2$ & &
\end{tabular}

Tabela 17: Análise conjunta da variância da produtividade de grãos $(\mathrm{kg} / \mathrm{ha})$. Topcrosses e testemunhas de milho. Quatro locais, Iowa, EUA, 1996.

\begin{tabular}{cccc}
\hline FV & $G L$ & $Q M$ & $F$ \\
\hline locais & 3 & $63.953 .769,67$ & $66,93 * *$ \\
repetiçóes/locais & 4 & $545.100,11$ & - \\
blocos / repetições / locais & 16 & $10.702 .096,46$ & - \\
[tratamentos] & {$[75]$} & {$[3.033 .829,45]$} & {$\left[3,20^{* *}\right]$} \\
[tratamentos x locais] & {$[225]$} & {$[951.106,20]$} & {$\left[1,50^{* *}\right]$} \\
progênies aj. & 67 & $1.872 .262,06$ & $2,19^{* *}$ \\
marcas (regressão) & 18 & $4.380 .854,08$ & $4,60^{* *}$ \\
desvios & 49 & $950.738,46$ & 1,11 \\
testemunhas & 7 & $4.894 .455,90$ & $4,83^{* *}$ \\
progênies vs. testemunhas & 1 & $67.834 .459,50$ & $9,55^{* *}$ \\
progênies $x$ locais & 201 & $852.907,07$ & $1,35 *$ \\
testemunhas $x$ locais & 21 & $1.012 .500,64$ & $1,60 *$ \\
(progênies vs. testemunhas) x locais & 3 & $7.100 .686,81$ & $11,21 * *$ \\
resíduo & 358 & $633.256,71$ & \\
\hline total & 681 & & \\
CV & 8,6 & & \\
média & $9.228,7$ & & \\
\hline
\end{tabular}


Verificando os valores dos coeficientes de variação (CV) nas tabelas 13 a 17, nota-se que a precisão dos experimentos foi muito boa. A produtividade também foi elevada, variando de $8.720,2$ a $10.073,5 \mathrm{~kg} / \mathrm{ha}$ nos quatro locais, o que reflete condições favoráveis para o desenvolvimento das plantas. Em três dos locais detectou-se significância dos efeitos de progênies, pelo teste $\mathrm{F}$; apenas no local quatro essa significância não foi alcançada, provavelmente devido à interação do tipo genótipos $\mathrm{x}$ ambientes. $\mathrm{Na}$ análise conjunta (tabela 17) é preciso ressaltar a significância dos efeitos gerais de progênies bem como a interação progênies $\mathrm{x}$ locais.

Tais resultados indicam boa qualidade dos resultados para as finalidades desta pesquisa. A significância da fonte de variação progênies $\mathrm{x}$ locais, por sua vez, é um alerta para a possibilidade de se obter resultados não totalmente concordantes de um local para outro, nas análises genéticas subsequentes.

\section{2. Cobertura do genoma pelas marcas utilizadas}

Para que a seleção assistida por marcadores seja eficaz, é imprescindivel a boa cobertura do genoma pelas marcas utilizadas. Além da necessidade de um grande número de sondas, é importante também que elas estejam bem distribuídas entre e dentro de todos os cromossomos, caso contrário não haverá a inspeção de todas as regiões que possam estar envolvidas na manifestação do caráter.

Conforme já mencionado, no presente trabalho a distância entre sondas variou de 11,12 a 28,61 cM nos dez cromossomos do milho, com média de 15,30 cM para todos os cromossomos. Segundo Falconer \& Mackay (1996), um espaçamento de aproximadamente $20 \mathrm{cM}$ entre os marcadores é suficiente para uma boa cobertura do genoma tendo em vista a seleção de QTL's em programas de melhoramento. Observa-se que essa distância minima foi de forma geral respeitada nos cromossomos, com exceção 
no cromossomo 4, cujo valor médio de cobertura foi de $28,61 \mathrm{cM}$. Outro ponto importante diz respeito ao valor do intervalo de posicionamento entre sondas nos cromossomos. Verificou-se que em alguns casos a distância entre os intervalos foi maior que $20 \mathrm{cM}$, enquanto em outros essa distância foi bem menor. Ocorreu também o posicionamento de várias sondas num mesmo ponto do cromossomo. É importante que se evite a saturação de regiões cromossômicas em detrimento de outras, pois todos os pontos devem ser investigados quanto à sua participação na manifestação do caráter, para que a seleção assistida possa apresentar vantagens em relação à seleção convencional.

\section{3. Detecção das marcas de efeito significativo}

As sondas selecionadas pelo procedimento stepwise em cada cromossomo podem ser vistas nas tabelas $18,19,20,21$ e 22 , para os locais $1,2,3,4$ e para a média dos locais, respectivamente.

Tabela 18: Detecção de marcas significativas por cromossomo. Produtividade de grãos de milho (kg/ha). Local 1, Iowa, EUA. 1996.

\begin{tabular}{ccc}
\hline Cromossomos & Marcas selecionadas & $\begin{array}{c}\text { Valor genotípico da marca } \\
\text { associada à produtividade } \\
\text { de grãos (kg/ha) }\end{array}$ \\
\hline 1 & $\mathrm{~S} 4$ & 255,07 \\
1 & $\mathrm{~S} 11$ & $-563,40$ \\
1 & $\mathrm{~S} 14$ & 779,78 \\
2 & $\mathrm{~S} 24$ & 304,09 \\
2 & $\mathrm{~S} 27$ & 204,76 \\
2 & $\mathrm{~S} 34$ & 178,26 \\
4 & $\mathrm{~S} 69$ & 200,71 \\
5 & $\mathrm{~S} 95$ & 148,14 \\
6 & $\mathrm{~S} 109$ & $-27,07$ \\
7 & $\mathrm{~S} 112$ & 223,61 \\
7 & $\mathrm{~S} 119$ & 215,40 \\
7 & $\mathrm{~S} 120$ & 214,49 \\
8 & $\mathrm{~S} 132$ & 95,33 \\
10 & $\mathrm{~S} 150$ & 113,61 \\
\hline
\end{tabular}


Tabela 19: Detecção de marcas significativas por cromossomo. Produtividade de grãos de milho (kg/ha). Local 2, Iowa, EUA. 1996.

\begin{tabular}{ccc}
\hline Cromossomos & Marcas selecionadas & $\begin{array}{c}\text { Valor genotípico da marca } \\
\text { associada à produtividade } \\
\text { de grãos (kg/ha) }\end{array}$ \\
\hline 1 & $\mathrm{~S} 4$ & $-29,78$ \\
1 & $\mathrm{~S} 11$ & $-371,38$ \\
1 & $\mathrm{~S} 14$ & 396,55 \\
2 & $\mathrm{~S} 26$ & 111,79 \\
2 & $\mathrm{~S} 27$ & 450,44 \\
8 & $\mathrm{~S} 132$ & 230,50 \\
9 & $\mathrm{~S} 136$ & 165,98 \\
9 & $\mathrm{~S} 143$ & 318,74 \\
9 & $\mathrm{~S} 148$ & 360,68 \\
10 & $\mathrm{~S} 152$ & 194,28 \\
10 & $\mathrm{~S} 154$ & 293,67 \\
\hline
\end{tabular}

Tabela 20: Detecção de marcas significativas por cromossomo. Produtividade de grãos de milho (kg/ha). Local 3, Iowa, EUA. 1996.

\begin{tabular}{ccc}
\hline Cromossomos & Marcas selecionadas & $\begin{array}{c}\text { Valor genotípico da marca } \\
\text { associada à produtividade } \\
\text { de grãos (kg/ha) }\end{array}$ \\
\hline 1 & $\mathrm{~S} 2$ & 252,32 \\
2 & $\mathrm{~S} 32$ & 120,51 \\
3 & $\mathrm{~S} 42$ & 258,27 \\
3 & $\mathrm{~S} 48$ & 368,75 \\
3 & $\mathrm{~S} 49$ & 89,88 \\
4 & $\mathrm{~S} 60$ & 179,16 \\
5 & $\mathrm{~S} 82$ & 23,86 \\
5 & $\mathrm{~S} 83$ & 280,55 \\
5 & $\mathrm{~S} 94$ & 150,41 \\
6 & $\mathrm{~S} 98$ & 127,90 \\
7 & $\mathrm{~S} 112$ & 108,30 \\
8 & $\mathrm{~S} 127$ & 233,22 \\
9 & $\mathrm{~S} 142$ & $-12,42$ \\
10 & $\mathrm{~S} 150$ & 217,98 \\
\hline
\end{tabular}


Tabela 21: Detecção de marcas significativas por cromossomo. Produtividade de grãos de milho (kg/ha). Local 4, Iowa, EUA. 1996.

\begin{tabular}{ccc}
\hline Cromossomos & Marcas selecionadas & $\begin{array}{c}\text { Valor genotípico da marca } \\
\text { associada à produtividade } \\
\text { de grãos (kg/ha) }\end{array}$ \\
\hline 1 & $\mathrm{~S} 15$ & 156,81 \\
2 & $\mathrm{~S} 25$ & 79,13 \\
2 & $\mathrm{~S} 27$ & $-6,84$ \\
4 & $\mathrm{~S} 65$ & 36,00 \\
4 & $\mathrm{~S} 67$ & 123,69 \\
4 & $\mathrm{~S} 70$ & 209,00 \\
5 & $\mathrm{~S} 76$ & 187,95 \\
5 & $\mathrm{~S} 92$ & 81,97 \\
6 & $\mathrm{~S} 99$ & 98,91 \\
6 & $\mathrm{~S} 105$ & 165,62 \\
6 & $\mathrm{~S} 107$ & 159,38 \\
6 & $\mathrm{~S} 109$ & 135,73 \\
7 & $\mathrm{~S} 110$ & 108,31 \\
9 & $\mathrm{~S} 138$ & 94,79 \\
9 & $\mathrm{~S} 142$ & 138,38 \\
$\mathrm{e}$ & $\mathrm{S} 159$ & 74,34 \\
\hline
\end{tabular}


Tabela 22: Deteç̧ão de marcas significativas por cromossomo. Produtividade de grãos de milho ( $\mathrm{kg} / \mathrm{ha}$ ). Análise conjunta dos quatro locais, Iowa, EUA. 1996.

\begin{tabular}{ccc}
\hline Cromossomos & Marcas selecionadas & $\begin{array}{c}\text { Valor genotípico da marca } \\
\text { associada à produtividade } \\
\text { de grãos (kg/ha) }\end{array}$ \\
\hline 1 & $\mathrm{~S} 2$ & 53,03 \\
1 & $\mathrm{~S} 4$ & 18,84 \\
1 & $\mathrm{~S} 15$ & 153,26 \\
2 & $\mathrm{~S} 27$ & 209,30 \\
2 & $\mathrm{~S} 30$ & 90,48 \\
2 & $\mathrm{~S} 34$ & 155,65 \\
3 & $\mathrm{~S} 49$ & 133,56 \\
3 & $\mathrm{~S} 57$ & 60,69 \\
5 & $\mathrm{~S} 82$ & 589,46 \\
6 & $\mathrm{~S} 98$ & $-508,36$ \\
6 & $\mathrm{~S} 105$ & 79,24 \\
7 & $\mathrm{~S} 110$ & $-12,85$ \\
8 & $\mathrm{~S} 132$ & 102,48 \\
9 & $\mathrm{~S} 141$ & 58,44 \\
9 & $\mathrm{~S} 142$ & 137,90 \\
9 & $\mathrm{~S} 143$ & 135,31 \\
9 & $\mathrm{~S} 148$ & 104,58 \\
10 & $\mathrm{~S} 152$ & 144,75 \\
\hline
\end{tabular}

Nas marcas detectadas, as estimativas dos valores genotipicos mostraram-se bastante contrastantes, não só de uma sonda para outra como de um local para outro. Apesar da manifestação da possivel interação de sondas $\mathrm{x}$ locais, há várias delas identificadas como importantes em pelo menos dois dos locais simultaneamente. Em alguns casos, observaram-se valores genotípicos muito baixos associados às marcas. Tais marcas, apesar dos valores baixos na regressão múltipla, apresentaram significância no processo stepwise por cromossomo, e por essa razão foram incluídas no modelo.

Também verificou-se que as sondas selecionadas nos quatro locais utilizados neste estudo não foram sempre as mesmas, o que pode ser conseqüência da interação QTL $x$ ambiente. A observação mais cautelosa mostra, porém, que regiões importantes 
foram detectadas na maior parte dos casos, para os locais 1,2 e 4 . No local 2 não foram selecionadas sondas em regiões detectadas como importantes nos outros locais, que é o caso da zona abrangida pelas sondas 11 a 15 no cromossomo 1. Verificou-se também, neste local, a ausência de sondas significativas referentes aos cromossomos 5,6 e 7, o que não ocorreu nos outros locais. O local dois também apresentou o menor número de sondas significativas (11) quando comparado com 14, 14 e 16 sondas significativas para os locais 1, 3 e 4, respectivamente. Comparando a análise de variância do local 2 com a dos outros locais, observa-se que neste o coeficiente de variação foi maior, apesar de se encontrar ainda dentro dos limites de precisão de experimentos de campo. Porém, isso pode estar ligado a uma condição ambiental menos favorável, que poderia ter influenciado a manifestação plena da característica, impedindo a expressão de alguns QTL's responsáveis pela produtividade de grãos que não puderam então ser detectados pela análise de regressão.

\section{4. Cálculo de $p$ para as marcas escolhidas}

Os valores de $\hat{p}$ e do $\mathrm{R}^{2}$, bem como alguns resultados obtidos nas análises de variância, podem ser vistos na tabela 23 .

Tabela 23: Resultados principais das análises de variância e valores calculados de $\hat{p}$ e $\mathrm{R}^{2}$. Quatro locais e análise conjunta, lowa, EUA. 1996.

\begin{tabular}{ccccccc}
\hline Locais & média & CV & QMprog & $p$ & $\mathbf{R}^{2}$ & Marcas \\
\hline 1 & $10.073,5$ & 7,81 & $1.091 .056,6$ & 0,239 & 29,09 & 14 \\
2 & $8.927,8$ & 10,57 & $1.687 .972,2$ & 0,745 & 43,88 & 11 \\
3 & $9.142,3$ & 7,84 & $991.085,2$ & $(1,480)$ & 77,53 & 14 \\
4 & $8.720,2$ & 8,14 & $710.371,7$ & $(1,299)$ & 52,84 & 16 \\
Conjunta & $8.228,7$ & 8,62 & $1.872 .262,1$ & 0,747 & 62,86 & 18 \\
\hline
\end{tabular}


Verificando as estimativas do parâmetro $p$ para os quatro locais na tabela 24 notam-se diferentes valores. O uso dos marcadores moleculares, no entanto, fica justificado em geral e principalmente na média dos locais. Pode-se verificar, também, que os valores obtidos de $\hat{p}$ foram superiores aos valores do coeficiente de determinação $\mathrm{R}^{2}$, também utilizado como medida da variação explicada pelos marcadores. O parâmetro $p$ se apresenta, portanto, como forma mais sensivel de quantificação desse fenòmeno.

\section{5. Construção do índice de seleção}

Conforme já mencionado, o objetivo deste estudo foi o de desenvolver um índice de seleção de linhagens para a montagem de sintéticos em milho, baseado nos valores de produtividade de grãos e nos dados da genotipagem de RFLP's. A seguir serão dados os fundamentos relativos à construção do índice.

\section{5. 1. Composição do índice}

A composição do índice de seleção baseia-se nos coeficientes $b_{j}$ de regressão e na constituição genotípica das linhagens. Inclui o comportamento próprio (per se) de cada linhagem $\left(L_{i}\right)$ bem como uma medida da complementaridade genotípica de cada linhagem com as demais $\left(D_{i i^{\prime}}\right)$.

Considerando a linhagem $i$ e sendo $m$ o número de locos marcadores pertinentes, a quantidade $L_{i}^{\prime}=\left(\sum_{j} b_{j} x_{i j}\right) / m$ reflete o comportamento próprio dessa linhagem. Por sua vez $L_{\max }=\left(\sum_{j}\left|b_{j}\right|\right) / m$ é uma medida do comportamento da 
linhagem ideal, ou seja, aquela em que todos os valores $X$, são iguais a 1 . Neste estudo, resolveu-se tomar $L_{i}$ como fração de $L_{\max }$, o que reflete o afastamento da linhagem $\mathrm{i}$ em relação a esse máximo, ou seja $L_{i}=L_{i}^{\prime} / L_{\text {inaix }}$. Da mesma forma, para a linhagem $i^{\prime}$, tem-se $L_{i}=L_{i}^{*} / L_{m i k r}$.

Para a combinação das linhagens $i . i^{\prime}$, portanto, o índice utilizado é dado por

$$
I_{i i^{\prime}}=L_{i i^{\prime}}+D_{i i^{\prime}}
$$

sendo $L_{i i^{\prime}}=\left(L_{i}+L_{i i^{\prime}}\right) / 2$. O paràmetro $D_{i i^{\prime}}$, por sua vez, é constituído de $D_{i i^{\prime}}=D_{n i^{\prime}}^{\prime} / D_{\text {max }}, \quad$ com

$$
\begin{aligned}
& D_{i i^{\prime}}^{\prime}=\sqrt{\sum\left[b_{i}\left(x_{i j}-x_{i \cdot i}\right)\right]^{2} / m} \\
& D_{\max }=2 \sqrt{\frac{\sum b_{i}^{2} / m}{}}
\end{aligned}
$$

A quantidade $D_{i i}^{\prime}$ é uma distância euclidiana entre as linhagens $i$ e $i$, baseada nos valores genotípicos aditivos $\left(b_{i}\right)$ relativos a cada loco marcador. Se duas linhagens forem idênticas, $x_{i j}=x_{i^{\prime},{ }_{i}}$ e $D_{i i^{\prime}}=0$. Por sua vez, a distância entre a linhagem ideal $\left(x_{i j}=1\right)$, e a linhagem pior possivel $\left(x_{i j}=-1\right)$ é a distância máxima $D_{m a x}=\sqrt{\sum_{j}^{2}[1-(-1)]^{2} / m}=2 \sqrt{\sum b_{j}^{2} / m}$

Conforme exposto, $D_{i j}$. também é tomado em relação a essa distància máxima, $D_{n k a}$. 
O índice usado (expressão 1) portanto, tem uma constituição que se assemelha ao que é sugerido pelo modelo representativo de comportamento de um híbrido entre duas linhagens, ou seja, $\bar{F}_{1}=M P+h$, em que $M P$ é a média dos genitores e $h$ a heterose, para o caráter estudado. Observa-se que a distância $D_{i i^{\prime}}$, como medida de complementaridade genotípica entre as linhagens $i i^{\prime}$, leva em conta todos os tipos de locos, independentemente do grau de dominância dos QTL's envolvidos. Nesse aspecto, $D_{i i}$, tende a ser superior à medida da heterose ou da capacidade específica de combinação as quais só detectam complementaridade nos locos com dominância. Por outro lado, $D_{i i}$, tem como desvantagem óbvia o fato de ter sensibilidade ou eficiência apenas naqueles locos (de marcadores e QTL's) em que há segregação, no conjunto de linhagens sob estudo. O mesmo vale para as medidas $L_{i}$. A eficiência de índices como o proposto, para auxiliar na seleção, depende muito também da cobertura genômica que se consegue com os marcadores.

\section{5. 2. Tabela dialélica e seleção de linhagens}

O índice de seleção $\left(I_{i i^{\prime}}\right)$, conforme exposto no item anterior, foi obtido para todas as combinações, duas a duas, das 68 linhagens estudadas. Isso gerou uma tabela dialélica com 2.278 valores. As linhagens candidatas a entrar na constituição de um sintético foram selecionadas com base na média marginal dos respectivos valores $I_{i i^{\prime}}$, ou seja, com base em $\bar{I}_{i .}=\left(\sum_{i^{\prime}} I_{i i^{\prime}}\right) /(n-1), \quad$ com $i, i^{\prime}=1,2, \ldots, n ; i^{\prime} \neq i \quad$ e $n=68$.

As quantidades $\bar{I}_{i}$, que se assemelham a capacidades gerais de combinação, foram ordenadas de forma descendente, selecionando-se como candidatas as com maior valor. Para fins de comparação, as linhagens também foram selecionadas com base nas médias de produtividade obtidas dos ensaios das progênies topcross $\left(\bar{Y}_{i}\right)$. Em ambos os 
casos, optou-se por sintéticos de diferentes tamanhos. O menor sintético considerado foi o de tamanho 5. Depois deste, foram elaborados outros aumentando-se o número de linhagens uma a uma, sempre com base na respectiva ordenação, até se chegar ao sintético amplo, composto de todas as 68 linhagens.

\section{5. 3. Critérios de avaliação dos sintéticos}

Com a finalidade de confrontar o emprego do índice com o critério das médias dos topcrosses e de identificar o tamanho mais adequado dos sintéticos foram adotados dois critérios, a saber: (1) baseados na frequêencia do alelo marcador associado a alelos favoráveis $\left(q_{j}\right)$, em cada loco marcador selecionado e no conjunto desses locos $(\bar{q})$ e $(2)$ baseado no valor genotípico médio $(\bar{b})$ inerente a um sintético, em função da quantidade de locos marcadores selecionados a alelos QTL's favoráveis.

No critério (1), dado no parágrafo anterior, a quantidade $q_{j}$ do loco $j$, foi calculada através da soma das linhagens contendo o genótipo marcador favorável, dividido pelo número total de linhagens constituintes do sintético. Para o dado sintético, como um todo, a frequêencia média $\bar{q}$, foi calculada de modo ponderado, ou seja, através de

$\bar{q}=\frac{\sum q_{j} b_{j}}{\sum b_{j}}$

Essa quantidade $(\bar{q})$ reflete a riqueza de alelos marcadores associados a genes QTL's favoráveis, dando-se peso maior às marcas que detectam QTL's mais importantes na expressào do caràter. 
No critério (2), que é complementar, considerou-se o coeficiente de regressão médio

$\bar{b}=\frac{\sum q_{j} b_{j}}{\sum q_{j}}$

para cada tamanho de sintético. Agora o interesse foi de mensurar o valor genotípico (aditivo) médio detectado pelas sondas, com ponderação pela freqüência com que os alelos marcadores favoráveis selecionados ocorrem, num dado sintético.

$\mathrm{Na}$ discussão dos resultados, serão abordados os aspectos favoráveis e desfavoráveis bem como os riscos inerentes ao uso desses critérios para mensurar a eficiência da seleção auxiliada pelos marcadores.

\section{6. Aplicação do índice de seleção}

O índice de seleção foi calculado para cada um dos quatro locais utilizados neste estudo, assim como para a análise conjunta dos locais. Neste trabalho, houve uma preocupação constante de se comparar os resultados obtidos com o método proposto de seleção assistida por marcadores moleculares com o que seria obtido segundo os procedimentos convencionais de seleção.

Os resultados obtidos pelo índice de seleção são apresentados na tabela 16 do apêndice para os locais separadamente e para a análise conjunta. Os valores relativos à capacidade geral de combinação de cada progènie, obtidos da análise dialélica, e a ordem das linhagens segundo a produtividade de grãos, podem ser observados nas tabelas 25 a 29 , para os locais $1,2,3,4$ e para a análise conjunta, respectivamente. 
Tabela 24: Ordenação das linhagens segundo os valores $\bar{I}_{i}$. obtidos da tabela dialélica, e segundo a produtividade de grãos no topcross $\left(\overline{Y_{i .}}\right)$ - local 1.

\begin{tabular}{|c|c|c|c|}
\hline \multicolumn{4}{|c|}{ Local 1} \\
\hline linhagens & $\bar{I}_{i}$ & linhagens & $\bar{Y}_{i}$ \\
\hline 24 & 0,7084 & 31 & 11987,76 \\
\hline 31 & 0,6759 & 15 & 11821,15 \\
\hline 14 & 0,6363 & 58 & 11767,88 \\
\hline 5 & 0,6059 & 5 & 11692,89 \\
\hline 62 & 0,6018 & 13 & 11408,37 \\
\hline 19 & 0,5757 & 62 & 11343,35 \\
\hline 39 & 0,5521 & 14 & 11159,07 \\
\hline 12 & 0,5470 & 9 & 11151,69 \\
\hline 58 & 0,5311 & 63 & 11093,69 \\
\hline 51 & 0,5142 & 17 & 10934,31 \\
\hline 34 & 0,4837 & 29 & 10907,05 \\
\hline 15 & 0,4774 & 24 & 10903,50 \\
\hline 63 & 0,4348 & 61 & 10884,77 \\
\hline 9 & 0,3646 & 19 & 10875,77 \\
\hline 2 & 0,3002 & 2 & 10868,42 \\
\hline 1 & 0,2645 & 54 & 10820,52 \\
\hline 49 & 0,2529 & 21 & 10723,77 \\
\hline 29 & 0,2495 & 4 & 10645,66 \\
\hline 52 & 0,2373 & 12 & 10573,84 \\
\hline 16 & 0,2266 & 37 & 10508,14 \\
\hline 22 & 0,2244 & 52 & 10487,13 \\
\hline 44 & 0,2219 & 60 & 10457,60 \\
\hline 21 & 0,2186 & 16 & 10248,26 \\
\hline 32 & 0,2171 & 10 & 10211,49 \\
\hline 54 & 0,2113 & 28 & 10189,70 \\
\hline 35 & 0,2098 & 49 & 10170,23 \\
\hline 37 & 0,2071 & 39 & 10158,79 \\
\hline 50 & 0,2070 & 64 & 10115,28 \\
\hline 20 & 0,2035 & 55 & 10109,35 \\
\hline 46 & 0,2026 & 30 & 10107,10 \\
\hline 64 & 0,1987 & 11 & 10002,65 \\
\hline 10 & 0,1968 & 66 & 9998,24 \\
\hline 28 & 0,1903 & 47 & 9977,12 \\
\hline 45 & 0,1901 & 25 & 9905,86 \\
\hline 18 & 0,1847 & 34 & 9879,48 \\
\hline
\end{tabular}




\begin{tabular}{|c|c|c|c|}
\hline linhagens & $\bar{I}_{i}$ & linhagens & $\bar{Y}_{i .}$ \\
\hline 17 & 0,1792 & 27 & 9826,81 \\
\hline 55 & 0,1790 & 53 & 9773,73 \\
\hline 61 & 0,1737 & 67 & 9742,67 \\
\hline 6 & 0,1587 & 33 & 9683,23 \\
\hline 65 & 0,1521 & 23 & 9664,01 \\
\hline 66 & 0,1357 & 35 & 9645,57 \\
\hline 25 & 0,1334 & 42 & 9641,81 \\
\hline 33 & 0,1311 & 68 & 9638,50 \\
\hline 13 & 0,1284 & 44 & 9634,90 \\
\hline 8 & 0,1270 & 8 & 9579,12 \\
\hline 67 & 0,1216 & 6 & 9568,00 \\
\hline 36 & 0,1187 & 1 & 9567,85 \\
\hline 40 & 0,1169 & 40 & 9564,11 \\
\hline 48 & 0,1074 & 20 & 9563,29 \\
\hline 56 & 0,1036 & 43 & 9548,00 \\
\hline 47 & 0,1007 & 46 & 9516,06 \\
\hline 42 & 0,0990 & 7 & 9510,03 \\
\hline 60 & 0,0987 & 45 & 9507,33 \\
\hline 27 & 0,0962 & 41 & 9490,09 \\
\hline 43 & 0,0956 & 18 & 9389,87 \\
\hline 68 & 0,0788 & 57 & 9356,39 \\
\hline 3 & 0,0776 & 32 & 9308,97 \\
\hline 11 & 0,0738 & 22 & 9295,53 \\
\hline 23 & 0,0723 & 36 & 9289,31 \\
\hline 41 & 0,0722 & 38 & 9245,82 \\
\hline 26 & 0,0719 & 48 & 9235,17 \\
\hline 57 & 0,0719 & 65 & 9182,18 \\
\hline 53 & 0,0668 & 56 & 9127,95 \\
\hline 7 & 0,0634 & 3 & 9127,01 \\
\hline 4 & 0,0634 & 50 & 9056,01 \\
\hline 30 & 0,0559 & 26 & 8983,68 \\
\hline 38 & 0,0423 & 51 & 8919,05 \\
\hline 59 & $-0,0011$ & 59 & 8765,18 \\
\hline
\end{tabular}


Tabela 25: Ordenação das linhagens segundo os valores $\bar{I}_{i}$. obtidos da tabela dialélica, e segundo a produtividade de grãos no topcross $\left(\overline{Y_{i .}}\right)$ - local 2.

\begin{tabular}{|c|c|c|c|}
\hline \multicolumn{4}{|c|}{ Local 2} \\
\hline linhagens & $\bar{I}_{i .}$ & linhagens & $\bar{Y}_{i .}$ \\
\hline 62 & 0,6489 & 13 & 11318,35 \\
\hline 21 & 0,5112 & 66 & 10509,94 \\
\hline 24 & 0,5076 & 39 & 10399,76 \\
\hline 1 & 0,4970 & 4 & 10308,65 \\
\hline 12 & 0,4948 & 1 & 10198,48 \\
\hline 63 & 0,4387 & 17 & 10148,07 \\
\hline 39 & 0,4184 & 62 & 10122,18 \\
\hline 9 & 0,4066 & 63 & 9953,79 \\
\hline 64 & 0,3988 & 18 & 9922,12 \\
\hline 34 & 0,3930 & 44 & 9913,39 \\
\hline 45 & 0,3927 & 6 & 9799,13 \\
\hline 46 & 0,3798 & 9 & 9780,92 \\
\hline 5 & 0,3790 & 52 & 9718,62 \\
\hline 47 & 0,3762 & 47 & 9704,45 \\
\hline 2 & 0,3760 & 5 & 9594,28 \\
\hline 4 & 0,3703 & 50 & 9516,91 \\
\hline 31 & 0,3633 & 21 & 9480,03 \\
\hline 19 & 0,3517 & 7 & 9460,52 \\
\hline 7 & 0,3336 & 34 & 9425,70 \\
\hline 61 & 0,3285 & 67 & 9410,98 \\
\hline 6 & 0,3165 & 15 & 9372,40 \\
\hline 50 & 0,3023 & 61 & 9286,31 \\
\hline 14 & 0,2974 & 24 & 9153,26 \\
\hline 52 & 0,2962 & 31 & 9145,94 \\
\hline 51 & 0,2903 & 28 & 9116,98 \\
\hline 13 & 0,2610 & 54 & 9080,57 \\
\hline 54 & 0,2512 & 19 & 9051,00 \\
\hline 27 & 0,2393 & 41 & 9020,49 \\
\hline 28 & 0,2297 & 46 & 8970,21 \\
\hline 10 & 0,2256 & 64 & 8935,29 \\
\hline 66 & 0,2067 & 11 & 8858,62 \\
\hline 58 & 0,1946 & 58 & 8839,17 \\
\hline 15 & 0,1945 & 45 & 8779,64 \\
\hline 32 & 0,1519 & 2 & 8757,31 \\
\hline
\end{tabular}




\begin{tabular}{|c|c|c|c|}
\hline linhagens & $\bar{I}_{i .}$ & linhagens & $\bar{Y}_{i}$ \\
\hline $\mathbf{1 8}$ & 0,1513 & $\mathbf{3 8}$ & 8751,00 \\
\hline $\mathbf{3 3}$ & 0,1377 & $\mathbf{4 3}$ & 8745,51 \\
\hline $\mathbf{1 7}$ & 0,1343 & $\mathbf{3 2}$ & 8715,47 \\
\hline $\mathbf{4 1}$ & 0,1301 & $\mathbf{4 9}$ & 8661,41 \\
\hline $\mathbf{4 9}$ & 0,1206 & $\mathbf{6 0}$ & 8617,00 \\
\hline $\mathbf{1 6}$ & 0,1109 & $\mathbf{5 3}$ & 8591,00 \\
\hline $\mathbf{4 4}$ & 0,1096 & $\mathbf{3 7}$ & 8561,85 \\
\hline $\mathbf{2 9}$ & 0,1018 & $\mathbf{1 4}$ & 8544,38 \\
\hline $\mathbf{5 9}$ & 0,1005 & $\mathbf{2 6}$ & 8490,74 \\
\hline $\mathbf{6 5}$ & 0,0963 & $\mathbf{2 7}$ & 8467,50 \\
\hline $\mathbf{6 7}$ & 0,0961 & $\mathbf{1 2}$ & 8440,68 \\
\hline $\mathbf{2 2}$ & 0,0931 & $\mathbf{3 6}$ & 8351,84 \\
\hline $\mathbf{2 0}$ & 0,0894 & $\mathbf{8}$ & 8294,99 \\
\hline $\mathbf{3}$ & 0,0829 & $\mathbf{5 7}$ & 8287,84 \\
\hline $\mathbf{4 8}$ & 0,0695 & $\mathbf{2 5}$ & 8259,63 \\
\hline $\mathbf{3 6}$ & 0,0659 & $\mathbf{2 9}$ & 8227,63 \\
\hline $\mathbf{3 7}$ & 0,0610 & $\mathbf{6 5}$ & 8219,79 \\
\hline $\mathbf{5 6}$ & 0,0607 & $\mathbf{3 5}$ & 8177,64 \\
\hline $\mathbf{8}$ & 0,0558 & $\mathbf{6 8}$ & 8124,07 \\
\hline $\mathbf{3 8}$ & 0,0516 & $\mathbf{5 9}$ & 8083,52 \\
\hline $\mathbf{4 0}$ & 0,0506 & $\mathbf{1 6}$ & 8065,80 \\
\hline $\mathbf{2 5}$ & 0,0463 & $\mathbf{4 0}$ & 8060,38 \\
\hline $\mathbf{2 3}$ & 0,0375 & $\mathbf{2 2}$ & 8001,32 \\
\hline $\mathbf{3 5}$ & 0,0324 & $\mathbf{3 3}$ & 7995,14 \\
\hline $\mathbf{5 3}$ & 0,0295 & $\mathbf{5 1}$ & 7922,47 \\
\hline $\mathbf{5 7}$ & 0,0204 & $\mathbf{1 0}$ & 7917,60 \\
\hline $\mathbf{2 6}$ & 0,0154 & $\mathbf{3}$ & 7897,59 \\
\hline $\mathbf{6 0}$ & 0,0154 & $\mathbf{4 8}$ & 7781,93 \\
\hline $\mathbf{4 3}$ & 0,0111 & $\mathbf{2 3}$ & 7730,17 \\
\hline $\mathbf{6 8}$ & $-0,0095$ & $\mathbf{5 6}$ & 7492,23 \\
\hline $\mathbf{4 2}$ & $-0,0220$ & $\mathbf{2 0}$ & 6944,17 \\
\hline $\mathbf{1 1}$ & $-0,0354$ & $\mathbf{3 0}$ & 6815,12 \\
\hline $\mathbf{3 0}$ & $-0,0354$ & $\mathbf{5 5}$ & 6748,31 \\
\hline $\mathbf{5 5}$ & $-0,0521$ & $\mathbf{4 2}$ & 6680,03 \\
\hline & & & \\
\hline
\end{tabular}


Tabela 26: Ordenação das linhagens segundo os valores $\bar{I}_{i}$ obtidos da tabela dialélica, e segundo a produtividade de grãos no topcross $\left(\overline{Y_{i}}\right)-$ local 3.

\begin{tabular}{|c|c|c|c|}
\hline \multicolumn{5}{|c|}{ Local 3 } \\
\hline linhagens & $\bar{I}_{i .}$ & linhagens & $\bar{Y}_{i}$ \\
\hline $\mathbf{9}$ & 0,7589 & $\mathbf{9}$ & 10851,24 \\
\hline $\mathbf{6 2}$ & 0,6128 & $\mathbf{6 4}$ & 10412,34 \\
\hline $\mathbf{4 7}$ & 0,5109 & $\mathbf{6 2}$ & 10403,45 \\
\hline $\mathbf{8}$ & 0,4892 & $\mathbf{5 4}$ & 10388,88 \\
\hline $\mathbf{6 0}$ & 0,4770 & $\mathbf{6 8}$ & 10138,64 \\
\hline $\mathbf{4 2}$ & 0,4674 & $\mathbf{3 8}$ & 10045,11 \\
\hline $\mathbf{6 8}$ & 0,4482 & $\mathbf{2 7}$ & 9955,40 \\
\hline $\mathbf{1 2}$ & 0,4147 & $\mathbf{4 1}$ & 9749,06 \\
\hline $\mathbf{3 8}$ & 0,3987 & $\mathbf{6 3}$ & 9513,71 \\
\hline $\mathbf{3 4}$ & 0,3904 & $\mathbf{6 1}$ & 9501,68 \\
\hline $\mathbf{6 6}$ & 0,3776 & $\mathbf{4 7}$ & 9387,40 \\
\hline $\mathbf{5 2}$ & 0,3683 & $\mathbf{5 3}$ & 9370,35 \\
\hline $\mathbf{4 6}$ & 0,3367 & $\mathbf{5 2}$ & 9355,02 \\
\hline $\mathbf{1 7}$ & 0,3288 & $\mathbf{1 2}$ & 9329,93 \\
\hline $\mathbf{4}$ & 0,3275 & $\mathbf{3 9}$ & 9256,94 \\
\hline $\mathbf{4 3}$ & 0,3263 & $\mathbf{4 5}$ & 9138,01 \\
\hline $\mathbf{5 4}$ & 0,3263 & $\mathbf{6 6}$ & 9120,80 \\
\hline $\mathbf{3 5}$ & 0,3216 & $\mathbf{1 4}$ & 9119,77 \\
\hline $\mathbf{6 3}$ & 0,2844 & $\mathbf{4 3}$ & 9118,01 \\
\hline $\mathbf{3 9}$ & 0,2703 & $\mathbf{5 0}$ & 9102,24 \\
\hline $\mathbf{5 6}$ & 0,2599 & $\mathbf{1 7}$ & 9099,23 \\
\hline $\mathbf{3 7}$ & 0,2596 & $\mathbf{4 4}$ & 9084,62 \\
\hline $\mathbf{1 9}$ & 0,2459 & $\mathbf{1 9}$ & 9047,09 \\
\hline $\mathbf{3 2}$ & 0,2341 & $\mathbf{6}$ & 9033,63 \\
\hline $\mathbf{6}$ & 0,2302 & $\mathbf{3 4}$ & 9029,92 \\
\hline $\mathbf{5 0}$ & 0,2291 & $\mathbf{3 0}$ & 9018,36 \\
\hline $\mathbf{1 0}$ & 0,2015 & $\mathbf{5 6}$ & 9001,75 \\
\hline $\mathbf{5 1}$ & 0,1938 & $\mathbf{6 5}$ & 8980,05 \\
\hline $\mathbf{2 3}$ & 0,1845 & $\mathbf{3 7}$ & 8954,67 \\
\hline $\mathbf{4 4}$ & 0,1733 & $\mathbf{5 5}$ & 8915,51 \\
\hline $\mathbf{5 3}$ & 0,1664 & $\mathbf{3 6}$ & 8886,90 \\
\hline $\mathbf{3 6}$ & 0,1516 & $\mathbf{4 9}$ & 8852,79 \\
\hline $\mathbf{6 4}$ & 0,1400 & $\mathbf{2 3}$ & 8815,71 \\
\hline $\mathbf{1 4}$ & 0,1267 & $\mathbf{1 1}$ & 8772,90 \\
\hline $\mathbf{2 5}$ & 0,1225 & $\mathbf{3 3}$ & 8749,63 \\
\hline
\end{tabular}




\begin{tabular}{|c|c|c|c|}
\hline linhagens & $\bar{I}_{i .}$ & linhagens & $\bar{Y}_{i .}$ \\
\hline $\mathbf{3 3}$ & 0,1212 & $\mathbf{3 5}$ & 8722,52 \\
\hline $\mathbf{1 3}$ & 0,1111 & $\mathbf{5 7}$ & 8684,33 \\
\hline $\mathbf{1 8}$ & 0,0984 & $\mathbf{3 2}$ & 8653,63 \\
\hline $\mathbf{2 1}$ & 0,0929 & $\mathbf{4 2}$ & 8520,06 \\
\hline $\mathbf{4 1}$ & 0,0893 & $\mathbf{4 6}$ & 8513,43 \\
\hline $\mathbf{6 5}$ & 0,0875 & $\mathbf{6 7}$ & 8461,96 \\
\hline $\mathbf{2 6}$ & 0,0846 & $\mathbf{4 8}$ & 8445,56 \\
\hline $\mathbf{3 0}$ & 0,0828 & $\mathbf{3 1}$ & 8427,29 \\
\hline $\mathbf{1 1}$ & 0,0819 & $\mathbf{5}$ & 8406,25 \\
\hline $\mathbf{2}$ & 0,0800 & $\mathbf{5 8}$ & 8395,57 \\
\hline $\mathbf{5 5}$ & 0,0737 & $\mathbf{6 0}$ & 8381,94 \\
\hline $\mathbf{4 9}$ & 0,0691 & $\mathbf{2 9}$ & 8315,42 \\
\hline $\mathbf{1 6}$ & 0,0676 & $\mathbf{2}$ & 8178,75 \\
\hline $\mathbf{7}$ & 0,0618 & $\mathbf{5 9}$ & 8142,38 \\
\hline $\mathbf{5 9}$ & 0,0602 & $\mathbf{7}$ & 8139,44 \\
\hline $\mathbf{2 7}$ & 0,0558 & $\mathbf{5 1}$ & 8133,05 \\
\hline $\mathbf{6 7}$ & 0,0532 & $\mathbf{8}$ & 8111,55 \\
\hline $\mathbf{5 7}$ & 0,0433 & $\mathbf{2 1}$ & 8035,67 \\
\hline $\mathbf{3}$ & 0,0376 & $\mathbf{2 5}$ & 8023,83 \\
\hline $\mathbf{4 5}$ & 0,0360 & $\mathbf{1 0}$ & 8008,00 \\
\hline $\mathbf{4 0}$ & 0,0344 & $\mathbf{4}$ & 7880,25 \\
\hline $\mathbf{3 1}$ & 0,0306 & $\mathbf{4 0}$ & 7772,18 \\
\hline $\mathbf{5}$ & 0,0212 & $\mathbf{2 0}$ & 7674,61 \\
\hline $\mathbf{5 8}$ & $-0,0243$ & $\mathbf{1 6}$ & 7631,74 \\
\hline $\mathbf{2 0}$ & $-0,0257$ & $\mathbf{3}$ & 7588,72 \\
\hline $\mathbf{2 2}$ & $-0,0268$ & $\mathbf{2 4}$ & 7568,77 \\
\hline $\mathbf{2 8}$ & $-0,0491$ & $\mathbf{2 6}$ & 7372,59 \\
\hline $\mathbf{6 1}$ & $-0,0502$ & $\mathbf{1 8}$ & 7337,79 \\
\hline $\mathbf{1 5}$ & $-0,0544$ & $\mathbf{2 8}$ & 7106,40 \\
\hline $\mathbf{4 8}$ & $-0,0645$ & $\mathbf{1 3}$ & 6961,75 \\
\hline $\mathbf{2 4}$ & $-0,0664$ & $\mathbf{2 2}$ & 6941,21 \\
\hline $\mathbf{1}$ & $-0,0747$ & $\mathbf{1}$ & 6601,78 \\
\hline $\mathbf{2 9}$ & $-0,0976$ & $\mathbf{1 5}$ & 5666,61 \\
\hline & & & \\
\hline
\end{tabular}




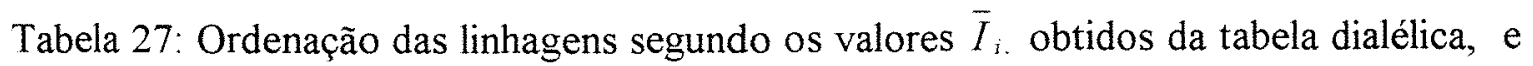
segundo a produtividade de grãos no topcross $\left(\overline{Y_{i .}}\right)$ - local 4.

\begin{tabular}{|c|c|c|c|}
\hline \multicolumn{4}{|c|}{ Local 4} \\
\hline linhagens & $\bar{I}_{i .}$ & linhagens & $\bar{Y}_{i}$ \\
\hline 9 & 0,7078 & 62 & 9975,78 \\
\hline 61 & 0,6152 & 43 & 9519,04 \\
\hline 23 & 0,5533 & 34 & 9463,58 \\
\hline 4 & 0,5448 & 53 & 9419,97 \\
\hline 6 & 0,5111 & 40 & 9410,12 \\
\hline 54 & 0,5073 & 22 & 9408,95 \\
\hline 62 & 0,4765 & 50 & 9402,15 \\
\hline 31 & 0,4467 & 1 & 9393,40 \\
\hline 28 & 0,4372 & 23 & 9332,19 \\
\hline 22 & 0,4321 & 6 & 9323,70 \\
\hline 44 & 0,4036 & 4 & 9299,72 \\
\hline 34 & 0,3853 & 56 & 9281,65 \\
\hline 51 & 0,3701 & 44 & 9259,32 \\
\hline 40 & 0,3478 & 39 & 9234,21 \\
\hline 47 & 0,3202 & 15 & 9187,48 \\
\hline 39 & 0,2987 & 17 & 9146,43 \\
\hline 42 & 0,2960 & 64 & 9083,34 \\
\hline 53 & 0,2847 & 47 & 9071,55 \\
\hline 1 & 0,2844 & 8 & 9044,11 \\
\hline 5 & 0,2744 & 27 & 9034,97 \\
\hline 18 & 0,2723 & 68 & 8987,46 \\
\hline 2 & 0,2597 & 3 & 8978,26 \\
\hline 17 & 0,2584 & 12 & 8958,91 \\
\hline 43 & 0,2530 & 2 & 8943,65 \\
\hline 14 & 0,2439 & 19 & 8919,69 \\
\hline 15 & 0,2403 & 29 & 8917,02 \\
\hline 3 & 0,2384 & 54 & 8915,77 \\
\hline 66 & 0,2337 & 51 & 8886,23 \\
\hline 24 & 0,2218 & 61 & 8879.81 \\
\hline 8 & 0,2016 & 28 & 8874,21 \\
\hline 12 & 0,1890 & 9 & 8841,42 \\
\hline 29 & 0,1883 & 5 & 8803,90 \\
\hline 36 & 0,1840 & 37 & 8797,79 \\
\hline 46 & 0,1832 & 35 & 8776,19 \\
\hline 45 & 0,1631 & 24 & 8766,40 \\
\hline
\end{tabular}




\begin{tabular}{|c|c|c|c|}
\hline linhagens & $\bar{I}_{i}$ & linhagens & $\bar{Y}_{i}$ \\
\hline 19 & 0,1602 & 33 & 8692,33 \\
\hline 60 & 0,1600 & 57 & 8621,75 \\
\hline 16 & 0,1526 & 63 & 8618,42 \\
\hline 50 & 0,1505 & 21 & 8594,80 \\
\hline 27 & 0,1233 & 60 & 8584,35 \\
\hline 48 & 0,1172 & 46 & 8560,12 \\
\hline 35 & 0,1138 & 11 & 8524,42 \\
\hline 58 & 0,1062 & 18 & 8516,67 \\
\hline 57 & 0,1059 & 31 & 8431,31 \\
\hline 38 & 0,1051 & 10 & 8424,96 \\
\hline 63 & 0,1040 & 13 & 8393,46 \\
\hline 32 & 0,0945 & 14 & 8373,56 \\
\hline 49 & 0,0781 & 42 & 8334,25 \\
\hline 68 & 0,0736 & 20 & 8273,72 \\
\hline 56 & 0,0710 & 36 & 8215,45 \\
\hline 59 & 0,0618 & 49 & 8177,76 \\
\hline 37 & 0,0582 & 26 & 8141,41 \\
\hline 33 & 0,0549 & 58 & 8139,03 \\
\hline 65 & 0,0426 & 48 & 8060,68 \\
\hline 11 & 0,0424 & 66 & 8049,49 \\
\hline 52 & 0,0366 & 32 & 8019,62 \\
\hline 20 & 0,0261 & 59 & 8013,28 \\
\hline 13 & 0,0238 & 65 & 7971,89 \\
\hline 25 & 0,0178 & 67 & 7943,00 \\
\hline 30 & 0,0135 & 16 & 7908,20 \\
\hline 21 & 0,0117 & 30 & 7853,36 \\
\hline 67 & $-0,0020$ & 38 & 7838,46 \\
\hline 26 & $-0,0025$ & 41 & 7773,61 \\
\hline 10 & $-0,0152$ & 52 & 7691,55 \\
\hline 7 & $-0,0209$ & 7 & 7664,71 \\
\hline 55 & $-0,0238$ & 25 & 7598,92 \\
\hline 64 & $-0,0422$ & 55 & 7483,29 \\
\hline 41 & $-0,0699$ & 45 & 7082,95 \\
\hline
\end{tabular}


Tabela 28: Ordenação das linhagens segundo os valores $\bar{I}_{i}$ obtidos da tabela dialélica, e segundo a produtividade de grãos no topcross $\left(\overline{Y_{i}}\right)$ - Dados conjuntos dos quatros locais.

\begin{tabular}{|c|c|c|c|}
\hline \multicolumn{4}{|c|}{ Conjunta } \\
\hline linhagens & $\bar{I}_{i}$ & linhagens & $\bar{Y}_{i}$ \\
\hline 63 & 0,5542 & 62 & 10461,19 \\
\hline 9 & 0,5329 & 9 & 10156,32 \\
\hline 62 & 0,5309 & 17 & 9832,01 \\
\hline 14 & 0,4266 & 54 & 9801,43 \\
\hline 12 & 0,4118 & 63 & 9794,90 \\
\hline 5 & 0,4077 & 39 & 9762,42 \\
\hline 47 & 0,3887 & 61 & 9638,14 \\
\hline 19 & 0,3830 & 64 & 9636,56 \\
\hline 54 & 0,3803 & 5 & 9624,33 \\
\hline 52 & 0,3787 & 47 & 9535,13 \\
\hline 46 & 0,3780 & 4 & 9533,57 \\
\hline 39 & 0,3663 & 13 & 9520,48 \\
\hline 60 & 0,3617 & 31 & 9498,07 \\
\hline 21 & 0,3571 & 19 & 9473,39 \\
\hline 18 & 0,3220 & 44 & 9473,06 \\
\hline 7 & 0,3208 & 34 & 9449,67 \\
\hline 8 & 0,3135 & 6 & 9431,11 \\
\hline 37 & 0,3018 & 66 & 9419,62 \\
\hline 50 & 0,2961 & 12 & 9325,84 \\
\hline 61 & 0,2946 & 27 & 9321,17 \\
\hline 38 & 0,2915 & 52 & 9313,08 \\
\hline 31 & 0,2854 & 14 & 9299,20 \\
\hline 51 & 0,2793 & 53 & 9288,76 \\
\hline 32 & 0,2741 & 58 & 9285,41 \\
\hline 2 & 0,2695 & 50 & 9269,32 \\
\hline 3 & 0,2681 & 43 & 9232,64 \\
\hline 1 & 0,2645 & 68 & 9222,17 \\
\hline 66 & 0,2534 & 21 & 9208,57 \\
\hline 24 & 0,2527 & 37 & 9205,61 \\
\hline 36 & 0,2486 & 2 & 9187,03 \\
\hline 34 & 0,2481 & 24 & 9097,98 \\
\hline 6 & 0,2469 & 29 & 9091,78 \\
\hline 23 & 0,2313 & 11 & 9039,65 \\
\hline 4 & 0,2291 & 15 & 9011,91 \\
\hline
\end{tabular}




\begin{tabular}{|c|c|c|c|}
\hline linhagens & $\bar{I}_{i}$ & linhagens & $\bar{Y}_{i}$ \\
\hline $\mathbf{5 8}$ & 0,2237 & $\mathbf{6 0}$ & 9010,22 \\
\hline $\mathbf{4 9}$ & 0,2220 & $\mathbf{4 1}$ & 9008,31 \\
\hline $\mathbf{1 0}$ & 0,2144 & $\mathbf{3 8}$ & 8970,10 \\
\hline $\mathbf{4 3}$ & 0,2098 & $\mathbf{4 9}$ & 8965,55 \\
\hline $\mathbf{1 6}$ & 0,2070 & $\mathbf{1}$ & 8940,37 \\
\hline $\mathbf{6 7}$ & 0,2034 & $\mathbf{4 6}$ & 8889,95 \\
\hline $\mathbf{1 3}$ & 0,1903 & $\mathbf{6 7}$ & 8889,65 \\
\hline $\mathbf{6 4}$ & 0,1887 & $\mathbf{2 3}$ & 8885,52 \\
\hline $\mathbf{4 0}$ & 0,1732 & $\mathbf{3 5}$ & 8830,48 \\
\hline $\mathbf{2 5}$ & 0,1688 & $\mathbf{2 8}$ & 8821,82 \\
\hline $\mathbf{4 5}$ & 0,1686 & $\mathbf{1 8}$ & 8791,61 \\
\hline $\mathbf{1 5}$ & 0,1601 & $\mathbf{3 3}$ & 8780,08 \\
\hline $\mathbf{6 8}$ & 0,1544 & $\mathbf{8}$ & 8757,44 \\
\hline $\mathbf{1 7}$ & 0,1508 & $\mathbf{5 7}$ & 8737,58 \\
\hline $\mathbf{2 7}$ & 0,1503 & $\mathbf{5 6}$ & 8725,89 \\
\hline $\mathbf{4 4}$ & 0,1436 & $\mathbf{4 0}$ & 8701,7 \\
\hline $\mathbf{2 9}$ & 0,1431 & $\mathbf{7}$ & 8693,68 \\
\hline $\mathbf{6 5}$ & 0,1413 & $\mathbf{3 6}$ & 8685,88 \\
\hline $\mathbf{3 5}$ & 0,1355 & $\mathbf{3 2}$ & 8674,42 \\
\hline $\mathbf{1 1}$ & 0,1354 & $\mathbf{1 0}$ & 8640,51 \\
\hline $\mathbf{2 2}$ & 0,1348 & $\mathbf{4 5}$ & 8626,98 \\
\hline $\mathbf{5 7}$ & 0,1332 & $\mathbf{6 5}$ & 8588,48 \\
\hline $\mathbf{2 6}$ & 0,1304 & $\mathbf{5 1}$ & 8465,20 \\
\hline $\mathbf{2 0}$ & 0,1224 & $\mathbf{1 6}$ & 8463,50 \\
\hline $\mathbf{5 6}$ & 0,1208 & $\mathbf{3 0}$ & 8448,49 \\
\hline $\mathbf{5 3}$ & 0,1155 & $\mathbf{2 5}$ & 8447,06 \\
\hline $\mathbf{3 0}$ & 0,1124 & $\mathbf{2 2}$ & 8411,75 \\
\hline $\mathbf{2 8}$ & 0,0969 & $\mathbf{3}$ & 8397,90 \\
\hline $\mathbf{4 2}$ & 0,0934 & $\mathbf{4 8}$ & 8380,84 \\
\hline $\mathbf{5 9}$ & 0,0679 & $\mathbf{5 5}$ & 8314,11 \\
\hline $\mathbf{3 3}$ & 0,0536 & $\mathbf{4 2}$ & 8294,04 \\
\hline $\mathbf{4 1}$ & 0,0474 & $\mathbf{5 9}$ & 8251,09 \\
\hline $\mathbf{4 8}$ & 0,0444 & $\mathbf{2 6}$ & 8247,10 \\
\hline $\mathbf{5 5}$ & 0,0410 & $\mathbf{2 0}$ & 8113,95 \\
\hline & & & \\
\hline
\end{tabular}


Em todos os casos, observa-se que a ordenação das progênies feitas pelo indice de seleção, que leva em conta as distâncias genéticas entre os indivíduos, é diferente daquela estabelecida pelo topcross, onde foram tomados por base apenas os valores obtidos de produtividade de grãos das progênies.

Considerando os dados das tabelas 24 a 28 nota-se, inicialmente, a influência da interação genótipos $x$ ambientes. Convém enfatizar que esses efeitos foram significativos a $5 \%$ pelo teste $\mathrm{F}\left(\mathrm{F}=1,35^{*}\right.$; tabela 17$)$. Tomando por base $o$ índice de seleção e como ponto de referência as melhores 15 linhagens em cada local e na médias destes, somente as linhagens de números $62,12,47,15,46,39,63$ e 9 foram superiores em pelo menos dois dos locais e na média dos locais. Por outro lado, com base no comportamento das progênies topcross, as superiores foram as de número $62,9,63$, $39,13,61,17,5$ e 4 , utilizando os mesmos critérios.

No confronto entre o critério do índice e o critério dos topcrosses, tendo ainda como referencial as melhores 15 linhagens na média dos quatro locais, coincidiram pelos dois critérios as de número $63,9,62,5,47,19,54$ e 39 . Houve pois uma coincidência de $8 / 15$ linhagens ou de aproximadamente 50\% delas. Essas últimas linhagens estão, sem margem de dúvida, entre as melhores do conjunto de 68 analisadas. A dúvida no processo de seleção surge, no entanto, diante das linhagens que se destacam por um critério mas não por outro. Na média dos quatro locais, por exemplo, as de número 46, 60 e 18 estão entre as 15 superiores mas classificam-se como intermediárias pelas médias topcross. Inversamente, as de número 17, 64 e 44 despontam nos topcrosses e não se situam bem pelo índice. Essa discordância está no fato de o índice levar em conta a complementaridade, e as médias topcross não. Lembrando que para o par de linhagens $i i^{\prime}, I_{i i^{\prime}}=L_{i i^{\prime}}+D_{i i^{\prime}}$, tem-se que a média marginal da tabela dialélica é $\bar{I}_{i .}=\bar{L}_{i .}+\bar{D}_{i .} ;$ a complementaridade média $\bar{D}_{i}$. é pois levada em conta na seleção pelo indice. $\mathrm{O}$ artificialismo desse índice está em que $\bar{L}_{i}$. e $\bar{D}_{i}$. receberam pesos iguais para 
compor $\bar{I}_{i}$. Outros pesos poderiam ser investigados visando uma possivel otimização desse índice. Um risco possivel com o uso de $\bar{I}_{i}$. está, por exemplo, na seleção de uma linhagem inferior para a qual $\bar{D}_{i}$. deve ser alto, devido ao forte contraste entre as freqüências gènicas desta com as demais. Tendo essa linhagem inferior um valor baixo de $\bar{L}_{i}$. ela mesmo assim poderá ser selecionada, conforme acontece, por exemplo, com a de número 51, no local 1 (tabela 24). Por essa razão utilizou-se como critério adicional de decisão sobre a composição de um sintético, as freqüências $\bar{q}$, conforme exposto.

Nas tabelas 29 a 33 são dadas as estimativas dos parâmetros de avaliação ( $\bar{q}$ e $\bar{b}$ ) relativos aos melhores sintéticos, com vários tamanhos, organizados através do índice de seleção e do comportamento das linhagens nos topcrosses. 
Tabela 29: Avaliação dos melhores sintéticos com diferentes tamanhos - Local 1 - Iowa, EUA, 1996.

\begin{tabular}{|c|c|c|c|c|c|}
\hline \multicolumn{6}{|c|}{ Índice } \\
\hline $\begin{array}{l}\text { número de } \\
\text { linhagens }\end{array}$ & $\begin{array}{l}\text { menor } \\
q\end{array}$ & $\begin{array}{l}\text { maior } \\
q\end{array}$ & média & $\bar{q}$ & $\bar{b}$ \\
\hline 5 & 0,00 & 1,00 & 0,40 & 0,43 & 268,64 \\
\hline 6 & 0,00 & 1,00 & 0,37 & 0,41 & 281,96 \\
\hline 7 & 0,00 & 1,00 & 0,36 & 0,41 & 288,79 \\
\hline 8 & 0,00 & D) 1,00 & 0,34 & 0,40 & 297,82 \\
\hline 9 & 0,00 & 1,00 & 0,33 & 0,39 & 297,33 \\
\hline 10 & 0,00 & 1,00 & 0,32 & 0,39 & 303,58 \\
\hline 11 & 0,00 & 1,00 & 0,31 & 0.38 & 311,84 \\
\hline 12 & 0,00 & 0,92 & 0,32 & 0.38 & 300,50 \\
\hline 13 & 0,08 & 0,92 & 0,32 & 0.38 & 296,48 \\
\hline 14 & 0,07 & 0,93 & \begin{tabular}{l|l|}
0,32 \\
\end{tabular} & 0,38 & 296,82 \\
\hline 15 & 0,07 & 0,93 & 0,31 & 0.36 & 290,25 \\
\hline 16 & 0,06 & 0,88 & 0,33 & 0.36 & 281,26 \\
\hline 17 & 0,06 & 0,88 & 0,33 & 0,37 & 279,04 \\
\hline 18 & 0,06 & 0,89 & 0,33 & 0.37 & 278,68 \\
\hline 19 & 0,05 & 0,84 & 0,33 & 0,37 & 279,16 \\
\hline 20 & 0,05 & \begin{tabular}{|l|l|} 
\\
\end{tabular} & 0,34 & 0,37 & 276,12 \\
\hline 21 & 0,05 & 0,81 & 0,33 & 0.35 & 272,51 \\
\hline 22 & 0,05 & 0,82 & 0,32 & 0,35 & 271,81 \\
\hline 23 & 0,04 & 0,83 & 0,33 & 0,35 & 270,59 \\
\hline 24 & 0,04 & 0,79 & 0,33 & 0.35 & 268,32 \\
\hline 25 & 0,04 & 0,76 & 0,33 & 0.35 & 264,15 \\
\hline 26 & 0,04 & 0,77 & 0,32 & 0.34 & 261,72 \\
\hline 27 & 0,04 & 0,78 & 0,33 & 0,34 & 260,93 \\
\hline 28 & 0,04 & \begin{tabular}{|l|} 
\\
\end{tabular} & 0,32 & 0,33 & 258,70 \\
\hline 29 & 0,03 & 0,79 & 0,31 & 0.32 & 257,90 \\
\hline 30 & 0,03 & 0,80 & 0,31 & 0.32 & 257.48 \\
\hline 31 & 0,03 & 0,77 & 0,32 & 0.32 & 256,54 \\
\hline 32 & 0,03 & 0,78 & 0,31 & 0.31 & 254,59 \\
\hline 33 & 0,03 & 0,76 & 0,31 & 0,31 & 254,13 \\
\hline 34 & 0,03 & 0,74 & 0,30 & 0,31 & 255,92 \\
\hline 35 & 0,03 & 0,74 & 0,30 & 0,30 & 255,65 \\
\hline 36 & 0,03 & 0,75 & 0,30 & 0,30 & 257,77 \\
\hline 37 & 0,03 & 0,76 & 0,30 & 0.30 & 257,39 \\
\hline 38 & 0,03 & 0,76 & 0,30 & 0.30 & 258,56 \\
\hline 39 & 0,03 & 0,77 & 0,29 & 0,30 & 256,84 \\
\hline 40 & 0,03 & 0,78 & 0,29 & 0.30 & 256,39 \\
\hline 41 & 0,02 & 0,78 & 0,29 & 0.30 & 255,96 \\
\hline 42 & 0,02 & 0,79 & 0,29 & 0.30 & 256,57 \\
\hline 43 & 0,02 & $\begin{array}{l}0,79 \\
\end{array}$ & 0,29 & 0.29 & 256,77 \\
\hline
\end{tabular}

\begin{tabular}{|c|c|c|c|c|c|}
\hline \multicolumn{7}{|c|}{ Topcross } \\
\hline $\begin{array}{l}\text { numero de } \\
\text { linhagens }\end{array}$ & $\begin{array}{l}\text { menor } \\
\text { quaior }\end{array}$ & $\begin{array}{l}\text { mádia } \\
q\end{array}$ & & $\bar{q}$ & $\bar{b}$ \\
\hline 5 & 0,00 & 1,00 & 0,34 & 0,36 & 265,31 \\
\hline 6 & 0,00 & 1,00 & 0,36 & 0,38 & 264,78 \\
\hline 7 & 0,00 & 0,86 & 0,36 & 0,38 & 266,36 \\
\hline 8 & 0,00 & 0,88 & 0,35 & 0,37 & 270,00 \\
\hline 9 & 0,00 & 0,89 & 0,36 & 0,38 & 268,79 \\
\hline 10 & 0,00 & 0,90 & 0,34 & 0,37 & 274,55 \\
\hline 11 & 0,09 & 0,91 & 0,34 & 0,38 & 274,41 \\
\hline 12 & 0,08 & 0,92 & 0,35 & 0,38 & 274,33 \\
\hline 13 & 0,08 & 0,92 & 0,34 & 0,37 & 276,50 \\
\hline 14 & 0,07 & 0,93 & 0,33 & 0,37 & 282,49 \\
\hline 15 & 0,07 & 0,93 & 0,32 & 0,36 & 276,74 \\
\hline 16 & 0,06 & 0,88 & 0,33 & 0,35 & 269,52 \\
\hline 17 & 0,06 & 0,88 & 0,33 & 0,35 & 268,03 \\
\hline 18 & 0,06 & 0,89 & 0,33 & 0,35 & 268,05 \\
\hline 19 & 0,05 & 0,89 & 0,32 & 0,35 & 272,82 \\
\hline 20 & 0,05 & 0,90 & 0,32 & 0,35 & 271,13 \\
\hline 21 & 0,05 & 0,86 & 0,32 & 0,35 & 271,90 \\
\hline 22 & 0,05 & 0,86 & 0,32 & 0,34 & 271,07 \\
\hline 23 & 0,04 & 0,87 & 0,32 & 0,34 & 268,79 \\
\hline 24 & 0,04 & 0,88 & 0,32 & 0,33 & 266,01 \\
\hline 25 & 0,04 & 0,84 & 0,31 & 0,33 & 265,00 \\
\hline 26 & 0,04 & 0,85 & 0,32 & 0,33 & 264,33 \\
\hline 27 & 0,04 & 0,85 & 0,32 & 0,34 & 266,91 \\
\hline 28 & 0,04 & 0,82 & 0,32 & 0,34 & 265,49 \\
\hline 29 & 0,03 & 0,83 & 0,32 & 0,34 & 264,75 \\
\hline 30 & 0,03 & 0,83 & 0,32 & 0,34 & 264,53 \\
\hline 31 & 0,03 & 0,84 & 0,32 & 0,33 & 266,05 \\
\hline 32 & 0,03 & 0,84 & 0,31 & 0,33 & 265,27 \\
\hline 33 & 0,03 & 0,85 & 0,31 & 0,33 & 264,76 \\
\hline 34 & 0,03 & 0,85 & 0,31 & 0,33 & 265,22 \\
\hline 35 & 0,03 & 0,86 & 0,31 & 0,33 & 268,30 \\
\hline 36 & 0,03 & 0,83 & 0,31 & 0,33 & 269,15 \\
\hline 37 & 0,03 & 0,81 & 0,30 & 0,32 & 269,48 \\
\hline 38 & 0,03 & 0,82 & 0,30 & 0,32 & 269,18 \\
\hline 39 & 0,03 & 0,82 & 0,30 & 0,32 & 269,17 \\
\hline 40 & 0,03 & 0,83 & 0,30 & 0,32 & 269,89 \\
\hline 41 & 0,02 & 0,83 & 0,29 & 0,31 & 268,12 \\
\hline 42 & 0,02 & 0,83 & 0,29 & 0,31 & 267,87 \\
\hline+3 & 0,02 & 0,84 & 0,29 & 0,31 & 267,88 \\
\hline & & & & \\
\hline & & &
\end{tabular}




\begin{tabular}{|c|r|r|r|r|c|}
\hline $\begin{array}{l}\text { numero de } \\
\text { linhagens }\end{array}$ & $\begin{array}{l}\text { menor } \\
q\end{array}$ & $\begin{array}{l}\text { maior } \\
q\end{array}$ & média & $\bar{q}$ & $\bar{b}$ \\
\hline 44 & 0,02 & 0,80 & 0,29 & 0,29 & 258,08 \\
\hline 45 & 0,02 & 0,80 & 0,29 & 0,30 & 259,03 \\
\hline 46 & 0,02 & 0,80 & 0,29 & 0,30 & 258,99 \\
\hline 47 & 0,02 & 0,79 & 0,29 & 0,29 & 259,14 \\
\hline 48 & 0,02 & 0,79 & 0,29 & 0,29 & 259,50 \\
\hline 49 & 0,02 & 0,80 & 0,28 & 0,29 & 259,64 \\
\hline 50 & 0,02 & 0,80 & 0,28 & 0,29 & 260,65 \\
\hline 51 & 0,02 & 0,80 & 0,28 & 0,29 & 260,38 \\
\hline 52 & 0,02 & 0,81 & 0,28 & 0,29 & 260,32 \\
\hline 53 & 0,02 & 0,81 & 0,28 & 0,29 & 260,16 \\
\hline 54 & 0,02 & 0,80 & 0,28 & 0,29 & 260,88 \\
\hline 55 & 0,02 & 0,78 & 0,28 & 0,29 & 260,82 \\
\hline 56 & 0,02 & 0,79 & 0,28 & 0,29 & 260,93 \\
\hline 57 & 0,02 & 0,77 & 0,28 & 0,29 & 261,24 \\
\hline 58 & 0,02 & 0,78 & 0,28 & 0,29 & 262,21 \\
\hline 59 & 0,02 & 0,78 & 0,27 & 0,29 & 262,83 \\
\hline 60 & 0,02 & 0,78 & 0,27 & 0,29 & 262,91 \\
\hline 61 & 0,02 & 0,79 & 0,27 & 0,29 & 262,98 \\
\hline 62 & 0,02 & 0,79 & 0,27 & 0,29 & 262,89 \\
\hline 63 & 0,02 & 0,78 & 0,27 & 0,28 & 263,16 \\
\hline 64 & 0,02 & 0,77 & 0,27 & 0,28 & 263,07 \\
\hline 65 & 0,02 & 0,77 & 0,27 & 0,28 & 263,14 \\
\hline 66 & 0,02 & 0,77 & 0,27 & 0,28 & 263,05 \\
\hline 67 & 0,01 & 0,78 & 0,27 & 0,28 & 263,11 \\
\hline 68 & 0,01 & 0,78 & 0,27 & 0,28 & 263,18 \\
\hline
\end{tabular}

\begin{tabular}{|c|c|c|c|c|c|}
\hline $\begin{array}{l}\text { número de } \\
\text { linhagens }\end{array}$ & $\begin{array}{l}\text { menor } \\
q\end{array}$ & $\begin{array}{l}\text { maior } \\
q\end{array}$ & média & $\bar{q}$ & $\bar{b}$ \\
\hline 44 & 0,02 & 0,84 & 0,29 & 0,31 & 267,59 \\
\hline 45 & 0,02 & 0,84 & 0,29 & 0,31 & 268,32 \\
\hline 46 & 0,02 & 0,85 & 0,29 & 0,30 & 266,73 \\
\hline 47 & 0,02 & 0,83 & 0,29 & 0,31 & 264,17 \\
\hline 48 & 0,02 & 0,83 & 0,29 & 0,31 & 264,42 \\
\hline 49 & 0,02 & 0,84 & 0,29 & 0,30 & 263,85 \\
\hline 50 & 0,02 & 0,82 & 0,29 & 0,30 & 263,74 \\
\hline 51 & 0,02 & 0,82 & 0,29 & 0,30 & 263,33 \\
\hline 52 & 0,02 & 0,81 & 0,29 & 0,30 & 263,22 \\
\hline 53 & 0,02 & 0,79 & 0,28 & 0,30 & 264,37 \\
\hline 54 & 0,02 & 0,80 & 0,28 & 0,30 & 264,43 \\
\hline 55 & 0,02 & 0,80 & 0,28 & 0,29 & 264,20 \\
\hline 56 & 0,02 & 0,80 & 0,28 & 0,29 & 264,08 \\
\hline 57 & 0,02 & 0,79 & 0,28 & 0,29 & 263,11 \\
\hline 58 & 0,02 & 0,78 & 0,28 & 0,29 & 261,69 \\
\hline 59 & 0,02 & 0,76 & 0,28 & 0,29 & 261,78 \\
\hline 60 & 0,02 & 0,77 & 0,28 & 0,29 & 261,86 \\
\hline 61 & 0,02 & 0,77 & 0,28 & 0,29 & 261,95 \\
\hline 62 & 0,02 & 0,77 & 0,28 & 0,29 & 261,56 \\
\hline 63 & 0,02 & 0,78 & 0,27 & 0,29 & 262,36 \\
\hline 64 & 0,02 & 0,77 & 0,27 & 0,28 & 262,63 \\
\hline 65 & 0,02 & 0,77 & 0,27 & 0,28 & 261,48 \\
\hline 66 & 0,02 & 0,77 & 0,27 & 0,28 & 261,57 \\
\hline 67 & 0,01 & 0,78 & 0,27 & 0,28 & 263,11 \\
\hline 68 & 0,01 & 0,78 & 0,27 & 0,28 & 263,18 \\
\hline & & & & \\
\hline
\end{tabular}

* Tamanho do sintético conforme o número de linhagens. 
Tabela 30: Avaliação dos melhores sintéticos com diferentes tamanhos - Local 2 - Iowa, EUA, 1996.

\begin{tabular}{|c|c|c|c|c|c|}
\hline \multicolumn{7}{|c|}{\begin{tabular}{l} 
Indice \\
\hline $\begin{array}{l}\text { numero de } \\
\text { linhagens }\end{array}$
\end{tabular}} & $\begin{array}{l}\text { menor } \\
q\end{array}$ & $\begin{array}{l}\text { maior } \\
q\end{array}$ & média & $\bar{q}$ & $\bar{b}$ \\
\hline 5 & 0,00 & 1,00 & 0,44 & 0,40 & 245,58 \\
\hline 6 & 0,00 & 0,83 & 0,42 & 0,40 & 251,13 \\
\hline 7 & 0,14 & 0,86 & 0,44 & 0,40 & 241,87 \\
\hline 8 & 0,13 & 0,88 & 0,42 & 0,39 & 245,28 \\
\hline 9 & 0,11 & 0,89 & 0,41 & 0,39 & 249,89 \\
\hline 10 & 0,10 & 0,90 & 0,42 & 0,39 & 247,74 \\
\hline 11 & 0,09 & 0,91 & 0,42 & 0,39 & 248,10 \\
\hline 12 & 0,08 & 0,92 & 0,42 & 0,39 & 247,57 \\
\hline 13 & 0,08 & 0,92 & 0,41 & 0,38 & 244,89 \\
\hline 14 & 0,07 & 0,93 & 0,42 & 0,38 & 244,30 \\
\hline 15 & 0,07 & 0,93 & 0,40 & 0,37 & 242,81 \\
\hline 16 & 0,06 & 0,94 & 0,41 & 0,37 & 241,49 \\
\hline 17 & 0,06 & 0,94 & 0,41 & 0,37 & 239,60 \\
\hline 18 & 0,06 & 0,94 & 0,40 & 0,36 & 239,62 \\
\hline 19 & 0,05 & 0,95 & 0,41 & 0,37 & 238,76 \\
\hline 20 & 0,05 & 0,95 & 0,41 & 0,37 & 238,47 \\
\hline 21 & 0,05 & 0,95 & 0,40 & 0,36 & 238,13 \\
\hline 22 & 0,05 & 0,95 & 0,39 & 0,35 & 236,79 \\
\hline 23 & 0,04 & 0,96 & 0,39 & 0,35 & 236,88 \\
\hline 24 & 0,04 & 0,96 & 0,39 & 0,35 & 236,31 \\
\hline 25 & 0,04 & 0,96 & 0,39 & 0,34 & 234,70 \\
\hline 26 & 0,04 & 0,96 & 0,38 & 0,34 & 234,25 \\
\hline 27 & 0,04 & 0,96 & 0,38 & 0,34 & 232,55 \\
\hline 28 & 0,04 & 0,96 & 0,38 & 0,33 & 232,20 \\
\hline 29 & 0,03 & 0,97 & 0,38 & 0,33 & 232,19 \\
\hline 30 & 0,03 & 0,97 & 0,38 & 0,33 & 230,75 \\
\hline 31 & 0,03 & 0,97 & 0,37 & 0,32 & 230,77 \\
\hline 32 & 0,03 & 0,97 & 0,37 & 0,32 & 230,49 \\
\hline 33 & 0,03 & 0,97 & 0,36 & 0,31 & 228,55 \\
\hline 34 & 0,03 & 0,97 & 0,36 & 0,31 & 228,63 \\
\hline 35 & 0,03 & 0,97 & 0,36 & 0,30 & 227,18 \\
\hline 36 & 0,03 & 0,97 & 0,35 & 0,30 & 227,28 \\
\hline 37 & 0,03 & 0,97 & 0,35 & 0,30 & 227,37 \\
\hline 38 & 0,03 & 0,97 & 0,35 & 0,30 & 226,67 \\
\hline 39 & 0,03 & 0,97 & 0,35 & 0,30 & 225,56 \\
\hline 40 & 0,03 & 0,98 & 0,35 & 0,30 & 225,71 \\
\hline 41 & 0,02 & 0,98 & 0,35 & 0,30 & 225,82 \\
\hline 42 & 0,02 & 0,98 & 0,35 & 0,30 & 225,73 \\
\hline 44 & 0,02 & 0,98 & 0,35 & 0,29 & 224,54 \\
\hline 0,02 & 0,98 & 0,35 & 0,29 & 224,67 \\
\hline & & & & \\
\hline & & &
\end{tabular}

\begin{tabular}{|c|c|c|c|c|c|c|}
\hline \multicolumn{6}{|c|}{ Topcross } \\
\hline $\begin{array}{l}\text { numero de } \\
\text { linhagens }\end{array}$ & $\begin{array}{l}\text { menor } \\
q\end{array}$ & $\begin{array}{l}\text { maior } \\
q\end{array}$ & média & $\bar{q}$ & $\bar{b}$ \\
\hline 5 & 0,00 & 1,00 & 0,45 & 0,38 & 225,01 \\
\hline 6 & 0,00 & 1,00 & 0,42 & 0,36 & 225,72 \\
\hline 7 & 0,00 & 1,00 & 0,44 & 0,38 & 229,31 \\
\hline 8 & 0,00 & 1,00 & 0,43 & 0,38 & 235,11 \\
\hline 9 & 0,00 & 0,89 & 0,39 & 0,34 & 229,84 \\
\hline 10 & 0,00 & 0,90 & 0,38 & 0,33 & 229,97 \\
\hline 11 & 0,00 & 0,91 & 0,37 & 0,32 & 229,84 \\
\hline 12 & 0,00 & 0,92 & 0,36 & 0,32 & 233,22 \\
\hline 13 & 0,08 & 0,92 & 0,37 & 0,32 & 232,45 \\
\hline 14 & 0,07 & 0,93 & 0,38 & 0,33 & 232,87 \\
\hline 15 & 0,07 & 0,93 & 0,38 & 0,33 & 231,26 \\
\hline 16 & 0,06 & 0,94 & 0,36 & 0,31 & 229,48 \\
\hline 17 & 0,06 & 0,94 & 0,36 & 0,32 & 231,87 \\
\hline 18 & 0,06 & 0,94 & 0,37 & 0,32 & 231,41 \\
\hline 19 & 0,05 & 0,95 & 0,37 & 0,32 & 231,32 \\
\hline 20 & 0,05 & 0,95 & 0,37 & 0,32 & 231,33 \\
\hline 21 & 0,05 & 0,95 & 0,36 & 0,31 & 228,25 \\
\hline 22 & 0,05 & 0,95 & 0,37 & 0,32 & 228,55 \\
\hline 23 & 0,04 & 0,96 & 0,37 & 0,32 & 227,69 \\
\hline 24 & 0,04 & 0,96 & 0,38 & 0,32 & 226,92 \\
\hline 25 & 0,04 & 0,96 & 0,37 & 0,32 & 227,06 \\
\hline 26 & 0,04 & 0,96 & 0,37 & 0,31 & 225,51 \\
\hline 27 & 0,04 & 0,96 & 0,37 & 0,31 & 225,90 \\
\hline 28 & 0,04 & 0,96 & 0,37 & 0,31 & 225,05 \\
\hline 29 & 0,03 & 0,97 & 0,37 & 0,31 & 225,59 \\
\hline 30 & 0,03 & 0,97 & 0,37 & 0,31 & 227,80 \\
\hline 31 & 0,03 & 0,97 & 0,36 & 0,31 & 227,36 \\
\hline 32 & 0,03 & 0,97 & 0,36 & 0,30 & 227,13 \\
\hline 33 & 0,03 & 0,97 & 0,36 & 0,31 & 228,07 \\
\hline 34 & 0,03 & 0,97 & 0,35 & 0,30 & 227,57 \\
\hline 35 & 0,06 & 0,97 & 0,35 & 0,30 & 225,87 \\
\hline 36 & 0,06 & 0,97 & 0,35 & 0,30 & 224,68 \\
\hline 37 & 0,05 & 0,97 & 0,35 & 0,30 & 224,87 \\
\hline 38 & 0,05 & 0,97 & 0,35 & 0,29 & 223,76 \\
\hline 39 & 0,05 & 0,97 & 0,35 & 0,29 & 223,92 \\
\hline 40 & 0,05 & 0,98 & 0,35 & 0,29 & 223,34 \\
\hline 41 & 0,05 & 0,98 & 0,35 & 0,29 & 223,09 \\
\hline 42 & 0,05 & 0,98 & 0,34 & 0,29 & 223,41 \\
\hline 43 & 0,05 & 0,98 & 0,34 & 0,29 & 223,56 \\
\hline & 0,05 & 0,98 & 0,34 & 0,29 & 223,53 \\
\hline
\end{tabular}




\begin{tabular}{|c|r|r|r|r|c|}
\hline $\begin{array}{l}\text { numero de } \\
\text { linhagens }\end{array}$ & $\begin{array}{l}\text { menor } \\
q\end{array}$ & $\begin{array}{l}\text { maior } \\
q\end{array}$ & média & $\bar{q}$ & $\bar{b}$ \\
\hline 45 & 0,02 & 0,98 & 0,35 & 0,29 & 224,79 \\
\hline 46 & 0,02 & 0,98 & 0,34 & 0,29 & 223,42 \\
\hline 47 & 0,02 & 0,98 & 0,34 & 0,29 & 222,72 \\
\hline 48 & 0,02 & 0,98 & 0,34 & 0,28 & 222,47 \\
\hline 49 & 0,02 & 0,98 & 0,34 & 0,28 & 222,62 \\
\hline 50 & 0,02 & 0,98 & 0,33 & 0,28 & 222,77 \\
\hline 51 & 0,02 & 0,98 & 0,33 & 0,28 & 222,57 \\
\hline 52 & 0,02 & 0,98 & 0,33 & 0,28 & 222,34 \\
\hline 53 & 0,02 & 0,98 & 0,33 & 0,28 & 222,48 \\
\hline 54 & 0,04 & 0,98 & 0,33 & 0,27 & 221,41 \\
\hline 55 & 0,04 & 0,98 & 0,33 & 0,27 & 221,56 \\
\hline 56 & 0,04 & 0,98 & 0,33 & 0,27 & 221,35 \\
\hline 57 & 0,04 & 0,98 & 0,33 & 0,27 & 220,61 \\
\hline 58 & 0,03 & 0,98 & 0,32 & 0,27 & 219,68 \\
\hline 59 & 0,03 & 0,98 & 0,32 & 0,27 & 219,34 \\
\hline 60 & 0,03 & 0,98 & 0,32 & 0,26 & 219,16 \\
\hline 61 & 0,03 & 0,98 & 0,32 & 0,26 & 219,33 \\
\hline 62 & 0,03 & 0,98 & 0,32 & 0,26 & 219,50 \\
\hline 63 & 0,03 & 0,98 & 0,32 & 0,26 & 218,84 \\
\hline 64 & 0,03 & 0,98 & 0,32 & 0,26 & 219,01 \\
\hline 65 & 0,03 & 0,98 & 0,32 & 0,26 & 218,37 \\
\hline 66 & 0,03 & 0,98 & 0,31 & 0,26 & 218,22 \\
\hline 67 & 0,03 & 0,99 & 0,31 & 0,26 & 218,07 \\
\hline 68 & 0,03 & 0,99 & 0,31 & 0,25 & 217,91 \\
\hline
\end{tabular}

\begin{tabular}{|c|c|c|c|c|c|}
\hline $\begin{array}{l}\text { número de } \\
\text { linhagens* }\end{array}$ & $\begin{array}{l}\text { menor } \\
q\end{array}$ & $\begin{array}{l}\text { maior } \\
q\end{array}$ & média & $\bar{q}$ & $\bar{b}$ \\
\hline 45 & 0,04 & 0,98 & 0,34 & 0,29 & 224,22 \\
\hline 46 & 0,04 & 0,98 & 0,34 & 0,29 & 224,35 \\
\hline 47 & 0,04 & 0,98 & 0,34 & 0,29 & 224,47 \\
\hline 48 & 0,04 & 0,98 & 0,34 & 0,28 & 224,20 \\
\hline 49 & 0,04 & 0,98 & 0,33 & 0,28 & 223,94 \\
\hline 50 & 0,04 & 0,98 & 0,33 & 0,28 & 223,90 \\
\hline 51 & 0,04 & 0,98 & 0,33 & 0,28 & 224,03 \\
\hline 52 & 0,04 & 0,98 & 0,33 & 0,27 & 222,99 \\
\hline 53 & 0,04 & 0,98 & 0,33 & 0,27 & 223,13 \\
\hline 54 & 0,04 & 0,98 & 0,33 & 0,27 & 222,17 \\
\hline 55 & 0,04 & 0,98 & 0,33 & 0,27 & 222,36 \\
\hline 56 & 0,04 & 0,98 & 0,33 & 0,27 & 222,49 \\
\hline 57 & 0,04 & 0,98 & 0,33 & 0,27 & 221,36 \\
\hline 58 & 0,03 & 0,98 & 0,32 & 0,27 & 221,50 \\
\hline 59 & 0,03 & 0,98 & 0,32 & 0,27 & 220,90 \\
\hline 60 & 0,03 & 0,98 & 0,32 & 0,27 & 220,22 \\
\hline 61 & 0,03 & 0,98 & 0,32 & 0,27 & 220,04 \\
\hline 62 & 0,03 & 0,98 & 0,32 & 0,26 & 220,20 \\
\hline 63 & 0,03 & 0,98 & 0,32 & 0,26 & 219,53 \\
\hline 64 & 0,03 & 0,98 & 0,32 & 0,26 & 219,36 \\
\hline 65 & 0,03 & 0,98 & 0,31 & 0,26 & 218,85 \\
\hline 66 & 0,03 & 0,98 & 0,31 & 0,26 & 218,69 \\
\hline 67 & 0,03 & 0,99 & 0,31 & 0,26 & 218,53 \\
\hline 68 & 0,03 & 0,99 & 0,31 & 0,25 & 217,91 \\
\hline
\end{tabular}

* Tamanho do sintético conforme o número de linhagens. 
Tabela 31: Avaliação dos melhores sintéticos com diferentes tamanhos - Local 3 - Iowa, EUA, 1996.

\begin{tabular}{|c|c|c|c|c|c|}
\hline \multicolumn{7}{|c|}{ Indice } \\
\hline $\begin{array}{l}\text { número de } \\
\text { linhagens }\end{array}$ & $\begin{array}{l}\text { menor } \\
q\end{array}$ & $\begin{array}{l}\text { maior } \\
q\end{array}$ & média & $\bar{q}$ & $\bar{b}$ \\
\hline 5 & 0,20 & 0,80 & 0,44 & 0,44 & 173,05 \\
\hline 6 & 0,17 & 0,67 & 0,43 & 0,44 & 177,22 \\
\hline 7 & 0,14 & 0,71 & 0,43 & 0,45 & 180,96 \\
\hline 8 & 0,13 & 0,75 & 0,43 & 0,44 & 179,04 \\
\hline 9 & 0,22 & 0,78 & 0,46 & 0,45 & 170,66 \\
\hline 10 & 0,30 & 0,80 & 0,44 & 0,44 & 172,57 \\
\hline 11 & 0,27 & 0,73 & 0,44 & 0,44 & 170,67 \\
\hline 12 & 0,33 & 0,75 & 0,44 & 0,43 & 168,03 \\
\hline 13 & 0,31 & 0,69 & 0,43 & 0,42 & 166,76 \\
\hline 14 & 0,29 & 0,64 & 0,42 & 0,40 & 166,97 \\
\hline 15 & 0,27 & 0,67 & 0,40 & 0,40 & 169,83 \\
\hline 16 & 0,25 & 0,69 & 0,39 & 0,39 & 172,10 \\
\hline 17 & 0,24 & 0,71 & 0,39 & 0,39 & 169,48 \\
\hline 18 & 0,22 & 0,72 & 0,39 & 0,39 & 169,74 \\
\hline 19 & 0,26 & 0,68 & 0,39 & 0,38 & 167,04 \\
\hline 20 & 0,25 & 0,70 & 0,39 & 0,37 & 165,60 \\
\hline 21 & 0,24 & 0,71 & 0,38 & 0,36 & 166,33 \\
\hline 22 & 0,23 & 0,68 & 0,38 & 0,36 & 163,41 \\
\hline 23 & 0,22 & 0,70 & 0,37 & 0,35 & 162,43 \\
\hline 24 & 0,21 & 0,67 & 0,37 & 0,34 & 160,36 \\
\hline 25 & 0,20 & 0,68 & 0,37 & 0,34 & 160,08 \\
\hline 26 & 0,19 & 0,69 & 0,37 & 0,34 & 160,04 \\
\hline 27 & 0,19 & 0,70 & 0,36 & 0,33 & 159,84 \\
\hline 28 & 0,18 & 0,71 & 0,36 & 0,33 & 161,48 \\
\hline 29 & 0,17 & 0,72 & 0,36 & 0,33 & 160,43 \\
\hline 30 & 0,17 & 0,73 & 0,35 & 0,33 & 159,86 \\
\hline 31 & 0,19 & 0,71 & 0,35 & 0,32 & 158,68 \\
\hline 32 & 0,19 & 0,72 & 0,35 & 0,32 & 157,31 \\
\hline 33 & 0,18 & 0,73 & 0,35 & 0,32 & 156,65 \\
\hline 34 & 0,18 & 0,71 & 0,35 & 0,31 & 154,37 \\
\hline 35 & 0,17 & 0,69 & 0,34 & 0,31 & 154,27 \\
\hline 36 & 0,17 & 0,67 & 0,34 & 0,30 & 153,24 \\
\hline 37 & 0,16 & 0,65 & 0,33 & 0,30 & 153,02 \\
\hline 38 & 0,16 & 0,66 & 0,33 & 0,29 & 152,40 \\
\hline 39 & 0,15 & 0,67 & 0,33 & 0,29 & 152,07 \\
\hline 40 & 0,15 & 0,65 & 0,33 & 0,29 & 151,29 \\
\hline 42 & 0,14 & 0,67 & 0,32 & 0,28 & 151,22 \\
\hline 43 & 0,14 & 0,67 & 0,32 & 0,28 & 151,48 \\
\hline & & & & \\
\hline & & & & \\
\hline & & & & &
\end{tabular}

\begin{tabular}{|c|c|c|c|c|c|}
\hline \multicolumn{7}{|c|}{ Topcross } \\
\hline $\begin{array}{c}\text { numero de } \\
\text { linhagens } *\end{array}$ & & $\begin{array}{l}\text { maior } \\
q\end{array}$ & média & $\bar{q}$ & $\bar{b}$ \\
\hline 5 & 0,00 & 0,80 & 0,43 & 0,41 & 165,97 \\
\hline 6 & 0,17 & 0,83 & 0,48 & 0,43 & 157,07 \\
\hline 7 & 0,14 & 0,71 & 0,42 & 0,37 & 153,55 \\
\hline 8 & 0,13 & 0,63 & 0,38 & 0,33 & 150,19 \\
\hline 9 & 0,11 & 0,56 & 0,38 & 0,32 & 146,38 \\
\hline 10 & 0,10 & 0,60 & 0,36 & 0,29 & 142,94 \\
\hline 11 & 0,09 & 0,55 & 0,35 & 0,30 & 150,32 \\
\hline 12 & 0,08 & 0,58 & 0,35 & 0,30 & 148,08 \\
\hline 13 & 0,08 & 0,62 & 0,36 & 0,30 & 147,15 \\
\hline 14 & 0,07 & 0,64 & 0,36 & 0,31 & 148,71 \\
\hline 15 & 0,07 & 0,67 & 0,36 & 0,31 & 147,85 \\
\hline 16 & 0,06 & 0,63 & 0,34 & 0,29 & 147,49 \\
\hline 17 & 0,12 & 0,59 & 0,35 & 0,30 & 147,75 \\
\hline 18 & 0,11 & 0,61 & 0,35 & 0,29 & 143,95 \\
\hline 19 & 0,11 & 0,58 & 0,34 & 0,29 & 147,00 \\
\hline 20 & 0,10 & 0,60 & 0,34 & 0,29 & 147,49 \\
\hline 21 & 0,14 & 0,57 & 0,33 & 0,29 & 148,26 \\
\hline 22 & 0,14 & 0,59 & 0,33 & 0,28 & 147,78 \\
\hline 23 & 0,13 & 0,57 & 0,33 & 0,28 & 147,25 \\
\hline 24 & 0,13 & 0,58 & 0,32 & 0,28 & 147,41 \\
\hline 25 & 0,12 & 0,60 & 0,32 & 0,28 & 149,28 \\
\hline 26 & 0,12 & 0,62 & 0,32 & 0,28 & 149,77 \\
\hline 27 & 0,11 & 0,63 & 0,31 & 0,27 & 150,72 \\
\hline 28 & 0,11 & 0,64 & 0,31 & 0,27 & 151,09 \\
\hline 29 & 0,10 & 0,62 & 0,31 & 0,27 & 149,03 \\
\hline 30 & 0,10 & 0,63 & 0,31 & 0,26 & 148,62 \\
\hline 31 & 0,10 & 0,65 & 0,31 & 0,26 & 147,38 \\
\hline 32 & 0,09 & 0,66 & 0,31 & 0,26 & 147,83 \\
\hline 33 & 0,09 & 0,67 & 0,31 & 0,26 & 147,24 \\
\hline 34 & 0,09 & 0,65 & 0,30 & 0,26 & 147,10 \\
\hline 35 & 0,09 & 0,66 & 0,30 & 0,25 & 146,00 \\
\hline 36 & 0,11 & 0,67 & 0,30 & 0,26 & 146,95 \\
\hline 37 & 0,11 & 0,68 & 0,30 & 0,25 & 146,80 \\
\hline 38 & 0,11 & 0,68 & 0,30 & 0,25 & 145,66 \\
\hline 39 & 0,13 & 0,69 & 0,30 & 0,26 & 147,41 \\
\hline 40 & 0,13 & 0,68 & 0,30 & 0,26 & 147,42 \\
\hline 42 & 0,12 & 0,67 & 0,29 & 0,25 & 146,43 \\
\hline 43 & 0,12 & 0,67 & 0,29 & 0,25 & 146,80 \\
\hline & & & & \\
\hline & & & &
\end{tabular}




\begin{tabular}{|c|c|c|c|c|c|}
\hline $\begin{array}{l}\text { número de } \\
\text { linhagens* }\end{array}$ & $\begin{array}{l}\text { menor } \\
q\end{array}$ & $\begin{array}{l}\text { maior } \\
q\end{array}$ & média & $\bar{q}$ & $\vec{b}$ \\
\hline 44 & 0,14 & 0,66 & 0,32 & 0,28 & 151,31 \\
\hline 45 & 0,13 & 0,64 & 0,31 & 0.27 & 151,15 \\
\hline 46 & 0,13 & 0,65 & 0,31 & 0,27 & 150,87 \\
\hline 47 & 0,13 & 0,66 & 0,31 & 0,27 & 151,12 \\
\hline 48 & 0,13 & 0,67 & 0,30 & 0,26 & 150,44 \\
\hline 49 & 0,12 & 0.67 & 0,30 & 0,26 & 149,96 \\
\hline 50 & 0,12 & 0,68 & 0,30 & 0,26 & 149,51 \\
\hline 51 & 0,12 & 0,69 & 0,30 & 0,25 & 148,86 \\
\hline 52 & 0,12 & 0,67 & 0,29 & 0,25 & 148,87 \\
\hline 53 & 0,11 & 0,68 & 0,29 & 0,25 & 148,74 \\
\hline 54 & 0,11 & 0,69 & 0,29 & 0,25 & 147,14 \\
\hline 55 & 0,11 & 0,67 & 0,29 & 0,24 & 147,02 \\
\hline 56 & 0,11 & 0,68 & 0,28 & 0,24 & 146,91 \\
\hline 57 & 0,11 & 0,68 & 0,28 & 0,24 & 147,19 \\
\hline 58 & 0,10 & 0.69 & 0,28 & 0,24 & 145,98 \\
\hline 59 & 0,10 & 0,69 & 0,28 & 0,23 & 145,88 \\
\hline 60 & 0,10 & 0,70 & 0,28 & 0,23 & 145,58 \\
\hline 61 & 0,10 & 0,69 & 0,27 & 0,23 & 145,50 \\
\hline 62 & 0,10 & 0.69 & 0,27 & 0,23 & 144,94 \\
\hline 63 & 0,10 & 0,70 & 0,27 & 0,22 & 144,22 \\
\hline 64 & 0,09 & 0,70 & 0,27 & 0,22 & 144,04 \\
\hline 65 & 0,09 & 0,71 & 0,26 & 0,22 & 143,35 \\
\hline 66 & 0,09 & 0,71 & 0.26 & 0,22 & 142,81 \\
\hline 67 & 0,09 & 0,72 & 0,26 & 0,21 & 142,18 \\
\hline 68 & 0,09 & 0,72 & 0,26 & 0,21 & 141,65 \\
\hline
\end{tabular}

\begin{tabular}{|c|c|c|c|c|c|}
\hline $\begin{array}{l}\text { número de } \\
\text { linhagens }\end{array}$ & menor q & $\begin{array}{l}\text { maior } \\
q\end{array}$ & média & $\bar{q}$ & $\bar{b}$ \\
\hline 44 & 0,11 & 0,68 & 0,29 & 0,24 & 145,25 \\
\hline 45 & 0,11 & 0,69 & 0,29 & 0,24 & 145,14 \\
\hline 46 & 0,11 & 0,67 & 0,29 & 0,24 & 144,76 \\
\hline 47 & 0,11 & 0,68 & 0,28 & 0,24 & 144,05 \\
\hline 48 & 0,10 & 0,67 & 0,28 & 0,23 & 143,93 \\
\hline 49 & 0,10 & 0,67 & 0,28 & 0,23 & 143,56 \\
\hline 50 & 0,10 & 0,68 & 0,28 & 0,23 & 143,16 \\
\hline 51 & 0,10 & 0,67 & 0,28 & 0,23 & 144,58 \\
\hline 52 & 0,12 & 0,67 & 0,28 & 0,23 & 145,16 \\
\hline 53 & 0,11 & 0,68 & 0,28 & 0,23 & 144,97 \\
\hline 54 & 0,11 & 0,69 & 0,28 & 0,23 & 144,99 \\
\hline 55 & 0,11 & 0,69 & 0,28 & 0,23 & 145,14 \\
\hline 56 & 0,11 & 0,68 & 0,28 & 0,23 & 146,57 \\
\hline 57 & 0,11 & 0,68 & 0,27 & 0,23 & 146,46 \\
\hline 58 & 0,10 & 0.69 & 0,27 & 0,23 & 146,13 \\
\hline 59 & 0,10 & 0,69 & 0,27 & 0,23 & 145,55 \\
\hline 60 & 0,10 & 0,70 & 0,27 & 0,23 & 144,08 \\
\hline 61 & 0,10 & 0,70 & 0,27 & 0,22 & 143,51 \\
\hline 62 & 0,10 & 0,71 & 0,27 & 0,22 & 143,33 \\
\hline 63 & 0,10 & 0,71 & 0,27 & 0,22 & 143,07 \\
\hline 64 & 0,09 & 0,72 & 0,26 & 0,22 & 142,52 \\
\hline 65 & 0,09 & 0,72 & 0,26 & 0,22 & 142,49 \\
\hline 66 & 0,09 & 0,71 & 0,26 & 0,21 & 142,43 \\
\hline 67 & 0,09 & 0,72 & 0,26 & 0,21 & 141,81 \\
\hline 68 & 0,09 & 0,72 & 0,26 & 0,21 & 141,65 \\
\hline
\end{tabular}

* Tamanho do sintético conforme o número de linhagens. 
Tabela 32: Avaliação dos melhores sintéticos com diferentes tamanhos - Local 4 - Iowa, EUA, 1996.

\begin{tabular}{|c|c|c|c|c|c|}
\hline \multicolumn{7}{|c|}{$\begin{array}{l}\text { Indice } \\
\text { numero de } \\
\text { linhagens }\end{array}$} & $\begin{array}{l}\text { menor } \\
q\end{array}$ & $\begin{array}{l}\text { maior } \\
q\end{array}$ & média & $\overline{9}$ & $\bar{b}$ \\
\hline 5 & 0,00 & 1,00 & 0,46 & 0,47 & 119,02 \\
\hline 6 & 0,00 & 1,00 & 0,44 & 0,47 & 123,90 \\
\hline 7 & 0,14 & 1,00 & 0,45 & 0,47 & 121,24 \\
\hline 8 & 0,13 & 0,88 & 0,43 & 0,45 & 121,47 \\
\hline 9 & 0,11 & 0,89 & 0,42 & 0,45 & 123,42 \\
\hline 10 & 0,10 & 0,80 & 0,44 & 0,45 & 118,82 \\
\hline 11 & 0,09 & 0,82 & 0,43 & 0,44 & 119,58 \\
\hline 12 & 0,08 & 0,75 & 0,42 & 0,43 & 117,97 \\
\hline 13 & 0,15 & 0,69 & 0,40 & 0,41 & 116,59 \\
\hline 14 & 0,14 & 0,71 & 0,41 & 0,40 & 115,25 \\
\hline 15 & 0,13 & 0,73 & 0,41 & 0,40 & 113,98 \\
\hline 16 & 0,13 & 0,75 & 0,40 & 0,39 & 112,53 \\
\hline 17 & 0,12 & 0,76 & 0,40 & 0,38 & 111,01 \\
\hline 18 & 0,17 & 0,78 & 0,40 & 0,38 & 110,86 \\
\hline 19 & 0,16 & 0,74 & 0,39 & 0,37 & 110,29 \\
\hline 20 & 0,15 & 0,70 & 0,39 & 0,37 & 110,49 \\
\hline 21 & 0,14 & 0,67 & 0,38 & 0,36 & 110,56 \\
\hline 22 & 0,14 & 0,68 & 0,38 & 0,36 & 109,96 \\
\hline 23 & 0,13 & 0,70 & 0,38 & 0,36 & 109,68 \\
\hline 24 & 0,13 & 0,71 & 0,38 & 0,35 & 108,71 \\
\hline 25 & 0,12 & 0,68 & 0,38 & 0,35 & 108,63 \\
\hline 26 & 0,12 & 0,69 & 0,37 & 0,34 & 108,34 \\
\hline 27 & 0,11 & 0,70 & 0,36 & 0,34 & 108,26 \\
\hline 28 & 0,11 & 0,68 & 0,36 & 0,34 & 108,25 \\
\hline 29 & 0,10 & 0,66 & 0,35 & 0,33 & 107,93 \\
\hline 30 & 0,13 & 0,67 & 0,35 & 0,33 & 107,78 \\
\hline 31 & 0,13 & 0,68 & 0,35 & 0,32 & 107,59 \\
\hline 32 & 0,13 & 0,69 & 0,35 & 0,32 & 106,74 \\
\hline 33 & 0,12 & 0,70 & 0,35 & 0,32 & 106,65 \\
\hline 34 & 0,12 & 0,71 & 0,35 & 0,32 & 106,87 \\
\hline 35 & 0,11 & 0,69 & 0,34 & 0,31 & 106,80 \\
\hline 36 & 0,11 & 0,69 & 0,34 & 0,31 & 107,24 \\
\hline 37 & 0,11 & 0,70 & 0,33 & 0,31 & 106,99 \\
\hline 38 & 0,13 & 0,71 & 0,33 & 0,30 & 106,51 \\
\hline 39 & 0,13 & 0,72 & 0,33 & 0,30 & 106,73 \\
\hline 40 & 0,13 & 0,73 & 0,33 & 0,30 & 106,37 \\
\hline 41 & 0,12 & 0,73 & 0,33 & 0,30 & 105,62 \\
\hline 42 & 0,12 & 0,74 & 0,33 & 0,30 & 105,57 \\
\hline 43 & 0,12 & 0,74 & 0,32 & 0,29 & 105,25 \\
\hline & & & & \\
\hline & & &
\end{tabular}

\begin{tabular}{|c|r|r|r|r|r|}
\hline \multicolumn{7}{|c|}{ Topcross } \\
\hline $\begin{array}{l}\text { número de } \\
\text { linhagens }\end{array}$ & $\begin{array}{l}\text { menor } \\
q\end{array}$ & $\begin{array}{l}\text { maior } \\
q\end{array}$ & média & $\bar{q}$ & $\bar{b}$ \\
\hline 5 & 0,00 & 0,80 & 0,39 & 0,33 & 99,52 \\
\hline 6 & 0,00 & 0,83 & 0,42 & 0,35 & 96,86 \\
\hline 7 & 0,00 & 0,86 & 0,39 & 0,33 & 98,74 \\
\hline 8 & 0,00 & 0,88 & 0,38 & 0,32 & 98,35 \\
\hline 9 & 0,11 & 0,89 & 0,38 & 0,33 & 101,58 \\
\hline 10 & 0,10 & 0,90 & 0,39 & 0,34 & 101,34 \\
\hline 11 & 0,09 & 0,91 & 0,39 & 0,35 & 103,65 \\
\hline 12 & 0,08 & 0,92 & 0,38 & 0,33 & 102,28 \\
\hline 13 & 0,08 & 0,92 & 0,37 & 0,33 & 104,10 \\
\hline 14 & 0,07 & 0,93 & 0,37 & 0,32 & 102,88 \\
\hline 15 & 0,07 & 0,87 & 0,35 & 0,31 & 102,48 \\
\hline 16 & 0,06 & 0,88 & 0,35 & 0,31 & 102,54 \\
\hline 17 & 0,06 & 0,88 & 0,34 & 0,30 & 101,59 \\
\hline 18 & 0,11 & 0,83 & 0,34 & 0,30 & 101,30 \\
\hline 19 & 0,16 & 0,84 & 0,34 & 0,30 & 101,37 \\
\hline 20 & 0,15 & 0,85 & 0,34 & 0,30 & 100,91 \\
\hline 21 & 0,14 & 0,86 & 0,34 & 0,29 & 100,46 \\
\hline 22 & 0,14 & 0,86 & 0,34 & 0,29 & 100,63 \\
\hline 23 & 0,13 & 0,87 & 0,33 & 0,29 & 100,59 \\
\hline 24 & 0,13 & 0,88 & 0,33 & 0,29 & 100,44 \\
\hline 25 & 0,12 & 0,88 & 0,33 & 0,29 & 101,22 \\
\hline 26 & 0,12 & 0,88 & 0,33 & 0,28 & 100,35 \\
\hline 27 & 0,11 & 0,85 & 0,33 & 0,29 & 102,46 \\
\hline 28 & 0,11 & 0,82 & 0,32 & 0,28 & 101,98 \\
\hline 29 & 0,10 & 0,79 & 0,33 & 0,29 & 103,12 \\
\hline 30 & 0,10 & 0,80 & 0,33 & 0,30 & 104,57 \\
\hline 31 & 0,10 & 0,81 & 0,33 & 0,30 & 105,45 \\
\hline 32 & 0,09 & 0,81 & 0,34 & 0,31 & 105,77 \\
\hline 33 & 0,09 & 0,79 & 0,33 & 0,30 & 105,64 \\
\hline 34 & 0,09 & 0,79 & 0,33 & 0,30 & 105,58 \\
\hline 35 & 0,09 & 0,77 & 0,33 & 0,30 & 105,33 \\
\hline 36 & 0,08 & 0,78 & 0,33 & 0,29 & 104,74 \\
\hline 37 & 0,08 & 0,78 & 0,32 & 0,29 & 104,60 \\
\hline 38 & 0,08 & 0,76 & 0,32 & 0,29 & 104,76 \\
\hline 39 & 0,08 & 0,77 & 0,32 & 0,29 & 105,05 \\
\hline 40 & 0,08 & 0,78 & 0,32 & 0,29 & 104,86 \\
\hline 41 & 0,07 & 0,78 & 0,32 & 0,29 & 105,11 \\
\hline 42 & 0,07 & 0,79 & 0,31 & 0,28 & 104,62 \\
\hline 43 & 0,07 & 0,79 & 0,31 & 0,28 & 104,77 \\
\hline & & & & \\
\hline & & & & &
\end{tabular}




\begin{tabular}{|c|c|c|c|c|c|}
\hline $\begin{array}{l}\text { número de } \\
\text { linhagens }\end{array}$ & $\begin{array}{l}\text { menor } \\
q\end{array}$ & $\begin{array}{l}\text { maior } \\
q\end{array}$ & média & $\bar{q}$ & $\bar{b}$ \\
\hline 44 & 0,11 & 0,75 & 0,32 & 0,29 & 105,12 \\
\hline 45 & 0,11 & 0,76 & 0,32 & 0,29 & 104,79 \\
\hline 46 & 0,11 & 0,74 & 0,32 & 0,29 & 104,92 \\
\hline 47 & 0,11 & 0,74 & 0,32 & 0,29 & 104,81 \\
\hline 48 & 0,10 & 0,73 & 0,31 & 0,28 & 104,65 \\
\hline 49 & 0,10 & 0,73 & 0,31 & 0,28 & 104,36 \\
\hline 50 & 0,10 & 0,74 & 0,31 & 0,28 & 103,96 \\
\hline 51 & 0,10 & 0,73 & 0,31 & 0,28 & 103,45 \\
\hline 52 & 0,10 & 0,71 & 0,31 & 0,27 & 103,40 \\
\hline 53 & 0,09 & 0,72 & 0,31 & 0,27 & 103,00 \\
\hline 54 & 0,09 & 0,72 & 0,31 & 0,27 & 102,87 \\
\hline 55 & 0,09 & 0,73 & 0,30 & 0,27 & 102,52 \\
\hline 56 & 0,09 & 0,73 & 0,30 & 0,27 & 102,23 \\
\hline 57 & 0,09 & 0,72 & 0,30 & 0,26 & 101,64 \\
\hline 58 & 0,09 & 0,72 & 0,30 & 0,26 & 101,88 \\
\hline 59 & 0,08 & 0,71 & 0,30 & 0,26 & 101,62 \\
\hline 60 & 0,08 & 0,72 & 0,29 & 0,26 & 101,52 \\
\hline 61 & 0,08 & 0,72 & 0,29 & 0,26 & 101,75 \\
\hline 62 & 0,08 & 0,73 & 0,29 & 0,26 & 101,66 \\
\hline 63 & 0,08 & 0,71 & 0,29 & 0,25 & 101,41 \\
\hline 64 & 0,08 & 0,70 & 0,29 & 0,25 & 101,70 \\
\hline 65 & 0,08 & 0,71 & 0,29 & 0,25 & 101,39 \\
\hline 66 & 0,08 & 0,71 & 0,29 & 0,25 & 101,30 \\
\hline 67 & 0,07 & 0,72 & 0,28 & 0,25 & 101,02 \\
\hline 68 & 0,07 & 0,71 & 0,28 & 0,24 & 100,71 \\
\hline
\end{tabular}

\begin{tabular}{|c|c|c|c|c|c|}
\hline $\begin{array}{l}\text { número de } \\
\text { linhagens }\end{array}$ & $\begin{array}{l}\text { menor } \\
q\end{array}$ & $\begin{array}{l}\text { maior } \\
q\end{array}$ & média & $\bar{q}$ & $\bar{b}$ \\
\hline 44 & 0,09 & 0,77 & 0,31 & 0,28 & 105,20 \\
\hline 45 & 0,09 & 0,76 & 0,31 & 0,28 & 105,56 \\
\hline 46 & 0,09 & 0,76 & 0,30 & 0,28 & 105,80 \\
\hline 47 & 0,09 & 0,74 & 0,30 & 0,28 & 105,82 \\
\hline 48 & 0,08 & 0,73 & 0,31 & 0,28 & 105,28 \\
\hline 49 & 0,08 & 0,71 & 0,30 & 0,27 & 104,58 \\
\hline 50 & 0,08 & 0,72 & 0,30 & 0,27 & 104,55 \\
\hline 51 & 0,08 & 0.71 & 0,30 & 0,27 & 104,40 \\
\hline 52 & 0,08 & 0,69 & 0.30 & 0,27 & 104,08 \\
\hline 53 & 0,08 & 0,70 & 0.29 & 0,26 & 103,81 \\
\hline 54 & 0,07 & 0,70 & 0,29 & 0,26 & 103,23 \\
\hline 55 & 0,07 & 0,71 & 0,29 & 0,26 & 103,32 \\
\hline 56 & 0,07 & 0,71 & 0,29 & 0,26 & 103,24 \\
\hline 57 & 0,07 & 0,70 & 0,29 & 0,26 & 102,77 \\
\hline 58 & 0,07 & 0,71 & 0,29 & 0,26 & 102,65 \\
\hline 59 & 0,07 & 0,71 & 0,29 & 0,26 & 102,53 \\
\hline 60 & 0,08 & 0,72 & 0.29 & 0,26 & 102,24 \\
\hline 61 & 0,08 & 0,72 & 0,29 & 0,25 & 102,13 \\
\hline 62 & 0,08 & 0,73 & 0,29 & 0,25 & 101,92 \\
\hline 63 & 0,08 & 0,71 & 0,29 & 0,25 & 101,59 \\
\hline 64 & 0,08 & 0,72 & 0,29 & 0,25 & 101,34 \\
\hline 65 & 0,08 & 0,72 & 0,28 & 0,25 & 101,03 \\
\hline 66 & 0,08 & 0,71 & 0.28 & 0,25 & 100,79 \\
\hline 67 & 0,07 & 0,72 & 0,28 & 0,24 & 100,71 \\
\hline 68 & 0,07 & 0.71 & 0,28 & 0,24 & 100,71 \\
\hline
\end{tabular}

* Tamanho do sintético conforme o número de linhagens. 
Tabela 33: Avaliação dos melhores sintéticos com diferentes tamanhos - Análise conjunta de quatro locais - Iowa, EUA, 1996.

\begin{tabular}{|c|c|c|c|c|c|}
\hline \multicolumn{6}{|c|}{ Índice } \\
\hline $\begin{array}{l}\text { numero de } \\
\text { linhagens }\end{array}$ & $\begin{array}{l}\text { menor } \\
q\end{array}$ & $\begin{array}{l}\text { maior } \\
q\end{array}$ & média & $\bar{q}$ & $\bar{b}$ \\
\hline 5 & 0,00 & 0,80 & 0,36 & 0,42 & 178,51 \\
\hline 6 & 0,00 & 0,83 & 0,33 & 0,40 & 184,02 \\
\hline 7 & 0,00 & 0,71 & 0,34 & 0,40 & 180,73 \\
\hline 8 & 0,00 & 0,75 & 0,32 & 0,39 & 185,37 \\
\hline 9 & 0,00 & 0,78 & 0,31 & 0,38 & 186,15 \\
\hline 10 & 0,10 & 0,80 & 0,32 & 0,38 & 184,69 \\
\hline 11 & 0,09 & 0,82 & 0,30 & 0,37 & 191,96 \\
\hline 12 & 0,08 & 0,83 & 0,30 & 0.37 & 191,85 \\
\hline 13 & 0,08 & 0,85 & 0.29 & 0,37 & 191,49 \\
\hline 14 & 0,07 & 0,79 & 0,29 & 0,37 & 191,69 \\
\hline 15 & 0,07 & 0,80 & 0,28 & 0,36 & 196,99 \\
\hline 16 & 0,06 & 0,75 & 0,27 & 0,36 & 198,28 \\
\hline 17 & 0,06 & 0,76 & 0,27 & 0,35 & 199,96 \\
\hline 18 & 0,06 & 0,78 & 0,26 & 0,35 & 201,20 \\
\hline 19 & 0,05 & 0,74 & 0,26 & 0,34 & 200,96 \\
\hline 20 & 0,05 & 0,70 & 0,26 & 0,34 & 200,61 \\
\hline 21 & 0,05 & 0,71 & 0,26 & 0,34 & 199,41 \\
\hline 22 & 0,05 & 0,68 & 0,27 & 0,34 & 195,75 \\
\hline 23 & 0,04 & 0,65 & 0,27 & 0,34 & 193,41 \\
\hline 24 & 0,04 & 0,67 & 0,27 & 0,34 & 192,17 \\
\hline 25 & 0,04 & 0,64 & 0,26 & 0,33 & 188,96 \\
\hline 26 & 0,04 & 0,65 & 0,26 & 0,32 & 191,46 \\
\hline 27 & 0,04 & 0,63 & 0,26 & 0,32 & 191,10 \\
\hline 28 & 0,04 & 0,61 & 0,26 & 0.32 & 190,71 \\
\hline 29 & 0,03 & 0,59 & 0,25 & 0,31 & 189,76 \\
\hline 30 & 0,03 & 0,60 & 0,25 & 0.31 & 191,76 \\
\hline 31 & 0,03 & 0,58 & 0,25 & 0,31 & 187,11 \\
\hline 32 & 0,03 & 0,56 & 0,25 & 0,30 & 183,77 \\
\hline 33 & \begin{tabular}{l|l}
0,03 \\
\end{tabular} & 0,58 & 0,25 & 0,30 & 186,55 \\
\hline 34 & 0,03 & 0,56 & 0,25 & 0,30 & 183,29 \\
\hline 35 & 0,03 & 0,54 & 0,24 & 0.30 & 184,53 \\
\hline 36 & 0,03 & 0,53 & 0,24 & 0.29 & 185,31 \\
\hline 37 & 0,03 & 0,51 & 0,24 & 0.29 & 184,87 \\
\hline 38 & 0,03 & 0,50 & 0,24 & 0,29 & 183,00 \\
\hline 39 & 0,03 & 0,49 & 0,24 & 0,29 & 183,28 \\
\hline 40 & 0,03 & 0,48 & 0,24 & 0.29 & 183,64 \\
\hline 41 & 0,02 & 0,46 & 0,24 & 0,29 & 183.21 \\
\hline 42 & \begin{tabular}{l|l|}
0,02 \\
\end{tabular} & 0,45 & 0,24 & 0.28 & 182,51 \\
\hline 43 & 0,02 & 0,47 & 0,24 & 0.28 & 182,90 \\
\hline 44 & 0,02 & 0,45 & 0,23 & 0.28 & 183,18 \\
\hline 45 & 0,02 & 0.47 & 0,23 & 0.28 & 182,65 \\
\hline
\end{tabular}

\begin{tabular}{|c|c|c|c|c|c|}
\hline \multicolumn{6}{|c|}{ Topcross } \\
\hline $\begin{array}{l}\text { número de } \\
\text { linhagens }\end{array}$ & $=\begin{array}{l}\text { menor } \\
q\end{array}$ & \begin{tabular}{|l|l} 
maior \\
$q$
\end{tabular} & média & $\bar{q}$ & $\overline{\bar{b}}$ \\
\hline 5 & 0,00 & 0,80 & 0,31 & 0,36 & 174,25 \\
\hline 6 & 0,00 & 0,83 & 0,31 & 0,35 & 176,71 \\
\hline 7 & 0,00 & 0,71 & 0,30 & 0,35 & 179,03 \\
\hline 8 & 0,00 & 0,63 & 0,28 & 0,33 & 176,27 \\
\hline 9 & 0,00 & 0,67 & 0,28 & 0,33 & 180,88 \\
\hline 10 & 0,00 & 0,60 & 0,29 & 0,34 & 178,58 \\
\hline 11 & 0,00 & 0,64 & 0,29 & 0,32 & 170,64 \\
\hline 12 & 0,08 & 0,67 & 0,28 & 0,31 & 170,25 \\
\hline 13 & 0,08 & 0,69 & 0,29 & 0,32 & 167,54 \\
\hline 14 & 0,07 & 0,64 & 0,28 & 0,32 & 171,10 \\
\hline 15 & 0,07 & 0,60 & 0,27 & 0,30 & 168,74 \\
\hline 16 & 0,06 & 0,63 & 0,27 & 0,29 & 162,25 \\
\hline 17 & 0,06 & 0,65 & 0,27 & 0,28 & 157,97 \\
\hline 18 & 0,06 & \begin{tabular}{l|l}
0,67 \\
\end{tabular} & 0,27 & 0,28 & 158,89 \\
\hline 19 & 0,05 & 0,68 & 0,28 & 0,29 & 157,65 \\
\hline 20 & 0,05 & 0,65 & 0,27 & 0,28 & 156,16 \\
\hline 21 & 0,05 & 0,62 & 0.28 & 0,28 & 157,09 \\
\hline 22 & 0,05 & 0,64 & 0,27 & 0,29 & 159,93 \\
\hline 23 & 0,04 & 0,65 & 0,27 & 0,28 & 157,45 \\
\hline 24 & 0,04 & 0,63 & 0,26 & 0,28 & 159,80 \\
\hline 25 & 0,04 & 0,60 & 0,26 & 0,28 & 161,03 \\
\hline 26 & 0,04 & 0,62 & 0,26 & 0,27 & 159,28 \\
\hline 27 & 0,04 & 0,63 & 0,26 & 0,27 & 156,92 \\
\hline 28 & 0,04 & 0,61 & 0,26 & 0,27 & 158,36 \\
\hline 29 & 0,03 & 0,59 & 0,26 & 0,27 & 160,07 \\
\hline 30 & 0,03 & \begin{tabular}{l|l}
0,60 \\
\end{tabular} & 0,26 & 0,26 & 158,24 \\
\hline 31 & \begin{tabular}{l|l|}
0,03 \\
\end{tabular} & 0,58 & 0,25 & 0,26 & 157,80 \\
\hline 32 & 0,03 & 0,59 & 0,25 & 0,26 & 157,99 \\
\hline 33 & 0,03 & 0,58 & 0,25 & 0,26 & 159,93 \\
\hline 34 & 0,03 & \begin{tabular}{l|l}
0,56 \\
\end{tabular} & 0,24 & 0,25 & 159,90 \\
\hline 35 & 0,03 & 0,54 & 0,24 & 0,25 & 160,79 \\
\hline 36 & 0,03 & 0,53 & 0,24 & 0,25 & 160,33 \\
\hline 37 & 0,03 & 0,54 & 0,24 & 0,25 & 160,86 \\
\hline 38 & 0,03 & 0,53 & 0,24 & 0,25 & 162,06 \\
\hline 39 & 0,03 & 0,51 & 0,24 & 0.25 & 162,68 \\
\hline 40 & 0,03 & 0,50 & 0,23 & 0,25 & 165,49 \\
\hline 41 & \begin{tabular}{l|l|}
0,02 \\
\end{tabular} & 0,49 & 0,23 & 0,25 & 166,17 \\
\hline 42 & 0,02 & 0,48 & 0,23 & 0,25 & 168,63 \\
\hline 43 & 0,02 & 0.49 & 0,23 & 0,25 & 169,05 \\
\hline 4 & 0,02 & 0,48 & 0,22 & 0,25 & 168,60 \\
\hline 45 & 0,02 & 0,47 & 0,22 & 0,24 & 170,98 \\
\hline
\end{tabular}




\begin{tabular}{|c|r|r|r|r|c|}
\hline $\begin{array}{l}\text { numero de } \\
\text { linhagens }\end{array}$ & $\begin{array}{l}\text { menor } \\
q\end{array}$ & $\begin{array}{l}\text { maior } \\
q\end{array}$ & média & $\bar{q}$ & $\bar{b}$ \\
\hline 46 & 0,02 & 0,46 & 0,23 & 0,27 & 182,51 \\
\hline 47 & 0,02 & 0,47 & 0,23 & 0,27 & 180,49 \\
\hline 48 & 0,02 & 0,48 & 0,23 & 0,27 & 179,19 \\
\hline 49 & 0,02 & 0,47 & 0,22 & 0,26 & 178,24 \\
\hline 50 & 0,02 & 0,46 & 0,22 & 0,26 & 177,30 \\
\hline 51 & 0,02 & 0,47 & 0,22 & 0,26 & 177,06 \\
\hline 52 & 0,02 & 0,46 & 0,22 & 0,26 & 178,06 \\
\hline 53 & 0,02 & 0,47 & 0,22 & 0,26 & 178,28 \\
\hline 54 & 0,02 & 0,46 & 0,22 & 0,26 & 179,43 \\
\hline 55 & 0,02 & 0,45 & 0,22 & 0,25 & 178,85 \\
\hline 56 & 0,02 & 0,45 & 0,21 & 0,25 & 179,06 \\
\hline 57 & 0,02 & 0,46 & 0,21 & 0,25 & 178,80 \\
\hline 58 & 0,02 & 0,45 & 0,21 & 0,25 & 180,29 \\
\hline 59 & 0,02 & 0,44 & 0,21 & 0,25 & 179,08 \\
\hline 60 & 0,02 & 0,45 & 0,21 & 0,24 & 177,61 \\
\hline 61 & 0,02 & 0,46 & 0,21 & 0,24 & 178,16 \\
\hline 62 & 0,02 & 0,45 & 0,21 & 0,24 & 177,77 \\
\hline 63 & 0,02 & 0,46 & 0,21 & 0,24 & 175,69 \\
\hline 64 & 0,02 & 0,45 & 0,20 & 0,24 & 177,10 \\
\hline 65 & 0,02 & 0,45 & 0,20 & 0,23 & 176,73 \\
\hline 66 & 0,02 & 0,44 & 0,20 & 0,23 & 176,37 \\
\hline 67 & 0,01 & 0,43 & 0,20 & 0,23 & 176,37 \\
\hline 68 & 0,01 & 0,44 & 0,20 & 0,22 & 174,84 \\
\hline
\end{tabular}

\begin{tabular}{|c|c|c|c|c|c|}
\hline $\begin{array}{l}\text { número de } \\
\text { linhagens }\end{array}$ & $\begin{array}{l}\text { menor } \\
q\end{array}$ & $\begin{array}{l}\text { maior } \\
q\end{array}$ & média & $\bar{q}$ & $\bar{b}$ \\
\hline 46 & 0,02 & 0,46 & 0,21 & 0.24 & 170,53 \\
\hline 47 & 0,02 & 0,45 & 0,21 & 0,24 & 171,75 \\
\hline 48 & 0,02 & 0,44 & 0,21 & 0,24 & 172,12 \\
\hline 49 & 0,02 & 0,43 & 0,21 & 0,24 & 170,76 \\
\hline 50 & 0,02 & 0,44 & 0,21 & 0,24 & 171,38 \\
\hline 51 & 0,02 & 0.43 & 0,21 & 0,24 & 172,44 \\
\hline 52 & 0,02 & 0,44 & 0,21 & 0,24 & 173,98 \\
\hline 53 & 0,02 & 0,45 & 0,21 & 0,24 & 173,75 \\
\hline 54 & 0,02 & 0,46 & 0,21 & 0,24 & 173,63 \\
\hline 55 & 0,02 & 0,47 & 0,21 & 0,24 & 173,25 \\
\hline 56 & 0,02 & 0,46 & 0,21 & 0,24 & 174,28 \\
\hline 57 & 0,02 & 0,46 & 0,21 & 0,24 & 173,47 \\
\hline 58 & 0,02 & 0,45 & 0,21 & 0,24 & 173,87 \\
\hline 59 & 0,02 & 0,46 & 0,21 & 0,24 & 174,48 \\
\hline 60 & 0,02 & 0.45 & 0,21 & 0,24 & 174,83 \\
\hline 61 & 0,02 & 0,44 & 0,20 & 0,23 & 174,32 \\
\hline 62 & 0,02 & 0,44 & 0,20 & 0,23 & 175,78 \\
\hline 63 & 0,02 & 0,43 & 0,20 & 0,23 & 175,78 \\
\hline 64 & 0,02 & 0,44 & 0,20 & 0,23 & 174,19 \\
\hline 65 & 0,02 & 0,45 & 0,20 & 0,23 & 172,16 \\
\hline 66 & 0,02 & 0,44 & 0,20 & 0,22 & 173,59 \\
\hline 67 & 0,01 & 0,45 & 0,20 & 0,23 & 173,44 \\
\hline 68 & 0,01 & 0,44 & 0,20 & 0,22 & 17 \\
\hline
\end{tabular}

* Tamanho do sintético conforme o número de linhagens. 
O tamanho ideal do sintético variou conforme o local avaliado. Assim, o número de linhagens presentes no sintético considerado ideal foi de $13,7,5,7$ e 10 para os locais $1,2,3,4$ e para a análise conjunta respectivamente. $O$ critério utilizado para definir esse número ideal de linhagens na composição do sintético foi o conjunto de linhagens a partir do qual não haverá fixação de alelos desfavoráveis em nenhum dos locos envolvidos. Na tabela 34 observam-se os tamanhos de sintéticos considerados ideais nos diferentes locais segundo o índice de seleção e segundo o topcross.

Tabela 34: Diferentes tamanhos de sintéticos considerados como ideais segundo o índice de seleção e segundo o topcross. Locais 1, 2, 3, 4 e análise conjunta. Iowa, EUA, 1996.

\begin{tabular}{ccc}
\cline { 2 - 3 } & \multicolumn{2}{c}{ Número de linhagens } \\
\hline Locais & Indice de seleção & Topcross \\
\hline 1 & 13 & 11 \\
2 & 7 & 13 \\
3 & 5 & 6 \\
4 & 7 & 9 \\
conjunta & 10 & 12 \\
\hline
\end{tabular}

Na maior parte dos casos o número de linhagens no sintético ideal segundo o indice de seleção foi inferior ao número de linhagens no sintético ideal segundo o topcross, exceção feita ao local 1, onde o indice indica 13 linhagens como o número ideal para compor o sintético e o topcross determina que sejam 11 linhagens. Uma explicação possivel para esse fato está na diferença existente entre os valores de $\hat{p}$ calculados para os diversos locais, pois valores elevados são recomendados quando se deseja fazer uso da seleção assistida por marcadores. Na tabela 23, observa-se que no local 1 os marcadores explicaram $23,9 \%$ da variância entre progênies, o que é muito pouco. Considerando os outros locais e na média dos locais, a proporção da variância explicada pelos marcadores foi elevada, variando de $74,5 \%$ a $100 \%$. Assim, no caso do local 1 , o indice não apresentou diferença em relação à seleção baseada no topcross 
quanto aos valores de $\bar{q}$, e exigiu maior número de linhagens na composição do sintético ideal, embora tenha levado a sintéticos com maiores valores de $\bar{b}$ quando comparados com os selecionados pelo critério do topcross.

Para a comparação entre os sintéticos formados por números diferentes de linhagens, o parâmetro da fixação alélica não é suficiente. É preciso verificar as frequêencias dos alelos favoráveis associados às sondas, pois o objetivo do índice de seleção foi o de obter sintéticos com maiores frequêencias de alelos favoráveis quando comparados aos sintéticos construídos pelo topcross, já que o índice leva em consideração a complementação gênica entre os locos avaliados. As comparações foram feitas entre sintéticos de diferentes tamanhos formados pelo mesmo método, e entre sintéticos de igual tamanho formados por métodos diferentes. Para as comparações entre os sintéticos utilizaram-se os paràmetros $\bar{q}$ e $\bar{b}$, como pode ser visto na tabela 35 .

Tabela 35: Valores de $\bar{q}$ e $\bar{b}$ calculados para sintéticos de diferentes tamanhos. Quatro locais e análise conjunta. Iowa, EUA, 1996

$\overline{\bar{q}} \overline{\bar{b}}$

\begin{tabular}{llllll}
\hline Locais & $\begin{array}{c}\text { Tamanho } \\
\text { do sintético }\end{array}$ & Índice & Topcross & Índice & Topcross \\
\hline 1 & 13 & 0,38 & 0,37 & 296,48 & 276,50 \\
1 & 11 & 0,38 & 0,38 & 311,84 & 274,41 \\
\hline 2 & 7 & 0,40 & 0,38 & 241,87 & 229,31 \\
2 & 13 & 0,38 & 0,32 & 244,89 & 323,45 \\
\hline 3 & 5 & 0,44 & 0,41 & 173,05 & 165,97 \\
3 & 6 & 0,44 & 0,43 & 177,22 & 157,07 \\
\hline 4 & 7 & 0,47 & 0,33 & 121,24 & 98,74 \\
4 & 9 & 0,45 & 0,33 & 123,42 & 101,58 \\
\hline Conjunta & 10 & 0,38 & 0,34 & 184,69 & 178,58 \\
Conjunta & 12 & 0,37 & 0,31 & 191,85 & 170,25 \\
\hline
\end{tabular}

* A primeira linha de cada local refere-se ao tamanho ideal de sintético segundo o índice de seleção, enquanto a segunda linha é referente ao tamanho do sintético de acordo com o topcross. 
Quanto às frequiências de sondas associadas aos alelos favoráveis, $\bar{q}$, os sintéticos formados pelo índice apresentaram valores superiores aos dos formados pelo topcross, exceção feita ao local 1 onde os valores foram semelhantes. O local que apresentou as maiores diferenças dos valores de $\bar{q}$ entre os dois grupos foi o local 4 . Quando o parâmetro de avaliação foi $\bar{b}$, o índice levou sempre a valores superiores em comparação aos dos obtidos com os topcrosses, indicando a seleção de locos com altos valores genotípicos associados a produtividade de grãos em milho.

Uma contribuição interessante, dada neste estudo, está na possibilidade de monitorar melhor as propriedades genéticas de um sintético qualquer. É preciso lembrar que $\bar{q}$ é uma medida da frequêencia de linhagens em que as marcas estão associadas a QTL's favoráveis. Sendo todas as linhagens homozigóticas esse parâmetro corresponde à freqüência média de alelos das marcas ligados a alelos superiores nos QTL's. Considerando o sintético amplo, esse valor é $\bar{q}=0,22$ (tabela 33). Nos melhores sintéticos, de tamanho 10 e 12, para a média dos locais, os valores correspondentes são $\bar{q}=0,38$ e $\bar{q}=0,37$ respectivamente. Ora, essa diferença $(0,38-0,22)=0,16$ ou $(0,37-0,22)=0,15$ é considerável em se tratando de um caráter quantitativo como o investigado. Da mesma forma, não é desprezivel a diferença entre $\bar{q}$, confrontando-se os sintéticos organizados com base no indice e com base nas médias topcross (tabela 35). $\mathrm{Na}$ tabela 36 observa-se as diferenças entre os valores de $\bar{q}$ no sintético amplo, no sintético ideal segundo o indice de seleção e no sintético de mesmo tamanho segundo o critério do topcross. Como pode ser visto, em todos os locais avaliados o índice foi competente em conduzir o sintético à valores de $\bar{q}$ mais elevados. 
Tabela 36: Valores de $\bar{q}$ no sintético amplo, no sintético ideal segundo o índice e no sintético de mesmo tamanho segundo o critério do topcross e diferenças em relação ao amplo.

\begin{tabular}{cccccc}
\cline { 2 - 6 } & \multicolumn{5}{c}{$\bar{q}$} \\
\hline $\begin{array}{c}\text { tamanho do } \\
\text { sintético }\end{array}$ & local 1 & local 2 & local 3 & local 4 & média \\
\hline amplo & 0,28 & 0,25 & 0,21 & 0,24 & 0,22 \\
\hline ideal (índice) & 0,38 & 0,40 & 0,44 & 0,47 & 0,38 \\
diferença & 0,10 & 0,15 & 0,23 & 0,23 & 0,16 \\
\hline topcross & 0,37 & 0,38 & 0,41 & 0,33 & 0,34 \\
diferença & 0,90 & 0,13 & 0,20 & 0,90 & 0,12 \\
\hline
\end{tabular}

Para melhor visualização das freqüências dos alelos favoráveis associados às sondas em cada loco, apresentam-se as figuras de 1 a 6 , referentes à média dos locais. Esses gráficos foram adicionados ao texto para esclarecer aspectos que podem ser do interesse do melhorista. No apêndice encontram-se as figuras de númerol a 6,7 a 12,13 a 18 e 19 a 24 referentes aos locais 1, 2, 3 e 4 respectivamente. Considerando os possíveis sintéticos organizados como base nas médias dos quatro locais pode-se notar alguns pontos conforme segue:

1) O sintético de menor tamanho, formado pelas cinco melhores linhagens, é superior ao sintético amplo para a maior parte dos locos. Porém, apresenta $q=0$ em alguns locos, o que não é desejável.

2) $\mathrm{O}$ sintético formado pelas 10 melhores linhagens, que foi considerado como ideal na média dos locais, apresentou em parte do locos freqüências menores de $q$, quando comparado com o sintético de tamanho 5. Apesar do maior número de linhagens componentes, apresenta como vantagem a ausência de locos com $q=0$. Por outro lado, quando comparado com o sintético amplo 
linhagens), o sintético 10 apresenta maior valor de $q$ para a maioria dos locos, exceção feita às marcas de número 10 e 12.

3) No intervalo de sintéticos formados por 10 até 13 linhagens, observa-se uma sincronia de freqüências de $q$ na maior parte dos locos. Neste caso, optou-se pelo sintético de menor tamanho, visando maior facilidade dos trabalhos de campo. 


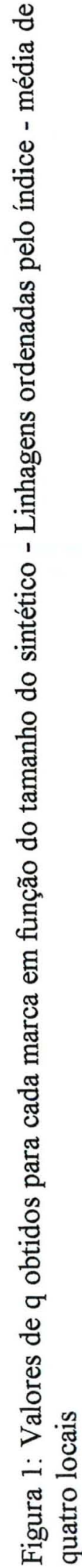

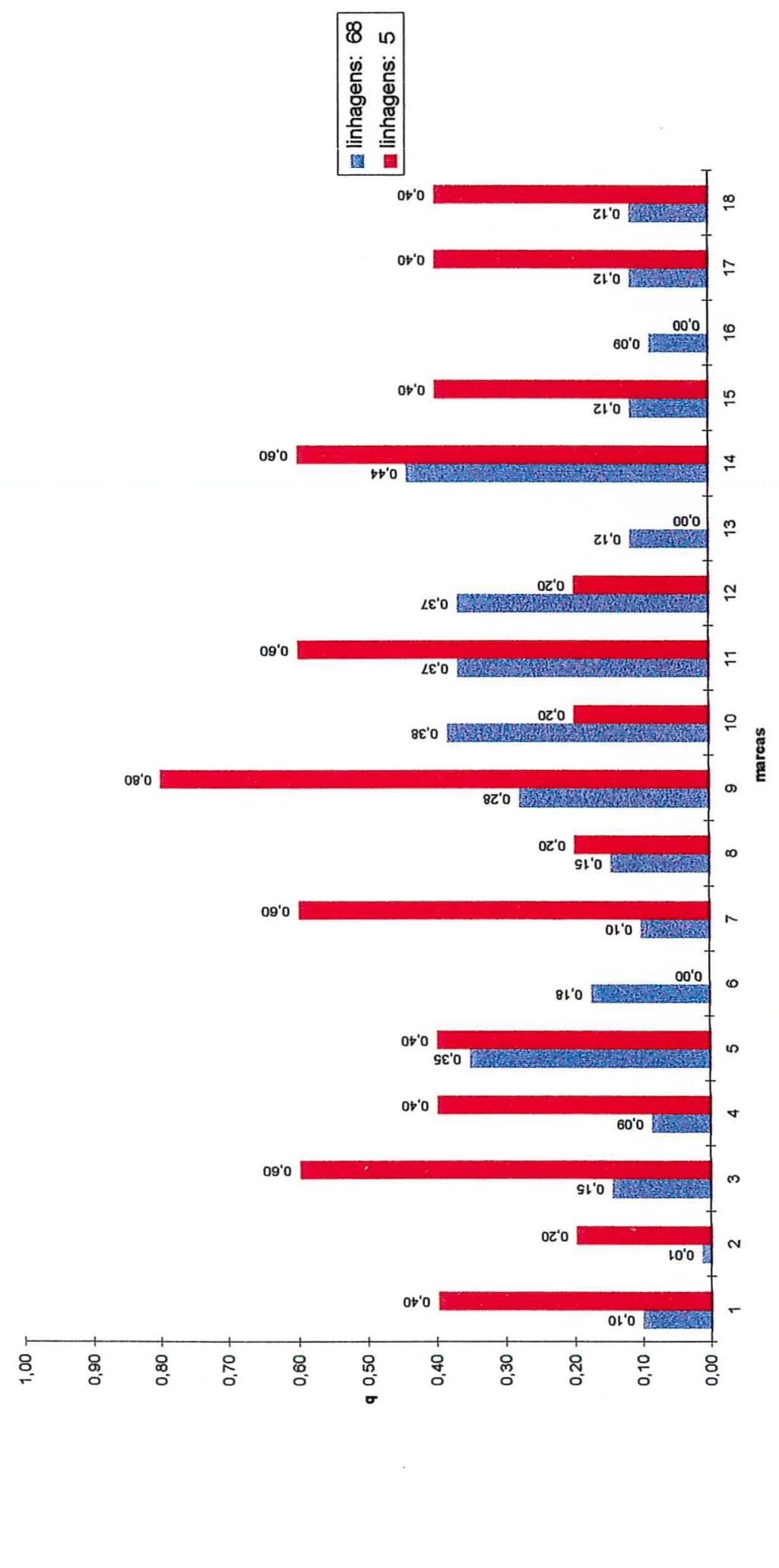




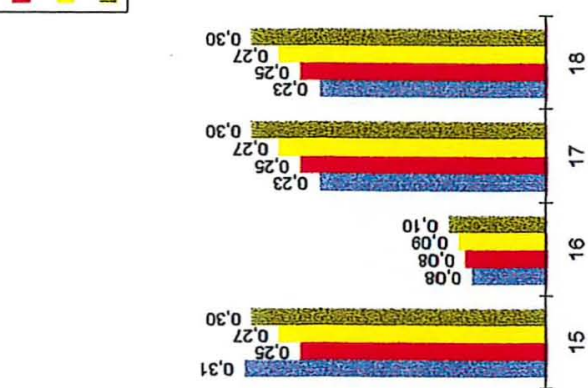

ปั

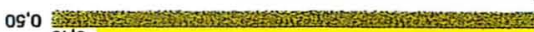
$0 \mathrm{~S}^{\prime} \mathrm{O}$

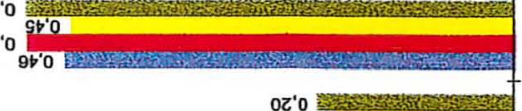

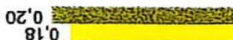

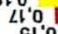

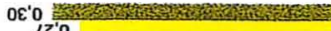
LZ'O

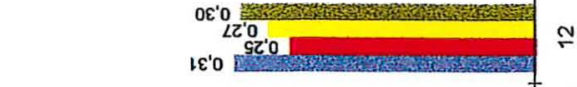

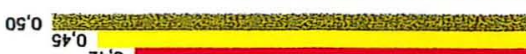

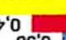

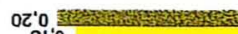

Li'o $288^{\prime} 0$

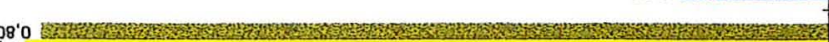

I్ㅛ $\varepsilon 8^{\prime} 0$
$98^{\prime} 0$

$0 \varepsilon^{\prime} 0$ vivs $\varepsilon \varepsilon^{\prime} 0$

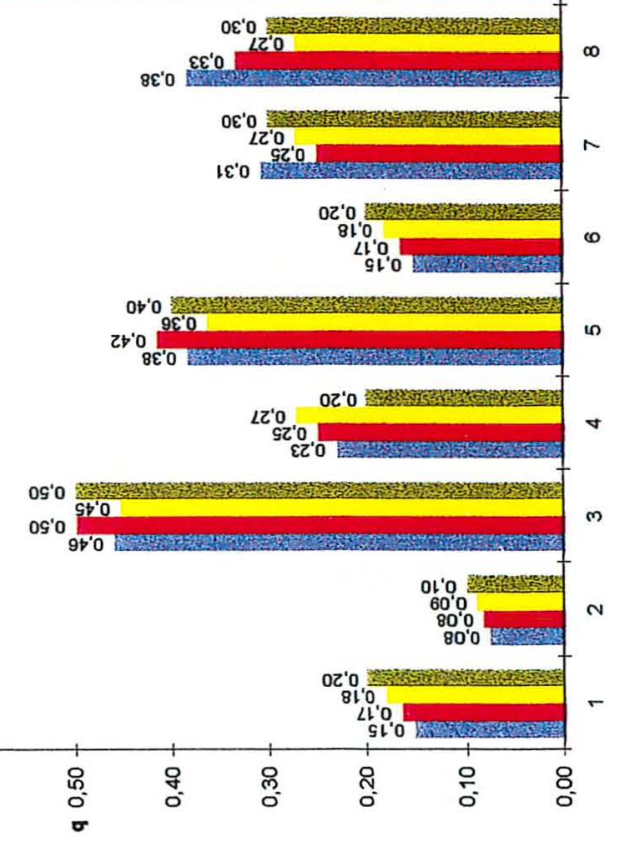

서 으

莺莺 


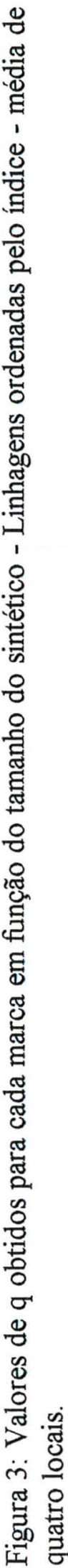

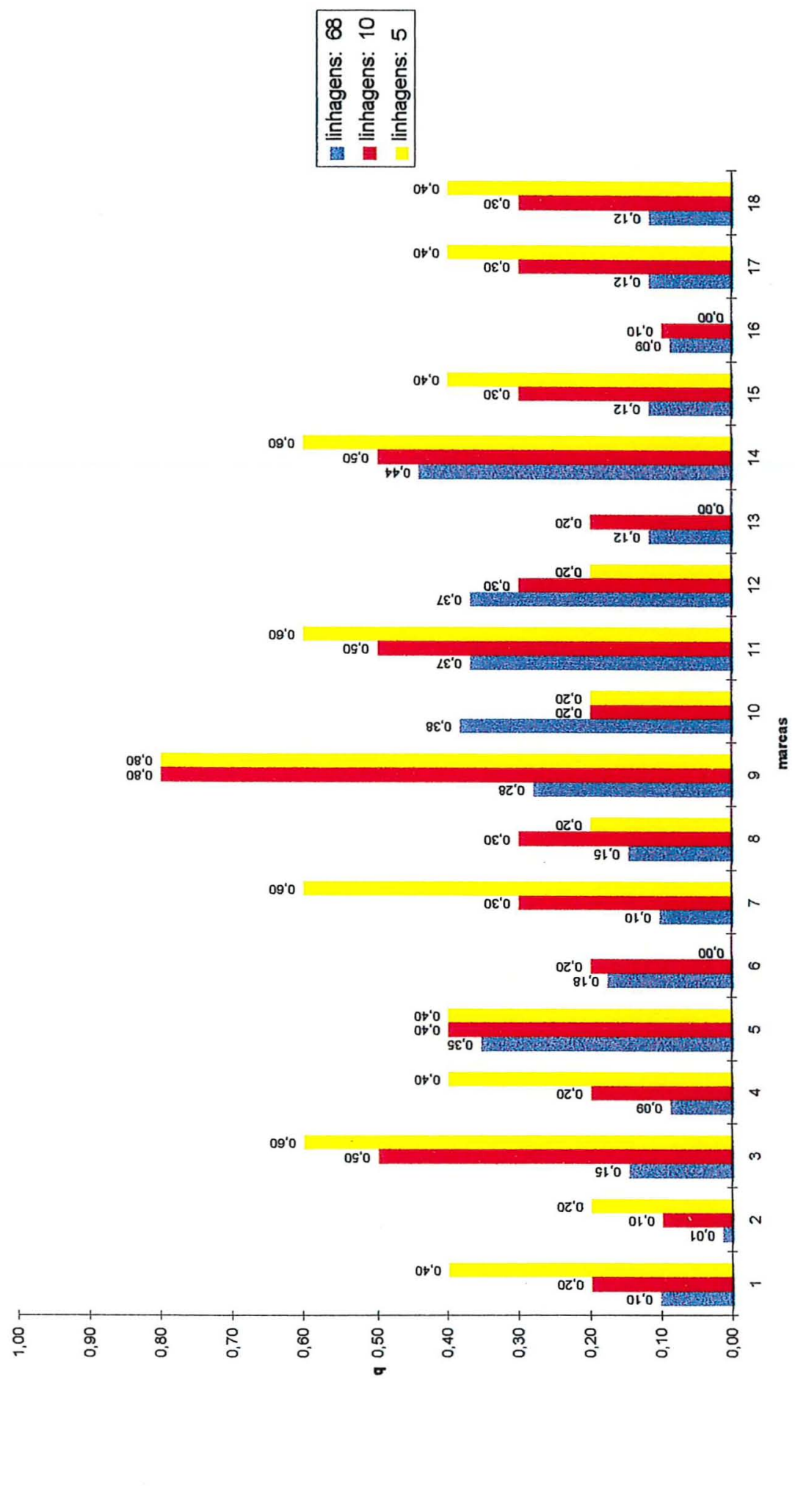




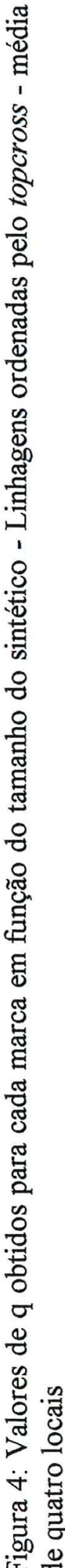

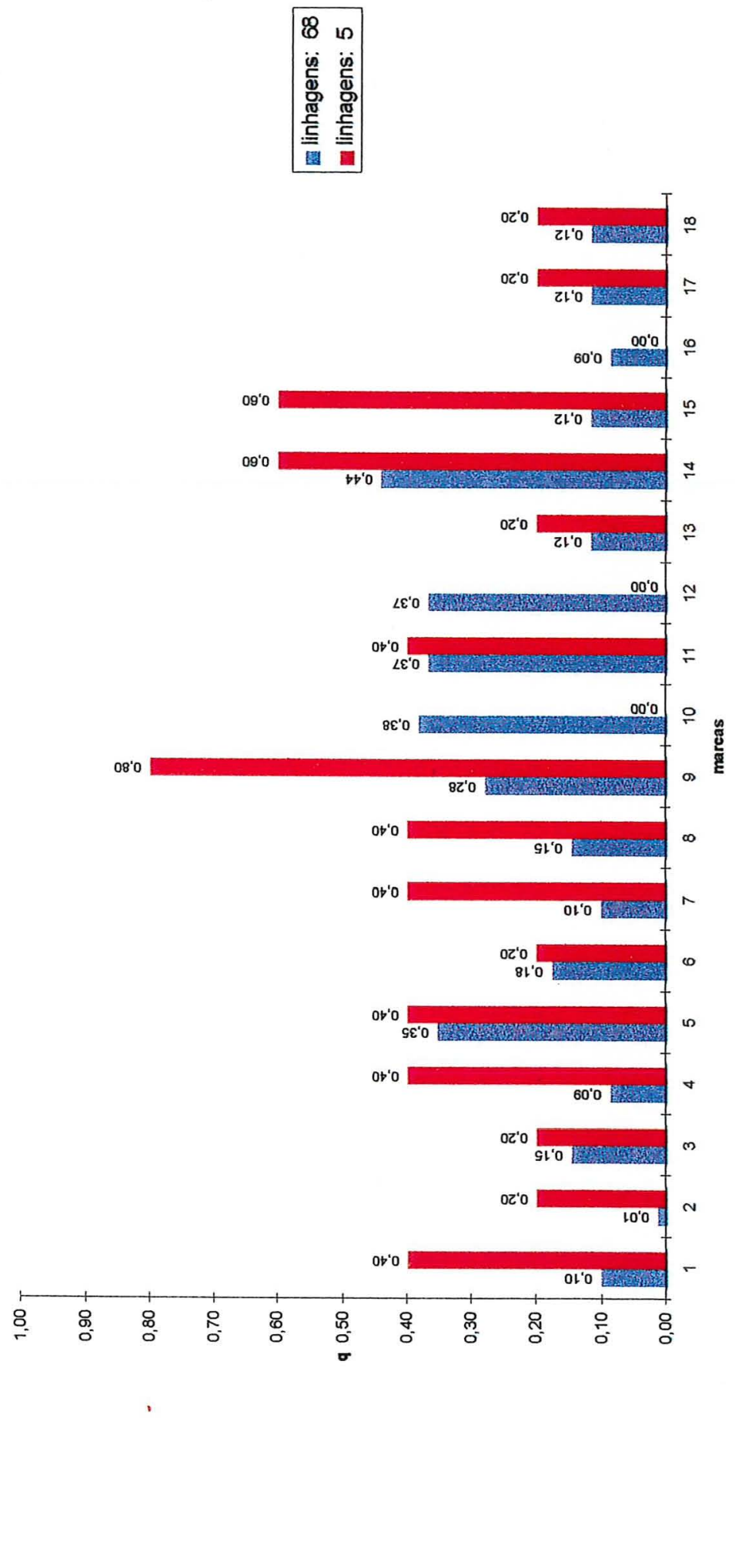




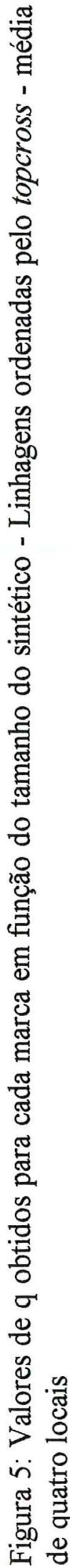




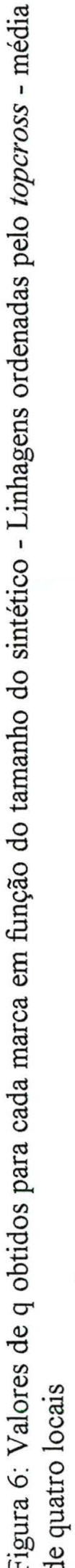
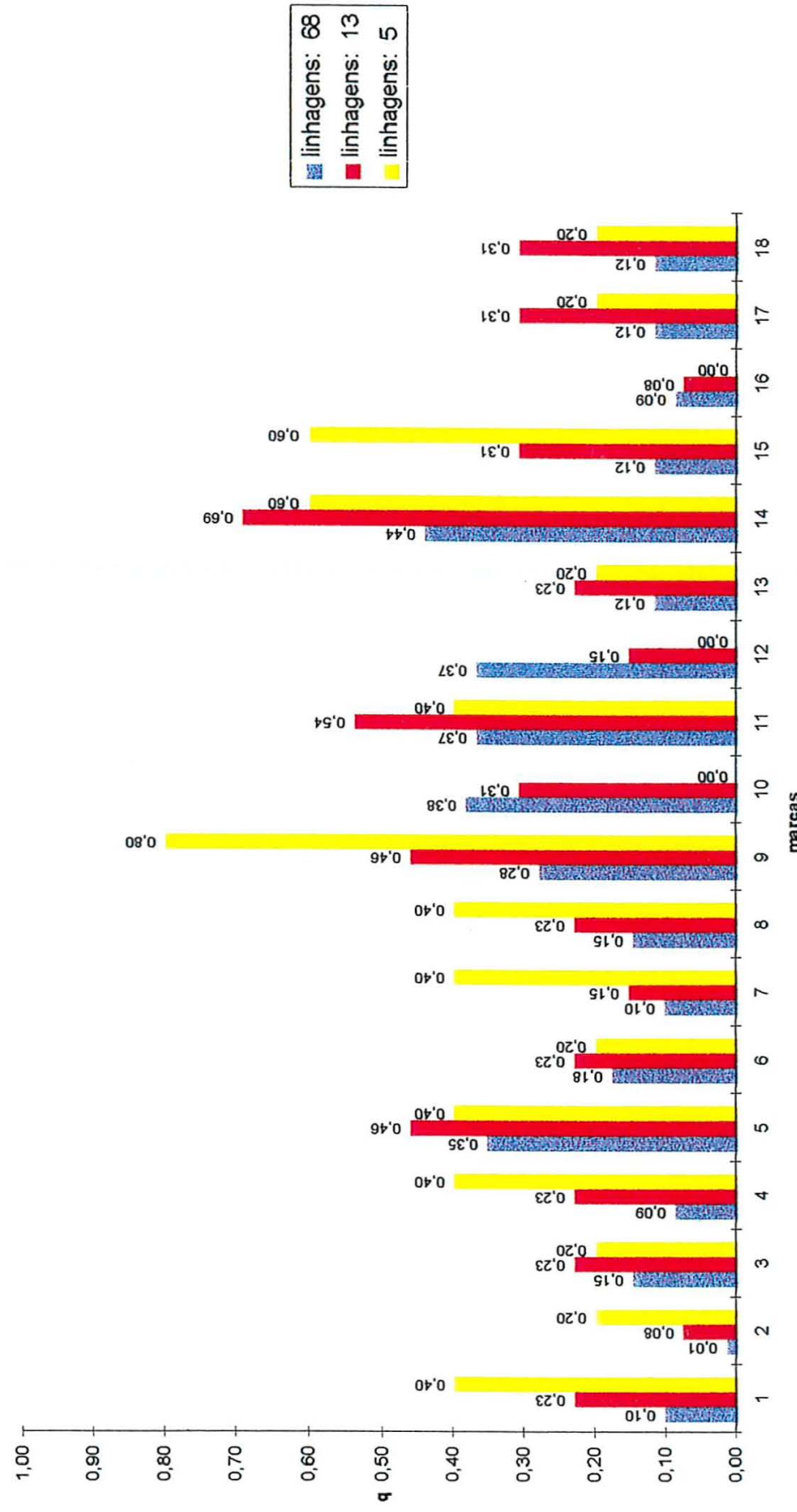


\section{CONCLUSÕES}

O presente trabalho permitiu chegar às seguintes conclusões principais:

a) O índice proposto possibilita obter um homólogo de tabela dialélica cuja utilidade fica evidente em situações nas quais é impraticável obter todos os cruzamentos possiveis entre as linhagens parentais.

b) A natureza do índice leva em conta não só o comportamento próprio das linhagens como a complementaridade genotípica de cada uma com todas as demais. Essa complementaridade é medida em todos os locos, independentemente do grau de dominância dos QTL's associados aos marcadores. Em relação a essa propriedade, o índice tende a ser superior aos parâmetros de capacidade específica de combinação ou de heterose que dependem da existência de dominância gênica.

c) Por levar em conta a complementaridade genotípica o índice tende a ser superior às seleções baseadas no comportamento das linhagens em topcross, já que esse último critério não mensura a complementaridade. 
d) Para ser de utilidade o indice requer o emprego de número adequado de marcadores co-dominantes, suficientemente bem distribuídos pelos cromossomos. Requer, portanto, que os marcadores expliquem grande parte da variância genética entre as progênies usadas como base inicial de todo o processo seletivo (alto valores de $\mathrm{p}$ e/ou de $\mathrm{R}^{2}$ ).

e) $\mathrm{O}$ uso do índice e dos demais parâmetros propostos permitem um monitoramento bastante rigoroso das propriedades genéticas e do potencial dos diferentes sintéticos que podem ser obtidos. Desse modo pode-se aumentar a eficiência do processo de escolha de sintéticos mais próximos do ideal.

f) Linhagens com freqüência elevada de alelos favoráveis de QTL's foram identificadas tanto através do índice como através das médias de suas progênies topcross. Essa concordância não foi observada nas linhagens logo abaixo das superiores pelo fato de o índice levar em consideração a complementaridade genotípica, o que não ocorre com o critério de seleção baseado nos topcrosses apenas.

g) A eficiência do índice pode ser incrementada incluindo-se avaliações das linhagens com mais de um testador. Pode também ser aumentada incorporando-se efeitos de dominância nas medidas de complementaridade.

h) Em relação aos QTL's associados aos marcadores utilizados, o índice proposto foi mais eficiente que o critério das médias dos topcrosses por levar a sintéticos com freqüèncias mais elevadas de alelos favoráveis. O mesmo obviamente não pode ser dito em relação aos QTL's não abrangidos pelos marcadores. 


\section{REFERÊNCIAS BIBLIOGRÁFICAS}

AJMONE-MARSAN, P., MONFREDINI, G., BRANDOLINI, A., MELCHINGER, A. E., GARAY, G.; MOTTO, M. Identification of QTL for grain yield in an elite hybrid of maize: repeatability of map position and effects in independent samples derived from the same population. Maydica, v. 41, p. $49-57,1996$

BEARZOTI, E. Simulação de seleção recorrente assistida por marcadores moleculares em espécies autógamas. Piracicaba, 1997. 230p. Tese (Doutorado) - Escola Superior de Agricultura "Luiz de Queiroz", Universidade de São Paulo.

BEARZOTI, E.; VENCOVSKY, R. Estimation of the proportion of genetic variance explained by molecular markers. Genetics and Molecular Biology, v. 21 , p. $557-566,1998$.

BEAVIS, W. D., SMITH, O. S., GRANT, D.; FINCHER, R. Identification of quantitative trait loci using a small sample of topcrossed and $F_{4}$ progeny of maize. Crop Sci.ence, v. 34, p. 882-896, 1994. 
BERKE, T. G.; ROCHEFORD, T. R. Quantitative trait loci for flowering, plant and ear height, and kernel traits in maize. Crop Science, v. 35, p. 1542$1549,1995$.

BERNARDO, R. Relationship between single-cross performance and molecular marker heterozygosity. T.A.G,. v. 83, p. 628-634, 1992.

BERNARDO, R. Prediction of maize single-cross performance using RFLPs and information of related hybrids. Crop Science, v. 34, p. 20-25, 1994.

BERNARDO, R. Selection response with marker-based assortative mating. Crop Science, v. 39, p. 69-73, 1999.

BUBECK, D. M., GOODMAN, M. M., BEAVIS, W. D.; GRANT, D. Quantitative trait loci controlling resistance to gray leaf spot in maize. Crop Science, v 33, p. 838-847, 1993.

DUbreUIL, P., DUfOUR, P., KREJCI, E., CAUSSE, M., VIENNE, D. de, GALLAIS, A.; CHARCOSSET, A. Organization of RFLP diversity among inbred lines of maize representing the most significant heterotic groups. Crop Science, 36: 790-799 1996.

DUDLEY, J. W. Molecular markers in plant improvement: manipulation of genes affecting quantitative traits. Crop Science, v. 33, p. 660-668, 1993. 
DUdLEY, J. W., SAGHAI MAROOF, M. A.; RUFENER, G. K. Molecular markers and grouping of parents in maize breeding programs. Crop Science, v. 31, p.718-723, 1991.

EDWARDS, M. \& JOHNSON, L. RFLPs for rapid recurrent selection. In: Proceedings of the symposium analysis of molecular marker data. American Society for Horticultural Science. Corvallis, 1994.

EDWARDS, M. D.; PAGE, N. J. Evaluation of marker-assisted selection through computer simulation. Theoretical and Applied Genetics, v.88, p.376-382, 1994.

FALCONER, D. S. ; MACKAY, T. F. C. Introduction to Quantitative Genetics. 4.ed. Essex: Longman, 1996. 464p.

GERDES, J. T.; TRACY, W. F. Diversity of historically important sweet corn inbreds as estimated by RFLPs, morphology, isozymes, and pedigree. Crop Science, v.34, p.26-33, 1994.

GODSHALK, E. B., LEE, M.; LANKEY, K. R. Relationship of restriction fragment length polymorphisms to single-cross hybrid performance of maize. Theoretical and Applied Genetics, v.80, p.273-280, 1990.

GOLDMAN, I. L., ROCHEFORD, T. R.; DUDLEY, J. W. Molecular markers associated with maize kernel oil concentration in an Illinois high protein $\mathrm{x}$ Illinois low protein cross. Crop Science, v.34, p.908-915, 1994. 
GOMES, F. P. Curso de Estatística Experimental. 13.ed. São Paulo: Livraria Nobel, 1990. 467p.

HAHN, V., BLANKENHORN, K., SCHWALL, M.; MELCHINGER, A. E. Relationships among early european maize inbreds: III. Genetic diversity revealed with RAPD markers and comparison with RFLP and pedigree data. Maydica, v.40, p.299-310, 1995.

HALLAUER, A. R. \& MIRANDA FILHO, J B. Quantitative Genetics in Maize Breeding. 1.ed. Iowa: Iowa State University Press. 1981. 468p.

HOSPITAL, F., CHEVALET, C.; MULSANT, P. Using markers in gene introgression breeding programs. Genetics, v.132, p.1199:1210, 1992.

JANSEN, R. C., VAN OOIJEN, J. W., STAM, P., LISTER, C.; DEAN, C. Genotype-by-environment interaction in genetic mapping of multiple quantitative trait loci. Theoretical and Applied Genetics, v.91, p.33-37, 1995

KENNARD, W. C.; HAVEY, M. J. Quantitative trait analysis of fruit quality in cucumber: QTL detection, confirmation, and comparison with mating-design variation. Theoretical and Applied Genetics, v.91, p.53-61, 1995.

KERNS, M. R., DUDLEY, J. W.; RUFENER II, G. K. Tester and type of progeny affect QTL detection in maize. Maydica, v.44, p.69-83, 1999. 
KOZUMPLICK, V., PEJIC, I., SENIOR, L., PAVLINA, R., GRAHAM, G.; STUBER, C. W. Use of molecular markers for QTL detection in segregating maize populations derived from exotic germplasm. Maydica, v.41, p.211$217,1996$.

LANDE, R.; THOMPSON R. Efficiency of marker-assisted selection in the improvement of quantitative traits. Genetics, v.124, p.743-756, 1990.

LANZA, L. L. B., SOUZA JR., C. L., OTTOBONI, L. M. M., VIEIRA, M. L. C.; SOUZA, A. P. de. Genetic distance of inbred lines and prediction of maize single-cross performance using RAPD markers. Theoretical and Applied Genetics, v.94, p.1023-1030, 1997.

LEE, M., GODSHALK, E. B., LAMKEY, K. R.; WOODMAN, W. W. Association of restriction fragment length polymorphisms among maize inbreds with agronomic performance of their crosses. Crop Science, v.29, p. 10067-1071, 1989.

LEE, S. H., BAILEY, M. A., MIAN, M. A. R., CARTER JR., T. E., ASHLEY, D. A., HUSSEY, R. S., PARROT, W. A.; BOERMA, H. R. Molecular markers associated with soybean plant heigth, lodging, and maturity across locations. Crop Science, v.36, p. 728-735, 1996.

LEON, A. J., LEE, M., RUFENER, G. K., BERRY, S. T.; MOWERS, R. P. Use of RFLP markers for genetic linkage analysis of oil percentage in sunflower seed. Crop Science, v.35, p.558-564, 1995. 
LYNCH, M. \& WALSH, B. Genetics and Analysis of Quantitative Traits. 1.ed. Sunderland: Sinauer Associates, Inc. 1998. 980p.

LORENZEN, L. L., BOUTIN, S., YOUNG, N., SPECHT, J. E.; SHOEMAKER, R. C. Soybean pedigree analysis using map-based molecular markers: I. Tracking RFLP markers in cultivars. Crop Science, v.35, p.1326-1336, 1995.

MA, Z. -Q; SORRELLS, M. E. Genetic analysis of fertility restoration in wheat using restriction fragment length polymorphisms. Crop Science, v.35, p. 1137-1143, 1995 .

MELCHINGER, A. E., LEE, M., LAMKEY, K. R.; WOODMAN, W. L. Genetic diversity for restriction fragment length polymorphisms: relation to estimated genetic effects in maize inbreds. Crop Science, v.30, p.1033-1040, 1990.

MESSMER, M. M., MELCHINGER, A. E., BOPPENMAIER, J., BRUNKLAUSJUNG, E.; HERRMANN, R. G. Relationships among early european maize inbreds: I. Genetic diversity among flint and dent lines revealed by RFLPs. Crop Science, v.32, p.1301-1309, 1992.

MESSMER, M. M., MELCHINGER, A. E., HERRMANN, R. G.; BOPPENMAIER, J. Relationships among early european maize inbreds: II. Comparison of pedigree and RFLP data. Crop Science, v.33, p.944-950, 1993. 
MOREAU, L., MONOD, H., CHARCOSSET, A.; GALLAIS, A. Marker-assisted selection with spatial analysis of unreplicated field trials. Theoretical and Applied Genetics, v.98, p.234-242, 1999.

MUMM, R. H.; DUDLEY, J. W. A classification of 148 U. S. maize inbreds: I. Cluster analysis based on RFLPs. Crop Science, v.34, p.842-851, 1994.

MUMM, R. H., HUBERT, L.; DUDLEY, J. W. A classification of 148 U. S. maize inbreds: II. Validation of cluster analysis based on RFLPs. Crop Science, v.34, p.852-865, 1994.

OGLIARI, J. B. Identificação e localização de um gene de resistência de milho a Exserohilum turcicum (Pass.) Leonard \& Suugs. Através do uso de marcadores microssatélites. Piracicaba, 1997. 115p. Tese (Doutorado) Escola Superior de Agricultura "Luiz de Queiroz", Universidade de São Paulo.

OPENSHAW, S. J., JARBOE, S. G.; BEAVIS, W. D. Marker-assisted selection in backcross breeding. In: Proceedings of the symposium analysis of molecular marker data. American Society for Horticultural Science. Corvallis, 1994.

RAGOT, M., SISCO, P. H., HOISINGTON, D. A.; STUBER, C. W. Molecularmarker-mediated characterization of favorable exotic alleles at quantitative trait loci in maize. Crop Science, v.35, p. 1306-1315, 1995.

SAS INSTITUTE INC. Statistical Analyses System. Release 6.12, (software). Cary, 1992. 
SCHÖN, C. C., MELCHINGER, A. E., BOPPENMAIER, J., BRUNKLAUSJUNG, E., HERRMANN, R. G.; SEITZER, J. F. RFLP mapping in maize: quantitative trait loci affecting testcross performance of elite european flint lines. Crop Science, v.34, p.378-389, 1994.

SELIG, L., LAMBERT, R. J., ROCHEFORD, T. R.; SILVA, W. J. da. RFLP and cluster analysis of introgression of exotic germplasm into U. s. maize inbreds. Maydica, v.44, p.85-92, 1999.

SMITH, O. S.; SMITH, J. S. C. Measurement of genetic diversity among maize hybrids; a comparison of isozymic, RFLP, pedigree, and heterosis data. Maydica, v.37, p.53-60, 1992.

STROMBERG, L. D., DUDLEY, J. W; RUFENER, G. K. Comparing conventional early generation selection with molecular marker assisted selection in maize. Crop Science, v.34, p.1221-1225, 1994.

STUBER, C. W. Enhancement of grain yield in maize hybrids using markerfacilitated introgression of QTLs. In: Proceedings of the symposium analysis of molecular marker data. American Society for Horticultural Science. Corvallis, 1994.

VELDBOOM, L. R.; LEE, M. Genetic mapping of quantitative trait loci in maize in stress and nonstress environments: II. Plant height and flowering. Crop Science, v.36, p.1320-1327, 1996. 
Tabela 1: Topcrosses de linhagens de milho. Iowa, Slater, EUA, 1996. Produtividade de grãos em $\mathrm{kg} / \mathrm{ha}$, em nível de parcelas. Bloco 1

\begin{tabular}{|c|c|c|c|c|c|c|c|c|c|}
\hline & \multicolumn{8}{|c|}{ Locais } \\
\hline & & \multicolumn{2}{|c|}{ Local I } & \multicolumn{2}{|c|}{ Local 2} & \multicolumn{2}{|c|}{ Local 3} & \multicolumn{2}{|c|}{ Local 4} \\
\hline bl. & trat. & rep 1 & rep 2 & rep 1 & rep 2 & rep 1 & rep 2 & rep 1 & rep 2 \\
\hline 1 & 1 & 9186,28 & 9051,74 & 978,25 & & 5896,85 & 7579,47 & 0818,08 & 7773,99 \\
\hline 1 & 2 & 1,16 & 00 & 23,54 & 7363,47 & 45,45 & & 8,79 & \\
\hline 1 & 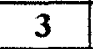 & 62,03 & 8094,32 & 6929,32 & 6738,26 & & 7789,07 & 580,73 & 81,06 \\
\hline 1 & 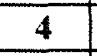 & 5,06 & & 55,05 & 4,65 & 3,44 & & 9.52 & \\
\hline 1 & 5 & 49 & 10965,62 & 89,14 & 8371,82 & & & 8,84 & .23 \\
\hline 1 & - & & & & & 8790,45 & & 2,79 & \\
\hline 1 & 7 & & & & 553,15 & & & 89 & 4,81 \\
\hline 1 & 8 & 33 & 23 & 46,14 & 7316,23 & & & 8,27 & 5,23 \\
\hline 1 & 4 & 5,26 & & 7.64 & 5,60 & 10923,66 & & 9,36 & 3,76 \\
\hline 1 & 11 & & & 96 & 3,64 & 7926,87 & & 5,86 & 8,34 \\
\hline 1 & 1 & 34 & 28 & 8049,79 & 753 & 9406,68 & 84 & 7929,07 & 5,05 \\
\hline 1 & 1 & & & 3,80 &, 95 & 10052,24 & &, 75 & 2,35 \\
\hline 1 & 13 &, 20 & 86 & 9751,50 & 10757,59 & & 10 & 4,63 & 7,57 \\
\hline 1 & 14 & 84 & & & 01 & & 12 & 3,52 & 8,87 \\
\hline 1 & 15 & 33 & 30 & 9982,39 & 81 & & 96 & 3,55 & 6,68 \\
\hline 1 & 1 &, 62 & 23 & 6662,19 & 80 & & 09 & 8258,64 & 3,03 \\
\hline 1 & 1 & 34 & & 68 & & 8832,28 & & 6,72 & \\
\hline 1 & 1 & & & 14 &, 49 & & 14 & 3,41 & 5,20 \\
\hline 1 & 1 & 3,52 & 34 & 7865,63 & 8,77 & 9119,51 & & 7,13 & 7,52 \\
\hline 1 & 2 & & & 5723,94 & & 8275,09 & 89 & 1,08 & 1,63 \\
\hline 1 & 21 & 25 & 61 & 5,03 & 7,42 & 7668,79 & 32 & 1,00 & 3,88 \\
\hline 1 & 2 & 65 & & 87 & 3,17 & & & 9197,46 & 5,71 \\
\hline 1 & & & & & & 9843,08 & & 1,37 & 8,29 \\
\hline 1 & 2 & 2,90 & 42 &, 82 & 9,09 & 7936,36 & 95 & 10048,53 & 7289,54 \\
\hline 1 & 25 & 84 & 20 & 2,92 &, 73 & 7549,26 & .17 & 8371,82 & 6631,29 \\
\hline 1 & 26 & & & 7220.95 &, 92 & & 94 & 6,75 & 1,34 \\
\hline 1 & 2 & 69 & 25 & 6400,28 &, 12 & & 5,75 & 9182,76 & 2,46 \\
\hline 1 & 28 & 85 & 2,87 & 4,76 & 60 & & 75 & 2,31 & 1,39 \\
\hline 1 & 29 & 3,09 & 3,33 & 7439,40 & 8,25 & 8947,22 & 39 & 9323,08 & 316,23 \\
\hline 1 & 30 & 70 & 8,83 & 5645,61 & 7,03 & 8828,95 &, 54 & 7998,10 & 513,90 \\
\hline 1 & 31 & 46 & 5,38 & 8372,51 & 7791,77 & &, 64 & 2,12 & 665,77 \\
\hline 1 & 3 & 80 & 47 & 7071,21 & 2,13 & 8390,10 & 9,92 & 7545,93 & 298,58 \\
\hline 1 & T 1 & 10027,80 & 11900,99 & 7443,55 & 9969,01 & & 4,35 & 9728,89 & 666,96 \\
\hline 1 & T 2 & 8,61 & 9993,51 & 6168,07 & & 8149,03 & 7874,99 & 8925,05 & 527,84 \\
\hline 1 & T 3 & .47 & 9708,48 & 8980,51 & 1,10 & & 10239,35 & 8966,88 & \\
\hline 1 & T4 & 9296,88 & 9084,27 & 7798,30 & 7955,07 & 9220,88 & 10150,28 & 8161,03 & 990,18 \\
\hline 1 & T5 & 10944,01 & 8558,68 & 10306,74 & 8003,69 & 11411,76 & 12074,72 & 9280,43 & 35,02 \\
\hline 1 & T6 & 9907,46 & \begin{tabular}{|l|}
11696,67 \\
\end{tabular} & 8829.26 & 8632,61 & 11436,26 & 10918,58 & 8986,60 & 9117,19 \\
\hline 1 & T 7 & 10380,42 & 9174,66 & & 10838,68 & 9895,34 & 11590,77 & 8558,11 & 8592,16 \\
\hline 1 & T 8 & 9350,59 & 10133,95 & 8181,25 & 9552,08 & 11184,07 & 9692,84 & 9061,91 & \\
\hline
\end{tabular}


Tabela 2: Topcrosses de linhagens de milho. Iowa, Slater, EUA, 1996. Produtividade de grãos em $\mathrm{kg} / \mathrm{ha}$, em nível de parcelas. Bloco 2

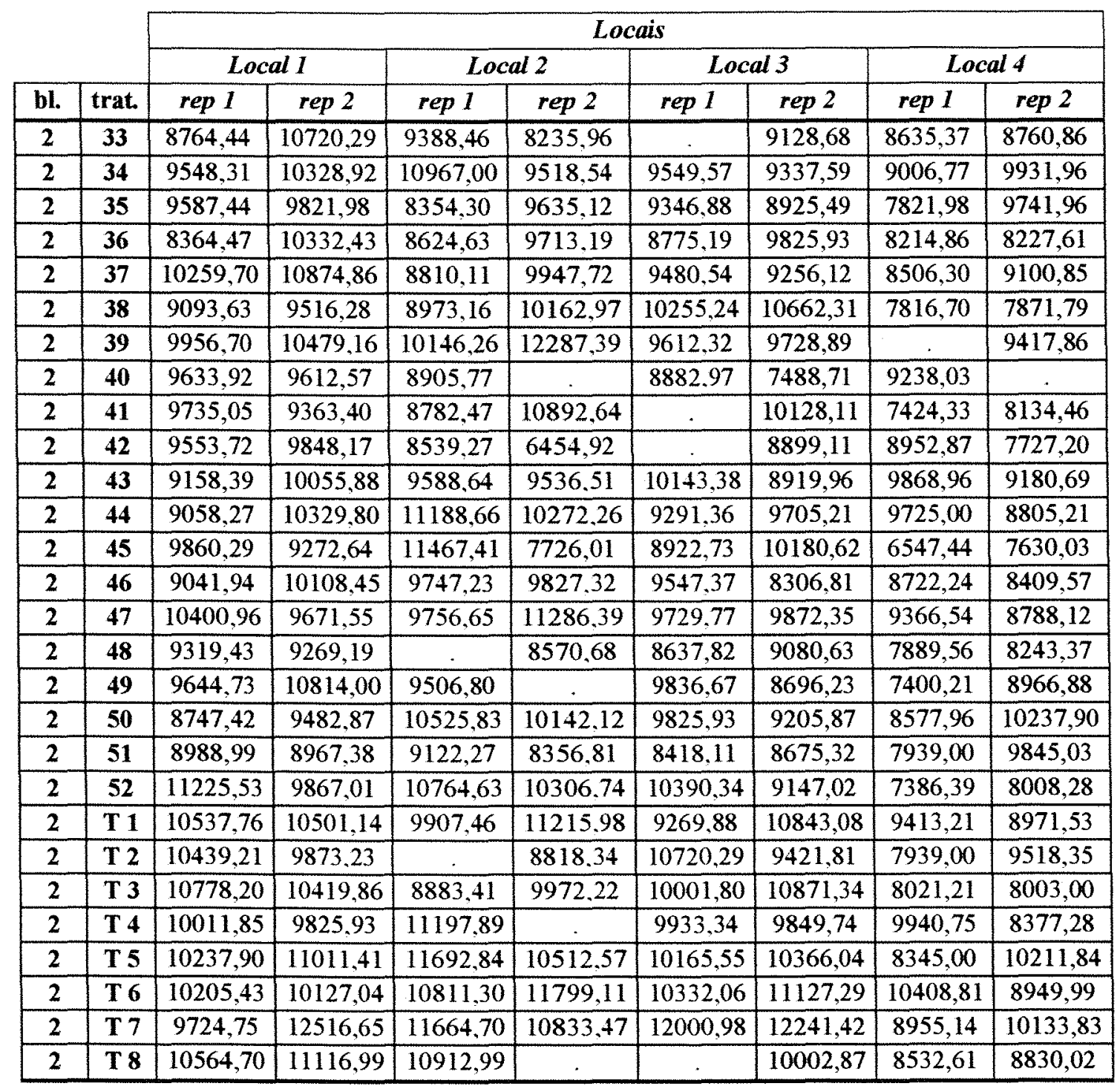


Tabela 3: : Topcrosses de linhagens de milho. Iowa, Slater, EUA, 1996. Produtividade de grãos em $\mathrm{kg} / \mathrm{ha}$, em nivel de parcelas. Bloco 3

\begin{tabular}{|c|c|c|c|c|c|c|c|c|c|}
\hline & \multicolumn{8}{|c|}{ Locais } \\
\hline & & \multicolumn{2}{|c|}{ Local 1} & \multicolumn{2}{|c|}{ Local 2} & \multicolumn{2}{|c|}{ Local 3} & \multicolumn{2}{|c|}{ Local 4} \\
\hline bl. & trat. & rep I & rep 2 & rep 1 & rep 2 & rep 1 & rep 2 & rep 1 & rep 2 \\
\hline 3 & 53 & 10667,15 & 9659,74 & 9671,11 & 8004,38 & 9351,09 & 8289,54 & 9158,95 & 9864,18 \\
\hline 3 & 54 & 10683,23 & 11737,24 & 9798,17 & 8856,46 & 10662,63 & 9015,06 & 8903,76 & 9110,97 \\
\hline 3 & 55 & 10565,14 & 10432,99 & 6133,21 & 7856,90 & 7859,85 & 8871,10 & 7450,02 & 7699.75 \\
\hline 3 & 56 & 9716,90 & 9318,43 & 8539,27 & 6938,68 & 8510,94 & & & 9285,27 \\
\hline 3 & 57 & 9903,76 & 9588,45 & 9041,25 & 8027,93 & 7502,65 & 5,95 & 8148,66 & 9278,04 \\
\hline 3 & 58 & . & 12303,10 & 9284,76 & & 7904,76 & & 7474,83 & 8986,42 \\
\hline 3 & 59 & 9575,82 & 8733,98 & 8894,84 & 7765,70 & 7259,01 & 7925,68 & 8201,60 & 8008,15 \\
\hline 3 & 60 & 10366,54 & 11328,10 & 9387,08 & 8340,41 & 8595,74 & 7068,07 & 9308,00 & 8043,89 \\
\hline 3 & 61 & 10284,89 & 12264,09 & 9238,79 & 9827,32 & 8602,08 & 9301,22 & 9591,78 & 8351,03 \\
\hline 3 & 62 & 11167,68 & 12298,45 & 11417,04 & 9320,82 & 10448,76 & 9258,07 & 10321,63 & 9813,12 \\
\hline 3 & 63 & 11337,90 & & 11049,54 & 9351,53 & 9741,96 & 8185,40 & 7632,48 & 9787,56 \\
\hline 3 & 64 & 10985,59 & 10024,41 & 8624,63 & 9739,44 & 9921,53 & & 9032,14 & 9317,74 \\
\hline 3 & 65 & 9091,56 & 10052,24 & 8915,00 & 8018,07 & 8691,46 & 8168,57 & 8329,74 & 7797,23 \\
\hline 3 & 66 & 10161,84 & 10614,07 & 9799,24 & 11714,13 & 8466,22 & 8675,32 & 9421,81 & 6860,36 \\
\hline 3 & 67 & 8941,95 & 11322,82 & 10340,47 & 8974,98 & 7971,15 & & 8678,27 & 7390,92 \\
\hline 3 & 68 & 9327,85 & 10728,58 & 8161,09 & 8580,54 & 9261,21 & 9916,00 & 8585,75 & 9572,37 \\
\hline 3 & T 1 & 11975,67 & 11005,07 & 10610,05 & 10006,64 & 9699,12 & & 9493,79 & 8512,39 \\
\hline 3 & T2 & 9368,87 & 12078,55 & 9401,59 & 10649,25 & 8157,95 & 8421,94 & 10341,92 & \\
\hline 3 & T 3 & 10472,81 & 9502.21 & 9675,50 & 8984,72 & 8684,74 & & 8474,07 & 8152,17 \\
\hline 3 & T 4 & 9410,57 & 9980,32 & 10015,68 & 8936,10 & 8558,74 & 8888,43 & 9077,87 & 8951,74 \\
\hline 3 & T5 & 9591,78 & 10525,76 & 11036,97 & 11606,66 & \begin{tabular}{|l|}
10187.53 \\
\end{tabular} & 9716,90 & 9122,59 & 9097,90 \\
\hline 3 & T 6 & 12753,76 & 13099,53 & 10583,23 & 10624,94 & 10630.72 & 11384,56 & 9437,33 & - \\
\hline 3 & $\mathrm{~T} 7$ & 10729,02 & 10612,38 & 10326,03 & 8097,15 & 10742,08 & 10312,96 & 9715,95 & 10368,61 \\
\hline 3 & T 8 & 12418,86 & 9656,16 & 8689,14 & 9979,19 & 9086,22 & & 9143,44 & 7595,74 \\
\hline
\end{tabular}


Tabela 4: Médias ajustadas das progênies topcross de milho, por local e na média dos locais. Iowa, Slater, EUA, 1996.

\begin{tabular}{|c|c|c|c|c|c|}
\hline Linhagens & local 1 & local 2 & local 3 & local 4 & conjunta \\
\hline 1 & 9567,85 & \begin{tabular}{|l|}
10198.48 \\
\end{tabular} & 6601.78 & 9393,4 & 8940,37 \\
\hline 2 & 10868,42 & 8757,31 & 8178,75 & 8943,65 & 9187.03 \\
\hline 3 & 9127,01 & 7897.59 & 7588.72 & 8978,26 & 8397,9 \\
\hline 4 & 10645,66 & 10308.65 & 7880.25 & 9299,72 & 9533.57 \\
\hline 5 & 11692,89 & 9594,28 & 8406.25 & 8803.9 & 9624.33 \\
\hline 6 & 9568,00 & 9799.13 & 9033.63 & 9323.7 & 9431,11 \\
\hline 7 & 9510,03 & 9460.52 & 8139.44 & 7664,71 & 8693.68 \\
\hline 8 & 9579,12 & 8294,99 & 8111.55 & 9044,11 & 8757.44 \\
\hline 9 & 11151,69 & 9780.92 & 10851.24 & 8841,42 & 10156.32 \\
\hline 10 & 10211,49 & 7917,6 & 8008 & 8424,96 & 8640.51 \\
\hline 11 & 10002,65 & 8858.62 & 8772.9 & 8524.42 & 9039.65 \\
\hline 12 & 10573,84 & 8440.68 & 9329,93 & 8958,91 & 9325.84 \\
\hline 13 & 11408,37 & 11318,35 & 6961.75 & $8393,+6$ & 9520.48 \\
\hline 14 & 11159,07 & 8544.38 & 9119.77 & 8373.56 & 9299.2 \\
\hline 15 & 11821,15 & 9372.4 & 5666.61 & 9187,48 & 9011.91 \\
\hline 16 & 10248,26 & 8065.8 & 7631.74 & 7908.2 & 8463.5 \\
\hline 17 & 10934,31 & 10148,07 & 9099.23 & 9146,43 & 9832.01 \\
\hline 18 & 9389,87 & 9922.12 & 7337.79 & 8516,67 & 8791.61 \\
\hline 19 & 10875,77 & 9051 & 9047.09 & 8919.69 & 9473,39 \\
\hline 20 & 9563,29 & 6944.17 & 7674.61 & 8273,72 & 8113,95 \\
\hline 21 & 10723,77 & 9480.03 & 8035.67 & 8594.8 & 9208.57 \\
\hline 22 & 9295,53 & 8001,32 & 6941.21 & 9408,95 & 8411.75 \\
\hline 23 & 9664,01 & 7730,17 & 8815.71 & 9332.19 & 8885.52 \\
\hline 24 & 10903,50 & 9153.26 & \begin{tabular}{|l|}
7568.77 \\
\end{tabular} & 8766.4 & 9097.98 \\
\hline 25 & 9905,86 & 8259.63 & \begin{tabular}{|l|}
8023.83 \\
\end{tabular} & 7598,92 & 8447.06 \\
\hline 26 & 8983,68 & 8490.74 & 7372.59 & 8141,41 & 8247.1 \\
\hline 27 & 9826,81 & 8467.5 & 9955.4 & 9034,97 & 9321.17 \\
\hline 28 & 10189,70 & 9116.98 & 7106.4 & 8874.21 & 8821.82 \\
\hline 29 & 10907,05 & 8227.63 & 8315.42 & 8917,02 & 9091.78 \\
\hline 30 & 10107,10 & 6815.12 & 9018.36 & 7853,36 & 8448.49 \\
\hline 31 & 11987,76 & 9145.94 & 8427.29 & 8431,31 & 9498.07 \\
\hline 32 & 9308,97 & 8715.47 & 8653.63 & 8019,62 & 8674.42 \\
\hline 33 & 9683,23 & 7995.14 & \begin{tabular}{|c|}
879,63 \\
\end{tabular} & 8692.33 & 8780.08 \\
\hline 34 & 9879,48 & 9425.7 & 9029.92 & 9463,58 & 9449.67 \\
\hline 35 & 9645,57 & 8177.64 & 8722.52 & 8776,19 & 8830.48 \\
\hline 36 & 9289,31 & 8351.84 & 8886.9 & 8215.45 & 8685.88 \\
\hline 37 & 10508,14 & 8561.85 & 8954.67 & 8797.79 & 9205.61 \\
\hline 38 & 9245,82 & 8751 & 10045.11 & $7838+6$ & 8970.1 \\
\hline 39 & 10158,79 & 10399.76 & 9256.94 & 9234.21 & 9762.42 \\
\hline 40 & 9564,11 & 8060.38 & 7772.18 & 9410,12 & 8701.7 \\
\hline 41 & 9490,09 & 9020.49 & 9749.06 & 7773.61 & 9008.31 \\
\hline 42 & 9641,81 & 6680.03 & 8520.06 & 8334.25 & 8294.04 \\
\hline
\end{tabular}




\begin{tabular}{|c|c|c|c|c|c|}
\hline Linhagens & local 1 & local 2 & local 3 & local 4 & conjunta \\
\hline 43 & 9548,00 & 8745,51 & 9118,01 & 9519,04 & 9232,64 \\
\hline 44 & 9634,90 & 9913,39 & 9084,62 & 9259,32 & 9473,06 \\
\hline 45 & 9507,33 & 8779,64 & 9138,01 & 7082,95 & 8626,98 \\
\hline 46 & 9516,06 & 8970,21 & 8513,43 & 8560,12 & 8889,95 \\
\hline 47 & 9977,12 & 9704,45 & 9387,4 & 9071,55 & 9535,13 \\
\hline 48 & 9235,17 & 7781,93 & 8445,56 & 8060,68 & 8380,84 \\
\hline 49 & 10170,23 & 8661,41 & 8852,79 & 8177,76 & 8965,55 \\
\hline 50 & 9056,01 & 9516,91 & 9102,24 & 9402,15 & 9269,32 \\
\hline 51 & 8919,05 & 7922,47 & 8133,05 & 8886,23 & 8465,2 \\
\hline 52 & 10487,13 & 9718,62 & 9355,02 & 7691,55 & 9313,08 \\
\hline 53 & 9773,73 & 8591 & 9370,35 & 9419,97 & 9288,76 \\
\hline 54 & 10820,52 & 9080,57 & 10388,88 & 8915,77 & 9801,43 \\
\hline 55 & 10109,35 & 6748,31 & 8915,51 & 7483,29 & 8314,11 \\
\hline 56 & 9127,95 & 7492,23 & 9001,75 & 9281,65 & 8725,89 \\
\hline 57 & 9356,39 & 8287,84 & 8684,33 & 8621,75 & 8737,58 \\
\hline 58 & 11767,88 & 8839,17 & 8395,57 & 8139,03 & 9285,41 \\
\hline 59 & 8765,18 & 8083,52 & 8142,38 & 8013,28 & 8251,09 \\
\hline 60 & 10457,60 & 8617 & 8381,94 & 8584,35 & 9010,22 \\
\hline 61 & 10884,77 & 9286,31 & 9501,68 & 8879,81 & 9638,14 \\
\hline 62 & 11343,35 & 10122,18 & 10403,45 & 9975,78 & 10461,19 \\
\hline 63 & 11093,69 & 9953,79 & 9513,71 & 8618,42 & 9794,9 \\
\hline 64 & 10115,28 & 8935,29 & 10412,34 & 9083,34 & 9636,56 \\
\hline 65 & 9182,18 & 8219,79 & 8980,05 & 7971,89 & 8588,48 \\
\hline 66 & 9998,24 & 10509,94 & 9120,8 & 8049,49 & 9419,62 \\
\hline 67 & 9742,67 & 9410,98 & 8461,96 & 7943 & 8889,65 \\
\hline 68 & 9638,50 & 8124,07 & 10138,64 & 8987,46 & 9222,17 \\
\hline & & & & & \\
\hline
\end{tabular}


Tabela 5: Genótipos das plantas-mãe das linhagens $\mathrm{S}_{2}$ de milho - cromossomo 1

\begin{tabular}{|c|c|c|c|c|c|c|c|c|c|c|c|c|c|c|c|c|c|c|c|c|c|c|}
\hline Linhagens & S1 & S2 & S3 & S4 & S5 & 56 & S7 & S8 & S9 & $\mathbf{S 1 0}$ & S11 & S12 & S13 & S14 & S15 & S16 & $\$ 17$ & S18 & S19 & $\mathbf{S 2 0}$ & $\mathbf{S 2 1}$ & S22 \\
\hline 1 & 1 & 0 & 1 & -1 & 1 & 1 & 1 & 1 & \begin{tabular}{|l|}
-1 \\
\end{tabular} & -1 & -1 & 1 & -1 & -1 & -1 & -1 & -1 & -1 & -1 & -1 & -1 & -1 \\
\hline 2 & 0 & 1 & 1 & -1 & 0 & 0 & 0 & 0 & -1 & -1 & 0 & 1 & 0 & 0 & 0 & 0 & 1 & 1 & 1 & 1 & 0 & 0 \\
\hline 3 & 1 & $\overline{0}$ & 0 & -1 & 0 & 1 & 0 & 0 & -1 & $\overline{0}$ & -1 & 1 & -1 & -1 & -1 & -1 & -1 & -1 & 0 & 1 & -1 & -1 \\
\hline 4 & 1 & -1 & -1 & -1 & -1 & -1 & -1 & -1 & \begin{tabular}{|l|}
-1 \\
\end{tabular} & 0 & -1 & 1 & -1 & -1 & -1 & -1 & -1 & -1 & -1 & 0 & -1 & -1 \\
\hline 5 & 0 & -1 & -1 & -1 & -1 & -1 & -1 & -1 & 1 & -1 & 1 & 1 & 1 & 1 & 1 & 1 & 1 & 0 & 0 & 1 & 0 & 1 \\
\hline 6 & 1 & \begin{tabular}{|l|}
-1 \\
\end{tabular} & 1 & -1 & 1 & 1 & 0 & 0 & 0 & 0 & 0 & 0 & 0 & 0 & 0 & 0 & 0 & 0 & 0 & 0 & -1 & -1 \\
\hline 7 & 1 & $\overline{0}$ & 0 & -1 & 0 & 0 & 0 & 1 & -1 & -1 & -1 & 0 & -1 & -1 & -1 & 1 & 0 & -1 & -1 & -1 & -1 & -1 \\
\hline 8 & $\overline{0}$ & -1 & 0 & -1 & 0 & -1 & -1 & -1 & \begin{tabular}{|l|}
-1 \\
\end{tabular} & -1 & -1 & 1 & -1 & -1 & -1 & -1 & -1 & 0 & 0 & 1 & 1 & 1 \\
\hline 9 & 1 & -1 & -1 & -1 & -1 & -1 & -1 & -1 & \begin{tabular}{|l|}
-1 \\
\end{tabular} & 1 & -1 & 1 & -1 & 0 & 0 & -1 & -1 & -1 & -1 & 1 & -1 & 0 \\
\hline 10 & 1 & 0 & 0 & -1 & 0 & 0 & 0 & 0 & -1 & -1 & 0 & 1 & 0 & 0 & -1 & 0 & 0 & -1 & 0 & 1 & -1 & -1 \\
\hline 11 & 1 & -1 & -1 & -1 & -1 & -1 & -1 & -1 & -1 & 0 & -1 & 1 & -1 & -1 & -1 & -1 & -1 & -1 & $\overline{0}$ & 1 & 0 & -1 \\
\hline 12 & -1 & -1 & -1 & -1 & -1 & -1 & -1 & -1 & -1 & -1 & 1 & 1 & 1 & 1 & 1 & 1 & 1 & 1 & 1 & 1 & $\overline{0}$ & 0 \\
\hline 13 & 0 & -1 & -1 & -1 & -1 & -1 & -1 & -1 & 1 & 0 & -1 & 0 & 0 & -1 & -1 & 0 & 0 & -1 & 1 & 1 & 0 & -1 \\
\hline 14 & 0 & -1 & 0 & -1 & 0 & 0 & 0 & 1 & -1 & 1 & 1 & 1 & 1 & 1 & 1 & 1 & 1 & 1 & 1 & 1 & 1 & 1 \\
\hline 15 & 0 & 0 & 0 & -1 & 0 & 0 & 0 & 0 & 0 & 0 & 0 & 0 & 1 & 0 & 0 & 0 & 0 & 0 & 1 & 1 & 1 & 1 \\
\hline 16 & 0 & 1 & 0 & -1 & -1 & -1 & -1 & -1 & \begin{tabular}{|l|}
-1 \\
\end{tabular} & 0 & -1 & 1 & -1 & -1 & -1 & -1 & -1 & -1 & -1 & 0 & -1 & -1 \\
\hline 17 & -1 & -1 & -1 & -1 & -1 & -1 & -1 & -1 & 0 & -1 & -1 & 1 & -1 & -1 & -1 & -1 & -1 & -1 & -1 & -1 & -1 & -1 \\
\hline 18 & 1 & -1 & -1 & -1 & -1 & -1 & -1 & -1 & 1 & 1 & 0 & 0 & 1 & 0 & 0 & 1 & 1 & -1 & -1 & 0 & -1 & -1 \\
\hline 19 & 0 & 0 & -1 & -1 & 1 & 1 & 1 & 1 & -1 & 0 & 1 & 1 & 1 & 1 & 1 & 1 & 1 & 1 & 1 & -1 & -1 & -1 \\
\hline 20 & 0 & -1 & -1 & -1 & -1 & -1 & -1 & -1 & -1 & 1 & 0 & 1 & 0 & 0 & 0 & $\overline{0}$ & 0 & 0 & 1 & 1 & 1 & 0 \\
\hline 21 & 1 & 1 & 0 & -1 & 0 & 0 & 0 & -1 & 1 & -1 & -1 & -1 & 1 & -1 & -1 & 1 & 1 & 0 & 1 & 1 & 1 & 1 \\
\hline 22 & 1 & -1 & -1 & -1 & -1 & -1 & \begin{tabular}{|l|}
-1 \\
\end{tabular} & $\begin{array}{ll}-1 \\
\end{array}$ & 1 & -1 & 0 & 0 & 1 & 0 & 0 & 1 & 1 & 0 & $\overline{0}$ & 1 & $\overline{0}$ & 1 \\
\hline 23 & 1 & 0 & -1 & -1 & -1 & -1 & -1 & -1 & -1 & 1 & -1 & 1 & -1 & -1 & -1 & -1 & -1 & -1 & -1 & 1 & -1 & -1 \\
\hline 24 & 1 & 0 & 0 & -1 & 1 & 1 & 1 & 1 & -1 & 0 & 1 & 1 & 1 & 1 & 1 & 1 & 1 & 0 & 0 & 0 & 0 & 1 \\
\hline 25 & 1 & -1 & -1 & -1 & -1 & -1 & -1 & -1 & -1 & -1 & -1 & 1 & -1 & -1 & -1 & -1 & -1 & 1 & 1 & 1 & 1 & 0 \\
\hline 26 & 1 & -1 & -1 & -1 & -1 & -1 & -1 & -1 & -1 & -1 & -1 & 1 & -1 & -1 & -1 & -1 & -1 & -1 & -1 & 0 & -1 & -1 \\
\hline 27 & 1 & 1 & 1 & -1 & 0 & -1 & -1 & -1 & 1 & 1 & -1 & -1 & 1 & -1 & -1 & 1 & 1 & -1 & -1 & 1 & -1 & -1 \\
\hline 28 & 1 & 0 & 0 & -1 & 0 & 0 & 0 & 0 & 0 & 1 & -1 & -1 & 1 & -1 & -1 & 1 & $\overline{1}$ & 0 & 1 & 1 & 0 & 0 \\
\hline 29 & 1 & -1 & -1 & -1 & 0 & -1 & -1 & \begin{tabular}{|l|}
-1 \\
\end{tabular} & \begin{tabular}{|l|}
-1 \\
\end{tabular} & -1 & -1 & 1 & -1 & -1 & -1 & -1 & -1 & -1 & -1 & 0 & -1 & -1 \\
\hline 30 & 1 & \begin{tabular}{|l|}
-1 \\
\end{tabular} & -1 & -1 & 0 & -1 & -1 & -1 & 0 & 0 & -1 & 0 & 0 & -1 & -1 & 0 & 1 & -1 & -1 & 1 & -1 & 0 \\
\hline 31 & 1 & -1 & -1 & -1 & 1 & 1 & 1 & 1 & -1 & 1 & 0 & 1 & 0 & 1 & 0 & 0 & 0 & 0 & 0 & 0 & 0 & 1 \\
\hline 32 & 1 & 0 & 1 & -1 & 0 & 0 & 0 & 0 & \begin{tabular}{|l|}
-1 \\
\end{tabular} & 1 & -1 & 1 & -1 & -1 & -1 & -1 & -1 & 0 & 0 & 0 & 0 & -1 \\
\hline 33 & 0 & 0 & 0 & -1 & 1 & -1 & -1 & -1 & -1 & -1 & -1 & 1 & -1 & -1 & -1 & -1 & -1 & -1 & 0 & 1 & -1 & -1 \\
\hline 34 & 0 & -1 & 0 & -1 & 0 & 0 & 0 & 1 & -1 & -1 & 1 & 1 & 1 & 1 & 1 & 1 & 1 & 1 & 1 & 1 & 0 & 0 \\
\hline 35 & 1 & -1 & -1 & -1 & -1 & -1 & -1 & -1 & 0 & -1 & 0 & 0 & 1 & 0 & -1 & 1 & 1 & -1 & 1 & -1 & -1 & -1 \\
\hline
\end{tabular}




\begin{tabular}{|c|c|c|c|c|c|c|c|c|c|c|c|c|c|c|c|c|c|c|c|c|c|c|}
\hline Linhagens & S1 & $\mathrm{S} 2$ & S3 & S4 & S5 & S6 & S7 & S8 & S9 & $\mathbf{S 1 0}$ & $\mathbf{S 1 1}$ & $\mathrm{S12}$ & $\$ 13$ & S14 & S15 & $\mathrm{S16}$ & $\mathbf{S 1 7}$ & S18 & S19 & $\mathbf{S 2 0}$ & $\mathrm{S} 21$ & $\mathrm{~S} 22$ \\
\hline 36 & 1 & 0 & 0 & -1 & 0 & 1 & 0 & 0 & -1 & -1 & -1 & 1 & -1 & -1 & -1 & -1 & -1 & -1 & 0 & 1 & -1 & -1 \\
\hline 37 & 1 & -1 & -1 & -1 & -1 & -1 & -1 & -1 & -1 & -1 & -1 & 1 & -1 & -1 & -1 & -1 & -1 & -1 & -1 & 0 & -1 & -1 \\
\hline 38 & -1 & -1 & \begin{tabular}{|c|}
-1 \\
\end{tabular} & -1 & -1 & -1 & -1 & -1 & -1 & -1 & -1 & 1 & -1 & -1 & -1 & -1 & -1 & 0 & 1 & 1 & 0 & 0 \\
\hline 39 & 1 & 1 & 1 & -1 & 0 & 1 & 1 & 0 & -1 & 0 & 1 & 1 & 1 & 1 & 1 & 1 & 1 & -1 & -1 & -1 & -1 & 1 \\
\hline 40 & 1 & -1 & -1 & \begin{tabular}{|l|}
-1 \\
\end{tabular} & -1 & -1 & -1 & -1 & -1 & -1 & -1 & -1 & 1 & -1 & -1 & 1 & 1 & -1 & -1 & 1 & -1 & -1 \\
\hline 41 & -1 & -1 & -1 & -1 & -1 & -1 & -1 & -1 & -1 & 0 & -1 & 1 & -1 & -1 & -1 & -1 & -1 & -1 & -1 & -1 & -1 & -1 \\
\hline 42 & 0 & -1 & -1 & -1 & -1 & -1 & -1 & -1 & -1 & 0 & -1 & 1 & -1 & -1 & -1 & -1 & -1 & -1 & 1 & 1 & 0 & 0 \\
\hline 43 & 1 & -1 & -1 & -1 & -1 & -1 & -1 & -1 & -1 & 0 & -1 & 1 & -1 & -1 & -1 & -1 & -1 & -1 & -1 & 0 & -1 & -1 \\
\hline 44 & -1 & 0 & 0 & -1 & 0 & 0 & 0 & -1 & -1 & 1 & -1 & 1 & 0 & -1 & -1 & 1 & 1 & 0 & 1 & 1 & 0 & 1 \\
\hline 45 & 1 & 1 & 0 & -1 & 0 & 1 & 1 & 0 & -1 & 1 & -1 & 1 & -1 & -1 & -1 & -1 & -1 & -1 & 1 & 1 & 0 & 0 \\
\hline 46 & 1 & 0 & 0 & -1 & 0 & 0 & 0 & -1 & -1 & -1 & -1 & 1 & -1 & -1 & -1 & -1 & -1 & -1 & -1 & 1 & 0 & $\mathrm{I}$ \\
\hline 47 & 1 & -1 & 0 & -1 & 0 & 0 & -1 & -1 & -1 & -1 & -1 & 1 & -1 & -1 & -1 & -1 & -1 & -1 & 0 & 0 & -1 & -1 \\
\hline 48 & 1 & -1 & -1 & -1 & -1 & -1 & -1 & -1 & 1 & 1 & -1 & -1 & 1 & -1 & -1 & 1 & 1 & -1 & 0 & -1 & -1 & -1 \\
\hline 49 & 1 & -1 & 1 & -1 & 0 & 1 & 0 & 0 & -1 & 1 & -1 & 1 & 1 & -1 & -1 & 0 & 1 & 0 & 1 & 1 & 0 & -1 \\
\hline 50 & 1 & 0 & -1 & -1 & 0 & 0 & 0 & 0 & 0 & -1 & 0 & 0 & 1 & 0 & 0 & $\mathrm{~T}$ & 1 & 0 & 1 & 1 & $\overline{0}$ & 0 \\
\hline 51 & 1 & -1 & 0 & -1 & 0 & 1 & 0 & 1 & -1 & 0 & 1 & 1 & 1 & 1 & 1 & 1 & 1 & 0 & 1 & 1 & 0 & 1 \\
\hline 52 & 1 & 0 & 0 & -1 & -1 & -1 & -1 & -1 & 1 & 0 & -1 & 0 & 1 & -1 & -1 & 0 & 1 & 1 & 1 & 1 & 1 & 1 \\
\hline 53 & 1 & -1 & -1 & -1 & -1 & -1 & -1 & -1 & -1 & -1 & -1 & 1 & -1 & -1 & -1 & -1 & -1 & -1 & -1 & 1 & -1 & -1 \\
\hline 54 & 0 & 0 & -1 & \begin{tabular}{|l|}
-1 \\
\end{tabular} & \begin{tabular}{|l|}
-1 \\
\end{tabular} & -1 & -1 & -1 & -1 & 1 & -1 & 1 & -1 & -1 & -1 & -1 & -1 & -1 & 1 & 1 & -1 & -1 \\
\hline 55 & 1 & 0 & -1 & \begin{tabular}{|c|}
-1 \\
\end{tabular} & 0 & -1 & -1 & -1 & 0 & -1 & -1 & 0 & 0 & -1 & -1 & 0 & 0 & 1 & 1 & 1 & 1 & 0 \\
\hline 56 & 1 & -1 & -1 & -1 & -1 & -1 & -1 & -1 & -1 & -1 & -1 & 1 & -1 & -1 & -1 & -1 & -1 & 1 & 1 & 1 & 1 & 0 \\
\hline 57 & 1 & -1 & -1 & -1 & \begin{tabular}{|l|}
-1 \\
\end{tabular} & -1 & -1 & -1 & 0 & 0 & -1 & 0 & 0 & -1 & -1 & 0 & 0 & -1 & -1 & -1 & -1 & 1 \\
\hline 58 & 1 & 0 & 0 & -1 & 0 & 0 & 0 & 0 & -1 & 0 & 1 & 1 & 1 & 1 & 1 & 1 & 1 & 0 & 0 & 1 & -1 & -1 \\
\hline 59 & -1 & -1 & -1 & -1 & -1 & -1 & -1 & -1 & -1 & 1 & -1 & 1 & -1 & -1 & -1 & -1 & -1 & -1 & 0 & 0 & -1 & -1 \\
\hline 60 & 1 & -1 & -1 & \begin{tabular}{|l|}
-1 \\
\end{tabular} & \begin{tabular}{|l|}
-1 \\
\end{tabular} & -1 & -1 & -1 & -1 & 0 & -1 & 0 & 0 & -1 & -1 & 0 & 0 & -1 & 0 & 1 & 1 & 1 \\
\hline 61 & 0 & 0 & 0 & \begin{tabular}{|l|} 
\\
\end{tabular} & 0 & -1 & -1 & -1 & 0 & 0 & -1 & 0 & 0 & -1 & -1 & 0 & 0 & 1 & 1 & -1 & -1 & -1 \\
\hline 62 & 0 & -1 & 1 & -1 & 1 & 1 & 1 & 0 & -1 & -1 & 1 & 1 & 1 & 1 & 1 & 1 & 1 & 0 & 1 & 1 & 1 & 1 \\
\hline 63 & 1 & -1 & -1 & 1 & -1 & -1 & -1 & -1 & -1 & 0 & -1 & 1 & -1 & -1 & -1 & -1 & -1 & -1 & 1 & 1 & $\overline{1}$ & 1 \\
\hline 64 & -1 & 0 & 1 & -1 & 0 & 0 & 0 & 0 & 0 & 0 & -1 & 0 & 0 & -1 & -1 & 0 & 0 & 0 & 1 & 1 & 0 & 1 \\
\hline 65 & -1 & -1 & -1 & -1 & -1 & -1 & -1 & -1 & -1 & -1 & -1 & -1 & 1 & -1 & -1 & 1 & 1 & -1 & 1 & 1 & -1 & -1 \\
\hline 66 & -1 & 0 & 1 & -1 & -1 & -1 & -1 & -1 & -1 & -1 & -1 & 0 & 0 & -1 & -1 & 0 & 0 & -1 & 1 & 1 & -1 & -1 \\
\hline 67 & -1 & 0 & 0 & -1 & -1 & -1 & -1 & -1 & 0 & -1 & -1 & 0 & 0 & -1 & -1 & 0 & 0 & -1 & -1 & -1 & -1 & -1 \\
\hline 68 & 1 & -1 & -1 & -1 & -1 & -1 & -1 & -1 & -1 & -1 & -1 & 1 & -1 & -1 & -1 & -1 & -1 & -1 & -1 & -1 & -1 & -1 \\
\hline
\end{tabular}


Tabela 6: Genótipos das plantas-mãe das linhagens $\mathrm{S}_{2}$ de milho - cromossomo 2.

\begin{tabular}{|c|c|c|c|c|c|c|c|c|c|c|c|c|c|c|c|}
\hline Linhagens & $\mathbf{S 2 3}$ & S24 & $\mathbf{S 2 5}$ & $\mathbf{S 2 6}$ & $\mathbf{S 2 7}$ & S28 & $\mathbf{S 2 9}$ & $\mathbf{S 3 0}$ & S31 & $\mathbf{S 3 2}$ & $\mathbf{S 3 3}$ & $\mathbf{S 3 4}$ & $\mathbf{S 3 5}$ & 536 & $\mathbf{S 3 7}$ \\
\hline 1 & 0 & -1 & -1 & I & 1 & -1 & 0 & -1 & -1 & -1 & -1 & -1 & -1 & 1 & -1 \\
\hline 2 & -1 & -1 & -1 & -1 & 0 & -1 & 0 & -1 & -1 & -1 & -1 & -1 & -1 & 1 & -1 \\
\hline 3 & -1 & 0 & -1 & 0 & $\overline{0}$ & -1 & -1 & 1 & 1 & -1 & -1 & -1 & -1 & 1 & -1 \\
\hline 4 & -1 & -1 & 1 & 1 & -1 & -1 & 1 & 0 & 0 & 0 & -1 & 0 & 1 & 1 & -1 \\
\hline 5 & 0 & -1 & 7 & 1 & 0 & -1 & 0 & 1 & 1 & 0 & 0 & 0 & 0 & 1 & -1 \\
\hline 6 & -1 & 0 & 1 & 0 & -1 & 0 & -1 & 1 & $\overline{0}$ & 0 & -1 & -1 & -1 & 0 & -1 \\
\hline 7 & $\overline{0}$ & -1 & -1 & 1 & -1 & -1 & 1 & 1 & 1 & 1 & 1 & 1 & 1 & 0 & -1 \\
\hline 8 & 0 & -1 & 0 & -1 & -1 & 0 & -1 & 1 & 1 & -1 & -1 & -1 & 0 & 0 & 0 \\
\hline 9 & -1 & 0 & -1 & -1 & 1 & -1 & 1 & 1 & 1 & -1 & -1 & -1 & -1 & 1 & $\overline{0}$ \\
\hline 10 & -1 & -1 & 0 & 0 & 0 & -1 & 1 & 1 & 1 & 0 & 0 & 0 & 0 & -1 & -1 \\
\hline 11 & -1 & -1 & -1 & -1 & -1 & 0 & -1 & 1 & 1 & 0 & 0 & 0 & 1 & 0 & -1 \\
\hline 12 & 0 & -1 & -1 & 0 & 0 & -1 & -1 & 1 & 1 & -1 & -1 & -1 & -1 & 0 & -1 \\
\hline 13 & T & -1 & -1 & 0 & 0 & 0 & -1 & -1 & -1 & -1 & -1 & -1 & 0 & 1 & -1 \\
\hline 14 & $\overline{0}$ & $\overline{0}$ & -1 & -1 & -1 & 1 & -1 & 0 & 0 & -1 & -1 & -1 & 0 & 1 & -1 \\
\hline 15 & -1 & 1 & 0 & $\mathrm{I}$ & -1 & -1 & 0 & 0 & 0 & 1 & 1 & 1 & 1 & 0 & 0 \\
\hline 16 & 0 & 0 & -1 & -1 & -1 & -1 & 1 & 0 & 0 & 1 & 1 & 1 & 1 & 1 & 1 \\
\hline 17 & -1 & 1 & 0 & 0 & 0 & -1 & -1 & 1 & 1 & -1 & -1 & -1 & -1 & 0 & 0 \\
\hline 18 & 1 & -1 & -1 & 0 & 0 & 0 & -1 & -1 & -1 & 0 & 0 & 0 & 1 & 1 & -1 \\
\hline 19 & 0 & 0 & -1 & 0 & 0 & -1 & $\overline{0}$ & -1 & \begin{tabular}{l|}
-1 \\
\end{tabular} & $\overline{0}$ & 0 & 0 & 0 & 1 & 0 \\
\hline 20 & $\overline{0}$ & -1 & -1 & -1 & -1 & 0 & -1 & 0 & 0 & -1 & -1 & -1 & -1 & -1 & -1 \\
\hline 21 & 1 & -1 & -1 & 0 & 0 & 0 & -1 & -1 & -1 & 0 & 0 & 0 & 1 & 1 & 1 \\
\hline 22 & -1 & -1 & 1 & 1 & -1 & -1 & 0 & -1 & -1 & 1 & 1 & 1 & 1 & 0 & $\overline{0}$ \\
\hline 23 & -1 & -1 & 1 & 1 & -1 & -1 & 0 & -1 & -1 & $\overline{0}$ & $\overline{0}$ & $\overline{0}$ & -1 & -1 & 0 \\
\hline 24 & -1 & 0 & 1 & 1 & 0 & -1 & 1 & -1 & -1 & 0 & 1 & 0 & 0 & 1 & -1 \\
\hline 25 & -1 & -1 & -1 & -1 & -1 & 1 & -1 & 0 & 0 & -1 & -1 & -1 & 1 & 0 & -1 \\
\hline 26 & -1 & 0 & -1 & -1 & -1 & 1 & -1 & 0 & 0 & -1 & -1 & -1 & 1 & 0 & -1 \\
\hline 27 & -1 & -1 & 0 & 0 & -1 & 0 & 0 & 1 & 1 & 0 & 1 & 0 & 1 & 1 & -1 \\
\hline 28 & -1 & 0 & -1 & 0 & 0 & 0 & -1 & 1 & 1 & -1 & -1 & -1 & 1 & 1 & -1 \\
\hline 29 & -1 & 0 & 0 & 0 & -1 & -1 & -1 & 0 & 0 & 0 & 0 & 0 & -1 & 1 & -1 \\
\hline 30 & 0 & -1 & -1 & -1 & -1 & 1 & -1 & $T$ & 1 & -1 & -1 & -1 & 1 & $\overline{0}$ & -1 \\
\hline 31 & -1 & 0 & 1 & 1 & -1 & -1 & 0 & 1 & 1 & 1 & 1 & 1 & 1 & $\overline{0}$ & -1 \\
\hline 32 & -1 & 1 & 0 & 0 & -1 & 0 & -1 & -1 & -1 & -1 & -1 & -1 & 1 & 1 & 0 \\
\hline 33 & -1 & 0 & 0 & 0 & -1 & -1 & -1 & 1 & 1 & -1 & -1 & -1 & -1 & -1 & -1 \\
\hline 34 & 0 & 0 & 1 & 1 & -1 & -1 & -1 & -1 & -1 & 0 & 0 & $\overline{0}$ & 0 & -1 & -1 \\
\hline 35 & 0 & 0 & 0 & 0 & -1 & -1 & 0 & 0 & 0 & 0 & 0 & 0 & 0 & -1 & -1 \\
\hline
\end{tabular}




\begin{tabular}{|c|c|c|c|c|c|c|c|c|c|c|c|c|c|c|c|}
\hline Linhagens & $\mathbf{S 2 3}$ & S24 & $\$ 25$ & S26 & S27 & S28 & $\mathbf{S 2 9}$ & $\mathbf{S 3 0}$ & S31 & $\mathbf{S 3 2}$ & $\mathbf{S 3 3}$ & $\mathbf{S 3 4}$ & S35 & S36 & $\mathbf{S 3 7}$ \\
\hline 36 & 0 & -1 & -1 & -1 & -1 & 0 & -1 & -1 & -1 & -1 & -1 & -1 & 0 & 1 & -1 \\
\hline 37 & -1 & 0 & -1 & -1 & -1 & 0 & 0 & 0 & 0 & 0 & 0 & 0 & 0 & 1 & -1 \\
\hline 38 & 0 & -1 & -1 & 1 & -1 & -1 & -1 & 1 & 1 & -1 & -1 & -1 & -1 & 1 & -1 \\
\hline 39 & -1 & -1 & -1 & 1 & -1 & -1 & 1 & 1 & 1 & 0 & -1 & -1 & 0 & 1 & -1 \\
\hline 40 & -1 & -1 & 1 & -1 & -1 & -1 & 0 & -1 & -1 & 1 & 1 & 1 & 1 & 1 & -1 \\
\hline 41 & 0 & -1 & -1 & 1 & -1 & 1 & 0 & 1 & 1 & -1 & -1 & -1 & 0 & 1 & -1 \\
\hline 42 & 0 & -1 & 1 & 1 & -1 & -1 & 1 & 1 & 1 & -1 & -1 & -1 & -1 & 0 & -1 \\
\hline 43 & -1 & -1 & 1 & 1 & -1 & -1 & 1 & 0 & 0 & 1 & 1 & 1 & 1 & 1 & -1 \\
\hline 44 & 0 & 0 & -1 & -1 & -1 & -1 & 0 & 1 & 1 & 0 & 0 & 0 & 0 & -1 & -1 \\
\hline 45 & -1 & 0 & -1 & 1 & 1 & -1 & 1 & -1 & -1 & -1 & -1 & -1 & -1 & 1 & -1 \\
\hline 46 & -1 & -1 & -1 & 1 & 1 & -1 & 0 & -1 & -1 & -1 & -1 & -1 & 0 & 0 & 1 \\
\hline 47 & -1 & -1 & -1 & 0 & -1 & -1 & 1 & 1 & 1 & $\overline{0}$ & 0 & 0 & 0 & 1 & -1 \\
\hline 48 & 0 & 0 & 1 & 0 & -1 & -1 & -1 & -1 & -1 & 0 & 0 & 0 & 0 & 0 & -1 \\
\hline 49 & -1 & 1 & -1 & 1 & -1 & -1 & 1 & -1 & -1 & 1 & 1 & 1 & 1 & 1 & 0 \\
\hline 50 & -1 & -1 & -1 & 0 & 0 & 0 & -1 & -1 & -1 & 0 & 0 & 0 & 1 & 1 & -1 \\
\hline 51 & -1 & -1 & -1 & 1 & -1 & -1 & 0 & 0 & 0 & 1 & 1 & 1 & 1 & 1 & 0 \\
\hline 52 & -1 & -1 & 1 & 1 & -1 & -1 & 0 & -1 & -1 & 1 & 1 & 1 & 1 & 0 & 1 \\
\hline 53 & -1 & 0 & 0 & 1 & -1 & -1 & 0 & 0 & 0 & 0 & 0 & 0 & 1 & 1 & 1 \\
\hline 54 & 1 & -1 & -1 & 1 & 0 & -1 & 0 & -1 & -1 & 1 & 1 & 1 & 1 & $\overline{0}$ & 1 \\
\hline 55 & -1 & 0 & -1 & -1 & -1 & 1 & -1 & 1 & 1 & -1 & -1 & -1 & 1 & 1 & -1 \\
\hline 56 & 0 & -1 & -1 & 0 & -1 & -1 & 0 & 0 & 0 & -1 & -1 & -1 & 0 & -1 & -1 \\
\hline 57 & -1 & -1 & -1 & 0 & -1 & 0 & -1 & -1 & -1 & $\overline{0}$ & -1 & -1 & 0 & 1 & -1 \\
\hline 58 & 0 & 0 & -1 & -1 & -1 & 1 & -1 & -1 & -1 & -1 & -1 & -1 & 1 & 1 & -1 \\
\hline 59 & 0 & -1 & I & 1 & -1 & -1 & 0 & -1 & -1 & 0 & -1 & -1 & -1 & 0 & -1 \\
\hline 60 & -1 & -1 & -1 & -1 & -1 & 1 & -1 & -1 & -1 & -1 & -1 & 0 & 0 & 1 & -1 \\
\hline 61 & -1 & 0 & 1 & 1 & -1 & -1 & 0 & 0 & 0 & 1 & 1 & 1 & 1 & 0 & 0 \\
\hline 62 & -1 & -1 & 0 & 1 & 1 & -1 & 1 & 0 & 0 & -1 & -1 & -1 & -1 & 1 & -1 \\
\hline 63 & -1 & 1 & -1 & 1 & 0 & -1 & 0 & 0 & 0 & 1 & 0 & 0 & 0 & -1 & -1 \\
\hline 64 & -1 & -1 & -1 & -1 & 1 & -1 & $\overline{0}$ & -1 & -1 & -1 & -1 & -1 & -1 & -1 & -1 \\
\hline 65 & -1 & 0 & 0 & 0 & -1 & -1 & 0 & -1 & -1 & 1 & 0 & 0 & 0 & -1 & 0 \\
\hline 66 & -1 & -1 & -1 & 0 & 0 & -1 & 0 & -1 & -1 & -1 & -1 & -1 & -1 & -1 & -1 \\
\hline 67 & -1 & 0 & -1 & -1 & -1 & -1 & 0 & 1 & 1 & 1 & 0 & 0 & 1 & 1 & -1 \\
\hline 68 & -1 & 0 & -1 & -1 & -1 & 0 & 0 & 1 & 1 & 1 & 0 & 0 & 1 & 1 & -1 \\
\hline
\end{tabular}


Tabela 7: Genótipos das plantas-mãe das linhagens $\mathrm{S}_{2}$ de milho - cromossomo 3.

\begin{tabular}{|c|c|c|c|c|c|c|c|c|c|c|c|c|c|c|c|c|c|c|c|c|c|c|}
\hline inhagens & $\mathbf{S 3 8}$ & $\mathbf{S 3 9}$ & $\mathbf{S 4 0}$ & $\longdiv { S 4 1 }$ & S42 & $\mathbf{S 4 3}$ & S44 & $\longdiv { \mathbf { S 4 5 } }$ & $\mathbf{S 4 6}$ & S47 & $\mathbf{S 4 8}$ & S49 & S50 & $\mathbf{S 5 1}$ & $\widehat{\mathbf{S 5 2}}$ & S53 & S54 & $\mathbf{S 5 5}$ & S56 & S57 & $\mathbf{S 5 8}$ & $\mathbf{S 5 9}$ \\
\hline 1 & 1 & -1 & -1 & -1 & 0 & 0 & 0 & 0 & 0 & 0 & -1 & -1 & 0 & -1 & 0 & 0 & 0 & 1 & -1 & -1 & -1 & -1 \\
\hline 2 & 0 & -1 & -1 & -1 & -1 & -1 & -1 & -1 & 0 & 0 & -1 & -1 & 0 & 0 & 0 & 1 & -1 & 1 & 0 & 0 & 1 & 1 \\
\hline 3 & 1 & 0 & 0 & 0 & 0 & 0 & 0 & 0 & 0 & 0 & -1 & -1 & 0 & 0 & -1 & 0 & 1 & 1 & -1 & -1 & -1 & -1 \\
\hline 4 & 1 & 0 & 1 & -1 & 1 & 1 & 1 & 1 & -1 & 1 & -1 & -1 & 1 & 0 & 1 & -1 & -1 & 0 & -1 & -1 & 0 & 0 \\
\hline 5 & 0 & 0 & 0 & -1 & 0 & 0 & 0 & 0 & 0 & 0 & -1 & -1 & 0 & -1 & 1 & 1 & 0 & 1 & 0 & 0 & 0 & 0 \\
\hline 6 & 1 & 0 & 1 & -1 & 0 & -1 & -1 & 0 & 0 & -1 & -1 & 0 & 0 & -1 & 0 & -1 & -1 & 0 & -1 & 0 & -1 & -1 \\
\hline 7 & 1 & 0 & 0 & -1 & 0 & 0 & 0 & 0 & 0 & 0 & -1 & -1 & 0 & -1 & -1 & -1 & 1 & 1 & -1 & -1 & -1 & -1 \\
\hline 8 & 0 & -1 & 1 & 1 & -1 & -1 & -1 & -1 & 1 & -1 & 1 & -1 & 0 & -1 & -1 & -1 & -1 & -1 & -1 & \begin{tabular}{|l|}
-1 \\
\end{tabular} & -1 & -1 \\
\hline 9 & 1 & 1 & 0 & 1 & -1 & -1 & -1 & -1 & 1 & -1 & 1 & 1 & -1 & -1 & 0 & -1 & -1 & 0 & 1 & 1 & 0 & 0 \\
\hline 10 & 1 & 0 & 1 & -1 & 1 & 1 & 1 & 1 & -1 & 1 & -1 & -1 & 1 & -1 & 1 & -1 & 0 & 0 & 0 & 0 & -1 & 0 \\
\hline 11 & 1 & 0 & 0 & -1 & 1 & 1 & 1 & 1 & 0 & 0 & -1 & -1 & $\overline{0}$ & 0 & -1 & -1 & 0 & 1 & -1 & -1 & 0 & 1 \\
\hline 12 & 0 & 0 & 1 & 1 & -1 & -1 & -1 & -1 & 1 & 0 & 1 & -1 & -1 & -1 & -1 & -1 & 0 & 1 & 0 & 0 & -1 & -1 \\
\hline 13 & $\overline{0}$ & -1 & -1 & -1 & 1 & 1 & 1 & 1 & -1 & 1 & -1 & -1 & 1 & 0 & 1 & 1 & 0 & -1 & 0 & 0 & -1 & -1 \\
\hline 14 & 0 & 0 & 1 & 0 & 0 & 0 & 0 & 0 & -1 & 1 & -1 & 1 & 1 & -1 & 1 & 1 & 0 & 0 & -1 & -1 & -1 & -1 \\
\hline 15 & 0 & 0 & 0 & -1 & -1 & -1 & -1 & -1 & 1 & -1 & -1 & 0 & -1 & -1 & 0 & -1 & 0 & 1 & -1 & -1 & -1 & -1 \\
\hline 16 & 0 & 1 & 1 & 0 & 0 & 0 & 0 & 0 & 0 & 0 & 0 & -1 & -1 & -1 & 0 & 0 & 0 & 1 & -1 & -1 & -1 & -1 \\
\hline 17 & $\mid-1$ & 1 & 1 & 0 & 0 & 0 & $\overline{0}$ & 0 & $\overline{0}$ & 0 & 0 & -1 & 0 & 1 & 1 & 0 & -1 & 1 & -1 & -1 & 1 & 1 \\
\hline 18 & 1 & -1 & -1 & -1 & 1 & 1 & 1 & 1 & -1 & 1 & -1 & -1 & 1 & -1 & -1 & -1 & -1 & -1 & -1 & -1 & -1 & -1 \\
\hline 19 & 0 & -1 & -1 & 0 & -1 & -1 & -1 & -1 & 1 & -1 & 0 & -1 & -1 & -1 & -1 & 0 & -1 & 1 & -1 & \begin{tabular}{|l|}
-1 \\
\end{tabular} & 0 & 0 \\
\hline 20 & 0 & 1 & -1 & -1 & -1 & -1 & -1 & -1 & 1 & -1 & -1 & -1 & -1 & -1 & -1 & -1 & -1 & 0 & -1 & -1 & 0 & 0 \\
\hline 21 & 1 & -1 & 1 & 0 & -1 & -1 & -1 & -1 & 1 & -1 & 0 & -1 & -1 & -1 & -1 & -1 & -1 & 1 & -1 & -1 & 1 & 1 \\
\hline 22 & 1 & -1 & -1 & -1 & -1 & -1 & 0 & 1 & 0 & 0 & -1 & -1 & 0 & 0 & 1 & -1 & 1 & 1 & -1 & -1 & -1 & 0 \\
\hline 23 & 1 & -1 & 1 & -1 & 1 & 1 & 1 & 1 & -1 & 1 & -1 & -1 & 0 & -1 & 1 & 1 & 0 & 0 & 0 & 0 & -1 & -1 \\
\hline 24 & 1 & 0 & 0 & -1 & 0 & 0 & 0 & 0 & -1 & 1 & -1 & 0 & 0 & -1 & 1 & 1 & 0 & 1 & -1 & -1 & -1 & -1 \\
\hline 25 & 1 & -1 & 1 & -1 & -1 & -1 & -1 & -1 & -1 & 1 & -1 & -1 & 1 & -1 & 1 & 0 & -1 & 1 & $\mathrm{~T}$ & 0 & 1 & 1 \\
\hline 26 & 1 & 1 & 1 & -1 & -1 & -1 & -1 & -1 & $T$ & -1 & 0 & -1 & 0 & -1 & 0 & -1 & 0 & 0 & -1 & -1 & -1 & -1 \\
\hline 27 & 1 & 1 & 1 & 0 & 0 & 0 & $\overline{0}$ & 0 & 0 & 0 & 0 & -1 & -1 & -1 & 0 & -1 & -1 & -1 & 0 & 0 & -1 & -1 \\
\hline 28 & 1 & -1 & -1 & -1 & -1 & -1 & -1 & -1 & 1 & -1 & -1 & -1 & -1 & -1 & -1 & -1 & -1 & 1 & 0 & 0 & 1 & 1 \\
\hline 29 & 1 & 1 & -1 & -1 & -1 & -1 & -1 & -1 & 1 & -1 & -1 & -1 & 0 & -1 & -1 & -1 & -1 & 0 & -1 & \begin{tabular}{|l|}
-1 \\
\end{tabular} & 0 & 0 \\
\hline 30 & 1 & -1 & -1 & -1 & 1 & 1 & 1 & 1 & 0 & 0 & -1 & -1 & 0 & -1 & 0 & -1 & -1 & 1 & -1 & -1 & -1 & -1 \\
\hline 31 & 1 & 0 & 0 & -1 & 1 & 1 & 1 & 1 & -1 & 1 & -1 & -1 & 1 & -1 & 1 & 0 & 1 & 1 & -1 & -1 & -1 & -1 \\
\hline 32 & 1 & -1 & -1 & -1 & -1 & -1 & -1 & -1 & 1 & -1 & -1 & -1 & -1 & -1 & 0 & 1 & 0 & 1 & 1 & 1 & 0 & 0 \\
\hline 33 & 0 & 0 & 0 & 0 & 0 & 0 & 0 & 0 & 0 & 0 & 0 & -1 & -1 & -1 & 0 & -1 & 0 & -1 & -1 & -1 & -1 & -1 \\
\hline 34 & 0 & 1 & 1 & 0 & $\overline{0}$ & 0 & 0 & 0 & -1 & 1 & -1 & -1 & 1 & 0 & 1 & -1 & -1 & 1 & 1 & 1 & -1 & -1 \\
\hline 35 & 1 & 1 & 1 & 1 & -1 & -1 & -1 & -1 & 1 & -1 & 1 & -1 & $\overline{0}$ & -1 & -1 & -1 & -1 & -1 & -1 & -1 & -1 & -1 \\
\hline
\end{tabular}


\begin{tabular}{|l|l|l|l|l|l|l|l|l|l|l|l|l|l|l|l|l|l|l|l|l|l|l|}
\hline Linhagens & $\mathbf{S 3 8}$ & $\mathbf{S 3 9}$ & $\mathbf{S 4 0}$ & $\mathbf{S 4 1}$ & $\mathbf{S 4 2}$ & $\mathbf{S 4 3}$ & $\mathbf{S 4 4}$ & $\mathbf{S 4 5}$ & $\mathbf{S 4 6}$ & $\mathbf{S 4 7}$ & $\mathbf{S 4 8}$ & $\mathbf{S 4 9}$ & $\mathbf{S 5 0}$ & $\mathbf{S 5 1}$ & $\mathbf{S 5 2}$ & $\mathbf{S 5 3}$ & $\mathbf{S 5 4}$ & $\mathbf{S 5 5}$ & $\mathbf{S 5 6}$ & $\mathbf{S 5 7}$ & $\mathbf{S 5 8}$ & $\mathbf{S 5 9}$ \\
\hline
\end{tabular}

\begin{tabular}{|c|c|c|c|c|c|c|c|c|c|c|c|c|c|c|c|c|c|c|c|c|c|c|}
\hline 36 & 1 & 0 & 0 & -1 & -1 & -1 & -1 & -1 & 1 & -1 & -1 & 0 & -1 & -1 & -1 & -1 & -1 & 1 & -1 & -1 & -1 & -1 \\
\hline 37 & 1 & -1 & 1 & 1 & -1 & -1 & -1 & -1 & 1 & -1 & 0 & 0 & -1 & -1 & -1 & 1 & -1 & 0 & -1 & -1 & -1 & -1 \\
\hline 38 & -1 & -1 & 0 & -1 & 1 & 1 & 1 & 1 & -1 & 1 & -1 & 1 & 1 & -1 & 0 & 1 & 1 & 0 & -1 & -1 & -1 & -1 \\
\hline 39 & 1 & -1 & -1 & 0 & 0 & 0 & 0 & 0 & 0 & 0 & -1 & 0 & 0 & -1 & -1 & -1 & -1 & 0 & 1 & 1 & 0 & 1 \\
\hline 40 & 1 & -1 & 0 & -1 & 1 & 1 & 1 & 1 & -1 & 1 & -1 & -1 & 1 & -1 & 1 & 0 & 1 & 1 & -1 & -1 & -1 & -1 \\
\hline 41 & -1 & -1 & -1 & -1 & 0 & 0 & 0 & 0 & 0 & 0 & -1 & -1 & 0 & -1 & 1 & 0 & 0 & 1 & -1 & -1 & -1 & -1 \\
\hline 42 & 0 & -1 & 1 & 1 & -1 & -1 & -1 & -1 & 1 & -1 & 1 & 0 & -1 & -1 & 1 & 0 & 0 & -1 & 1 & 1 & -1 & -1 \\
\hline 43 & 1 & 1 & -1 & -1 & 1 & 1 & 1 & 1 & -1 & 1 & -1 & 0 & 1 & 1 & 1 & -1 & -1 & 1 & -1 & -1 & 1 & 1 \\
\hline 44 & -1 & 0 & -1 & 1 & -1 & -1 & -1 & -1 & 0 & 0 & 0 & -1 & -1 & -1 & 1 & -1 & 1 & 0 & -1 & -1 & -1 & -1 \\
\hline 45 & 1 & 1 & -1 & -1 & 0 & 0 & 0 & 0 & -1 & 1 & -1 & 0 & 0 & 1 & -1 & 0 & -1 & -1 & -1 & -1 & -1 & -1 \\
\hline 46 & 1 & -1 & -1 & -1 & 1 & 1 & 1 & 1 & -1 & 1 & -1 & 0 & 0 & 0 & 0 & 0 & -1 & 0 & -1 & -1 & 0 & 0 \\
\hline 47 & 1 & -1 & 1 & 1 & -1 & -1 & -1 & -1 & 0 & 0 & 1 & -1 & 0 & 1 & 1 & 0 & 0 & 1 & -1 & -1 & -1 & -1 \\
\hline 48 & 1 & 1 & -1 & -1 & -1 & -1 & -1 & -1 & 1 & -1 & -1 & -1 & -1 & -1 & 0 & -1 & 0 & -1 & -1 & -1 & 0 & 1 \\
\hline 49 & 1 & 0 & 1 & -1 & 1 & 1 & 1 & 1 & -1 & 1 & -1 & -1 & 0 & -1 & -1 & 1 & -1 & 1 & -1 & -1 & 1 & 1 \\
\hline 50 & 1 & -1 & 1 & 0 & -1 & -1 & -1 & -1 & 1 & -1 & 0 & -1 & -1 & -1 & -1 & -1 & -1 & 0 & 1 & 1 & 0 & 0 \\
\hline 51 & 1 & 1 & -1 & -1 & 1 & 1 & 1 & 1 & -1 & 1 & -1 & -1 & -1 & 1 & 1 & 0 & -1 & -1 & -1 & -1 & -1 & -1 \\
\hline 52 & 1 & 0 & 0 & 0 & -1 & -1 & -1 & -1 & 1 & -1 & 0 & -1 & -1 & -1 & -1 & -1 & 1 & 1 & 1 & 1 & -1 & -1 \\
\hline 53 & 1 & -1 & -1 & -1 & 1 & 1 & 1 & 1 & -1 & 1 & -1 & 1 & 1 & -1 & -1 & -1 & -1 & -1 & -1 & -1 & -1 & -1 \\
\hline 54 & 0 & 0 & 0 & 0 & 0 & 0 & 0 & 0 & 0 & 1 & 0 & -1 & 0 & -1 & 0 & -1 & 0 & 0 & 1 & 1 & -1 & -1 \\
\hline 55 & 1 & -1 & -1 & 0 & -1 & -1 & -1 & -1 & 1 & -1 & 0 & -1 & -1 & -1 & -1 & -1 & -1 & -1 & -1 & -1 & -1 & -1 \\
\hline 56 & 1 & -1 & -1 & -1 & 0 & 0 & 0 & 0 & -1 & 1 & -1 & -1 & 1 & 0 & 1 & -1 & -1 & 0 & 0 & 0 & 0 & 0 \\
\hline 57 & 1 & 0 & 1 & -1 & 1 & 1 & 1 & 1 & -1 & 1 & -1 & -1 & 1 & 0 & -1 & 0 & -1 & -1 & 1 & 1 & -1 & -1 \\
\hline 58 & 1 & 1 & 1 & -1 & 1 & 1 & 1 & 1 & -1 & 1 & -1 & -1 & 0 & -1 & 1 & 0 & 1 & 0 & -1 & -1 & 0 & 0 \\
\hline 59 & -1 & 1 & -1 & -1 & 0 & 0 & 0 & 0 & 0 & 0 & -1 & -1 & 0 & 0 & 1 & -1 & -1 & 1 & -1 & -1 & 1 & 1 \\
\hline 60 & 1 & -1 & 0 & 0 & 0 & 0 & 0 & 0 & 0 & 0 & 0 & 1 & 0 & 1 & 1 & -1 & -1 & 0 & 1 & 1 & -1 & -1 \\
\hline 61 & 0 & -1 & -1 & -1 & -1 & -1 & -1 & -1 & 1 & -1 & -1 & -1 & -1 & -1 & 0 & -1 & 1 & -1 & -1 & -1 & 0 & 0 \\
\hline 62 & 1 & 1 & 1 & -1 & 1 & 1 & 1 & 1 & 0 & 0 & 0 & -1 & 0 & 1 & 1 & -1 & -1 & -1 & 0 & 0 & -1 & -1 \\
\hline 63 & 0 & 0 & -1 & -1 & 0 & 0 & 1 & 1 & -1 & 1 & -1 & 1 & 1 & 1 & 1 & -1 & -1 & 0 & -1 & -1 & 0 & 0 \\
\hline 64 & 1 & -1 & -1 & 0 & 0 & 0 & 0 & 0 & 0 & 0 & 0 & -1 & 0 & -1 & 0 & -1 & -1 & -1 & -1 & -1 & -1 & -1 \\
\hline 65 & -1 & 1 & -1 & -1 & -1 & -1 & -1 & -1 & 0 & 0 & -1 & -1 & 0 & -1 & 1 & -1 & 0 & 0 & -1 & -1 & -1 & -1 \\
\hline 66 & 1 & -1 & 0 & -1 & 1 & 1 & 1 & 1 & -1 & 1 & -1 & 1 & 1 & 0 & 1 & -1 & 0 & 0 & -1 & -1 & 0 & 0 \\
\hline 67 & -1 & 0 & 0 & -1 & -1 & -1 & -1 & -1 & 1 & -1 & -1 & -1 & 0 & 0 & 0 & -1 & 0 & 0 & -1 & -1 & -1 & -1 \\
\hline 68 & -1 & 0 & 0 & -1 & 1 & 1 & 1 & 1 & -1 & 1 & -1 & -1 & 1 & 0 & 1 & 1 & -1 & 1 & -1 & -1 & -1 & 0 \\
\hline
\end{tabular}


Tabela 8: Genótipos das plantas-mãe das linhagens $S_{2}$ de milho - cromossomo 4

\begin{tabular}{|c|c|c|c|c|c|c|c|c|c|c|c|c|c|c|c|}
\hline Linhagens & 560 & S61 & 562 & $S 63$ & S64 & 565 & 566 & $\$ 567$ & 568 & S69 & S70 & S71 & $\mathbf{S 7 3}$ & S74 & S75 \\
\hline 1 & 0 & 0 & -1 & -1 & 1 & -1 & 0 & 0 & 0 & -1 & 0 & 0 & 1 & 1 & 1 \\
\hline 2 & 1 & 1 & 0 & 0 & 1 & -1 & -1 & -1 & -1 & 0 & -1 & -1 & 0 & 0 & 1 \\
\hline 3 & -1 & -1 & -1 & -1 & 1 & -1 & 1 & 0 & 0 & -1 & 0 & 0 & 1 & 1 & 0 \\
\hline 4 & 0 & 0 & -1 & -1 & -1 & 1 & 0 & 0 & 0 & -1 & 1 & -1 & 1 & 1 & 1 \\
\hline 5 & 1 & 1 & 1 & 1 & 0 & 0 & 0 & 0 & -1 & 0 & -1 & -1 & 1 & 1 & 1 \\
\hline 6 & 7 & 0 & -1 & 0 & 0 & 0 & 0 & 0 & 0 & -1 & 0 & 0 & 1 & $T$ & 0 \\
\hline 7 & 0 & 0 & -1 & -1 & -1 & 1 & -1 & -1 & -1 & -1 & -1 & -1 & 1 & 1 & 1 \\
\hline 8 & -1 & -1 & -1 & -1 & 0 & 0 & -1 & -1 & -1 & 1 & -1 & -1 & -1 & -1 & -1 \\
\hline 9 & 0 & 0 & -1 & -1 & 1 & -1 & 1 & 1 & 1 & -1 & 1 & 1 & -1 & -1 & 0 \\
\hline 10 & -1 & -1 & -1 & 0 & 0 & 0 & -1 & -1 & -1 & -1 & -1 & -1 & 1 & 1 & 1 \\
\hline 11 & 0 & 0 & -1 & -1 & -1 & 1 & 0 & -1 & -1 & -1 & -1 & -1 & -1 & -1 & -1 \\
\hline 12 & 0 & 0 & 1 & 1 & 1 & -1 & -1 & -1 & $\overline{-1}$ & 0 & -1 & -1 & 0 & 0 & -1 \\
\hline 13 & 0 & 0 & 1 & 1 & 0 & 0 & -1 & -1 & -1 & 0 & -1 & 1 & 1 & 1 & 1 \\
\hline 14 & -1 & -1 & 0 & -1 & 0 & 0 & 0 & 0 & -1 & 1 & -1 & -1 & 0 & 0 & 0 \\
\hline 15 & 0 & 0 & 0 & 0 & -1 & $\bar{I}$ & 1 & 1 & 0 & 1 & 0 & -1 & 0 & 0 & 0 \\
\hline 16 & 0 & 0 & -1 & -1 & -1 & 1 & 0 & 0 & 0 & -1 & 0 & 0 & 1 & 1 & 1 \\
\hline 17 & -1 & -1 & 1 & 1 & 1 & -1 & -1 & -1 & -1 & -1 & -1 & -1 & 1 & 1 & -1 \\
\hline 18 & 1 & 1 & 1 & 1 & -1 & 1 & 1 & 1 & 0 & -1 & 0 & 0 & 0 & 0 & -1 \\
\hline 19 & 0 & 0 & -1 & -1 & $\overline{0}$ & 0 & 0 & 0 & -1 & -1 & -1 & -1 & 1 & 1 & 1 \\
\hline 20 & 0 & 0 & -1 & -1 & 1 & -1 & 1 & 1 & -1 & 1 & -1 & -1 & -1 & -1 & -1 \\
\hline 21 & -1 & -1 & 1 & 1 & -1 & 1 & -1 & -1 & -1 & 1 & -1 & -1 & 0 & 0 & -1 \\
\hline 22 & 1 & 1 & 0 & 0 & -1 & -1 & -1 & -1 & -1 & 0 & -1 & -1 & 1 & 1 & 0 \\
\hline 23 & 1 & 1 & -1 & 0 & 0 & 0 & 1 & 1 & 1 & -1 & 1 & 1 & 1 & 1 & 1 \\
\hline 24 & 0 & 0 & -1 & 0 & 1 & -1 & 0 & 0 & -1 & 0 & -1 & -1 & 1 & 1 & 0 \\
\hline 25 & 0 & 0 & -1 & -1 & -1 & 1 & -1 & -1 & -1 & 1 & -1 & -1 & 1 & 1 & 1 \\
\hline 26 & -1 & -1 & -1 & -1 & -1 & 1 & -1 & -1 & -1 & -1 & -1 & 1 & 1 & 1 & -1 \\
\hline 27 & 0 & 0 & 0 & 0 & -1 & 1 & 1 & 1 & -1 & -1 & -1 & -1 & -1 & -1 & -1 \\
\hline 28 & 1 & 1 & 0 & 0 & -1 & 1 & 1 & 1 & 1 & -1 & 1 & 1 & 1 & 1 & -1 \\
\hline 29 & -1 & -1 & 0 & 0 & 1 & -1 & -1 & -1 & -1 & -1 & -1 & -1 & 1 & 1 & 0 \\
\hline 30 & 1 & 1 & 1 & 1 & -1 & 1 & -1 & -1 & -1 & -1 & -1 & -1 & 1 & 1 & -1 \\
\hline 31 & 1 & 0 & -1 & -1 & -1 & 1 & 1 & 1 & 1 & 0 & 1 & 1 & 1 & 1 & -1 \\
\hline 32 & 1 & 1 & -1 & -1 & -1 & 1 & 1 & 1 & -1 & 0 & -1 & -1 & 0 & 0 & 0 \\
\hline 33 & -1 & -1 & -1 & 0 & 1 & -1 & -1 & -1 & -1 & -1 & -1 & -1 & 1 & 1 & 0 \\
\hline 34 & -1 & -1 & 0 & 0 & 0 & 0 & -1 & -1 & -1 & 0 & -1 & -1 & 1 & 1 & 1 \\
\hline 35 & -1 & -1 & 0 & 0 & 0 & 0 & -1 & -1 & -1 & -1 & -1 & -1 & 0 & 0 & 0 \\
\hline
\end{tabular}




\begin{tabular}{|c|c|c|c|c|c|c|c|c|c|c|c|c|c|c|c|}
\hline Linhagens & 560 & S61 & S62 & $S 63$ & 564 & S65 & $\$ 566$ & $\$ 67$ & S68 & $\$ 69$ & $\$ 70$ & S71 & $\mathbf{S 7 3}$ & S74 & S75 \\
\hline 36 & -1 & -1 & -1 & 0 & 0 & 0 & -1 & -1 & -1 & -1 & -1 & -1 & 1 & 1 & 0 \\
\hline 37 & -1 & -1 & -1 & -1 & 0 & 0 & -1 & -1 & -1 & -1 & -1 & -1 & 1 & 1 & 0 \\
\hline 38 & -1 & -1 & -1 & -1 & 1 & -1 & -1 & -1 & -1 & 0 & -1 & -1 & 0 & 0 & -1 \\
\hline 39 & 0 & 0 & 0 & 0 & 0 & -1 & 1 & 0 & -1 & -1 & -1 & -1 & -1 & -1 & -1 \\
\hline 40 & 0 & 0 & -1 & -1 & -1 & 1 & -1 & -1 & -1 & -1 & -1 & -1 & 1 & 1 & 1 \\
\hline 41 & 0 & 0 & -1 & 0 & 0 & $\overline{0}$ & 0 & 0 & -1 & -1 & -1 & -1 & 1 & 1 & 0 \\
\hline 42 & 1 & 1 & -1 & 0 & 1 & -1 & -1 & -1 & 0 & $\overline{0}$ & 0 & 0 & 1 & 1 & 1 \\
\hline 43 & 0 & 0 & 0 & -1 & -1 & 1 & 0 & 0 & 0 & -1 & 0 & 0 & 1 & 1 & 0 \\
\hline 44 & 1 & 1 & -1 & 1 & 0 & 0 & 1 & 1 & 1 & 0 & 1 & 1 & 1 & 1 & 0 \\
\hline 45 & 1 & 1 & -1 & 0 & 1 & -1 & 1 & 1 & 0 & $\overline{0}$ & 0 & 0 & 0 & $\overline{0}$ & 1 \\
\hline 46 & -1 & -1 & 0 & 0 & 0 & 0 & -1 & -1 & -1 & 0 & -1 & -1 & 1 & 1 & 1 \\
\hline 47 & -1 & -1 & -1 & 0 & 0 & 0 & -1 & -1 & -1 & -1 & -1 & -1 & 1 & 1 & 1 \\
\hline 48 & 1 & 1 & 0 & 0 & 0 & 0 & 1 & 1 & 0 & -1 & -1 & 0 & 1 & 1 & $\overline{0}$ \\
\hline 49 & 1 & 0 & $\overline{0}$ & 1 & -1 & 1 & 1 & 1 & $\overline{0}$ & -1 & $\overline{0}$ & 0 & 0 & 0 & -1 \\
\hline 50 & -1 & -1 & 0 & 1 & -1 & 1 & -1 & -1 & -1 & 0 & -1 & -1 & 0 & 0 & -1 \\
\hline 51 & 1 & 1 & -1 & 0 & -1 & 1 & 0 & 0 & 0 & 0 & 0 & 0 & 1 & 1 & -1 \\
\hline 52 & 0 & 0 & 1 & -1 & -1 & 1 & 0 & 0 & -1 & 1 & -1 & -1 & 0 & 0 & 1 \\
\hline 53 & 1 & 1 & -1 & 1 & -1 & 1 & -1 & -1 & -1 & -1 & 0 & -1 & 0 & 0 & -1 \\
\hline 54 & 1 & 1 & 0 & 0 & -1 & 1 & 1 & 1 & 1 & -1 & 1 & 1 & 1 & 1 & 0 \\
\hline 55 & 0 & $\overline{0}$ & 0 & 0 & -1 & 1 & -1 & -1 & -1 & 1 & -1 & -1 & -1 & -1 & 0 \\
\hline 56 & -1 & -1 & -1 & -1 & 0 & 0 & -1 & -1 & -1 & 1 & -1 & -1 & 1 & 1 & 0 \\
\hline 57 & 1 & 0 & 0 & 1 & $\overline{0}$ & 0 & 0 & 0 & -1 & -1 & -1 & -1 & 1 & 1 & 1 \\
\hline 58 & 1 & 1 & 0 & 0 & -1 & 1 & 0 & 0 & -1 & -1 & -1 & 0 & 1 & 1 & 0 \\
\hline 59 & 0 & 0 & 1 & 1 & 1 & -1 & 1 & 1 & -1 & -1 & -1 & -1 & 0 & 0 & 1 \\
\hline 60 & 0 & 0 & 0 & 1 & $\overline{0}$ & 0 & 0 & 0 & -1 & 1 & -1 & -1 & 1 & 1 & 1 \\
\hline 61 & -1 & -1 & -1 & 0 & -1 & 1 & 0 & 0 & 1 & -1 & 1 & -1 & 1 & 1 & -1 \\
\hline 62 & 0 & 0 & -1 & 0 & 1 & -1 & 1 & -1 & -1 & 1 & -1 & -1 & 1 & 1 & 1 \\
\hline 63 & 0 & 0 & -1 & 0 & 0 & 0 & 0 & 0 & -1 & 1 & -1 & -1 & $\overline{0}$ & 0 & 0 \\
\hline 64 & 0 & 0 & -1 & 1 & 1 & -1 & 0 & 0 & -1 & -1 & -1 & -1 & 1 & 1 & 1 \\
\hline 65 & -1 & -1 & -1 & 1 & 0 & 0 & 1 & -1 & -1 & -1 & -1 & -1 & 1 & 1 & 0 \\
\hline 66 & -1 & -1 & 0 & 1 & 1 & -1 & 1 & -1 & -1 & -1 & -1 & -1 & 1 & 1 & 1 \\
\hline 67 & -1 & -1 & 0 & 0 & -1 & 1 & 1 & -1 & -1 & -1 & -1 & -1 & 1 & 1 & 1 \\
\hline 68 & 1 & 1 & 1 & 0 & -1 & 1 & 1 & -1 & $\overline{0}$ & -1 & -1 & -1 & 1 & 1 & 0 \\
\hline
\end{tabular}


Tabela 9: Genótipos das plantas-mãe das linhagens $S_{2}$ de milho - cromossomo 5.

\begin{tabular}{|c|c|c|c|c|c|c|c|c|c|c|c|c|c|c|c|c|c|c|c|c|c|}
\hline Linhagens & S76 & \begin{tabular}{|l|} 
S77 \\
\end{tabular} & S78 & S79 & S80 & S81 & 582 & $\mathbf{S 8 3}$ & S84 & S85 & $\mathbf{S 8 6}$ & $\mathbf{S 8 7}$ & S88 & S89 & 590 & S91 & S92 & $\$ 93$ & S94 & S95 & S96 \\
\hline 1 & -1 & 0 & 1 & 0 & 0 & -1 & -1 & 0 & 0 & 0 & 0 & -1 & 0 & -1 & 1 & -1 & -1 & -1 & -1 & 1 & 1 \\
\hline 2 & -1 & 1 & 1 & 0 & 0 & -1 & 0 & 0 & 0 & 0 & 0 & 0 & 1 & 0 & 1 & 1 & 1 & 0 & 0 & 0 & 0 \\
\hline 3 & -1 & -1 & 1 & 0 & 0 & -1 & 1 & 0 & 1 & -1 & -1 & -1 & $\overline{0}$ & -1 & 0 & -1 & 1 & -1 & 1 & -1 & -1 \\
\hline 4 & -1 & 0 & 0 & -1 & 1 & 0 & 0 & 0 & 1 & -1 & -1 & -1 & 0 & 0 & 1 & 0 & $\overline{0}$ & -1 & -1 & -1 & 0 \\
\hline 5 & -1 & 1 & 0 & -1 & 1 & 0 & 1 & 0 & 0 & 0 & 0 & 0 & 0 & 0 & 1 & -1 & 0 & 0 & 1 & 1 & 1 \\
\hline 6 & -1 & -1 & 0 & 0 & 1 & -1 & 0 & 0 & 0 & -1 & -1 & 0 & 0 & -1 & 1 & 0 & 0 & -1 & -1 & 0 & -1 \\
\hline 7 & -1 & -1 & $\overline{1}$ & -1 & $\overline{1}$ & -1 & -1 & $\overline{-1}$ & $\overline{0}$ & $\overline{-1}$ & $\begin{array}{ll}-1 \\
\end{array}$ & -1 & 1 & 0 & 1 & 0 & 1 & -1 & 1 & -1 & -1 \\
\hline 8 & -1 & 0 & 0 & 1 & -1 & -1 & 1 & 1 & 1 & -1 & -1 & -1 & 1 & -1 & 0 & -1 & 1 & -1 & -1 & -1 & -1 \\
\hline 9 & -1 & 0 & 0 & -1 & 1 & -1 & 1 & -1 & -1 & 1 & 1 & -1 & -1 & -1 & 1 & -1 & -1 & 0 & 0 & $\overline{0}$ & 0 \\
\hline 10 & 0 & -1 & -1 & -1 & 1 & 0 & -1 & 0 & 0 & 0 & 0 & 0 & 0 & -1 & 1 & 0 & 1 & 0 & 0 & 0 & -1 \\
\hline 11 & -1 & $\overline{0}$ & 0 & 1 & $\overline{0}$ & 0 & -1 & 1 & 1 & -1 & -1 & -1 & 0 & -1 & 0 & 0 & 1 & -1 & -1 & -1 & -1 \\
\hline 12 & -1 & -1 & 1 & -1 & 1 & -1 & -1 & -1 & -1 & $\overline{0}$ & 0 & -1 & -1 & -1 & 1 & 1 & 1 & -1 & -1 & -1 & -1 \\
\hline 13 & -1 & -1 & -1 & 1 & 0 & -1 & -1 & 0 & 0 & 0 & 0 & -1 & 0 & 0 & -1 & -1 & 1 & -1 & -1 & 0 & -1 \\
\hline 14 & 1 & -1 & 0 & 1 & 0 & -1 & 1 & 1 & 1 & -1 & -1 & -1 & 0 & -1 & -1 & -1 & 1 & -1 & -1 & 1 & 1 \\
\hline 15 & 0 & 0 & 0 & -1 & 1 & 1 & 0 & 1 & 1 & -1 & -1 & 1 & 1 & 1 & 1 & 1 & 1 & 1 & 1 & 1 & 1 \\
\hline 16 & -1 & -1 & 1 & -1 & 1 & -1 & -1 & -1 & -1 & -1 & -1 & -1 & -1 & -1 & 1 & 1 & 1 & -1 & -1 & -1 & -1 \\
\hline 17 & -1 & -1 & 1 & 0 & 0 & -1 & $\overline{0}$ & 1 & 1 & -1 & -1 & 1 & 1 & 0 & 1 & 0 & 1 & 0 & 0 & -1 & -1 \\
\hline 18 & -1 & 0 & 0 & 0 & 0 & -1 & 1 & 0 & 0 & -1 & -1 & 0 & 0 & -1 & -1 & -1 & 1 & 0 & 1 & 0 & 0 \\
\hline 19 & -1 & -1 & 0 & -1 & 1 & -1 & 1 & -1 & $\overline{0}$ & -1 & -1 & -1 & 0 & -1 & 1 & 1 & 1 & -1 & -1 & -1 & -1 \\
\hline 20 & 0 & -1 & 0 & -1 & 1 & 0 & -1 & 0 & 0 & -1 & -1 & 0 & 1 & 1 & 1 & $\overline{0}$ & 1 & l & 1 & 0 & -1 \\
\hline 21 & -1 & -1 & 0 & -1 & 1 & -1 & -1 & -1 & 0 & -1 & -1 & -1 & -1 & -1 & 1 & 1 & 1 & -1 & -1 & -1 & -1 \\
\hline 22 & -1 & .1 & -1 & -1 & 1 & -1 & 0 & 1 & 1 & -1 & -1 & -1 & 1 & 1 & 1 & -1 & -1 & -1 & -1 & $\overline{0}$ & 1 \\
\hline 23 & -1 & -1 & -1 & -1 & 1 & 0 & 1 & 0 & 0 & 0 & 0 & -1 & -1 & -1 & 1 & -1 & 0 & 0 & 0 & 1 & 0 \\
\hline 24 & 1 & -1 & 1 & $\overline{0}$ & 0 & -1 & 0 & 0 & 0 & -1 & -1 & -1 & 1 & -1 & 0 & 0 & 1 & 0 & 1 & -1 & 0 \\
\hline 25 & 1 & -1 & -1 & -1 & 1 & -1 & -1 & -1 & -1 & 1 & 1 & -1 & -1 & -1 & 1 & 0 & 0 & -1 & -1 & $\overline{1}$ & 1 \\
\hline 26 & 1 & -1 & -1 & 0 & -1 & -1 & -1 & 1 & 1 & -1 & -1 & -1 & 0 & -1 & 1 & 0 & 0 & -1 & -1 & 0 & 0 \\
\hline 27 & -1 & -1 & 0 & $\overline{-1}$ & 1 & $\overline{0}$ & $\overline{0}$ & -1 & 0 & 0 & 0 & -1 & -1 & -1 & 1 & -1 & 1 & 1 & 1 & 1 & 1 \\
\hline 28 & -1 & -1 & $\overline{0}$ & -1 & 1 & -1 & 0 & -1 & -1 & $\overline{0}$ & 0 & -1 & -1 & -1 & 1 & -1 & 1 & 1 & 1 & 1 & 0 \\
\hline 29 & -1 & 0 & 0 & 0 & $\overline{0}$ & 0 & -1 & 1 & 1 & -1 & -1 & 0 & 1 & 1 & 1 & 1 & 1 & 1 & 1 & 1 & 1 \\
\hline 30 & -1 & 1 & 1 & 0 & 0 & 0 & -1 & 1 & 1 & -1 & -1 & -1 & 0 & -1 & 0 & 0 & 1 & -1 & -1 & -1 & -1 \\
\hline 31 & 1 & -1 & 1 & 0 & 1 & -1 & -1 & 1 & 1 & -1 & -1 & 0 & 1 & -1 & 0 & 0 & 1 & 0 & 1 & 1 & $\overline{0}$ \\
\hline 32 & -1 & -1 & 1 & -1 & 1 & -1 & 1 & -1 & 0 & 1 & 1 & -1 & -1 & -1 & 1 & 0 & 0 & -1 & -1 & 0 & 0 \\
\hline 33 & -1 & 0 & 0 & $\overline{-1}$ & 1 & 1 & $\overline{0}$ & 1 & 1 & -1 & -1 & 1 & 0 & 0 & 1 & 1 & $I$ & 0 & 0 & 0 & 0 \\
\hline 34 & -1 & -1 & 0 & -1 & 1 & -1 & 0 & -1 & -1 & 1 & 1 & -1 & -1 & -1 & 1 & 0 & 0 & 0 & 0 & -1 & -1 \\
\hline 35 & -1 & 1 & 1 & 1 & -1 & -1 & -1 & 1 & 1 & -1 & -1 & -1 & 1 & -1 & -1 & -1 & 1 & -1 & -1 & 0 & 0 \\
\hline
\end{tabular}


\begin{tabular}{|l|l|l|l|l|l|l|l|l|l|l|l|l|l|l|l|l|l|l|l|l|l|}
\hline Linhagens & $\mathbf{S 7 6}$ & $\mathbf{S 7 7}$ & $\mathbf{S 7 8}$ & $\mathbf{S 7 9}$ & $\mathbf{S 8 0}$ & $\mathbf{S 8 1}$ & $\mathbf{S 8 2}$ & $\mathbf{S 8 3}$ & $\mathbf{S 8 4}$ & $\mathbf{S 8 5}$ & $\mathbf{S 8 6}$ & $\mathbf{S 8 7}$ & $\mathbf{S 8 8}$ & $\mathbf{S 8 9}$ & $\mathbf{S 9 0}$ & $\mathbf{S 9 1}$ & $\mathbf{S 9 2}$ & $\mathbf{S 9 3}$ & $\mathbf{S 9 4}$ & $\mathbf{S 9 5}$ & $\mathbf{S 9 6}$ \\
\hline
\end{tabular}

\begin{tabular}{|c|c|c|c|c|c|c|c|c|c|c|c|c|c|c|c|c|c|c|c|c|c|}
\hline 36 & -1 & -1 & 1 & 0 & 0 & -1 & 1 & 0 & 0 & -1 & -1 & -1 & -1 & -1 & 1 & 1 & 1 & 0 & 0 & 0 & 0 \\
\hline 37 & 0 & -1 & 0 & -1 & 1 & -1 & 1 & -1 & -1 & -1 & -1 & -1 & 0 & -1 & 1 & 1 & 1 & 1 & -1 & 0 & 0 \\
\hline 38 & -1 & -1 & -1 & 0 & 0 & 0 & 1 & 1 & 1 & -1 & -1 & 0 & 1 & 0 & 0 & 0 & 1 & 0 & -1 & 0 & 0 \\
\hline 39 & -1 & -1 & -1 & -1 & 1 & -1 & 1 & -1 & -1 & 1 & 1 & -1 & 1 & 0 & 1 & 0 & 1 & 1 & 1 & 1 & 1 \\
\hline 40 & -1 & 0 & 0 & -1 & 1 & 1 & -1 & 1 & 1 & -1 & -1 & 1 & 1 & 1 & 1 & -1 & -1 & 1 & 0 & 1 & 1 \\
\hline 41 & 0 & 1 & 1 & 1 & -1 & -1 & 0 & 1 & 1 & -1 & -1 & -1 & 1 & -1 & -1 & -1 & 1 & -1 & -1 & -1 & -1 \\
\hline 42 & 0 & 0 & $\overline{0}$ & -1 & 1 & -1 & 0 & -1 & -1 & 1 & 1 & -1 & -1 & -1 & 1 & -1 & -1 & -1 & -1 & 0 & 0 \\
\hline 43 & -1 & 0 & 0 & -1 & 1 & 0 & 0 & 0 & 0 & -1 & -1 & 0 & 0 & 0 & 1 & 1 & 0 & -1 & -1 & 0 & 0 \\
\hline 44 & -1 & -1 & 0 & -1 & 1 & -1 & 0 & 0 & 0 & -1 & -1 & 1 & 1 & -1 & -1 & -1 & 0 & -1 & -1 & -1 & -1 \\
\hline 45 & 0 & -1 & 0 & -1 & 1 & -1 & 0 & -1 & -1 & -1 & -1 & -1 & 0 & -1 & 1 & 1 & 1 & -1 & 0 & 0 & 0 \\
\hline 46 & -1 & 0 & 0 & 0 & 0 & -1 & 1 & 0 & 0 & -1 & -1 & -1 & 0 & -1 & 0 & -1 & 1 & -1 & -1 & -1 & -1 \\
\hline 47 & 1 & -1 & 0 & -1 & 1 & 0 & -1 & 0 & 0 & -1 & -1 & 0 & -1 & -1 & 1 & 0 & 1 & -1 & -1 & -1 & -1 \\
\hline 48 & -1 & -1 & 1 & -1 & 0 & -1 & 0 & 1 & 1 & -1 & -1 & 0 & 1 & -1 & 0 & -1 & 0 & -1 & 0 & 0 & 0 \\
\hline 49 & 0 & -1 & 0 & 1 & -1 & -1 & -1 & 1 & 1 & -1 & -1 & -1 & 1 & -1 & -1 & -1 & 0 & -1 & 1 & -1 & -1 \\
\hline 50 & -1 & -1 & 0 & -1 & 1 & -1 & -1 & -1 & -1 & 1 & 1 & -1 & -1 & -1 & 1 & -1 & -1 & -1 & -1 & -1 & 0 \\
\hline 51 & 0 & -1 & 0 & 0 & 0 & -1 & -1 & 0 & 0 & -1 & -1 & -1 & 0 & -1 & 1 & 1 & 1 & -1 & -1 & 0 & 0 \\
\hline 52 & -1 & 0 & 1 & -1 & 1 & -1 & 1 & -1 & -1 & 1 & 1 & -1 & 0 & -1 & 1 & -1 & 1 & -1 & -1 & -1 & 0 \\
\hline 53 & -1 & 0 & 1 & -1 & 1 & -1 & 0 & -1 & -1 & -1 & -1 & -1 & -1 & -1 & 1 & 0 & 0 & -1 & -1 & -1 & -1 \\
\hline 54 & 0 & 0 & 0 & -1 & 1 & -1 & 1 & -1 & 0 & 1 & 1 & -1 & -1 & -1 & 1 & -1 & -1 & -1 & -1 & 1 & 1 \\
\hline 55 & -1 & 1 & 1 & 0 & 0 & -1 & 0 & 0 & 0 & -1 & -1 & -1 & 0 & -1 & 0 & -1 & 1 & -1 & 0 & -1 & -1 \\
\hline 56 & -1 & -1 & 1 & -1 & 1 & -1 & 0 & 0 & -1 & 0 & 0 & -1 & -1 & -1 & 1 & 0 & 0 & -1 & 0 & 0 & -1 \\
\hline 57 & -1 & -1 & -1 & -1 & 1 & $\overline{0}$ & -1 & 0 & 0 & 0 & 0 & $\overline{0}$ & 0 & 0 & 0 & 0 & 1 & 1 & 1 & 0 & -1 \\
\hline 58 & -1 & -1 & -1 & -1 & 1 & 1 & -1 & 1 & 1 & -1 & -1 & 1 & 1 & 1 & 1 & 1 & 1 & 1 & 1 & 1 & 0 \\
\hline 59 & 1 & -1 & -1 & -1 & 0 & -1 & -1 & 1 & 1 & -1 & -1 & -1 & 1 & -1 & -1 & -1 & 1 & -1 & -1 & -1 & -1 \\
\hline 60 & -1 & 0 & 1 & -1 & 1 & 0 & 1 & 0 & 0 & -1 & -1 & -1 & 0 & -1 & 1 & 0 & 1 & 0 & 0 & -1 & -1 \\
\hline 61 & 0 & 1 & 1 & 1 & -1 & -1 & -1 & 1 & 1 & -1 & -1 & -1 & 1 & -1 & 0 & 1 & 1 & 0 & 0 & 0 & 0 \\
\hline 62 & 0 & -1 & -1 & -1 & 1 & 0 & 1 & 0 & 0 & 0 & 0 & 0 & 0 & -1 & 1 & -1 & -1 & -1 & -1 & 1 & 0 \\
\hline 63 & 0 & 0 & 1 & 1 & -1 & -1 & 1 & 1 & 1 & -1 & -1 & -1 & 0 & -1 & 0 & -1 & 0 & -1 & -1 & 0 & 0 \\
\hline 64 & -1 & 0 & 1 & 1 & -1 & -1 & 0 & 1 & 1 & -1 & -1 & -1 & 1 & -1 & -1 & -1 & 0 & -1 & -1 & 1 & 0 \\
\hline 65 & -1 & 1 & -1 & -1 & 1 & -1 & -1 & 0 & 0 & -1 & -1 & 1 & 1 & 1 & 1 & 1 & 0 & 1 & 1 & 1 & 0 \\
\hline 66 & -1 & 1 & 0 & -1 & 1 & 1 & -1 & 1 & 0 & -1 & -1 & -1 & -1 & -1 & 1 & 0 & 1 & -1 & -1 & 1 & 0 \\
\hline 67 & -1 & -1 & 1 & -1 & 1 & -1 & -1 & -1 & -1 & -1 & -1 & -1 & -1 & -1 & 1 & 0 & 1 & -1 & -1 & -1 & -1 \\
\hline 68 & -1 & 0 & 0 & 1 & -1 & -1 & 0 & 1 & 1 & -1 & -1 & -1 & 1 & -1 & 0 & 0 & 1 & -1 & -1 & 0 & -1 \\
\hline
\end{tabular}


Tabela 10: Genótipos das plantas-mãe das linhagens $S_{2}$ de milho - cromossomo 6.

\begin{tabular}{|c|c|c|c|c|c|c|c|c|c|c|c|c|c|}
\hline Linhagens & S97 & S98 & 599 & $\mathbf{S 1 0 0}$ & S101 & $\mathrm{S102}$ & $\mathbf{S 1 0 3}$ & $\$ 104$ & 5105 & 5106 & $\mathbf{5 1 0 7}$ & $\mathbf{5 1 0 8}$ & $\mathbf{S 1 0 9}$ \\
\hline 1 & -1 & 1 & 1 & -1 & -1 & 1 & -1 & -1 & 1 & 0 & -1 & -1 & -1 \\
\hline 2 & -1 & 0 & 0 & $\overline{-1}$ & -1 & 1 & -1 & -1 & 1 & 0 & 0 & 1 & -1 \\
\hline 3 & 0 & -1 & -1 & -1 & -1 & 1 & 1 & 1 & 0 & -1 & -1 & -1 & -1 \\
\hline 4 & 0 & -1 & -1 & -1 & -1 & -1 & -1 & -1 & 1 & 0 & 0 & 0 & -1 \\
\hline 5 & 0 & -1 & -1 & 1 & 1 & 1 & -1 & -1 & 1 & $\overline{0}$ & 0 & 0 & -1 \\
\hline 6 & 0 & -1 & -1 & -1 & -1 & 0 & -1 & -1 & 0 & 0 & -1 & -1 & -1 \\
\hline 7 & -1 & $\overline{0}$ & 0 & -1 & -1 & 0 & -1 & -1 & 0 & 0 & -1 & -1 & -1 \\
\hline 8 & -1 & -1 & -1 & 0 & $\overline{0}$ & 0 & -1 & -1 & $\overline{0}$ & 0 & -1 & -1 & 1 \\
\hline 9 & 1 & -1 & -1 & -1 & -1 & 1 & -1 & -1 & 1 & -1 & -1 & -1 & 0 \\
\hline 10 & -1 & -1 & -1 & -1 & -1 & -1 & -1 & -1 & 0 & -1 & -1 & -1 & -1 \\
\hline 11 & -1 & 7 & 1 & -1 & -1 & 0 & -1 & -1 & 0 & 0 & 0 & -1 & 0 \\
\hline 12 & -1 & 1 & 1 & -1 & -1 & 1 & -1 & -1 & $\overline{1}$ & 1 & 0 & -1 & 0 \\
\hline 13 & -1 & -1 & -1 & -1 & -1 & -1 & 1 & 1 & 1 & -1 & -1 & -1 & 0 \\
\hline 14 & -1 & -1 & -1 & -1 & -1 & 1 & -1 & -1 & 0 & 1 & -1 & -1 & -1 \\
\hline 15 & 0 & -1 & -1 & -1 & -1 & 1 & -1 & -1 & -1 & 0 & -1 & -1 & 0 \\
\hline 16 & -1 & 0 & 0 & -1 & -1 & 0 & -1 & -1 & 0 & 0 & -1 & -1 & 1 \\
\hline 17 & $\overline{0}$ & -1 & -1 & 0 & 0 & 0 & 0 & $\overline{0}$ & 0 & 0 & -1 & -1 & 0 \\
\hline 18 & 0 & -1 & -1 & -1 & -1 & -1 & -1 & -1 & -1 & 0 & -1 & -1 & 0 \\
\hline 19 & 1 & -1 & -1 & -1 & -1 & -1 & -1 & -1 & -1 & 0 & 1 & 0 & 0 \\
\hline 20 & -1 & 0 & 0 & -1 & -1 & 0 & -1 & -1 & 0 & 0 & 9 & -1 & 0 \\
\hline 21 & -1 & -1 & -1 & -1 & -1 & 1 & -1 & -1 & 1 & $\overline{0}$ & -1 & -1 & -1 \\
\hline 22 & -1 & -1 & 0 & 0 & 0 & 1 & -1 & -1 & 1 & 0 & -1 & -1 & -1 \\
\hline 23 & 0 & -1 & -1 & 0 & 0 & 1 & -1 & -1 & 0 & 0 & -1 & -1 & 1 \\
\hline 24 & 0 & 0 & 0 & 0 & 0 & 1 & 0 & 0 & 0 & -1 & -1 & 1 & 0 \\
\hline 25 & -1 & 1 & 0 & -1 & -1 & 1 & 0 & 0 & 1 & 0 & $\overline{0}$ & 0 & 0 \\
\hline 26 & -1 & 1 & 1 & -1 & -1 & 1 & -1 & -1 & 1 & 1 & 1 & 1 & -1 \\
\hline 27 & -1 & -1 & -1 & 0 & 0 & 1 & 0 & 0 & 1 & 0 & -1 & -1 & 0 \\
\hline 28 & -1 & -1 & -1 & 0 & 0 & 0 & 0 & 0 & 0 & 0 & -1 & -1 & -1 \\
\hline 29 & -1 & 1 & 1 & -1 & -1 & 1 & 0 & 0 & 1 & 1 & -1 & -1 & 0 \\
\hline 30 & -1 & -1 & -1 & -1 & -1 & -1 & -1 & -1 & -1 & 1 & 0 & 0 & -1 \\
\hline 31 & -1 & 1 & 1 & -1 & -1 & 1 & -1 & -1 & 1 & -1 & -1 & $\overline{-1}$ & 1 \\
\hline 32 & -1 & -1 & -1 & 1 & 1 & 1 & -1 & -1 & -1 & $\overline{1}$ & -1 & -1 & -1 \\
\hline 33 & 0 & -1 & -1 & -1 & -1 & -1 & -1 & -1 & -1 & 0 & -1 & -1 & -1 \\
\hline 34 & -1 & -1 & 0 & 0 & 0 & 1 & 0 & 0 & 1 & -1 & 0 & 1 & 0 \\
\hline 35 & -1 & 0 & -1 & -1 & -1 & -1 & -1 & -1 & -1 & 1 & -1 & -1 & -1 \\
\hline
\end{tabular}




\begin{tabular}{|c|c|c|c|c|c|c|c|c|c|c|c|c|c|}
\hline Linhagens & S97 & S98 & S99 & $\mathbf{S 1 0 0}$ & S101 & S102 & S103 & S104 & $\mathbf{S 1 0 5}$ & S106 & S107 & $\mathbf{S 1 0 8}$ & $\mathbf{S 1 0 9}$ \\
\hline 36 & -1 & -1 & -1 & 1 & 1 & 1 & 0 & 0 & 0 & 0 & -1 & -1 & -1 \\
\hline 37 & 0 & -1 & -1 & 0 & 0 & 1 & 0 & 0 & -1 & 0 & -1 & -1 & 0 \\
\hline 38 & 1 & -1 & -1 & -1 & -1 & 1 & -1 & -1 & -1 & 1 & -1 & -1 & -1 \\
\hline 39 & -1 & -1 & 0 & 0 & 0 & 1 & -1 & -1 & -1 & 1 & -1 & -1 & 0 \\
\hline 40 & -1 & 1 & -1 & 0 & 0 & 1 & 0 & 0 & 1 & 1 & 0 & 0 & 0 \\
\hline 41 & 0 & -1 & 0 & -1 & -1 & 0 & -1 & -1 & 0 & 0 & -1 & -1 & -1 \\
\hline 42 & 0 & 0 & -1 & -1 & -1 & 1 & -1 & -1 & 0 & 1 & -1 & -1 & -1 \\
\hline 43 & 0 & -1 & -1 & -1 & -1 & 0 & 0 & 0 & 1 & -1 & 0 & 1 & -1 \\
\hline 44 & -1 & -1 & -1 & 0 & 0 & 0 & 1 & 1 & 1 & 0 & -1 & -1 & -1 \\
\hline 45 & -1 & -1 & -1 & 0 & $\overline{0}$ & 0 & $\frac{-1}{1}$ & -1 & -1 & 1 & 1 & 1 & $\overline{0}$ \\
\hline 46 & -1 & -1 & -1 & 1 & 1 & 1 & -1 & -1 & 0 & 1 & 0 & -1 & -1 \\
\hline 47 & -1 & 1 & 0 & 0 & 0 & 1 & 0 & 0 & 0 & 0 & -1 & -1 & 4 \\
\hline 48 & -1 & 0 & 0 & 0 & 0 & 1 & 0 & 0 & 0 & -1 & -1 & 0 & -1 \\
\hline 49 & -1 & -1 & -1 & -1 & -1 & -1 & -1 & -1 & 0 & -1 & 1 & -1 & -1 \\
\hline 50 & -1 & -1 & -1 & -1 & -1 & 1 & -1 & -1 & 1 & -1 & -1 & -1 & -1 \\
\hline 51 & -1 & 0 & 0 & 0 & 0 & 1 & -1 & -1 & 1 & -1 & -1 & -1 & 0 \\
\hline 52 & -1 & -1 & -1 & 1 & 1 & $\overline{1}$ & 1 & 1 & 1 & -1 & 1 & 0 & 0 \\
\hline 53 & -1 & 0 & -1 & -1 & -1 & 7 & -1 & -1 & 0 & 0 & -1 & -1 & -1 \\
\hline 54 & 0 & -1 & -1 & -1 & -1 & 1 & 0 & 0 & 0 & 1 & -1 & 0 & -1 \\
\hline 55 & -1 & -1 & -1 & 0 & 0 & 0 & 0 & 0 & 0 & $\overline{0}$ & -1 & -1 & -1 \\
\hline 56 & 0 & 0 & 0 & -1 & -1 & 7 & 0 & 0 & 7 & -1 & -1 & 0 & 0 \\
\hline 57 & -1 & -1 & -1 & -1 & -1 & -1 & -1 & -1 & 0 & -1 & -1 & -1 & -1 \\
\hline 58 & -1 & 1 & 1 & -1 & -1 & 1 & -1 & -1 & 1 & 1 & 1 & 1 & -1 \\
\hline 59 & -1 & -1 & -1 & 0 & 0 & 0 & 0 & 0 & -1 & -1 & -1 & -1 & -1 \\
\hline 60 & 1 & -1 & -1 & -1 & -1 & 1 & -1 & -1 & -1 & 0 & -1 & -1 & -1 \\
\hline 61 & -1 & -1 & -1 & -1 & -1 & -1 & -1 & -1 & -1 & 7 & -1 & -1 & 0 \\
\hline 62 & -1 & -1 & -1 & 1 & 1 & 1 & 1 & 1 & 1 & -1 & -1 & -1 & -1 \\
\hline 63 & 1 & -1 & -1 & -1 & -1 & 1 & -1 & -1 & -1 & 0 & -1 & -1 & -1 \\
\hline 64 & -1 & 0 & 0 & 0 & 0 & 1 & 0 & 0 & 1 & 0 & 0 & 0 & -1 \\
\hline 65 & -1 & -1 & -1 & -1 & -1 & -1 & -1 & -1 & 0 & 0 & 0 & 0 & -1 \\
\hline 66 & -1 & 1 & 0 & 0 & 0 & 7 & -1 & -1 & -1 & 1 & -1 & -1 & -1 \\
\hline 67 & -1 & -1 & -1 & -1 & -1 & 0 & -1 & -1 & -1 & 0 & -1 & -1 & -1 \\
\hline 68 & -1 & -1 & $\begin{array}{l}-1 \\
\end{array}$ & 1 & 1 & 1 & 0 & 0 & 0 & 0 & -1 & -1 & -1 \\
\hline
\end{tabular}


Tabela 11: Genótipos das plantas-mãe das linhagens $\mathrm{S}_{2}$ de milho - cromossomo 7.

\begin{tabular}{|c|c|c|c|c|c|c|c|c|c|c|c|}
\hline Linhagens & $\mathbf{S 1 1 0}$ & S111 & $\mathrm{S} 112$ & S113 & S114 & S115 & $\mathbf{S 1 1 6}$ & $\mathbf{S 1 1 7}$ & S118 & S119 & $\mathbf{S 1 2 0}$ \\
\hline 1 & -1 & 1 & 1 & 1 & -1 & 1 & 1 & -1 & -1 & 0 & 0 \\
\hline 2 & 1 & 0 & 0 & 0 & 0 & 1 & 0 & 1 & 0 & 1 & 1 \\
\hline 3 & 0 & -1 & -1 & -1 & 0 & 0 & -1 & -1 & -1 & 0 & 0 \\
\hline 4 & 0 & -1 & 0 & -1 & 0 & 0 & -1 & 0 & 0 & 1 & 0 \\
\hline 5 & 1 & 0 & 1 & 0 & 0 & 1 & 0 & 0 & 0 & 1 & -1 \\
\hline 6 & 1 & -1 & -1 & -1 & 1 & 1 & -1 & 1 & 0 & 1 & -1 \\
\hline 7 & 0 & -1 & -1 & -1 & 0 & 0 & -1 & 0 & 0 & -1 & -1 \\
\hline 8 & 0 & 1 & 1 & 1 & -1 & 1 & l & -1 & -1 & 1 & -1 \\
\hline 9 & 1 & -1 & 1 & 1 & -1 & 1 & 1 & -1 & -1 & 1 & -1 \\
\hline 10 & -1 & 1 & -1 & -1 & 1 & 1 & -1 & 1 & 1 & 1 & 0 \\
\hline 11 & 0 & -1 & 1 & -1 & 1 & 1 & -1 & 1 & 1 & 1 & -1 \\
\hline 12 & -1 & -1 & -1 & -1 & -1 & -1 & -1 & -1 & -1 & 1 & 1 \\
\hline 13 & -1 & 1 & 1 & 0 & $\overline{0}$ & 1 & -1 & 1 & 1 & 1 & -1 \\
\hline 14 & 1 & -1 & 1 & -1 & 1 & 1 & -1 & 1 & 1 & 0 & 0 \\
\hline 15 & 0 & -1 & 1 & -1 & 1 & 1 & -1 & 1 & 1 & 1 & -1 \\
\hline 16 & -1 & 1 & 1 & 1 & -1 & 1 & 1 & -1 & -1 & 1 & -1 \\
\hline 17 & 0 & 0 & 0 & 0 & -1 & 0 & 0 & -1 & -1 & 1 & -1 \\
\hline 18 & 1 & -1 & 0 & -1 & 1 & 1 & -1 & 1 & 1 & 1 & -1 \\
\hline 19 & -1 & 1 & 1 & 1 & -1 & 1 & 0 & 1 & 0 & 1 & 0 \\
\hline 20 & 0 & 0 & 0 & 0 & 0 & 1 & 0 & 0 & 0 & 1 & -1 \\
\hline 21 & 0 & -1 & 1 & -1 & 1 & 1 & -1 & 1 & 1 & $\overline{1}$ & -1 \\
\hline 22 & 1 & -1 & 0 & -1 & 0 & 1 & 0 & 0 & -1 & 0 & 0 \\
\hline 23 & 0 & 0 & 0 & 1 & -1 & 1 & 1 & -1 & -1 & 1 & -1 \\
\hline 24 & 0 & 0 & 1 & 0 & 0 & 1 & -1 & 0 & 0 & 1 & 1 \\
\hline 25 & -1 & 0 & 0 & 0 & -1 & 0 & 0 & -1 & -1 & 1 & -1 \\
\hline 26 & -1 & 0 & 0 & 0 & -1 & 1 & 0 & -1 & -1 & 1 & -1 \\
\hline 27 & 1 & -1 & 1 & -1 & 1 & 1 & -1 & 1 & 1 & 0 & -1 \\
\hline 28 & 1 & -1 & 0 & -1 & 1 & 1 & -1 & 0 & 0 & -1 & 1 \\
\hline 29 & -1 & 1 & 1 & 1 & -1 & 1 & 1 & -1 & -1 & 1 & 1 \\
\hline 30 & 0 & 0 & 1 & 0 & 0 & 1 & -1 & 0 & 0 & 1 & -1 \\
\hline 31 & -1 & 0 & 0 & 0 & -1 & 1 & 1 & -1 & -1 & 1 & 0 \\
\hline 32 & -1 & -1 & -1 & -1 & -1 & -1 & -1 & -1 & -1 & -1 & -1 \\
\hline 33 & 0 & -1 & 0 & -1 & 0 & 0 & -1 & 0 & 0 & 1 & 0 \\
\hline 34 & -1 & -1 & -1 & -1 & 1 & 1 & -1 & 1 & 1 & 1 & -1 \\
\hline 35 & -1 & -1 & -1 & -1 & 1 & 1 & -1 & 1 & 1 & 1 & -1 \\
\hline
\end{tabular}




\begin{tabular}{|c|c|c|c|c|c|c|c|c|c|c|c|}
\hline Linhagens & S110 & S111 & S112 & S113 & S114 & S115 & S116 & S117 & S118 & S119 & S120 \\
\hline 36 & 0 & 0 & 0 & 0 & 0 & 1 & 0 & 0 & 0 & -1 & 1 \\
\hline 37 & -1 & 0 & 1 & -1 & 1 & 1 & -1 & 1 & 0 & 1 & -1 \\
\hline 38 & -1 & 0 & -1 & 1 & -1 & 1 & 1 & 1 & 1 & 1 & -1 \\
\hline 39 & 0 & 0 & 1 & 0 & 0 & 1 & 0 & 0 & -1 & 1 & 0 \\
\hline 40 & 0 & -1 & 0 & -1 & 1 & 1 & 0 & 1 & 1 & 1 & -1 \\
\hline 41 & 0 & 0 & 0 & 0 & 0 & 0 & -1 & 0 & 0 & 1 & 0 \\
\hline 42 & -1 & -1 & 1 & -1 & 1 & 1 & -1 & 1 & 1 & 1 & -1 \\
\hline 43 & 0 & -1 & 0 & -1 & 0 & 1 & -1 & 1 & 1 & 0 & 0 \\
\hline 44 & 0 & -1 & 0 & -1 & 0 & 0 & -1 & 0 & 0 & 1 & 1 \\
\hline 45 & 0 & -1 & 0 & -1 & 0 & 0 & 0 & -1 & -1 & 0 & 0 \\
\hline 46 & 1 & -1 & 1 & -1 & 1 & 1 & -1 & -1 & -1 & 1 & -1 \\
\hline 47 & 1 & -1 & 0 & -1 & 1 & 1 & -1 & 1 & 0 & 1 & -1 \\
\hline 48 & 1 & -1 & -1 & -1 & 0 & 0 & -1 & 0 & 0 & 1 & 0 \\
\hline 49 & -1 & 1 & 1 & -1 & 1 & 1 & -1 & 1 & 1 & 1 & -1 \\
\hline 50 & 0 & -1 & -1 & -1 & 0 & 0 & -1 & 0 & 1 & 1 & -1 \\
\hline 51 & 0 & 0 & 0 & 0 & 0 & 1 & 0 & 0 & 1 & 1 & -1 \\
\hline 52 & -1 & 0 & 0 & 1 & -1 & 1 & 1 & -1 & -1 & 0 & 1 \\
\hline 53 & -1 & -1 & -1 & -1 & -1 & 0 & -1 & -1 & -1 & -1 & 0 \\
\hline 54 & 0 & -1 & -1 & -1 & 1 & 1 & -1 & 1 & 1 & 0 & 0 \\
\hline 55 & -1 & 1 & 1 & 1 & -1 & 1 & 0 & 0 & -1 & 1 & -1 \\
\hline 56 & -1 & 0 & 0 & 0 & -1 & 0 & 0 & -1 & -1 & 1 & -1 \\
\hline 57 & -1 & 0 & 1 & 0 & 1 & 1 & -1 & 1 & 1 & 1 & -1 \\
\hline 58 & 0 & -1 & 0 & -1 & 0 & 0 & -1 & 1 & 0 & 1 & 0 \\
\hline 59 & 0 & 0 & -1 & -1 & -1 & -1 & -1 & -1 & -1 & 1 & -1 \\
\hline 60 & -1 & -1 & -1 & -1 & -1 & -1 & -1 & -1 & 0 & 1 & -1 \\
\hline 61 & 1 & -1 & -1 & 0 & 0 & 1 & 0 & 0 & -1 & 1 & 0 \\
\hline 62 & 1 & -1 & -1 & -1 & 1 & 1 & -1 & 1 & 1 & 1 & 0 \\
\hline 63 & 0 & -1 & -1 & -1 & 0 & 1 & -1 & 1 & 1 & 1 & -1 \\
\hline 64 & 0 & -1 & 0 & -1 & 0 & 0 & -1 & 0 & 0 & -1 & 1 \\
\hline 65 & 0 & -1 & 0 & -1 & 0 & 0 & -1 & 0 & 0 & 1 & 0 \\
\hline 66 & -1 & -1 & -1 & -1 & -1 & -1 & -1 & -1 & -1 & 1 & 0 \\
\hline 67 & -1 & 1 & 1 & -1 & 1 & 1 & -1 & 1 & 1 & 1 & -1 \\
\hline 68 & 0 & -1 & -1 & -1 & 1 & 1 & -1 & 1 & 1 & 1 & -1 \\
\hline
\end{tabular}


Tabela 12: Genótipos das plantas-mãe das linhagens $S_{2}$ de milho - cromossomo 8 .

\begin{tabular}{|c|c|c|c|c|c|c|c|c|c|c|}
\hline Linhagens & S121 & S122 & S123 & $\mathbf{S 1 2 4}$ & S126 & $\mathbf{S 1 2 7}$ & $\mathbf{S 1 2 9}$ & $\mathbf{S 1 3 0}$ & S131 & S132 \\
\hline 1 & $\overline{0}$ & 1 & 1 & 0 & 0 & 1 & 1 & 0 & 1 & 1 \\
\hline 2 & 1 & 0 & 0 & 1 & 1 & $\overline{0}$ & 0 & 1 & 0 & 0 \\
\hline 3 & -1 & 1 & 1 & 0 & 1 & 1 & -1 & $\overline{0}$ & -1 & -1 \\
\hline 4 & -1 & 1 & 1 & -1 & -1 & -1 & -1 & -1 & -1 & -1 \\
\hline 5 & 1 & 1 & 1 & 1 & 1 & 1 & -1 & -1 & 0 & 0 \\
\hline 6 & 0 & 0 & 0 & 0 & -1 & -1 & -1 & 0 & 0 & -1 \\
\hline 7 & -1 & 1 & 1 & -1 & -1 & -1 & -1 & 1 & 0 & 0 \\
\hline 8 & -1 & 1 & 1 & -1 & -1 & 1 & -1 & -1 & -1 & -1 \\
\hline 9 & 0 & 1 & 1 & 0 & -1 & -1 & -1 & -1 & -1 & -1 \\
\hline 10 & 0 & 1 & 1 & -1 & -1 & -1 & -1 & 0 & -1 & -1 \\
\hline 11 & 1 & 1 & 1 & -1 & -1 & 0 & -1 & -1 & -1 & -1 \\
\hline 12 & -1 & -1 & -1 & -1 & -1 & -1 & 0 & -1 & 0 & 0 \\
\hline 13 & 0 & 0 & 0 & 0 & 1 & 1 & -1 & -1 & -1 & -1 \\
\hline 14 & 1 & 0 & 0 & 0 & 1 & 1 & 0 & -1 & 0 & 0 \\
\hline 15 & 1 & -1 & -1 & -1 & -1 & -1 & 0 & 0 & 0 & 0 \\
\hline 16 & -1 & 1 & 1 & 0 & 0 & 1 & 1 & 1 & 1 & 1 \\
\hline 17 & 1 & 0 & 0 & 0 & 0 & 0 & 0 & -1 & -1 & -1 \\
\hline 18 & 1 & 0 & 0 & -1 & -1 & -1 & -1 & -1 & -1 & -1 \\
\hline 19 & 1 & 0 & 0 & 1 & 0 & -1 & -1 & 0 & -1 & -1 \\
\hline 20 & 0 & 0 & 0 & -1 & -1 & -1 & 0 & -1 & -1 & $\overline{-1}$ \\
\hline 21 & -1 & 1 & 1 & 0 & -1 & -1 & 0 & 0 & 0 & 0 \\
\hline 22 & 0 & 0 & 0 & 1 & -1 & 0 & -1 & -1 & -1 & -1 \\
\hline 23 & 1 & -1 & -1 & -1 & -1 & -1 & -1 & 0 & -1 & -1 \\
\hline 24 & -1 & 1 & 1 & 1 & 1 & 1 & 0 & 0 & 0 & 1 \\
\hline 25 & 0 & -1 & -1 & 0 & 0 & 0 & -1 & $\overline{-1}$ & -1 & -1 \\
\hline 26 & 1 & 0 & 0 & -1 & -1 & -1 & -1 & -1 & -1 & -1 \\
\hline 27 & 1 & 0 & 1 & -1 & -1 & 0 & -1 & 1 & -1 & -1 \\
\hline 28 & 0 & -1 & I & 0 & -1 & 0 & -1 & 0 & -1 & -1 \\
\hline 29 & -1 & 1 & 1 & 0 & -1 & 0 & -1 & -1 & -1 & -1 \\
\hline 30 & 1 & 1 & 0 & 0 & -1 & -1 & -1 & -1 & -1 & -1 \\
\hline 31 & 0 & 0 & 1 & -1 & -1 & -1 & 1 & -1 & 1 & 1 \\
\hline 32 & 0 & 1 & 0 & 1 & 0 & 0 & 1 & 1 & 1 & 1 \\
\hline 33 & 1 & 0 & -1 & -1 & -1 & 0 & 0 & 0 & 0 & 0 \\
\hline 34 & -1 & 1 & -1 & -1 & -1 & -1 & -1 & -1 & -1 & -1 \\
\hline 35 & 0 & -1 & -1 & -1 & -1 & -1 & 0 & -1 & 0 & 0 \\
\hline
\end{tabular}




\begin{tabular}{|c|c|c|c|c|c|c|c|c|c|c|}
\hline Linhagens & S121 & S122 & $\mathbf{S 1 2 3}$ & S124 & S126 & $\mathbf{S 1 2 7}$ & $\mathbf{S 1 2 9}$ & $\mathbf{S 1 3 0}$ & S131 & S132 \\
\hline 36 & 0 & 0 & 1 & 0 & -1 & -1 & -1 & 0 & 0 & 0 \\
\hline 37 & -1 & 1 & 1 & 0 & 1 & 1 & 1 & -1 & 1 & 1 \\
\hline 38 & -1 & -1 & -1 & -1 & 1 & -1 & -1 & -1 & -1 & -1 \\
\hline 39 & -1 & 0 & 0 & 0 & 0 & -1 & 0 & 1 & 0 & 0 \\
\hline 40 & 0 & 1 & 1 & 0 & 0 & 0 & -1 & -1 & -1 & -1 \\
\hline 41 & 1 & 1 & 1 & 1 & 1 & 0 & 0 & -1 & 0 & 0 \\
\hline 42 & -1 & 0 & 0 & -1 & 0 & -1 & -1 & -1 & -1 & -1 \\
\hline 43 & 0 & 1 & 1 & -1 & -1 & -1 & -1 & -1 & -1 & -1 \\
\hline 44 & 0 & 1 & 1 & -1 & -1 & -1 & 0 & 0 & 0 & 0 \\
\hline 45 & 0 & 0 & 0 & -1 & -1 & 0 & -1 & 1 & -1 & -1 \\
\hline 46 & -1 & 1 & 1 & -1 & 0 & 0 & 0 & 0 & 0 & 0 \\
\hline 47 & 0 & 1 & 1 & 1 & 1 & -1 & 1 & 0 & 1 & 1 \\
\hline 48 & 1 & -1 & -1 & -1 & -1 & 0 & 0 & -1 & 0 & -1 \\
\hline 49 & 1 & 1 & 1 & 0 & 1 & -1 & -1 & 0 & -1 & -1 \\
\hline 50 & -1 & 1 & 1 & -1 & -1 & -1 & -1 & 0 & 0 & 0 \\
\hline 51 & 0 & 1 & 1 & -1 & -1 & -1 & -1 & -1 & -1 & -1 \\
\hline 52 & -1 & 0 & 0 & 1 & -1 & -1 & 0 & 0 & 0 & 0 \\
\hline 53 & 1 & 1 & 1 & 0 & -1 & 0 & -1 & -1 & -1 & -1 \\
\hline 54 & -1 & 1 & -1 & -1 & -1 & -1 & 1 & -1 & 1 & 1 \\
\hline 55 & -1 & 1 & 1 & 0 & -1 & -1 & -1 & 1 & -1 & -1 \\
\hline 56 & 1 & 0 & 0 & 1 & -1 & -1 & -1 & -1 & -1 & -1 \\
\hline 57 & -1 & 1 & 1 & -1 & 1 & 1 & -1 & -1 & -1 & -1 \\
\hline 58 & 0 & 1 & 1 & 0 & 0 & 0 & -1 & 0 & -1 & -1 \\
\hline 59 & 0 & 0 & 0 & $\overline{-1}$ & -1 & -1 & -1 & -1 & -1 & -1 \\
\hline 60 & 0 & 0 & 0 & 0 & -1 & -1 & -1 & -1 & -1 & -1 \\
\hline 61 & 1 & 1 & 1 & -1 & -1 & 0 & 0 & 0 & 0 & 0 \\
\hline 62 & 0 & 1 & 1 & 0 & 0 & 0 & -1 & 1 & -1 & -1 \\
\hline 63 & 1 & 0 & 0 & -1 & -1 & 0 & -1 & -1 & -1 & 0 \\
\hline 64 & 1 & -1 & -1 & -1 & -1 & -1 & 1 & 1 & 0 & -1 \\
\hline 65 & 1 & -1 & -1 & -1 & -1 & -1 & -1 & -1 & -1 & -1 \\
\hline 66 & -1 & 1 & 1 & -1 & -1 & 0 & 0 & 0 & 0 & 0 \\
\hline 67 & 0 & 1 & 1 & -1 & -1 & 0 & -1 & 0 & -1 & -1 \\
\hline 68 & 0 & 1 & 1 & -1 & 1 & -1 & 0 & -1 & -1 & -1 \\
\hline
\end{tabular}


Tabela 13: Genótipos das plantas-mãe das linhagens $S_{2}$ de milho - cromossomo 9.

\begin{tabular}{|c|c|c|c|c|c|c|c|c|c|c|c|c|c|c|c|c|}
\hline Linhagens & S133 & S134 & S135 & S136 & $\mathbf{S 1 3 7}$ & $\mathbf{S 1 3 8}$ & $\mathbf{S 1 3 9}$ & $\mathrm{S140}$ & S141 & $\mathbf{S 1 4 2}$ & $\mathbf{S 1 4 3}$ & S144 & S145 & S146 & $\mathbf{S 1 4 7}$ & $\mathbf{S 1 4 8}$ \\
\hline 1 & 0 & 0 & 0 & 0 & 0 & 0 & -1 & 0 & 0 & -1 & 1 & 1 & -1 & 0 & -1 & -1 \\
\hline 2 & 0 & -1 & -1 & 0 & $\overline{0}$ & -1 & -1 & -1 & 1 & 0 & 1 & 1 & -1 & 1 & 1 & 1 \\
\hline 3 & -1 & -1 & -1 & 0 & -1 & -1 & 0 & -1 & 0 & -1 & 1 & 1 & -1 & -1 & -1 & -1 \\
\hline 4 & -1 & 0 & 0 & 0 & 1 & -1 & -1 & -1 & 1 & 0 & 1 & 1 & -1 & 0 & 0 & 1 \\
\hline 5 & -1 & -1 & -1 & 0 & 1 & 0 & 0 & $\overline{0}$ & 0 & -1 & 1 & $\overline{1}$ & -1 & -1 & -1 & -1 \\
\hline 6 & 1 & 0 & 0 & 0 & 0 & 0 & -1 & -1 & 1 & -1 & 1 & 1 & -1 & 1 & 0 & 1 \\
\hline 7 & 1 & 1 & 1 & 1 & -1 & 0 & $\overline{0}$ & 1 & 0 & -1 & -1 & 0 & 0 & 0 & -1 & $\overline{0}$ \\
\hline 8 & 1 & 1 & 1 & 1 & -1 & 0 & 0 & -1 & 0 & -1 & 0 & 0 & 0 & -1 & -1 & -1 \\
\hline 9 & 0 & 0 & 0 & 0 & 0 & 0 & 0 & 1 & 0 & 0 & 0 & 1 & -1 & -1 & -1 & -1 \\
\hline 10 & -1 & 1 & 1 & 1 & 1 & 1 & 0 & 0 & 1 & -1 & 1 & 1 & -1 & 1 & -1 & -1 \\
\hline 11 & 0 & -1 & -1 & 0 & -1 & 1 & 1 & 1 & -1 & -1 & 1 & -1 & 1 & -1 & -1 & -1 \\
\hline 12 & 1 & 1 & 1 & 0 & -1 & 0 & -1 & -1 & 1 & -1 & 1 & 1 & -1 & 1 & 1 & 1 \\
\hline 13 & 1 & 1 & 1 & 1 & 1 & 1 & 0 & 0 & 1 & -1 & 0 & $\overline{0}$ & 0 & -1 & -1 & -1 \\
\hline 14 & 1 & 1 & 1 & 1 & 1 & 1 & 1 & -1 & 1 & -1 & 1 & 1 & -1 & 0 & 0 & 0 \\
\hline 15 & 0 & 1 & 0 & 0 & 0 & 1 & 1 & 1 & -1 & -1 & 0 & 0 & 0 & 1 & -1 & -1 \\
\hline 16 & 0 & 0 & 0 & 1 & 0 & 0 & 0 & 0 & 0 & -1 & 1 & 1 & -1 & -1 & -1 & -1 \\
\hline 17 & -1 & -1 & -1 & 0 & 1 & -1 & -1 & -1 & 1 & 1 & 1 & 1 & -1 & -1 & -1 & -1 \\
\hline 18 & 1 & 1 & 1 & 1 & -1 & 1 & 1 & 1 & 0 & -1 & 1 & 1 & -1 & 1 & $\overline{0}$ & 0 \\
\hline 19 & 1 & 1 & 1 & 1 & -1 & 0 & 0 & 0 & 0 & 0 & 0 & 0 & 1 & -1 & -1 & -1 \\
\hline 20 & -1 & -1 & -1 & 0 & -1 & 1 & 1 & 0 & 0 & -1 & 1 & 1 & -1 & 0 & -1 & -1 \\
\hline 21 & 0 & -1 & -1 & 0 & -1 & 1 & 1 & 1 & -1 & -1 & -1 & -1 & 1 & -1 & 1 & 1 \\
\hline 22 & 1 & -1 & -1 & 0 & -1 & 1 & 1 & 1 & -1 & 0 & 1 & 1 & -1 & -1 & -1 & -1 \\
\hline 23 & 0 & -1 & 0 & 0 & 1 & 0 & 0 & 0 & 0 & -1 & 1 & 1 & -1 & 0 & -1 & -1 \\
\hline 24 & -1 & -1 & -1 & 0 & 1 & 1 & 1 & 1 & -1 & -1 & 1 & 1 & -1 & 1 & $\overline{-1}$ & 0 \\
\hline 25 & 1 & -1 & -1 & 0 & 1 & 0 & 0 & 0 & 0 & -1 & 1 & 1 & -1 & 1 & 0 & 0 \\
\hline 26 & 0 & 1 & 1 & 0 & 0 & -1 & -1 & -1 & 1 & -1 & 1 & 1 & -1 & 0 & 0 & -1 \\
\hline 27 & 1 & 1 & 1 & 1 & 0 & 1 & 0 & 0 & 0 & -1 & 0 & 1 & 0 & 1 & 0 & 0 \\
\hline 28 & 0 & 0 & $\overline{0}$ & 0 & -1 & 1 & 1 & 1 & -1 & -1 & 0 & 0 & 0 & 0 & -1 & -1 \\
\hline 29 & 1 & 1 & 1 & 1 & -1 & -1 & -1 & -1 & 1 & -1 & 1 & 1 & 0 & 1 & -1 & -1 \\
\hline 30 & -1 & -1 & -1 & 0 & 0 & -1 & -1 & -1 & 1 & -1 & 1 & 1 & 0 & -1 & -1 & -1 \\
\hline 31 & 1 & 0 & 1 & 1 & 1 & 1 & 0 & -1 & 1 & -1 & 1 & 1 & -1 & -1 & -1 & -1 \\
\hline 32 & -1 & -1 & -1 & 0 & -1 & -1 & -1 & -1 & 1 & -1 & 1 & 1 & -1 & 1 & 1 & -1 \\
\hline 33 & 1 & 0 & 0 & 0 & 0 & 1 & 0 & 1 & -1 & -1 & 0 & 0 & 0 & -1 & 1 & -1 \\
\hline 34 & -1 & -1 & -1 & 1 & 1 & -1 & -1 & -1 & 1 & 0 & -1 & -1 & 1 & 0 & -1 & -1 \\
\hline 35 & 0 & -1 & $\overline{0}$ & 1 & -1 & -1 & -1 & -1 & 1 & -1 & 1 & 1 & -1 & 0 & 0 & -1 \\
\hline
\end{tabular}




\begin{tabular}{|c|c|c|c|c|c|c|c|c|c|c|c|c|c|c|c|c|}
\hline Linhagens & \begin{tabular}{|l|l|} 
S133 \\
\end{tabular} & $\mathbf{S 1 3 4}$ & $\mathbf{S 1 3 5}$ & S136 & $\mathbf{S 1 3 7}$ & S138 & S139 & S140 & S141 & S142 & S143 & S144 & S145 & $\mathbf{S 1 4 6}$ & S147 & $\mathbf{S 1 4 8}$ \\
\hline 36 & 0 & 0 & 0 & 1 & -1 & -1 & -1 & -1 & 1 & -1 & 1 & 1 & -1 & -1 & -1 & -1 \\
\hline 37 & -1 & 0 & 0 & 1 & -1 & 0 & 0 & 0 & 0 & -1 & 1 & 1 & -1 & 0 & -1 & -1 \\
\hline 38 & 1 & -1 & -1 & -1 & 0 & -1 & -1 & -1 & 1 & -1 & 1 & $\mathrm{~T}$ & -1 & 0 & 0 & -1 \\
\hline 39 & 0 & 0 & 0 & -1 & -1 & -1 & -1 & -1 & 1 & -1 & 1 & 1 & -1 & 0 & -1 & -1 \\
\hline 40 & 0 & 0 & 0 & 0 & 1 & -1 & -1 & -1 & 1 & -1 & 1 & 1 & -1 & -1 & -1 & -1 \\
\hline 41 & 0 & 0 & 0 & 0 & 1 & 1 & $\mathrm{I}$ & 1 & -1 & -1 & 1 & 1 & -1 & 0 & -1 & -1 \\
\hline 42 & 1 & 0 & 0 & 1 & 0 & -1 & -1 & -1 & 1 & -1 & 1 & 0 & 0 & -1 & -1 & -1 \\
\hline 43 & 0 & 0 & $\overline{0}$ & 0 & 1 & -1 & -1 & -1 & $\mathrm{~T}$ & 1 & 1 & 1 & -1 & -1 & -1 & -1 \\
\hline 44 & -1 & -1 & -1 & 1 & 1 & 0 & 0 & 0 & 0 & -1 & 1 & 1 & -1 & 1 & -1 & 0 \\
\hline 45 & -1 & 0 & 0 & 0 & -1 & 0 & 0 & -1 & 1 & 0 & 1 & 1 & -1 & 1 & -1 & -1 \\
\hline 46 & -1 & 0 & 0 & 0 & $\overline{0}$ & -1 & -1 & 0 & 0 & 0 & 1 & 1 & -1 & -1 & -1 & -1 \\
\hline 47 & 1 & $\overline{1}$ & 1 & 1 & 1 & -1 & -1 & -1 & 1 & 1 & 1 & 1 & -1 & $T$ & 1 & 1 \\
\hline 48 & -1 & 0 & 0 & 1 & -1 & 1 & 0 & 0 & 0 & -1 & 0 & 0 & -1 & -1 & -1 & -1 \\
\hline 49 & 1 & 1 & 1 & 1 & -1 & 1 & 0 & 1 & -1 & -1 & 0 & 0 & 0 & -1 & -1 & 0 \\
\hline 50 & 0 & 1 & $\overline{0}$ & 1 & -1 & 1 & 1 & 1 & -1 & -1 & -1 & -1 & 1 & -1 & 1 & -1 \\
\hline 51 & 0 & 1 & $\overline{0}$ & 1 & 1 & 0 & -1 & 0 & 0 & 1 & 0 & 0 & 0 & 0 & -1 & 0 \\
\hline 52 & -1 & -1 & -1 & 1 & -1 & 1 & 0 & 1 & -1 & -1 & -1 & -1 & 1 & -1 & -1 & -1 \\
\hline 53 & -1 & 0 & 0 & 1 & -1 & 1 & 0 & $\overline{0}$ & 1 & -1 & 1 & 1 & -1 & 0 & -1 & -1 \\
\hline 54 & 1 & 0 & 0 & 0 & 0 & -1 & -1 & -1 & 1 & -1 & 1 & 1 & -1 & 1 & -1 & -1 \\
\hline 55 & 1 & 1 & 1 & 1 & -1 & -1 & -1 & -1 & 1 & -1 & 1 & 1 & -1 & 0 & -1 & -1 \\
\hline 56 & 1 & 0 & 0 & 0 & 1 & 0 & 0 & 0 & 0 & 0 & 1 & 1 & -1 & 1 & 0 & 0 \\
\hline 57 & 1 & 1 & $T$ & 1 & 1 & -1 & -1 & $\overline{0}$ & 0 & -1 & 0 & $\overline{0}$ & 0 & -1 & -1 & -1 \\
\hline 58 & 0 & 1 & 1 & 1 & 0 & 0 & 0 & 0 & 0 & -1 & 1 & 1 & -1 & 0 & 0 & 0 \\
\hline 59 & 0 & -1 & -1 & $\overline{0}$ & 0 & 0 & $\overline{0}$ & 0 & $\overline{0}$ & -1 & 1 & 1 & -1 & 1 & -1 & -1 \\
\hline 60 & -1 & -1 & -1 & 0 & 1 & 1 & 1 & 1 & -1 & 1 & 1 & 1 & -1 & 1 & -1 & -1 \\
\hline 61 & 1 & 1 & 1 & 1 & 0 & -1 & -1 & -1 & 1 & -1 & 1 & 1 & -1 & 1 & 1 & 1 \\
\hline 62 & 1 & 1 & 0 & 0 & 0 & 0 & 0 & 0 & 1 & 1 & 0 & 0 & 0 & 0 & -1 & -1 \\
\hline 63 & 1 & 1 & 1 & 1 & 1 & 1 & 1 & 1 & -1 & 1 & 0 & 0 & 0 & 1 & 1 & 1 \\
\hline 64 & 1 & 1 & 1 & 1 & -1 & 1 & 1 & 1 & -1 & -1 & -1 & 0 & 0 & 0 & -1 & -1 \\
\hline 65 & 0 & -1 & 0 & 0 & 1 & 1 & 1 & 1 & -1 & -1 & 0 & 0 & -1 & 1 & -1 & -1 \\
\hline 66 & -1 & 1 & -1 & 0 & 1 & -1 & -1 & -1 & 1 & 0 & 1 & 1 & -1 & -1 & -1 & -1 \\
\hline 67 & 1 & 1 & 1 & 0 & 0 & 1 & 1 & 1 & -1 & 0 & 1 & 1 & -1 & 1 & -1 & 0 \\
\hline 68 & 1 & 0 & 0 & 1 & 1 & -1 & -1 & -1 & 1 & 1 & 1 & 1 & -1 & -1 & -1 & -1 \\
\hline
\end{tabular}


Tabela 14: Genótipos das plantas-mãe das linhagens $S_{2}$ de milho - cromossomo 10.

\begin{tabular}{|c|c|c|c|c|c|c|}
\hline Linhagens & S149 & $\mathbf{S 1 5 0}$ & $\mathbf{S 1 5 1}$ & $\mathbf{S 1 5 2}$ & $\mathbf{S 1 5 3}$ & $\mathbf{S 1 5 4}$ \\
\hline 1 & 0 & 0 & 0 & 0 & 0 & 1 \\
\hline 2 & -1 & 0 & 0 & 0 & 1 & 0 \\
\hline 3 & -1 & -1 & -1 & -1 & 0 & 0 \\
\hline 4 & -1 & -1 & -1 & 1 & 1 & 1 \\
\hline 5 & -1 & -1 & -1 & -1 & 1 & 1 \\
\hline 6 & -1 & -1 & -1 & $\overline{0}$ & 0 & 1 \\
\hline 7 & -1 & 0 & -1 & -1 & 1 & 1 \\
\hline 8 & -1 & -1 & -1 & -1 & -1 & 1 \\
\hline 9 & 0 & 1 & -1 & -1 & 0 & 0 \\
\hline 10 & 1 & 1 & 1 & 1 & 1 & 1 \\
\hline 11 & -1 & 0 & -1 & -1 & -1 & 0 \\
\hline 12 & -1 & -1 & -1 & -1 & -1 & 0 \\
\hline 13 & 1 & 1 & 1 & 1 & 1 & 1 \\
\hline 14 & -1 & -1 & -1 & -1 & 0 & 1 \\
\hline 15 & -1 & -1 & -1 & -1 & 0 & 1 \\
\hline 16 & -1 & -1 & -1 & -1 & 1 & 1 \\
\hline 17 & -1 & -1 & -1 & -1 & -1 & 1 \\
\hline 18 & 0 & 0 & 0 & -1 & -1 & -1 \\
\hline 19 & -1 & -1 & -1 & -1 & 1 & 1 \\
\hline 20 & -1 & -1 & 0 & 0 & 0 & 1 \\
\hline 21 & -1 & -1 & -1 & -1 & -1 & 0 \\
\hline 22 & -1 & -1 & -1 & -1 & 0 & 1 \\
\hline 23 & 0 & 1 & 0 & 0 & 1 & 0 \\
\hline 24 & 0 & 1 & -1 & -1 & 0 & 1 \\
\hline 25 & $\overline{0}$ & -1 & -1 & -1 & 1 & -1 \\
\hline 26 & -1 & -1 & -1 & -1 & -1 & 1 \\
\hline 27 & -1 & -1 & -1 & 1 & -1 & 1 \\
\hline 28 & 0 & 0 & 0 & 0 & -1 & 1 \\
\hline 29 & 1 & 1 & 1 & 1 & 0 & 1 \\
\hline 30 & -1 & -1 & -1 & -1 & -1 & 0 \\
\hline 31 & 1 & 1 & 0 & 0 & -1 & 1 \\
\hline 32 & -1 & -1 & -1 & -1 & 0 & 1 \\
\hline 33 & -1 & -1 & -1 & -1 & 0 & 1 \\
\hline 34 & -1 & -1 & -1 & -1 & 1 & 1 \\
\hline 35 & -1 & -1 & -1 & -1 & 0 & -1 \\
\hline
\end{tabular}




\begin{tabular}{|c|c|c|c|c|c|c|}
\hline Linhagens & S149 & S150 & S151 & S152 & S153 & S154 \\
\hline 36 & -1 & -1 & -1 & 0 & 0 & 1 \\
\hline 37 & -1 & -1 & -1 & -1 & 0 & 0 \\
\hline 38 & 0 & 0 & -1 & -1 & -1 & 0 \\
\hline 39 & 0 & 1 & 1 & 1 & -1 & 1 \\
\hline 40 & 0 & 0 & 0 & 0 & -1 & 1 \\
\hline 41 & -1 & -1 & 0 & 0 & 0 & 1 \\
\hline 42 & 0 & 0 & -1 & -1 & 1 & 0 \\
\hline 43 & -1 & -1 & -1 & -1 & 0 & -1 \\
\hline 44 & -1 & -1 & -1 & -1 & 1 & 1 \\
\hline 45 & 0 & 0 & 0 & 0 & 1 & 1 \\
\hline 46 & -1 & -1 & -1 & 0 & 1 & 0 \\
\hline 47 & 1 & 1 & 1 & 1 & 1 & 0 \\
\hline 48 & -1 & -1 & -1 & -1 & 0 & 1 \\
\hline 49 & -1 & -1 & -1 & -1 & -1 & -1 \\
\hline 50 & -1 & -1 & -1 & -1 & -1 & 0 \\
\hline 51 & -1 & -1 & -1 & -1 & -1 & -1 \\
\hline 52 & 0 & 0 & 0 & 0 & 0 & 1 \\
\hline 53 & -1 & -1 & -1 & -1 & -1 & 1 \\
\hline 54 & 1 & 1 & 1 & 0 & 0 & -1 \\
\hline 55 & -1 & -1 & -1 & -1 & 0 & -1 \\
\hline 56 & -1 & -1 & -1 & -1 & 0 & -1 \\
\hline 57 & -1 & -1 & -1 & -1 & 1 & 0 \\
\hline 58 & -1 & -1 & -1 & -1 & 0 & -1 \\
\hline 59 & 0 & 0 & 0 & 1 & 1 & 0 \\
\hline 60 & -1 & -1 & -1 & -1 & 1 & 1 \\
\hline 61 & -1 & -1 & 0 & 0 & -1 & 1 \\
\hline 62 & -1 & -1 & -1 & 1 & 1 & 1 \\
\hline 63 & -1 & -1 & -1 & -1 & 0 & 1 \\
\hline 64 & -1 & -1 & -1 & -1 & 1 & -1 \\
\hline 65 & -1 & -1 & -1 & -1 & 0 & 1 \\
\hline 66 & -1 & 0 & 0 & 0 & 1 & 1 \\
\hline 67 & -1 & 0 & 0 & -1 & 1 & 1 \\
\hline 68 & 0 & -1 & -1 & -1 & 0 & 1 \\
\hline
\end{tabular}


Tabela 15: Genótipos das plantas-mãe das linhagens $S_{2}$ de milho - marcas extras.

\begin{tabular}{|c|c|c|c|c|c|}
\hline Linhagens & $\mathbf{S 1 5 5}$ & $\mathbf{S 1 5 6}$ & S157 & S158 & S159 \\
\hline 1 & -1 & 0 & -1 & 1 & 1 \\
\hline 2 & -1 & 0 & -1 & 0 & 0 \\
\hline 3 & -1 & -1 & -1 & -1 & -1 \\
\hline 4 & 0 & -1 & 0 & 1 & 0 \\
\hline 5 & 0 & 0 & 0 & 1 & 1 \\
\hline 6 & -1 & 0 & 0 & 0 & 0 \\
\hline 7 & 1 & -1 & -1 & -1 & -1 \\
\hline 8 & -1 & -1 & -1 & -1 & -1 \\
\hline 9 & -1 & -1 & -1 & 1 & 1 \\
\hline 10 & 0 & -1 & 0 & 1 & 1 \\
\hline 11 & -1 & 0 & 0 & -1 & -1 \\
\hline 12 & -1 & -1 & -1 & -1 & -1 \\
\hline 13 & -1 & -1 & -1 & -1 & -1 \\
\hline 14 & -1 & -1 & -1 & 1 & 1 \\
\hline 15 & 1 & -1 & 0 & $\overline{1}$ & 1 \\
\hline 16 & 0 & -1 & -1 & -1 & -1 \\
\hline 17 & 0 & -1 & 0 & 0 & 0 \\
\hline 18 & 0 & -1 & 0 & 0 & 0 \\
\hline 19 & 0 & -1 & -1 & -1 & -1 \\
\hline 20 & -1 & -1 & 0 & 0 & 0 \\
\hline 21 & 0 & -1 & -1 & -1 & -1 \\
\hline 22 & 1 & -1 & -1 & 1 & 1 \\
\hline 23 & 0 & -1 & 0 & 1 & 1 \\
\hline 24 & 0 & -1 & -1 & 0 & 0 \\
\hline 25 & -1 & -1 & -1 & 0 & 0 \\
\hline 26 & -1 & 0 & 0 & 0 & 0 \\
\hline 27 & 0 & -1 & 0 & 1 & 1 \\
\hline 28 & -1 & 0 & -1 & 1 & 1 \\
\hline 29 & 0 & 1 & 0 & 1 & 1 \\
\hline 30 & -1 & 0 & 0 & -1 & -1 \\
\hline 31 & 1 & -1 & 0 & 0 & -1 \\
\hline 32 & -1 & 1 & -1 & 0 & 0 \\
\hline 33 & 0 & -1 & 1 & 1 & 0 \\
\hline 34 & 0 & -1 & 1 & 1 & 0 \\
\hline 35 & 0 & -1 & -1 & -1 & -1 \\
\hline
\end{tabular}



Tabela 16: Valores calculados do índice de seleção nos quatro locais avaliados e na média dos locais. Iowa, Slater, Eua, 1996.

\begin{tabular}{|c|c|c|c|c|c|}
\hline & \multicolumn{5}{|c|}{$I i^{\prime}$} \\
\hline $\begin{array}{l}\text { Pares de } \\
\text { linhagens }\end{array}$ & local 1 & local 2 & local 3 & local 4 & média \\
\hline 12 & 0,3761 & 0.6280 & $-0,2365$ & 0,4253 & 0,3261 \\
\hline 13 & 0,0558 & 0.2639 & $-0,4488$ & 0,3455 & 0,5662 \\
\hline 14 & 0,0595 & 0.7105 & 0,1579 & 0.5863 & 0,3499 \\
\hline 15 & 0,8021 & 0.6233 & $-0,4184$ & 0,4766 & 0,7070 \\
\hline 16 & 0,3106 & 0,7154 & 0,0299 & 0,4860 & 0,3687 \\
\hline 17 & 0,0541 & 0.6783 & $-0,1687$ & 0,0837 & 0,1414 \\
\hline 18 & 0.1221 & 0.4347 & 0,2773 & 0,4124 & 0,5472 \\
\hline 19 & 0,3767 & 0,4752 & 0,6547 & 0,6558 & 0,8031 \\
\hline 110 & 0,3115 & 0,4310 & $-0,0348$ & 0,1416 & $-0,0846$ \\
\hline 111 & 0,0559 & 0.3484 & $-0,2298$ & 0.0673 & $-0,0792$ \\
\hline 112 & 0,7554 & 0.7968 & 0,2630 & 0.2308 & 0,1500 \\
\hline 113 & 0,0453 & 0.4212 & $-0,2989$ & 0,1833 & $-0,1537$ \\
\hline 114 & 0,8420 & 0,6951 & $-0,2463$ & 0,3830 & 0,7466 \\
\hline 115 & 0,6167 & 0.5583 & $-0,3332$ & 0,2738 & 0,2794 \\
\hline 116 & 0,2100 & 0.3813 & $-0,2800$ & 0,1364 & $-0,0269$ \\
\hline 117 & 0,1867 & 0.2830 & 0,0873 & 0,4772 & 0,2151 \\
\hline 118 & 0,2897 & 0.4470 & $-0,1623$ & 0,3912 & 0,6298 \\
\hline 119 & 0,7887 & 0.6516 & 0,0938 & 0.3225 & 0,6900 \\
\hline 120 & 0,3385 & 0.4749 & $-0,3527$ & 0,1324 & $-0,1124$ \\
\hline 121 & 0,1655 & 0.7440 & $-0,0942$ & 0.1968 & 0,0872 \\
\hline 122 & 0,3491 & 0.4772 & $-0,3451$ & 0,3749 & 0,3412 \\
\hline 123 & 0,0512 & 0.3988 & $-0,0618$ & 0.5485 & 0,5569 \\
\hline 124 & 0,9068 & 0.7405 & $-0,6251$ & 0,2923 & 0,3071 \\
\hline 125 & 0,1251 & 0.4446 & $-0,1292$ & 0.0982 & $-0,0640$ \\
\hline 126 & 0,0803 & 0.3780 & $-0,0986$ & -0.0254 & $-0,1170$ \\
\hline 127 & 0,0223 & 0.6029 & $-0,2257$ & 0.3109 & 0,2756 \\
\hline 128 & 0,0826 & 0,3940 & -0.3672 & 0,4467 & 0,1597 \\
\hline 129 & 0,2035 & 0.4327 & $-0,5015$ & 0.1526 & $-0,0859$ \\
\hline 130 & 0,0242 & 0.3484 & $-0,1796$ & 0,1987 & $-0,1148$ \\
\hline 131 & 0,8689 & 0.6813 & $-0,2615$ & 0,3315 & 0,0657 \\
\hline 132 & 0,2156 & 0,4112 & 0,0280 & 0,2257 & 0,5798 \\
\hline 133 & 0,1051 & 0,4673 & $-0,1861$ & 0,2403 & 0,1534 \\
\hline 134 & 0,7365 & 0.8041 & 0,2316 & 0,4460 & 0,3626 \\
\hline 135 & 0,3598 & 0.4165 & 0,1588 & 0,2948 & $-0,0997$ \\
\hline 136 & 0,0152 & 0.3792 & $-0,0644$ & 0,3230 & 0,5644 \\
\hline 137 & 0,1597 & 0.3536 & $-0,0065$ & 0,1467 & 0.6218 \\
\hline 138 & 0,0617 & 0.4097 & 0,1882 & 0.2775 & 0,6146 \\
\hline 139 & 0,7468 & 0.7637 & 0,0656 & 0,3901 & 0,6885 \\
\hline 140 & 0,1089 & 0.4019 & $-0,3085$ & 0.4524 & $-0,0418$ \\
\hline 141 & 0.0319 & 0.4249 & -0.1976 & 0.0265 & 0,1422 \\
\hline 142 & 0,0654 & 0.3529 & 0,3036 & 0,2085 & 0,2026 \\
\hline 143 & 0,0700 & 0,3834 & 0,1508 & 0.3164 & 0,3305 \\
\hline
\end{tabular}




\begin{tabular}{|c|c|c|c|c|c|}
\hline $\begin{array}{c}\text { Pares de } \\
\text { linhagens }\end{array}$ & local 1 & local 2 & local 3 & local 4 & média \\
\hline 144 & 0,2242 & 0,4502 & 0,0065 & 0,4050 & 0,2552 \\
\hline 145 & 0,0889 & 0,2987 & $-0,3705$ & 0,2442 & 0,1733 \\
\hline 146 & 0,0691 & 0,2429 & 0,0992 & 0,3121 & 0,6345 \\
\hline 147 & 0,0683 & 0,6737 & 0,3908 & 0,4896 & 0,1946 \\
\hline 148 & 0,1423 & 0.4451 & $-0,4375$ & 0,1979 & 0,1532 \\
\hline 149 & 0,2910 & 0,5249 & $-0,2035$ & 0,0804 & 0,0331 \\
\hline 150 & 0,3336 & 0.5506 & 0,0622 & 0.2804 & $-0,0060$ \\
\hline 151 & 0,7498 & 0,7372 & $-0,0468$ & 0,3711 & 0,2365 \\
\hline 152 & 0,2215 & 0.6132 & 0,2560 & 0,1959 & 0,6914 \\
\hline 153 & 0,0771 & 0.3823 & $-0,1504$ & 0,1719 & 0,2281 \\
\hline 154 & 0,1192 & 0,3434 & 0,1785 & 0.4842 & 0,6671 \\
\hline 155 & 0,1966 & 0.3333 & $-0,1165$ & 0,1271 & 0,1463 \\
\hline 156 & 0,1102 & 0.4561 & 0,0792 & 0,1491 & 0,2318 \\
\hline 157 & 0,0232 & 0.4147 & $-0,4286$ & 0,2051 & $-0,1071$ \\
\hline 158 & 0,7544 & 0,6365 & $-0,4160$ & 0,1388 & 0,0047 \\
\hline 159 & 0,0191 & 0,4412 & $-0,1969$ & 0,2381 & $-0,1785$ \\
\hline 160 & 0,1493 & 0,3780 & 0,3612 & 0,1408 & 0,6851 \\
\hline 161 & 0,2012 & 0.6527 & $-0,3697$ & 0,6920 & 0,1129 \\
\hline 162 & 0,7999 & 0,7941 & 0,4324 & 0,5978 & 0,7948 \\
\hline 163 & 0,4667 & 0.6301 & 0,0708 & 0,1776 & 0,8523 \\
\hline 164 & 0,0158 & 0,5042 & $-0,0990$ & 0,0468 & 0,1845 \\
\hline 165 & 0,1461 & 0.4670 & $-0,1395$ & 0,2316 & $-0,0811$ \\
\hline 166 & 0,0481 & 0,2713 & 0,1196 & 0,1835 & $-0,0671$ \\
\hline 167 & 0,1301 & 0.4704 & $-0,2130$ & 0,1517 & 0,0142 \\
\hline 168 & 0,1238 & 0,3562 & 0,2956 & 0,2563 & 0,2750 \\
\hline 23 & 0,2351 & 0.2974 & $-0,1291$ & 0,2543 & 0,2948 \\
\hline 24 & 0,2280 & 0.4246 & 0,3442 & 0,6454 & 0,0953 \\
\hline 25 & 0,4364 & 0.4334 & $-0,1827$ & 0,2488 & 0,4217 \\
\hline 26 & 0,0627 & 0.2451 & 0,1896 & 0,5767 & 0,1174 \\
\hline 27 & 0,2416 & 0,5501 & 0,0286 & $-0,0062$ & 0,4402 \\
\hline 28 & 0,2841 & 0.3764 & 0,4696 & 0,2372 & 0,3316 \\
\hline 29 & 0,3492 & 0.5125 & 0,6782 & 0,8294 & 0,5416 \\
\hline 210 & 0,0107 & 0.3388 & 0,1500 & 0,1054 & 0,3336 \\
\hline 211 & 0,2618 & 0.2499 & 0,0678 & 0,0430 & 0,2793 \\
\hline 212 & 0,3191 & 0,2783 & 0,3172 & 0,1269 & 0,4193 \\
\hline 213 & 0,2892 & 0.4949 & $-0,0123$ & 0,1482 & 0,2868 \\
\hline 214 & 0,4633 & 0,2940 & 0,0151 & 0,2375 & 0,4214 \\
\hline 215 & 0,4333 & 0,4089 & $-0,2043$ & 0,4081 & 0,1809 \\
\hline 216 & 0,4196 & 0.3776 & 0,0085 & 0,3195 & 0,3422 \\
\hline 217 & 0,3637 & 0.3702 & 0.2184 & 0,1859 & 0,0899 \\
\hline 218 & 0,0473 & 0,0951 & 0,0773 & 0,3660 & 0,3114 \\
\hline 219 & 0,4093 & 0.4370 & 0,1338 & 0,2291 & 0,3972 \\
\hline 220 & 0,0539 & 0.2737 & $-0,2231$ & 0,0728 & 0,2373 \\
\hline 221 & 0,3691 & 0,5222 & 0,0195 & 0,0718 & 0,4009 \\
\hline 222 & 0,0776 & 0.3024 & $-0,2545$ & 0,4376 & 0,1318 \\
\hline
\end{tabular}




\begin{tabular}{|c|c|c|c|c|c|}
\hline $\begin{array}{l}\text { Pares de } \\
\text { linhagens }\end{array}$ & local I & local 2 & local 3 & local 4 & média \\
\hline 223 & 0,2593 & 0,3243 & 0,1008 & 0,7664 & 0,2729 \\
\hline 224 & 0,5107 & 0,4384 & $-0,2080$ & 0,2623 & 0,1284 \\
\hline 225 & 0,2884 & 0,1813 & $-0,1279$ & 0,0685 & 0,2563 \\
\hline 226 & 0,2705 & 0,3207 & 0,0245 & $-0,0027$ & 0,2518 \\
\hline 227 & 0,2818 & 0,4323 & $-0,0466$ & 0,1927 & 0,1026 \\
\hline 228 & 0,3169 & 0,4741 & $-0,3064$ & 0,5863 & 0,0682 \\
\hline 229 & 0,3906 & 0,3872 & $-0,2786$ & 0,1602 & 0,2770 \\
\hline 230 & 0,2343 & 0,2499 & 0,0597 & 0,0737 & 0,2416 \\
\hline 231 & 0,5252 & 0,4912 & 0,0146 & 0,6194 & 0,4091 \\
\hline 232 & 0,3897 & 0,4216 & 0,0010 & 0.1455 & 0,3006 \\
\hline 233 & 0,2999 & 0,4479 & 0,0459 & 0,1157 & 0,0559 \\
\hline 234 & 0,3409 & 0,5522 & 0,2068 & 0,3440 & 0,2125 \\
\hline 235 & 0,1208 & 0,1770 & 0,2708 & 0,1094 & 0,2713 \\
\hline 236 & 0,2353 & 0,3499 & 0,0196 & 0,1262 & 0,2820 \\
\hline 237 & 0,3981 & 0,3070 & 0,1764 & 0,2023 & 0,3532 \\
\hline 238 & 0,2085 & 0,3351 & 0,3720 & 0,0880 & 0,3433 \\
\hline 239 & 0,3631 & 0,5075 & 0,1010 & 0,1864 & 0,3941 \\
\hline 240 & 0,3057 & 0,3450 & 0,0136 & 0,3603 & 0,3058 \\
\hline 241 & 0,2215 & 0,4219 & 0,0079 & $-0,0282$ & 0,0372 \\
\hline 242 & 0,2719 & 0,2783 & 0,3456 & 0,4840 & 0,0856 \\
\hline 243 & 0,2671 & 0,2702 & 0,2978 & 0,3916 & 0,2101 \\
\hline 244 & 0,3566 & 0,2854 & 0,0924 & 0,5521 & 0,0833 \\
\hline 245 & 0,3281 & 0,5491 & $-0,1591$ & 0,3220 & 0,0967 \\
\hline 246 & 0,3387 & 0,5048 & 0,3099 & 0,1915 & 0,3759 \\
\hline 247 & 0,2766 & 0,3757 & 0,4533 & 0,2009 & 0,4324 \\
\hline 248 & 0,2840 & 0,3983 & -0.2765 & 0,1468 & 0,0410 \\
\hline 249 & 0.4567 & 0,2943 & 0,0776 & 0.2752 & 0,3359 \\
\hline 250 & 0,0601 & 0,4442 & 0.0647 & 0,1847 & 0,3930 \\
\hline 251 & 0,3631 & 0,3030 & 0.1183 & 0,3895 & 0,2890 \\
\hline 252 & 0,3506 & 0,5980 & 0.2144 & 0,1924 & 0,4286 \\
\hline 253 & 0,2397 & 0,3485 & 0,1108 & 0,4680 & 0,1268 \\
\hline 254 & 0.3504 & 0,4009 & 0.2137 & 0,6304 & 0,4071 \\
\hline 255 & 0,3514 & 0,1983 & -0.0003 & 0,0889 & 0,0295 \\
\hline 256 & 0,2631 & 0,2040 & 0,1453 & 0,0997 & 0,0143 \\
\hline 257 & 0,2511 & 0,3286 & -0.0744 & 0,1393 & 0,2525 \\
\hline 258 & 0,3613 & 0,1693 & $-0,0589$ & 0,0539 & 0,2806 \\
\hline 259 & 0,1708 & 0,3666 & $-0,0495$ & 0,1198 & 0,1891 \\
\hline 260 & 0,2590 & 0,3207 & 0,3616 & 0,2968 & 0,4017 \\
\hline 261 & 0,3489 & 0,3829 & -0.2132 & 0,7019 & 0,3685 \\
\hline 262 & 0.3931 & 0,6771 & 0,5616 & 0,3940 & 0,5109 \\
\hline 263 & 0,5894 & 0,4516 & 0,1731 & 0,1964 & 0,5260 \\
\hline 264 & 0,2933 & 0,5490 & 0.0694 & $-0,0104$ & 0,1378 \\
\hline 265 & 0,3313 & 0,4205 & 0.0066 & 0,1076 & 0,2788 \\
\hline 266 & 0,2625 & 0,4190 & 0.3396 & 0,2283 & 0,3415 \\
\hline 267 & 0.3254 & 0,2817 & -0.1071 & 0,1032 & 0,3084 \\
\hline
\end{tabular}




\begin{tabular}{|c|c|c|c|c|c|}
\hline $\begin{array}{l}\text { Pares de } \\
\text { linhagens }\end{array}$ & local 1 & local 2 & local 3 & local 4 & média \\
\hline 268 & 0,2791 & 0,2988 & 0,4222 & 0,1137 & 0,1436 \\
\hline 34 & $-0,1653$ & 0,3126 & 0,2652 & 0,3324 & 0,2708 \\
\hline 35 & 0,6869 & 0,3341 & $-0,3291$ & 0,3770 & $-0,0358$ \\
\hline 36 & 0,0664 & 0,3069 & 0,1161 & 0,4961 & 0,2764 \\
\hline 37 & $-0,1908$ & 0,2902 & $-0,0507$ & 0,0804 & 0,6721 \\
\hline 38 & $-0,0311$ & $-0,0588$ & 0,3986 & 0,2567 & 0,0527 \\
\hline 39 & 0,2395 & 0,1578 & 0,7564 & 0,6201 & 0,1039 \\
\hline $3 \quad 10$ & 0,1154 & 0,1008 & 0,0824 & 0,0799 & 0,5526 \\
\hline 311 & $-0,0976$ & $-0,2339$ & $-0,0607$ & 0,1709 & 0,4871 \\
\hline $\begin{array}{ll}3 & 12\end{array}$ & 0,5797 & 0,4755 & 0,3772 & 0,3035 & 0,7318 \\
\hline 313 & $-0,0479$ & 0,0776 & $-0,1219$ & 0,1231 & 0,5262 \\
\hline $\begin{array}{ll}314 \\
\end{array}$ & 0,6985 & 0,3276 & $-0,1527$ & 0,3588 & 0,0518 \\
\hline 315 & 0,4477 & 0,1597 & $-0,2006$ & 0,2581 & 0,2047 \\
\hline 316 & 0,0541 & 0,0064 & $-0,1095$ & 0,1725 & 0,5604 \\
\hline 317 & $-0,1210$ & $-0,1750$ & 0,1946 & 0,2408 & 0,1441 \\
\hline 318 & 0,1319 & $-0,0116$ & $-0,0916$ & 0,2477 & $-0,1257$ \\
\hline 319 & 0,6264 & 0,3157 & 0,1927 & 0,2806 & $-0,0223$ \\
\hline 320 & 0,1664 & 0,0246 & $-0,2057$ & 0,1359 & 0,4714 \\
\hline 321 & 0,0630 & 0,4041 & 0,0606 & 0,0922 & 0,6917 \\
\hline 322 & 0,1763 & 0,0173 & $-0,2801$ & 0,5879 & $-0,0095$ \\
\hline $\begin{array}{ll}323 \\
\end{array}$ & $-0,1106$ & $-0,1424$ & 0,0105 & 0,5014 & $-0,2215$ \\
\hline 324 & 0,7630 & 0,4965 & $-0,4538$ & 0,3869 & 0,2851 \\
\hline 325 & $-0,0353$ & $-0,1233$ & 0,0076 & 0,1016 & 0,5200 \\
\hline 326 & $-0,1816$ & $-0,1399$ & 0,0379 & 0,0827 & 0,4786 \\
\hline 322 & -0.0734 & 0,1809 & $-0,0924$ & 0,1901 & 0,1832 \\
\hline 328 & $-0,1209$ & 0,0058 & $-0,2599$ & 0,3176 & 0,0870 \\
\hline 329 & 0,0470 & $-0,0136$ & $-0,3123$ & 0,2476 & 0,5012 \\
\hline 330 & $-0,1294$ & $-0,2339$ & $-0,0171$ & 0,0941 & 0,4522 \\
\hline 331 & 0,7132 & 0,3680 & $-0,1177$ & 0,4625 & 0,6342 \\
\hline 332 & $-0,0756$ & 0,0397 & 0,0870 & 0,0457 & $-0,1597$ \\
\hline 333 & $-0,1331$ & 0,0332 & $-0,0788$ & 0,1361 & 0,0644 \\
\hline 334 & 0,5242 & 0,4164 & 0,3212 & 0,4810 & 0,2943 \\
\hline 335 & 0,1322 & $-0,0692$ & 0,2732 & 0,0767 & 0,4929 \\
\hline 336 & $-0,1477$ & $-0,0449$ & 0,0108 & 0,1508 & $-0,2039$ \\
\hline 337 & 0,0313 & $-0,0752$ & 0,0915 & 0,1789 & $-0,1238$ \\
\hline 338 & $-0,1925$ & $-0,1525$ & 0,2454 & 0,0544 & $-0,1635$ \\
\hline 339 & 0,6229 & 0,4315 & 0,1642 & 0,3515 & $-0,0463$ \\
\hline 340 & $-0,0518$ & $-0,0896$ & $-0,1581$ & 0,3792 & 0,5280 \\
\hline 341 & $-0,1650$ & 0,0106 & $-0,0903$ & 0,0210 & 0,0563 \\
\hline 342 & $-0,0604$ & $-0,2092$ & 0,4253 & 0,3192 & 0,1047 \\
\hline 343 & $-0,1219$ & $-0,2021$ & 0,2581 & 0,2307 & 0,2517 \\
\hline 344 & $-0,0271$ & 0,0183 & 0,1139 & 0,2089 & 0,1752 \\
\hline 345 & $-0,1247$ & 0,1027 & $-0,2632$ & 0,1164 & 0,1488 \\
\hline 346 & 0,0064 & 0,0769 & 0,1969 & 0,2702 & $-0,0905$ \\
\hline 347 & $-0,0933$ & 0,3293 & 0,5183 & 0,3521 & 0,7276 \\
\hline
\end{tabular}




\begin{tabular}{|c|c|c|c|c|c|}
\hline $\begin{array}{c}\text { Pares de } \\
\text { linhagens }\end{array}$ & local 1 & local 2 & local 3 & local 4 & média \\
\hline 348 & $-0,1905$ & $-0,0446$ & $-0,3679$ & 0,2004 & 0,0764 \\
\hline 349 & 0,0461 & $-0,0118$ & $-0,0395$ & 0,0321 & 0,5825 \\
\hline 350 & 0,1391 & 0,2025 & 0,1771 & 0,2565 & 0,6353 \\
\hline 351 & 0,5866 & 0,2900 & 0,0616 & 0,3936 & 0,5077 \\
\hline 352 & 0,0376 & 0,2364 & 0,3401 & 0,1389 & 0,0103 \\
\hline 353 & $-0,2855$ & $-0,1175$ & $-0,0720$ & 0,3078 & 0,1427 \\
\hline 354 & $-0,0225$ & 0,0083 & 0,2423 & 0,3074 & $-0,0320$ \\
\hline 355 & $-0,0078$ & $-0,2562$ & 0,0116 & 0,0630 & 0,0470 \\
\hline 356 & $-0,0762$ & $-0,1091$ & 0,1865 & 0,1483 & 0,1490 \\
\hline 357 & $-0,1013$ & $-0,1310$ & $-0,2378$ & 0,0704 & 0,4823 \\
\hline 358 & 0,5806 & 0,1772 & $-0,2605$ & 0,2402 & 0,5663 \\
\hline 359 & $-0,2681$ & $-0,0567$ & $-0,0783$ & 0,0699 & 0,4140 \\
\hline 360 & $-0,1129$ & $-0,1399$ & 0,4258 & 0,2685 & $-0,0096$ \\
\hline 361 & $-0,0828$ & 0,2819 & $-0,2494$ & 0,4356 & 0,6425 \\
\hline 362 & 0,6423 & 0,5763 & 0,4984 & 0,5754 & 0,1247 \\
\hline 363 & 0,2011 & 0,3327 & 0,1242 & 0,2056 & 0,1994 \\
\hline 364 & $-0,0823$ & 0,1527 & 0,0083 & 0,0400 & 0,1683 \\
\hline 365 & $-0,0821$ & $-0,0273$ & $-0,0038$ & 0,1279 & 0,4991 \\
\hline 366 & $-0,1274$ & $-0,0371$ & 0,2364 & 0,2712 & 0,5784 \\
\hline 367 & $-0,0815$ & $-0,0229$ & $-0,0494$ & 0,0891 & 0,5558 \\
\hline 368 & $-0,1968$ & $-0,1557$ & 0,3864 & 0,1592 & 0,1802 \\
\hline 45 & 0,6732 & 0,6691 & 0,2672 & 0,6972 & 0,4202 \\
\hline 46 & 0,0990 & 0,2420 & 0,1712 & 0,7088 & 0,0566 \\
\hline 47 & $-0,1899$ & 0,4302 & 0,0864 & 0,4595 & 0,3625 \\
\hline 48 & $-0,1128$ & 0,2599 & 0,6579 & 0,6245 & 0,2681 \\
\hline 49 & 0,2664 & 0,6901 & 0,9351 & 0,7153 & 0,5535 \\
\hline 410 & 0,1146 & 0,4270 & 0,2243 & 0,4438 & 0,2932 \\
\hline $\begin{array}{lll}4 & 11 \\
\end{array}$ & $-0,2380$ & 0,1714 & 0,0856 & 0,5203 & 0,2096 \\
\hline 412 & 0,5935 & 0,6444 & 0,7202 & 0,6472 & 0,4358 \\
\hline 413 & $-0,1120$ & 0,4265 & 0,2937 & 0,5031 & 0,2752 \\
\hline 414 & 0,7117 & 0,4895 & 0,2607 & 0,7060 & 0,4076 \\
\hline 415 & 0,4540 & 0,4404 & 0,1667 & 0,4937 & 0,1104 \\
\hline 416 & $-0,0093$ & 0,3141 & 0,3010 & 0,4262 & 0,2799 \\
\hline 417 & $-0,0143$ & 0,3399 & 0,4937 & 0,6185 & 0,0707 \\
\hline 418 & 0,1114 & 0,3476 & 0,1801 & 0,5115 & 0,2981 \\
\hline 419 & 0,6317 & 0,6522 & 0,4026 & 0,6272 & 0,3933 \\
\hline 420 & 0,1445 & 0,2857 & 0,2116 & 0,5073 & 0,2057 \\
\hline 421 & $-0,0099$ & 0,5683 & 0,3373 & 0,4822 & 0,3788 \\
\hline 422 & 0,1460 & 0,3076 & 0,1925 & 0,8844 & 0,0676 \\
\hline 423 & $-0,2066$ & 0,1936 & 0,3113 & 0,5523 & 0,2188 \\
\hline 424 & 0,7685 & 0,7282 & 0,1618 & 0,6963 & 0,1838 \\
\hline 425 & $-0,0851$ & 0,1436 & 0,3925 & 0,4741 & 0,2112 \\
\hline 426 & $-0,1729$ & 0,1963 & 0,2635 & 0,4366 & 0,2017 \\
\hline 427 & $-0,1545$ & 0,2012 & 0,3122 & 0,5449 & $-0,0098$ \\
\hline 428 & $-0,0133$ & 0,4244 & 0,2258 & 0,4056 & 0,0527 \\
\hline
\end{tabular}




\begin{tabular}{|c|c|c|c|c|c|}
\hline $\begin{array}{c}\text { Pares de } \\
\text { linhagens }\end{array}$ & local 1 & local 2 & local 3 & local 4 & média \\
\hline 429 & $-0,0005$ & 0,2018 & 0,1494 & 0,5944 & 0,2152 \\
\hline 430 & $-0,2398$ & 0,1714 & 0,1636 & 0,4840 & 0,1905 \\
\hline 431 & 0,7117 & 0,5967 & 0,1175 & 0,5344 & 0,3561 \\
\hline $4 \quad 32$ & 0,0668 & 0,3443 & 0,4399 & 0,4352 & 0,2735 \\
\hline $4 \quad 33$ & $-0,1249$ & 0,3435 & 0,3584 & 0,5146 & 0,0000 \\
\hline 434 & 0,5420 & 0,6641 & 0,5550 & 0,7886 & 0,1943 \\
\hline 435 & 0,1520 & 0,3028 & 0,6010 & 0,4780 & 0,2165 \\
\hline 436 & $-0,1374$ & 0,2306 & 0,3489 & 0,5731 & 0,2475 \\
\hline $4 \quad 37$ & $-0,0143$ & 0,2860 & 0,4667 & 0,5481 & 0,3019 \\
\hline 438 & $-0,2204$ & 0,2316 & 0,4780 & 0,4846 & 0,2930 \\
\hline $4 \quad 39$ & 0,6067 & 0,6267 & 0,4747 & 0,7227 & 0,3823 \\
\hline 440 & $-0,1613$ & 0,1938 & 0,1372 & 0,7199 & 0,2351 \\
\hline 441 & $-0,2648$ & 0,2725 & 0,1613 & 0,4085 & $-0,0274$ \\
\hline 442 & $-0,1569$ & 0,1748 & 0,7848 & 0,5358 & 0,0246 \\
\hline 443 & $-0,2175$ & 0,2157 & 0,1934 & 0,4228 & 0,0911 \\
\hline 444 & $-0,0456$ & 0,1624 & 0,3597 & 0,2811 & $-0,0344$ \\
\hline 445 & $-0,0074$ & 0,5867 & 0,2207 & 0,3917 & 0,1369 \\
\hline 446 & $-0,0212$ & 0,6057 & 0,2906 & 0,6381 & 0,3908 \\
\hline 447 & $-0,1892$ & 0,2682 & 0,6769 & 0,6996 & 0,3737 \\
\hline $4 \quad 48$ & $-0,1629$ & 0,2684 & 0,1945 & 0,5313 & $-0,0388$ \\
\hline 449 & 0,0450 & 0,2320 & 0,0327 & 0,3038 & 0,2600 \\
\hline 450 & 0,1390 & 0,6108 & 0,5202 & 0,6233 & 0,3889 \\
\hline 451 & 0,5674 & 0,5089 & 0,2196 & 0,6244 & 0,2383 \\
\hline 452 & $-0,0239$ & 0,4767 & 0,6453 & 0,4743 & 0,3704 \\
\hline 453 & $-0,1740$ & 0,1993 & 0,2968 & 0,5355 & 0,0424 \\
\hline 454 & $-0,0244$ & 0,4767 & 0,5688 & 0,3826 & 0,3808 \\
\hline 455 & $-0,0291$ & 0,1684 & 0,3221 & 0,4445 & $-0,0419$ \\
\hline 456 & $-0,1319$ & 0,1509 & 0,2902 & 0,5257 & $-0,0697$ \\
\hline 457 & $-0,2062$ & 0,2421 & 0,2316 & 0,4893 & 0,2160 \\
\hline 458 & 0,5944 & 0,4066 & 0,0983 & 0,5758 & 0,2695 \\
\hline 459 & $-0,3032$ & 0,2146 & 0,2218 & 0,4340 & 0,1481 \\
\hline 460 & $-0,1574$ & 0,1963 & 0,5774 & 0,6074 & 0,3478 \\
\hline 461 & $-0,0853$ & 0,1427 & 0,1850 & 0,4235 & 0,2968 \\
\hline 462 & 0,6648 & 0,9124 & 0,5917 & 0,8948 & 0,5397 \\
\hline 463 & 0,2848 & 0,4314 & 0,2960 & 0,5665 & 0,4950 \\
\hline 464 & $-0,0174$ & 0,6752 & $-0,3599$ & 0,4347 & 0,1721 \\
\hline 465 & $-0,1021$ & 0,2889 & 0,1217 & 0,5020 & 0,2159 \\
\hline 466 & $-0,1186$ & 0,3958 & 0,3610 & 0,6346 & 0,3301 \\
\hline 467 & $-0,1387$ & 0,1173 & 0,1668 & 0,4605 & 0,2362 \\
\hline 468 & $-0,1707$ & 0,1762 & 0,2381 & 0,5241 & 0,0295 \\
\hline 56 & 0,3302 & 0,4193 & 0,1531 & 0,5203 & 0,4137 \\
\hline 57 & 0,6361 & 0,6321 & $-0,0225$ & 0,0540 & 0,8016 \\
\hline 58 & 0,6919 & 0,3743 & 0,3923 & 0,2885 & 0,2413 \\
\hline 59 & 0,6494 & 0,4848 & 0,6690 & 0,8096 & 0,2403 \\
\hline 510 & 0,3495 & 0,2110 & 0,0484 & 0,0745 & 0,6935 \\
\hline
\end{tabular}




\begin{tabular}{|c|c|c|c|c|c|}
\hline $\begin{array}{c}\text { Pares de } \\
\text { linhagens }\end{array}$ & local 1 & local 2 & local 3 & local 4 & média \\
\hline 511 & 0,6604 & 0,2893 & $-0,0783$ & 0,1477 & 0,6291 \\
\hline 512 & 0,2442 & 0,3168 & 0,3598 & 0,2164 & 0,8419 \\
\hline $\begin{array}{ll}513 \\
\end{array}$ & 0,7011 & 0,5186 & $-0,2209$ & 0,1434 & 0,6734 \\
\hline $\begin{array}{|ll|}5 & 14\end{array}$ & 0,2657 & 0,1057 & $-0,1529$ & 0,0602 & 0,1357 \\
\hline $\begin{array}{ll}5 & 15\end{array}$ & 0,5973 & 0,2295 & $-0,2185$ & 0,2705 & 0,3113 \\
\hline 516 & 0,7978 & 0,3778 & $-0,1273$ & 0,3313 & 0,6863 \\
\hline 517 & 0,7618 & 0,3649 & 0,2232 & 0,3623 & 0,3156 \\
\hline $\begin{array}{ll}518 \\
\end{array}$ & 0,3084 & 0,2059 & $-0,0839$ & 0,2418 & 0,0071 \\
\hline $\begin{array}{lll}5 & 19\end{array}$ & 0,2143 & 0,0529 & 0,1880 & 0,0901 & 0,0417 \\
\hline 520 & 0,3260 & 0,1434 & $-0,1683$ & 0,0044 & 0,6053 \\
\hline 521 & 0,7729 & 0,7759 & 0,0442 & 0,0645 & 0,8273 \\
\hline 522 & 0,3619 & 0,1192 & $-0,2684$ & 0,4013 & 0,0912 \\
\hline 523 & 0,6631 & 0,3582 & $-0,0548$ & 0,6891 & $-0,0330$ \\
\hline 524 & 0,3683 & 0,1796 & $-0,4466$ & 0,1151 & 0,3658 \\
\hline 525 & 0,7018 & 0,3759 & $-0,1400$ & 0,1890 & 0,6671 \\
\hline 526 & 0,6829 & 0,3216 & 0,0407 & 0,1604 & 0,6271 \\
\hline 527 & 0,6674 & 0,5691 & $-0,2078$ & 0,0856 & 0,3318 \\
\hline 528 & 0,7646 & 0,4838 & $-0,3590$ & 0,5356 & 0,2577 \\
\hline 529 & 0,8266 & 0,4078 & $-0,3132$ & 0,3704 & 0,6410 \\
\hline 530 & 0,6423 & 0,2893 & $-0,0342$ & 0,0664 & 0,6051 \\
\hline $\begin{array}{ll}531 \\
\end{array}$ & 0,4866 & 0,2374 & $-0,1115$ & 0,5814 & 0,7412 \\
\hline 532 & 0,7798 & 0,4116 & $-0,0405$ & 0,2030 & 0,0282 \\
\hline 533 & 0,7456 & 0,4369 & $-0,0350$ & 0,0834 & 0,2331 \\
\hline 534 & 0,1748 & 0,2494 & 0,2250 & 0,4127 & 0,3817 \\
\hline 535 & 0,3753 & 0,1120 & 0,2979 & 0,2425 & 0,6334 \\
\hline 536 & 0,6958 & 0,3684 & 0,0297 & 0,3018 & 0,0055 \\
\hline 537 & 0,7868 & 0,3453 & 0,0875 & 0,1973 & 0,0438 \\
\hline 538 & 0,6384 & 0,3513 & 0,2944 & 0,2492 & 0,0608 \\
\hline 539 & 0,1303 & 0,1936 & 0,0071 & 0,2861 & 0,0267 \\
\hline 540 & 0,6954 & 0,3627 & $-0,1492$ & 0,4560 & 0,6590 \\
\hline 541 & 0,6786 & 0,4185 & $-0,0635$ & $-0,0030$ & 0,2216 \\
\hline 542 & 0,6804 & 0,2945 & 0,3267 & 0,4402 & 0,2716 \\
\hline 543 & 0,6902 & 0,3187 & 0,2605 & 0,3277 & 0,3865 \\
\hline 544 & 0,8226 & 0,4159 & 0,1290 & 0,5572 & 0,3197 \\
\hline 545 & 0,7711 & 0,5445 & $-0,2015$ & 0,2737 & 0,3229 \\
\hline 546 & 0,7518 & 0,5407 & 0,1932 & 0,2008 & 0,1141 \\
\hline 547 & 0,6898 & 0,6722 & 0,5254 & 0,4294 & 0,8616 \\
\hline 548 & 0,7242 & 0,3858 & $-0,2969$ & 0,0766 & 0,2315 \\
\hline 549 & 0,8180 & 0,4547 & $-0,0567$ & 0,2168 & 0,7157 \\
\hline 550 & 0,3481 & 0.3329 & 0,0745 & 0,1150 & 0,7519 \\
\hline 551 & 0,1006 & 0,2059 & 0,0654 & 0,4071 & 0,6011 \\
\hline 552 & 0,8016 & 0,5864 & 0,2221 & 0,1040 & 0,1329 \\
\hline 553 & 0,6678 & 0,3267 & $-0,0185$ & 0,4409 & 0,2975 \\
\hline 554 & 0,7770 & 0,4752 & 0,1299 & 0,6835 & 0,0840 \\
\hline $5 \quad 55$ & 0,7523 & 0,2668 & $-0,0052$ & 0,0815 & 0,2196 \\
\hline
\end{tabular}




\begin{tabular}{|c|c|c|c|c|c|}
\hline $\begin{array}{c}\text { Pares de } \\
\text { Linhagens }\end{array}$ & local 1 & local 2 & local 3 & local 4 & média \\
\hline 556 & 0,6831 & 0,3881 & 0,1319 & 0,2430 & 0,3134 \\
\hline 557 & 0,6562 & 0,3530 & $-0,3553$ & 0,2569 & 0,6302 \\
\hline 558 & 0,1876 & 0,0987 & $-0,2497$ & 0,0235 & 0,6813 \\
\hline 559 & 0,6000 & 0,4143 & $-0,0339$ & 0,0798 & 0,5667 \\
\hline 560 & 0,6790 & 0,3216 & 0,3959 & 0,2842 & 0,1610 \\
\hline 561 & 0,7764 & 0,6219 & $-0,2139$ & 0,7456 & 0,7741 \\
\hline 562 & 0,2484 & 0,3835 & 0,4803 & 0,3616 & 0,2093 \\
\hline 563 & 0,9684 & 0,6848 & 0,1517 & 0,1827 & 0,3627 \\
\hline 564 & 0,7453 & 0,6027 & 0,0434 & 0,0188 & 0,3337 \\
\hline 565 & 0,7589 & 0,4086 & $-0,0013$ & 0,0720 & 0,6410 \\
\hline 566 & 0,7201 & 0,4340 & 0,2846 & 0,4180 & 0,7272 \\
\hline 567 & 0,7172 & 0,4101 & $-0,0666$ & 0,1073 & 0,6999 \\
\hline 568 & 0,6890 & 0,2990 & 0,4033 & 0,1326 & 0,3347 \\
\hline 67 & 0,0697 & 0,4359 & $-0,0353$ & 0,4031 & 0,3985 \\
\hline 68 & 0,1686 & 0,2505 & 0,5516 & 0,5950 & 0,2728 \\
\hline 69 & 0,1968 & 0,6094 & 0,8211 & 0,7552 & 0,5361 \\
\hline 610 & $-0,1155$ & 0,3067 & 0,1372 & 0,4182 & 0,3117 \\
\hline 611 & 0,1166 & 0,1630 & 0,0475 & 0,4760 & 0,2306 \\
\hline 612 & 0,2478 & 0,3514 & 0,5514 & 0,5922 & 0,4125 \\
\hline $\begin{array}{lll}6 & 13 \\
\end{array}$ & 0,1752 & 0,4599 & 0,2331 & 0,4804 & 0,2926 \\
\hline 614 & 0,3558 & 0,1764 & 0,1184 & 0,4530 & 0,3650 \\
\hline 615 & 0,2442 & 0,2859 & $-0,0115$ & 0,3946 & 0,1228 \\
\hline $6 \quad 16$ & 0.2577 & 0,3026 & 0,2247 & 0.5298 & 0,3200 \\
\hline 617 & 0,1478 & 0,3360 & 0,4857 & 0,6327 & 0,1150 \\
\hline 618 & $-0,1158$ & 0,1881 & 0,1247 & 0,4895 & 0,3105 \\
\hline $6 \quad 19$ & 0,2798 & 0,4021 & 0,2604 & 0,5437 & 0,4030 \\
\hline 620 & $-0,0767$ & 0,1245 & 0,0053 & 0,4130 & 0,2015 \\
\hline 621 & 0,2766 & 0,5639 & 0,2058 & 0,4217 & 0,4139 \\
\hline 622 & $-0,0158$ & 0,1426 & 0,0587 & 0,5520 & 0,1245 \\
\hline 623 & 0,0944 & 0,2244 & 0,2405 & 0,7555 & 0,2477 \\
\hline 624 & 0,4458 & 0,4612 & 0,0372 & 0,4845 & 0,1590 \\
\hline 625 & 0,1547 & 0,1385 & 0,2600 & 0,4687 & 0,2239 \\
\hline 626 & 0,0679 & 0,1899 & 0,0709 & 0,4351 & 0,2166 \\
\hline 627 & 0,1367 & 0,2807 & 0,2086 & 0,4501 & 0,0340 \\
\hline 628 & 0,2025 & 0,4395 & 0,0548 & 0,6045 & 0,0510 \\
\hline 629 & 0,2796 & 0,2513 & 0,0008 & 0,5542 & 0,2456 \\
\hline 630 & 0,0890 & 0,1630 & 0,1203 & 0,4235 & 0,1921 \\
\hline 631 & 0,3933 & 0,4014 & 0,0621 & 0,7134 & 0,3809 \\
\hline 632 & 0,1767 & 0,3402 & 0,2622 & 0,4541 & 0,2810 \\
\hline 633 & 0,1424 & 0,3408 & 0,2440 & 0,4470 & $-0,0049$ \\
\hline 634 & 0,1360 & 0,4251 & 0,5115 & 0,6627 & 0,2092 \\
\hline 635 & $-0,1994$ & 0,1555 & 0,4367 & 0,5110 & 0,2386 \\
\hline 636 & 0,1479 & 0,2459 & 0,2089 & 0,4755 & 0,2521 \\
\hline 637 & 0,2350 & 0,2730 & 0,3465 & 0,4446 & 0,3128 \\
\hline 638 & 0,0390 & 0,2368 & 0,4282 & 0,5160 & 0,2727 \\
\hline
\end{tabular}




\begin{tabular}{|c|c|c|c|c|c|}
\hline $\begin{array}{c}\text { Pares de } \\
\text { Linhagens }\end{array}$ & local 1 & local 2 & local 3 & local 4 & média \\
\hline 639 & 0,2616 & 0,3928 & 0,3803 & 0,5606 & 0,3401 \\
\hline 640 & 0,1418 & 0,2126 & 0,1149 & 0,5926 & 0,2845 \\
\hline 641 & 0,1014 & 0,3051 & 0.0403 & 0,3488 & $-0,0258$ \\
\hline 642 & 0,1420 & 0,1800 & 0,6339 & 0,4997 & $-0,0061$ \\
\hline 643 & 0,1377 & 0,2150 & 0,3083 & 0,4992 & 0,1861 \\
\hline 644 & 0,2514 & 0,1678 & 0,1528 & 0,5989 & 0,0192 \\
\hline 645 & 0,2110 & 0,5952 & 0,1082 & 0,4687 & 0,1510 \\
\hline 646 & 0,2472 & 0,6118 & 0,3551 & 0,4560 & 0,4067 \\
\hline 647 & 0,1289 & 0,3382 & 0,6033 & 0,6919 & 0,4203 \\
\hline 648 & 0,0979 & 0,2664 & $-0,0081$ & 0,4187 & 0,0116 \\
\hline 649 & 0,2495 & 0,2381 & $-0,0019$ & 0,3954 & 0,3072 \\
\hline 650 & $-0,0919$ & 0,4756 & 0,3612 & 0,4945 & 0,4041 \\
\hline 651 & 0,2142 & 0,2468 & 0,2580 & 0,5554 & 0,2830 \\
\hline 652 & 0,2905 & 0,4925 & 0,5164 & 0,4497 & 0,4134 \\
\hline 653 & 0,0577 & 0,2073 & 0,1976 & 0,4401 & 0,0407 \\
\hline 654 & 0,2341 & 0,4862 & 0,4520 & 0,6806 & 0,4202 \\
\hline 655 & 0,2020 & 0,1548 & 0,1886 & 0,4221 & $-0,0404$ \\
\hline 656 & 0,1295 & 0,1541 & 0,2725 & 0,5248 & $-0,0147$ \\
\hline 657 & 0,1058 & 0,2380 & 0,1710 & 0,4343 & 0,2273 \\
\hline 658 & 0,1952 & 0,1265 & 0,0422 & 0,4646 & 0,2591 \\
\hline 659 & $-0,0143$ & 0,2676 & 0,0651 & 0,3962 & 0,1600 \\
\hline 660 & 0,1064 & 0,1899 & 0,5075 & 0,4395 & 0,3712 \\
\hline 661 & 0,1733 & 0,2380 & 0,0248 & 0,7568 & 0,3354 \\
\hline 662 & 0,3067 & 0,7189 & 0,6156 & 0,6452 & 0,5467 \\
\hline 663 & 0,3995 & 0,4461 & 0,2796 & 0,4144 & 0,5185 \\
\hline 664 & 0,2260 & 0,6512 & 0,2126 & 0,3723 & 0,1952 \\
\hline 665 & 0,1656 & 0,2876 & $-0,1109$ & 0,4361 & 0,2469 \\
\hline 666 & 0,1392 & 0,4125 & 0,3682 & 0,5163 & 0,3320 \\
\hline 667 & 0,1457 & 0,1279 & 0,0669 & 0,4467 & 0,2665 \\
\hline 668 & 0,0576 & 0,1691 & 0,3139 & 0,4831 & 0,1081 \\
\hline 78 & $-0,0555$ & 0,0753 & 0,4502 & $-0,0358$ & 0,6032 \\
\hline 79 & 0,2765 & 0,5896 & 0,7397 & 0,6581 & 0,9260 \\
\hline 710 & 0,0929 & 0,4650 & $-0,0296$ & $-0,3303$ & 0,0194 \\
\hline 711 & $-0,1566$ & 0,1476 & $-0,0753$ & $-0,3705$ & $-0,0866$ \\
\hline 712 & 0,5615 & 0,7040 & 0,4058 & $-0,0691$ & 0,2522 \\
\hline $7 \quad 13$ & $-0,0454$ & 0,3552 & 0,0702 & $-0,2825$ & 0,0238 \\
\hline 714 & 0,6709 & 0,4905 & 0,0616 & 0,0417 & 0,8191 \\
\hline 715 & 0,4229 & 0,2709 & $-0,2350$ & 0,1229 & 0,2789 \\
\hline 716 & $-0,0133$ & 0,2132 & 0,0225 & $-0,0543$ & $-0,0470$ \\
\hline 717 & $-0,0008$ & 0,3168 & 0,2788 & 0,0496 & 0,3382 \\
\hline 718 & 0,0912 & 0,3743 & $-0,0881$ & 0,1160 & 0,7166 \\
\hline 719 & 0,6091 & 0,5488 & 0,1862 & $-0,0426$ & 0,7743 \\
\hline 720 & 0,1326 & 0,3032 & $-0,2142$ & $-0,2287$ & $-0,0349$ \\
\hline 721 & 0,0157 & 0,4178 & $-0,0080$ & $-0,3671$ & 0,0833 \\
\hline 722 & 0,0951 & 0,2851 & $-0,1426$ & 0,2076 & 0,3887 \\
\hline
\end{tabular}




\begin{tabular}{|c|c|c|c|c|c|}
\hline $\begin{array}{c}\text { Pares de } \\
\text { Linhagens }\end{array}$ & local 1 & local 2 & local 3 & local 4 & média \\
\hline 723 & $-0,1701$ & 0,2154 & 0,0532 & 0,4751 & 0,6264 \\
\hline 724 & 0,7453 & 0,7189 & $-0,1534$ & 0,0287 & 0,4142 \\
\hline 725 & $-0,0581$ & 0,1956 & 0,0390 & $-0,2686$ & $-0,0169$ \\
\hline 726 & $-0,1273$ & 0,1715 & $-0,0800$ & $-0,3357$ & $-0,0354$ \\
\hline 727 & $-0,1621$ & 0,2151 & 0,0003 & $-0,1228$ & 0,2739 \\
\hline 728 & $-0,0471$ & 0,3221 & $-0,1641$ & 0,3121 & 0,2614 \\
\hline 729 & 0,0886 & 0,2549 & $-0,2630$ & $-0,0608$ & $-0,0619$ \\
\hline 730 & $-0,1493$ & 0,1476 & $-0,0735$ & $-0,3654$ & $-0,0630$ \\
\hline 731 & 0,6652 & 0,5525 & $-0,2008$ & 0,3336 & 0,0416 \\
\hline 732 & $-0,0655$ & 0,2575 & 0,1501 & $-0,0858$ & 0,6705 \\
\hline 733 & $-0,0601$ & 0,1328 & 0,0476 & $-0,2938$ & 0,2022 \\
\hline 734 & 0,4889 & 0,4793 & 0,2882 & 0,2305 & 0,3844 \\
\hline 735 & 0,1029 & 0,2461 & 0,2791 & $-0,1202$ & $-0,0797$ \\
\hline 736 & $-0,1783$ & 0,2021 & $-0,0167$ & $-0,0460$ & 0,6546 \\
\hline 737 & 0,0014 & 0,1898 & 0,2180 & $-0,2053$ & 0,6898 \\
\hline 738 & $-0,2062$ & 0,2238 & 0,2574 & $-0,1350$ & 0,6876 \\
\hline 739 & 0,5860 & 0,6555 & 0,1845 & 0,1319 & 0,7652 \\
\hline 740 & $-0,1529$ & 0,2164 & $-0,1468$ & 0,1738 & $-0,0523$ \\
\hline 741 & $-0,1600$ & 0,2613 & $-0,0840$ & $-0,4684$ & 0,2164 \\
\hline 742 & $-0,0822$ & 0,1339 & 0,4786 & 0,1296 & 0,2725 \\
\hline 743 & $-0,2368$ & 0,1936 & 0,1517 & 0,0697 & 0,3550 \\
\hline 744 & 0,0205 & 0,1717 & 0,0665 & 0,3059 & 0,2818 \\
\hline 745 & $-0,0118$ & 0,5995 & $-0,0771$ & 0,0054 & 0,3654 \\
\hline 746 & 0,0170 & 0,5957 & 0,2248 & $-(0,1258$ & 0,7847 \\
\hline 747 & $-0,1851$ & 0,4317 & 0,4691 & 0,0969 & 0,1618 \\
\hline 748 & $-0,1349$ & 0,0773 & $-0,2225$ & $-0,1684$ & 0,1888 \\
\hline 749 & 0,0516 & 0,1407 & $-0,1950$ & $-0,0937$ & $-0,0892$ \\
\hline 750 & 0,0901 & 0,3602 & 0,1527 & $-0,1380$ & 0,0695 \\
\hline 751 & 0,5183 & 0,4520 & 0,0449 & 0,2435 & 0,2011 \\
\hline 752 & $-0,0455$ & 0,1539 & 0,3482 & $-0,2159$ & 0,7242 \\
\hline 753 & $-0,2994$ & 0,1562 & 0,0577 & 0,1071 & 0,2785 \\
\hline 754 & $-0,1327$ & 0,4422 & 0,2691 & 0,4355 & 0,7578 \\
\hline 755 & 0,0174 & 0,1328 & $-0,0356$ & $-0,3673$ & 0,2159 \\
\hline 756 & $-0,0972$ & 0,2044 & 0,0497 & $-0,2285$ & 0,2941 \\
\hline 757 & $-0,1219$ & 0,0651 & $-0,0323$ & $-0,0881$ & $-0,0536$ \\
\hline 758 & 0,5679 & 0,4262 & $-0,2081$ & $-0,1974$ & 0,0736 \\
\hline 759 & $-0,2776$ & 0,2812 & $-0,1242$ & $-0,1410$ & $-0,0895$ \\
\hline 760 & $-0,1723$ & 0,1715 & 0,4237 & $-0,0544$ & 0,7520 \\
\hline 761 & $-0,1022$ & 0,3471 & $-0,2396$ & 0,5370 & 0,0160 \\
\hline 762 & 0,6269 & 0,8787 & 0,5339 & 0,3101 & 0,9229 \\
\hline 763 & 0,2373 & 0,3860 & 0,1518 & $-0,1433$ & 0,9126 \\
\hline 764 & $-0,0522$ & 0,4917 & 0,0461 & $-0,4491$ & 0,3417 \\
\hline 765 & $-0,0457$ & 0,1184 & $-0,2032$ & $-0,3134$ & $-0,1004$ \\
\hline 766 & $-0,0953$ & 0,3851 & 0,2255 & 0,0200 & 0,1269 \\
\hline 767 & $-0,0816$ & 0,1901 & $-0,0929$ & $-0,3353$ & $-0,0332$ \\
\hline
\end{tabular}




\begin{tabular}{|c|c|c|c|c|c|}
\hline $\begin{array}{c}\text { Pares de } \\
\text { Linhagens }\end{array}$ & local 1 & local 2 & local 3 & local 4 & média \\
\hline 768 & $-0,1812$ & 0,1344 & 0,2795 & $-0,2695$ & 0,3124 \\
\hline 89 & 0,2986 & 0,3187 & 0,7490 & 0,8145 & 0,3720 \\
\hline $8 \quad 10$ & 0,2151 & 0,1454 & 0,6569 & $-0,0492$ & 0,5101 \\
\hline 811 & $-0,1579$ & $-0,2537$ & 0,4344 & $-0,0085$ & 0,4270 \\
\hline $\begin{array}{lll}8 & 12 \\
\end{array}$ & 0,6458 & 0,5347 & 0,5122 & 0,1853 & 0,6983 \\
\hline $\begin{array}{lll}8 & 13 \\
\end{array}$ & $-0,1540$ & 0,0578 & 0,4789 & $-0,1029$ & 0,4793 \\
\hline 814 & 0,7166 & 0,2612 & 0,3759 & 0,2968 & 0,2589 \\
\hline $8 \quad 15$ & 0,4522 & 0,0298 & 0,3638 & 0,2957 & 0,1953 \\
\hline 816 & 0,0699 & $-0,1035$ & 0,1780 & 0,1090 & 0,5070 \\
\hline 817 & 0,0490 & $-0,0442$ & 0,5172 & 0,0904 & 0,1737 \\
\hline 818 & 0,1760 & 0,1270 & 0,5869 & 0,3012 & 0,1589 \\
\hline 819 & 0,6771 & 0,2959 & 0,4048 & 0,1395 & 0,2184 \\
\hline 820 & 0,1313 & $-0,0552$ & 0,3925 & 0,0216 & 0,4138 \\
\hline 821 & $-0,0920$ & 0,3906 & 0,2867 & $-0,0328$ & 0,6441 \\
\hline 822 & 0,2096 & $-0,0456$ & 0,3591 & 0,4860 & 0,1727 \\
\hline 823 & $-0,0941$ & $-0,1378$ & 0,6868 & 0,5874 & 0,0293 \\
\hline 824 & 0,8063 & 0,5315 & 0,2944 & 0,2393 & 0,3227 \\
\hline 825 & $-0,1448$ & $-0,0814$ & 0,4747 & $-0,0584$ & 0,4631 \\
\hline 826 & $-0,0904$ & $-0,2572$ & 0,2678 & 0,0229 & 0,4181 \\
\hline $\begin{array}{l}827 \\
\end{array}$ & $-0,0901$ & 0,0098 & 0,3407 & 0,0450 & 0,1646 \\
\hline 828 & 0,0974 & 0,0142 & 0,3528 & 0,5507 & 0,0972 \\
\hline 829 & 0,1186 & $-0,1202$ & 0,2439 & 0,1418 & 0,4439 \\
\hline 830 & $-0,1943$ & $-0,2537$ & 0,5365 & $-0,0311$ & 0,3938 \\
\hline 831 & 0,7594 & 0,3075 & 0,5249 & 0,5261 & 0,5816 \\
\hline 832 & 0,1092 & $-0,0382$ & 0,5561 & 0,0822 & 0,0718 \\
\hline 833 & $-0,0063$ & $-0,1720$ & 0,3303 & $-0,0002$ & 0,0406 \\
\hline 834 & 0,5817 & 0,2785 & 0,8047 & 0,3678 & 0,2775 \\
\hline 835 & 0,2331 & $-0,0463$ & 0,3923 & 0,0395 & 0,4360 \\
\hline 836 & $-0,0110$ & $-0,1722$ & 0,4902 & 0,1314 & 0,0454 \\
\hline 837 & 0,0460 & $-0,1166$ & 0,1520 & $-0,0245$ & 0,1079 \\
\hline 838 & $-0,1615$ & $-0,1224$ & 0,7900 & 0,0387 & 0,0798 \\
\hline 839 & 0,6454 & 0,3983 & 0,7075 & 0,2893 & 0,1791 \\
\hline 840 & $-0,0317$ & $-0,1988$ & 0,4510 & 0,2328 & 0,4743 \\
\hline 841 & $-0,1123$ & $-0,0641$ & 0,3857 & $-0,0541$ & 0,0417 \\
\hline 842 & $-0,2084$ & $-0,2317$ & 0,6094 & 0,3575 & 0,0973 \\
\hline 843 & $-0,0398$ & $-0,1322$ & 0,7310 & 0,3080 & 0,2540 \\
\hline 844 & 0,0659 & $-0,0950$ & 0,3307 & 0,5156 & 0,1667 \\
\hline 845 & 0,0386 & 0,3045 & 0,4723 & 0,1849 & 0,2134 \\
\hline 846 & $-0,0451$ & 0,3279 & 0,6274 & 0,1629 & 0,2219 \\
\hline 847 & $-0,0768$ & 0,3021 & 0,4866 & 0,1648 & 0,6761 \\
\hline 848 & 0,0070 & $-0,3392$ & 0,3239 & 0,1388 & 0,0568 \\
\hline 849 & 0,1160 & $-0,0441$ & 0,4979 & 0,1654 & 0,5204 \\
\hline 850 & 0,1912 & 0,1737 & 0,5396 & 0,1492 & 0,5848 \\
\hline 851 & 0,6033 & 0,2632 & 0,6819 & 0,4439 & 0,5415 \\
\hline 852 & 0,0443 & 0,0026 & 0,6072 & $-0,0713$ & 0,1897 \\
\hline
\end{tabular}




\begin{tabular}{|c|c|c|c|c|c|}
\hline $\begin{array}{c}\text { Pares de } \\
\text { Linhagens }\end{array}$ & local 1 & local 2 & local 3 & local 4 & média \\
\hline 853 & $-0,0315$ & $-0,2320$ & 0,5930 & 0,3507 & 0,1417 \\
\hline 854 & 0,1314 & 0,1928 & 0,6748 & 0,6190 & 0,2298 \\
\hline 855 & $-0,1350$ & $-0,2274$ & 0,2888 & $-0,0552$ & 0,0362 \\
\hline 856 & $-0,2094$ & $-0,0581$ & 0,6297 & $-0,0198$ & 0,1402 \\
\hline 857 & $-0,1621$ & $-0,2854$ & 0,4432 & 0,0903 & 0,4180 \\
\hline 858 & 0,6439 & 0,1805 & 0,4314 & 0,1783 & 0,5135 \\
\hline 859 & $-0,1734$ & $-0,0560$ & 0,5044 & 0,0503 & 0,3566 \\
\hline 860 & $-0,1417$ & $-0,2572$ & 0,7565 & 0,2048 & 0,1960 \\
\hline 861 & 0,0894 & 0,2126 & 0,2926 & 0,6484 & 0,5926 \\
\hline 862 & 0,6907 & 0,6454 & 0,7825 & 0,5118 & 0,3805 \\
\hline 863 & 0,3052 & 0,3200 & 0,6143 & 0,1346 & 0,4144 \\
\hline 864 & 0,0911 & 0,2685 & 0,4444 & $-0,0327$ & 0,2074 \\
\hline 865 & 0,0348 & $-0,2654$ & 0,3670 & $-0,0120$ & 0,4309 \\
\hline 866 & 0,0199 & 0,0659 & 0,6818 & 0,2529 & 0,5395 \\
\hline 867 & $-0,0698$ & $-0,1186$ & 0,2970 & $-0,0275$ & 0,4978 \\
\hline 868 & $-0,0368$ & $-0,3065$ & 0,7915 & 0,0415 & 0,1706 \\
\hline 910 & 0,2497 & 0,3324 & 0,8243 & 0,6831 & 0,8030 \\
\hline 911 & 0,2429 & 0,2394 & 0,8190 & 0,6907 & 0,7549 \\
\hline 912 & 0,6249 & 0,6251 & 0,7123 & 0,7982 & 0,9647 \\
\hline $\begin{array}{ll}9 & 13 \\
\end{array}$ & 0,2641 & 0,3570 & 0,8214 & 0,7004 & 0,7698 \\
\hline 914 & 0,6971 & 0,5510 & 0,7923 & 0,7509 & 0,2949 \\
\hline $\begin{array}{ll}9 & 15 \\
\end{array}$ & 0,5112 & 0,4428 & 0,6129 & 0,5461 & 0,4683 \\
\hline 916 & 0,3866 & 0,4157 & 0,6981 & 0,5878 & 0,8290 \\
\hline 917 & 0,2767 & 0,2389 & 0,8469 & 0,8627 & 0,4054 \\
\hline 918 & 0,1944 & 0,2209 & 0,8354 & 0,5470 & 0,2039 \\
\hline $\begin{array}{ll}919 \\
\end{array}$ & 0,6028 & 0,4124 & 0,6796 & 0,7375 & 0,2208 \\
\hline 920 & 0,2640 & 0,3525 & 0,6436 & 0,5970 & 0,7330 \\
\hline 921 & 0,3751 & 0,6016 & 0,6515 & 0,6826 & 0,9305 \\
\hline 922 & 0,3129 & 0,3604 & 0,6452 & 0,9288 & 0,2773 \\
\hline 923 & 0,2605 & 0,3322 & 0,8392 & 0,6458 & 0,1662 \\
\hline 924 & 0,7596 & 0,6500 & 0,6634 & 0,7759 & 0,5159 \\
\hline 925 & 0,3228 & 0,3021 & 0,6644 & 0,6740 & 0,7849 \\
\hline 926 & 0,2322 & 0,3106 & 0,5814 & 0,6549 & 0,7444 \\
\hline 927 & 0,2646 & 0,5341 & 0,5668 & 0,6643 & 0,4728 \\
\hline 928 & 0,3398 & 0,3040 & 0,5818 & 0,5302 & 0,3579 \\
\hline 929 & 0,4088 & 0,4116 & 0,5926 & 0,8172 & 0,7686 \\
\hline 930 & 0,2146 & 0,2394 & 0,8510 & 0,6845 & 0,7243 \\
\hline 931 & 0,6841 & 0,6064 & 0,7908 & 0,6702 & 0,8926 \\
\hline 932 & 0,3837 & 0,4599 & 0,7000 & 0,6707 & 0,2072 \\
\hline 933 & 0,3079 & 0,4150 & 0,7141 & 0,7259 & 0,3679 \\
\hline 934 & 0,5545 & 0,5720 & 0,9034 & 0,9438 & 0,5265 \\
\hline 935 & 0,2653 & 0,2620 & 0,7256 & 0,7774 & 0,7645 \\
\hline 936 & 0,3186 & 0,3824 & 0,7886 & 0,7917 & 0,1552 \\
\hline 937 & 0,3605 & 0,3464 & 0,7240 & 0,7110 & 0,2242 \\
\hline 938 & 0,2471 & 0,3249 & 1,0899 & 0,7610 & 0,1604 \\
\hline
\end{tabular}




\begin{tabular}{|c|c|c|c|c|c|}
\hline $\begin{array}{c}\text { Pares de } \\
\text { Linhagens }\end{array}$ & local 1 & local 2 & local 3 & local 4 & média \\
\hline 939 & 0,6074 & 0,6638 & 0,7659 & 0,8177 & 0,2371 \\
\hline 940 & 0,3095 & 0,3527 & 0,8224 & 0,8945 & 0,7945 \\
\hline 941 & 0,2686 & 0,4541 & 0,7921 & 0,5837 & 0,3647 \\
\hline 942 & 0,2682 & 0,2681 & 0,5741 & 0,7122 & 0,3856 \\
\hline 943 & 0,3066 & 0,2602 & 0,9696 & 0,6383 & 0,5065 \\
\hline 944 & 0,4202 & 0,4315 & 0,6584 & 0,5215 & 0,4768 \\
\hline 945 & 0,3064 & 0,3216 & 0,7406 & 0,5116 & 0,3745 \\
\hline 946 & 0,3063 & 0,2976 & 0,9908 & 0,7698 & 0,1271 \\
\hline 947 & 0,2963 & 0,6927 & 0,7779 & 0,8675 & 0,9805 \\
\hline 948 & 0,3062 & 0,3409 & 0,6398 & 0,6636 & 0,3743 \\
\hline 949 & 0,3791 & 0,3609 & 0,7653 & 0,4729 & 0,8428 \\
\hline 950 & 0,2657 & 0,3044 & 0,5926 & 0,7340 & 0,8611 \\
\hline 951 & 0,5916 & 0,4842 & 0,8889 & 0,6788 & 0,7407 \\
\hline 952 & 0,4625 & 0,5409 & 0,7134 & 0,6909 & 0,3133 \\
\hline 953 & 0,2651 & 0,3386 & 0,9343 & 0,7202 & 0,4085 \\
\hline 954 & 0,4102 & 0,3581 & 0,7081 & 0,5655 & 0,2836 \\
\hline 955 & 0,3298 & 0,1883 & 0,6107 & 0,6704 & 0,3595 \\
\hline 956 & 0,2974 & 0,3240 & 0,7853 & 0,7242 & 0,4356 \\
\hline 957 & 0,2306 & 0,2691 & 0,7353 & 0,7149 & 0,7404 \\
\hline 958 & 0,5839 & 0,4013 & 0,7568 & 0,6881 & 0,8168 \\
\hline 959 & 0,1938 & 0,3918 & 0,8151 & 0,6501 & 0,6857 \\
\hline 960 & 0,3138 & 0,3106 & 0,8075 & 0,7403 & 0,2338 \\
\hline 961 & 0,3808 & 0,6618 & 0.6758 & 0,7333 & 0,9121 \\
\hline 962 & 0,6573 & 0,5927 & 0,9262 & 0,9440 & 0,2537 \\
\hline 963 & 0,5768 & 0,5911 & 0,9002 & 0,6776 & 0,3943 \\
\hline 964 & 0,3359 & 0,2060 & 0,7176 & 0,6062 & 0,3973 \\
\hline 965 & 0,3316 & 0,3625 & 0,6378 & 0,7171 & 0,7582 \\
\hline 966 & 0,3131 & 0,3415 & 1,0421 & 0,8341 & 0,8013 \\
\hline 967 & 0,2691 & 0,4025 & 0,6932 & 0,6869 & 0,8187 \\
\hline 968 & 0,2662 & 0,2887 & 1,0467 & 0,7246 & 0,4586 \\
\hline 1011 & 0,1513 & 0,0726 & 0,0203 & $-0,1872$ & $-0,2408$ \\
\hline 1012 & 0,2429 & 0,4347 & 0,5206 & 0,0012 & 0,1261 \\
\hline $10 \quad 13$ & 0,2062 & 0,1828 & 0,0789 & $-0,3674$ & $-0,1754$ \\
\hline $10 \quad 14$ & 0,4184 & 0,2239 & 0,2055 & 0,0590 & 0,7294 \\
\hline $10 \quad 15$ & 0,3519 & 0,1875 & 0,0119 & 0,1015 & 0,2194 \\
\hline 1016 & 0,3146 & 0,2012 & 0,2019 & $-0,0342$ & $-0,1253$ \\
\hline $10 \quad 17$ & 0,2482 & 0,1202 & 0,4586 & 0,0338 & 0,1859 \\
\hline 1018 & $-0,1399$ & 0,1102 & 0,0071 & 0,1605 & 0,6173 \\
\hline 1019 & 0,3162 & 0,1816 & 0,3850 & $-0,0893$ & 0,6767 \\
\hline 1020 & $-0,0248$ & $-0,0198$ & 0,0045 & $-0,1736$ & $-0,2089$ \\
\hline 1021 & 0,2970 & 0,6256 & 0,2380 & $-0,3492$ & 0,0833 \\
\hline 1022 & $-0,0488$ & 0,0355 & 0,0854 & 0,2759 & 0,3016 \\
\hline 1023 & 0,1287 & 0,1097 & 0,0174 & 0,4582 & 0,5298 \\
\hline 1024 & 0,4666 & 0,4025 & $-0,0048$ & 0,0312 & 0,3153 \\
\hline 1025 & 0,2014 & 0,1860 & 0,1429 & $-0,2810$ & $-0,1545$ \\
\hline
\end{tabular}




\begin{tabular}{|c|c|c|c|c|c|}
\hline $\begin{array}{c}\text { Pares de } \\
\text { Linhagens }\end{array}$ & local 1 & local 2 & local 3 & local 4 & média \\
\hline 1026 & 0,1530 & 0,0969 & 0,1599 & $-0,2713$ & $-0,2213$ \\
\hline 1027 & 0,1716 & 0,2827 & 0,0839 & $-0,0798$ & 0,2085 \\
\hline 1028 & 0,2340 & 0,2036 & $-0,0080$ & 0,3449 & 0,1316 \\
\hline 1029 & 0,3147 & 0,0902 & $-0,0023$ & $-0,0012$ & $-0,2249$ \\
\hline 1030 & 0,1358 & 0,0726 & 0,0221 & $-0,3473$ & $-0,2508$ \\
\hline 1031 & 0,4335 & 0,2700 & $-0,1062$ & 0,3459 & $-0,0420$ \\
\hline 1032 & 0,2867 & 0,2528 & 0,2245 & $-0,1427$ & 0,5705 \\
\hline 1033 & 0,2083 & 0,2519 & 0,2155 & $-0,3238$ & 0,1108 \\
\hline 1034 & 0,2079 & 0,3288 & 0,3442 & 0,2213 & 0,3159 \\
\hline 1035 & $-0,0651$ & 0,0500 & 0,4593 & $-0,1968$ & $-0,2238$ \\
\hline 1036 & 0,1611 & 0,1131 & 0,2632 & $-0,0423$ & 0,5534 \\
\hline 1037 & 0,3042 & 0,1741 & 0,4485 & $-0,2989$ & 0,6019 \\
\hline 1038 & 0,0862 & 0,1627 & 0,3892 & $-0,1959$ & 0,5829 \\
\hline 1039 & 0,2911 & 0,2733 & 0,2064 & 0,1833 & 0,6618 \\
\hline 1040 & 0,1638 & 0,0935 & $-0,0081$ & 0,1518 & $-0,1682$ \\
\hline 1041 & 0,1301 & 0,1888 & 0,1219 & $-0,3621$ & 0,1010 \\
\hline 1042 & 0,1887 & 0,0743 & 0,5417 & 0,0388 & 0,1415 \\
\hline 1043 & 0,1420 & 0,1306 & 0,2843 & 0,0459 & 0,2606 \\
\hline 1044 & 0,2864 & 0,2153 & 0,2785 & 0,3067 & 0,2010 \\
\hline 1045 & 0,2436 & 0,2858 & 0,0630 & $-0,0100$ & 0,1904 \\
\hline 1046 & 0,2636 & 0,3196 & 0,3696 & $-0,0579$ & 0,6550 \\
\hline 1047 & 0,1635 & 0,4692 & 0,6649 & 0,1659 & 0,1243 \\
\hline 1048 & 0,1513 & 0,1608 & 0,0075 & $-0,0760$ & 0,1042 \\
\hline 1049 & 0,3380 & 0,2677 & $-0,1009$ & $-0,1513$ & $-0,0803$ \\
\hline 1050 & $-0,1095$ & 0,2696 & 0,2283 & $-0,1290$ & $-0,0214$ \\
\hline 1051 & 0,2363 & 0,2763 & 0,1410 & 0,2838 & 0,1598 \\
\hline 1052 & 0,2826 & 0,3777 & 0,4514 & $-0,3247$ & 0,6659 \\
\hline 1053 & 0,1101 & 0,0982 & 0,1372 & 0,0546 & 0,1681 \\
\hline 1054 & 0,2232 & 0,2929 & 0,2807 & 0,4285 & 0,6592 \\
\hline 1055 & 0,2816 & 0,0570 & 0,2178 & $-0,4682$ & 0,0889 \\
\hline 1056 & 0,1763 & 0,2021 & 0,1971 & $-0,2003$ & 0,1885 \\
\hline 1057 & 0,1526 & 0,1354 & $-0,0330$ & $-0,1376$ & $-0,1883$ \\
\hline 1058 & 0,2611 & 0,1596 & $-0,1129$ & $-0,0702$ & $-0,0455$ \\
\hline 1059 & 0,0329 & 0,1309 & 0,0416 & $-0,2091$ & $-0,2615$ \\
\hline 1060 & 0,1410 & 0,0969 & 0,4961 & $-0,1008$ & 0,6557 \\
\hline 1061 & 0,2136 & 0,4204 & 0,0441 & 0,5412 & 0,0063 \\
\hline 1062 & 0,3050 & 0,4032 & 0,5668 & 0,3235 & 0,8005 \\
\hline 1063 & 0,4823 & 0,5123 & 0,3462 & $-0,1593$ & 0,8422 \\
\hline 1064 & 0,2106 & 0,4153 & 0,1835 & $-0,3195$ & 0,2140 \\
\hline 1065 & 0,2187 & 0,1973 & 0,0589 & $-0,3373$ & $-0,1871$ \\
\hline 1066 & 0,1503 & 0,1697 & 0,3584 & 0,0336 & $-0,0700$ \\
\hline 1067 & 0,2155 & 0,1971 & 0,1685 & $-0,4274$ & $-0,1274$ \\
\hline 1068 & 0,1303 & 0,0599 & 0,3758 & $-0,2563$ & 0,2020 \\
\hline 1112 & 0,6212 & 0,4199 & 0,4509 & $-0,1324$ & 0,0856 \\
\hline 1113 & $-0,1628$ & 0,0623 & $-0,1605$ & $-0,1901$ & $-0,1961$ \\
\hline
\end{tabular}




\begin{tabular}{|c|c|c|c|c|c|}
\hline $\begin{array}{l}\text { Pares de } \\
\text { Linhagens }\end{array}$ & local 1 & local 2 & local 3 & local 4 & média \\
\hline 1114 & 0,7088 & 0,1875 & $-0,1026$ & 0,1300 & 0,6508 \\
\hline 1115 & 0,4354 & 0,0115 & $-0,0993$ & 0,1741 & 0,1265 \\
\hline 1116 & $-0,0528$ & $-0,1743$ & $-0,0932$ & $-0,0950$ & $-0,2401$ \\
\hline 1117 & $-0,0159$ & $-0,1399$ & 0,3101 & 0,1141 & 0,1310 \\
\hline 1118 & 0,1096 & $-0,0388$ & $-0,0724$ & 0,1691 & 0,5516 \\
\hline 1119 & 0,6287 & 0,2647 & 0,2105 & 0,0164 & 0,6111 \\
\hline 1120 & 0,1426 & $-0,1481$ & $-0,0562$ & $-0,2240$ & $-0,3285$ \\
\hline 1121 & $-0,0513$ & 0,3611 & 0,0503 & $-0,1865$ & 0,0246 \\
\hline 1122 & 0,1630 & $-0,1383$ & $-0,0534$ & 0,2451 & 0,2146 \\
\hline 1123 & $-0,2081$ & $-0,3448$ & 0,0647 & 0,4853 & 0,4498 \\
\hline 1124 & 0,7751 & 0,4471 & $-0,2157$ & 0,0301 & 0,2506 \\
\hline 1125 & $-0,0864$ & $-0,3180$ & 0,1005 & $-0,2626$ & $-0,2634$ \\
\hline 1126 & $-0,1732$ & $-0,3673$ & 0,0281 & $-0,3578$ & $-0,3308$ \\
\hline 1127 & $-0,2056$ & 0,0216 & $-0,0020$ & $-0,0536$ & 0,1219 \\
\hline 1128 & 0,0370 & 0,0068 & $-0,0726$ & 0,3758 & 0,0704 \\
\hline 1129 & 0,0298 & $-0,1905$ & $-0,1513$ & $-0,1258$ & $-0,3422$ \\
\hline 1130 & $-0,3176$ & $-0,5684$ & $-0,2251$ & $-0,1847$ & $-0,3622$ \\
\hline 1131 & 0,7204 & 0,2340 & $-0,1803$ & 0,2700 & $-0,1414$ \\
\hline 1132 & 0,0879 & $-0,1337$ & 0,2034 & 0,0050 & 0,4944 \\
\hline 1133 & $-0,0830$ & $-0,1465$ & 0,0572 & $-0,1287$ & 0,0171 \\
\hline 1134 & 0,5505 & 0,2889 & 0,3850 & 0,2307 & 0,2374 \\
\hline 1135 & 0,1697 & $-0,2303$ & 0,3281 & $-0,0115$ & $-0,3367$ \\
\hline 1136 & $-0,0762$ & $-0,2416$ & 0,1456 & 0,0632 & 0,4746 \\
\hline 1137 & $-0,0581$ & $-0,2663$ & 0,2019 & $-0,1264$ & 0,5207 \\
\hline 1138 & $-0,1775$ & $-0,3587$ & 0,2637 & $-0,0255$ & 0,5041 \\
\hline 1139 & 0,6036 & 0,3021 & 0,2548 & 0,1328 & 0,5856 \\
\hline 1140 & $-0,1622$ & $-0,3041$ & $-0,2334$ & 0,2293 & $-0,2722$ \\
\hline 1141 & $-0,2010$ & $-0,1625$ & $-0,1366$ & $-0,3682$ & 0,0069 \\
\hline 1142 & $-0,2139$ & $-0,4155$ & 0,5431 & 0,2154 & 0,0622 \\
\hline 1143 & $-0,1659$ & $-0,3908$ & 0,1489 & 0,1655 & 0,1768 \\
\hline 1144 & 0,0267 & $-0,1655$ & 0,1196 & 0,3697 & 0,1118 \\
\hline 1145 & 0,0203 & 0,2172 & $-0,0500$ & 0,0620 & 0,1620 \\
\hline 1146 & $-0,0602$ & 0,1978 & 0,1172 & 0,0054 & 0,6046 \\
\hline 1147 & $-0,1908$ & 0,1847 & 0,5202 & 0,0589 & 0,0330 \\
\hline 1148 & $-0,0824$ & $-0,2277$ & $-0,0969$ & $-0,1163$ & 0,0150 \\
\hline 1149 & 0,0123 & $-0,1696$ & $-0,2102$ & $-0,0034$ & $-0,2001$ \\
\hline 1150 & 0,1569 & 0,1651 & 0,2750 & $-0,0125$ & $-0,0670$ \\
\hline 1151 & 0,5652 & 0,1608 & 0,0549 & 0,2437 & 0,0687 \\
\hline 1152 & 0,0368 & 0,0909 & 0,4054 & $-0,1393$ & 0,5850 \\
\hline 1153 & $-0,1121$ & $-0,3005$ & $-0,0855$ & 0,1919 & 0,0841 \\
\hline 1154 & 0,0362 & 0,0030 & 0,3441 & 0,4926 & 0,5987 \\
\hline 1155 & $-0,0668$ & $-0,4737$ & 0,0682 & $-0,2121$ & 0,0044 \\
\hline 1156 & $-0,1331$ & $-0,2921$ & 0,2133 & $-0,2209$ & 0,1023 \\
\hline 1157 & $-0,2740$ & $-0,3298$ & $-0,1623$ & 0,0106 & $-0,2888$ \\
\hline 1158 & 0,6022 & 0,0363 & $-0,2701$ & $-0,2174$ & $-0,1473$ \\
\hline
\end{tabular}




\begin{tabular}{|c|c|c|c|c|c|}
\hline $\begin{array}{c}\text { Pares de } \\
\text { Linhagens }\end{array}$ & local 1 & local 2 & local 3 & local $A$ & média \\
\hline 1159 & $-0,2528$ & $-0,2335$ & $-0,1062$ & $-0,0418$ & $-0,3791$ \\
\hline 1160 & $-0,1198$ & $-0,3673$ & 0,4664 & 0,0392 & 0,5749 \\
\hline 1161 & $-0,0132$ & 0,1398 & $-0,1182$ & 0,5717 & $-0,0878$ \\
\hline 1162 & 0,6825 & 0,5962 & 0,5384 & 0,3895 & 0,7532 \\
\hline 1163 & 0,3042 & 0,3009 & 0,1852 & $-0,0256$ & 0,7740 \\
\hline 1164 & 0,0314 & 0,2088 & 0,0800 & $-0,3451$ & 0,1762 \\
\hline 1165 & $-0,0614$ & $-0,2147$ & $-0,0290$ & $-0,1435$ & $-0,3210$ \\
\hline 1166 & $-0,0477$ & $-0,0276$ & 0,1721 & 0,0587 & $-0,1077$ \\
\hline 1167 & $-0,1960$ & $-0,2176$ & $-0,0835$ & $-0,1851$ & $-0,2598$ \\
\hline 1168 & $-0,1296$ & $-0,3733$ & 0,2192 & $-0,1156$ & 0,1179 \\
\hline 1213 & 0,6649 & 0,6860 & 0,4262 & 0,0074 & 0,1040 \\
\hline 1214 & 0,2763 & 0,1788 & 0,4803 & 0,1995 & 0,8501 \\
\hline 1215 & 0,6164 & 0,4528 & 0,2364 & 0,2969 & 0,4236 \\
\hline 1216 & 0,7644 & 0,5411 & 0,2376 & 0,0991 & 0,1703 \\
\hline $12 \quad 17$ & 0,6945 & 0,5423 & 0,5086 & 0,2543 & 0,3943 \\
\hline 1218 & 0,2770 & 0,1779 & 0,4714 & 0,3267 & 0,7679 \\
\hline 1219 & 0,1915 & 0,3364 & 0,3429 & $-0,0093$ & 0,8341 \\
\hline 1220 & 0,2815 & 0,3514 & 0,2137 & $-0,0942$ & 0,0155 \\
\hline 1221 & 0,7341 & 0,7141 & 0,1431 & 0,0581 & 0,2085 \\
\hline 1222 & 0,3065 & 0,3475 & 0,2992 & 0,3974 & 0,4880 \\
\hline 1223 & 0,6213 & 0,4983 & 0,5142 & 0,6568 & 0,7170 \\
\hline 1224 & 0,2803 & 0,2865 & 0,3009 & 0,0430 & 0,4256 \\
\hline 1225 & 0,6534 & 0,3734 & 0,3291 & $-0,0926$ & 0,0387 \\
\hline 1226 & 0,6253 & 0,4858 & 0,1601 & $-0,1847$ & 0,0603 \\
\hline 1227 & 0,6464 & 0,6368 & 0,2003 & 0,2016 & 0,3890 \\
\hline 1228 & 0,6777 & 0,6559 & 0,2247 & 0,5759 & 0,3419 \\
\hline 1229 & 0,7669 & 0,5721 & 0,2068 & $-0,0216$ & 0,0901 \\
\hline 1230 & 0.5965 & 0,4199 & 0,4083 & 0,0599 & 0,0434 \\
\hline 1231 & 0,4591 & 0,4767 & 0,3870 & 0,3571 & 0,1970 \\
\hline 1232 & 0,7013 & 0,5815 & 0,4612 & 0,1118 & 0,7448 \\
\hline 1233 & 0,6685 & 0,6052 & 0,2571 & 0,1017 & 0,3160 \\
\hline 1234 & 0,0768 & 0,4645 & 0,6312 & 0,1175 & 0,4752 \\
\hline 1235 & 0,3046 & 0,2299 & 0,0583 & 0,0932 & 0,0873 \\
\hline 1236 & 0,5996 & 0,5322 & 0,4317 & 0,2069 & 0,7284 \\
\hline 1237 & 0,7564 & 0,4754 & 0,4298 & 0,0620 & 0,7847 \\
\hline 1238 & 0,5596 & 0,4916 & 0,7167 & 0,0742 & 0,7634 \\
\hline 1239 & 0,1603 & 0,4442 & 0,5362 & 0,0510 & 0,8060 \\
\hline 1240 & 0,6602 & 0,5257 & 0,4129 & 0,3729 & 0,1460 \\
\hline 1241 & 0,5921 & 0,5939 & 0,4356 & $-0,0948$ & 0,3052 \\
\hline 1242 & 0,6441 & 0,4348 & 0,2668 & 0,3736 & 0,3504 \\
\hline 1243 & 0,6266 & 0,4236 & 0,7174 & 0,3695 & 0,4912 \\
\hline 1244 & 0,7235 & 0,4798 & 0,2192 & 0,5189 & 0,3768 \\
\hline 1245 & 0,6939 & 0,7180 & 0,3831 & 0,2600 & 0,4006 \\
\hline 1246 & 0,7063 & 0,6820 & 0,7368 & 0,2616 & 0,8307 \\
\hline 1247 & 0,6293 & 0,6113 & 0,4251 & 0,2462 & 0,2487 \\
\hline
\end{tabular}




\begin{tabular}{|c|c|c|c|c|c|}
\hline $\begin{array}{c}\text { Pares de } \\
\text { Linhagens }\end{array}$ & local 1 & local 2 & local 3 & local 4 & média \\
\hline 1248 & 0,6328 & 0,5516 & 0,2229 & 0,1462 & 0,3268 \\
\hline 1249 & 0,7836 & 0,4630 & 0,4484 & 0,1652 & 0,1670 \\
\hline 1250 & 0,2604 & 0,4937 & 0,2110 & 0,1198 & 0,1992 \\
\hline 1251 & 0,1365 & 0,1860 & 0,5630 & 0,2376 & 0,2939 \\
\hline 1252 & 0,7092 & 0,7488 & 0,3618 & 0,0522 & 0,8546 \\
\hline 1253 & 0,5679 & 0,5005 & 0,5025 & 0,3571 & 0,3896 \\
\hline 1254 & 0,7015 & 0,5824 & 0,3959 & 0,6174 & 0,8473 \\
\hline 1255 & 0,7062 & 0,3619 & 0,1652 & $-0,0146$ & 0,2986 \\
\hline 1256 & 0,6255 & 0,3901 & 0,5942 & $-0,0502$ & 0,3548 \\
\hline 1257 & 0,6198 & 0,4862 & 0,3927 & 0,1140 & 0,0811 \\
\hline 1258 & 0,1342 & 0,0585 & 0,3565 & $-0,2140$ & 0,0175 \\
\hline 1259 & 0,5120 & 0,5517 & 0,3182 & 0,1261 & 0,0180 \\
\hline 1260 & 0,5977 & 0,4858 & 0,6119 & 0,2058 & 0,8446 \\
\hline 1261 & 0,6916 & 0,5941 & 0,2313 & 0,7236 & 0,1733 \\
\hline 1262 & 0,1196 & 0,6166 & 0,8474 & 0,4231 & 0,9459 \\
\hline 1263 & 0,8963 & 0,6537 & 0,6635 & 0,1886 & 0,9841 \\
\hline 1264 & 0,6584 & 0,6940 & 0,2208 & $-0,0754$ & 0,4152 \\
\hline 1265 & 0,6978 & 0,5752 & 0,3805 & 0,0932 & 0,1154 \\
\hline 1266 & 0,6310 & 0,6120 & 0,7310 & 0,1575 & 0,1878 \\
\hline 1267 & 0,6778 & 0,4739 & 0,3614 & 0,0108 & 0,1136 \\
\hline 1268 & 0,6169 & 0,4623 & 0,8010 & 0,1204 & 0,4268 \\
\hline 1314 & 0,7436 & 0,4972 & $-0,0726$ & 0,1279 & 0,6981 \\
\hline $13 \quad 15$ & 0,4803 & 0,2997 & $-0,0326$ & 0,1332 & 0,2098 \\
\hline 1316 & 0,0773 & 0,1949 & $-0,1249$ & $-0,0771$ & $-0,0923$ \\
\hline $13 \quad 17$ & 0,0339 & 0,0888 & 0,3030 & 0,0460 & 0,1642 \\
\hline $13 \quad 18$ & 0,1645 & 0,2735 & 0.0155 & 0,1679 & 0,5900 \\
\hline $13 \quad 19$ & 0,6875 & 0,4443 & 0,3079 & $-(0,0940$ & 0,6439 \\
\hline 1320 & 0,1692 & 0,1810 & $-0,0157$ & $-0,1590$ & $-0,2429$ \\
\hline 1321 & $-0,0548$ & 0,5364 & 0,1135 & $-0,2982$ & 0,0086 \\
\hline 1322 & 0,2308 & 0,2200 & $-0,0340$ & 0,3400 & 0,2809 \\
\hline 1323 & $-0,1294$ & 0,0936 & 0,0506 & 0,4647 & 0,5003 \\
\hline 1324 & 0,8254 & 0,6773 & $-0,2670$ & 0,0895 & 0,2875 \\
\hline 1325 & $-0,1107$ & 0,1880 & $-0,0179$ & $-0,2513$ & $-0,1991$ \\
\hline 1326 & $-0,1067$ & 0,0823 & 0,1450 & $-0,1954$ & $-0,2625$ \\
\hline 1327 & $-0,1266$ & 0,1905 & $-0,0578$ & $-0,0656$ & 0,1866 \\
\hline 1328 & 0,0636 & 0,0359 & $-0,1253$ & 0,3861 & 0,0975 \\
\hline 1329 & 0,0995 & 0,0614 & $-0,1425$ & 0,0167 & $-0,2232$ \\
\hline 1330 & $-0,2033$ & 0,0623 & $-0,0987$ & $-0,2962$ & $-0,2443$ \\
\hline 1331 & 0,7773 & 0,5080 & $-0,0812$ & 0,3728 & $-0,0006$ \\
\hline 1332 & 0,1296 & 0,2471 & 0,1433 & $-0,0836$ & 0,5356 \\
\hline 1333 & $-0,0182$ & 0,1724 & 0,0532 & $-0,2408$ & 0,0810 \\
\hline 1334 & 0,6096 & 0,5077 & 0,3068 & 0,2526 & 0,2616 \\
\hline 1335 & 0,2400 & 0,2053 & 0,3638 & $-0,1305$ & $-0,2035$ \\
\hline 1336 & $-0,0145$ & 0,0930 & 0,1931 & 0,0022 & 0,5153 \\
\hline $13 \quad 37$ & 0,0346 & 0,1707 & 0,2138 & $-0,3053$ & 0,5815 \\
\hline
\end{tabular}




\begin{tabular}{|c|c|c|c|c|c|}
\hline $\begin{array}{c}\text { Pares de } \\
\text { Linhagens }\end{array}$ & local 1 & local 2 & local 3 & local 4 & média \\
\hline 1338 & $-0,1456$ & 0,1558 & 0,3092 & $-0,1498$ & 0,5586 \\
\hline 1339 & 0,6552 & 0,5638 & 0.1736 & 0,1915 & 0,6374 \\
\hline 1340 & $-0,0585$ & 0,0716 & $-0,1823$ & 0,1820 & $-0,1622$ \\
\hline 1341 & $-0,1120$ & 0,1706 & $-0,0246$ & $-0,2918$ & 0,0812 \\
\hline 1342 & $-0,2037$ & 0,0628 & 0,4731 & 0,1281 & 0,1198 \\
\hline 1343 & $-0,0489$ & 0,1294 & 0,2863 & 0,1189 & 0,2561 \\
\hline 1344 & 0,0982 & 0,2079 & 0,2247 & 0,3481 & 0,1929 \\
\hline 1345 & $-0,0023$ & 0,2638 & $-0,0532$ & 0,0067 & 0,1511 \\
\hline 1346 & $-0,0997$ & 0,3064 & 0,2031 & $-0,0131$ & 0,6178 \\
\hline 1347 & $-0,0731$ & 0,4743 & 0,5901 & 0,1645 & 0,1341 \\
\hline 1348 & 0,0016 & 0,0715 & $-0,0889$ & $-0,0060$ & 0,0644 \\
\hline 1349 & 0,1256 & 0,2175 & $-0,0251$ & $-0,0913$ & $-0,0917$ \\
\hline 1350 & 0,2047 & 0,3168 & 0,2146 & $-0,0833$ & $-0,1112$ \\
\hline 1351 & 0,6265 & 0,4853 & 0,1274 & 0,3057 & 0,1447 \\
\hline $13 \quad 52$ & 0,1014 & 0,2403 & 0,3444 & $-0,3021$ & 0,6298 \\
\hline 1353 & $-0,0212$ & 0,0820 & $-0,0618$ & 0,1118 & 0,1514 \\
\hline 1354 & 0,0974 & 0,2885 & 0,2802 & 0,4785 & 0,6384 \\
\hline 1355 & $-0,0521$ & 0,0550 & 0,1290 & $-0,4104$ & 0,0674 \\
\hline 1356 & $-0,1440$ & 0,2038 & 0,2551 & $-0,2186$ & 0,1535 \\
\hline 1357 & $-0,1975$ & 0,0565 & $-0,3468$ & $-0,0929$ & $-0,2887$ \\
\hline 1358 & 0,6538 & 0,4107 & $-0,2253$ & $-0,0277$ & $-0,1065$ \\
\hline 1359 & $-0,1698$ & 0,1123 & $-0,0268$ & $-0,0973$ & $-0,3132$ \\
\hline 1360 & $-0,0756$ & 0,0823 & 0,5000 & $-0,0567$ & 0,6293 \\
\hline 1361 & 0,0874 & 0,4214 & $-0,0946$ & 0.5834 & 0,0323 \\
\hline 1362 & 0,7001 & 0,6554 & 0,5665 & 0,3888 & 0,7616 \\
\hline 1363 & 0,3250 & 0,4567 & 0,2627 & $-0,0939$ & 0,8150 \\
\hline 1364 & 0,0350 & 0,3181 & 0,1269 & $-0,2728$ & 0,1421 \\
\hline 1365 & 0,0106 & 0,1116 & 0,1342 & $-0,2535$ & $-0,2294$ \\
\hline 1366 & $-0,0287$ & 0,1305 & 0,2375 & 0,0765 & $-0,1140$ \\
\hline 1367 & $-0,0691$ & 0,1887 & 0,0054 & $-0,3723$ & $-0,0908$ \\
\hline 1368 & $-0,0438$ & 0,0437 & 0,4002 & $-0,2081$ & 0,1993 \\
\hline 1415 & 0,5827 & 0,1491 & $-0,0869$ & 0,1995 & 0,3310 \\
\hline 1416 & 0,8332 & 0,2636 & $-0,0738$ & 0,3104 & 0,7132 \\
\hline $14 \quad 17$ & 0,7734 & 0,3606 & 0,3237 & 0,3685 & 0,3581 \\
\hline $14 \quad 18$ & 0,3979 & 0,1363 & 0,0639 & 0,2316 & 0,0607 \\
\hline 1419 & 0,2689 & 0,1075 & 0,1940 & 0,0833 & 0,1341 \\
\hline 1420 & 0,3570 & 0,0296 & $-0,0243$ & $-0,0372$ & 0,6154 \\
\hline 1421 & 0,8135 & 0,6658 & 0,1074 & 0,0546 & 0,8392 \\
\hline 1422 & 0,3970 & 0,0389 & $-0,1117$ & 0,3328 & 0,1437 \\
\hline 1423 & 0,7116 & 0,2772 & 0,1764 & 0,6973 & 0,0112 \\
\hline 1424 & 0,3603 & 0,1744 & $-0,2852$ & 0,0321 & 0,3767 \\
\hline 1425 & 0,7265 & 0,2256 & 0,1111 & 0,1236 & 0,6694 \\
\hline 1426 & 0,7051 & 0,2192 & 0,0872 & 0,0971 & 0,6371 \\
\hline 1427 & 0,7063 & 0,4155 & 0,0381 & 0,1067 & 0,3516 \\
\hline 1428 & 0,7570 & 0,4759 & $-0,0975$ & 0,5131 & 0,3079 \\
\hline
\end{tabular}




\begin{tabular}{|c|c|c|c|c|c|}
\hline $\begin{array}{c}\text { Pares de } \\
\text { Linhagens }\end{array}$ & local I & local 2 & local 3 & local 4 & média \\
\hline 1429 & 0,8360 & 0,3053 & $-0,1587$ & 0,3294 & 0,6605 \\
\hline 1430 & 0,6840 & 0,1875 & 0,0243 & 0,0563 & 0,6146 \\
\hline 1431 & 0,5042 & 0,1358 & 0,0326 & 0,5536 & 0,7723 \\
\hline 1432 & 0,7559 & 0,3199 & 0,1561 & 0,2066 & 0,0322 \\
\hline 1433 & 0,7579 & 0,3454 & 0,0678 & 0,1041 & 0,2496 \\
\hline 1434 & 0,2013 & 0,1516 & 0,4503 & 0,3955 & 0,4114 \\
\hline 1435 & 0,4125 & 0,0018 & 0,3674 & 0,2469 & 0,6485 \\
\hline 1436 & 0,6987 & 0,2541 & 0,1160 & 0,2366 & $-0,0354$ \\
\hline 1437 & 0,8157 & 0,2321 & 0,0639 & 0,1053 & 0,0383 \\
\hline 1438 & 0,6714 & 0,2815 & 0,3281 & 0,2310 & $-0,0093$ \\
\hline 1439 & 0,2101 & 0,1356 & 0,2836 & 0,2170 & $-0,0003$ \\
\hline 1440 & 0,7504 & 0,2606 & $-0,0462$ & 0,4374 & 0,6840 \\
\hline 1441 & 0,7105 & 0,3376 & $-0,1086$ & $-0,0446$ & 0,2406 \\
\hline 1442 & 0,7138 & 0,2021 & 0,5432 & 0,3979 & 0,2700 \\
\hline 1443 & 0,7257 & 0,2376 & 0,2945 & 0,3589 & 0,4070 \\
\hline 1444 & 0,8235 & 0,2442 & 0,1335 & 0,5339 & 0,3356 \\
\hline 1445 & 0,7829 & 0,6162 & $-0,0592$ & 0,2322 & 0,3559 \\
\hline 1446 & 0,8028 & 0,6110 & 0,1648 & 0,1298 & 0,1753 \\
\hline 1447 & 0,7379 & 0,4749 & 0,5587 & 0,3655 & 0,8587 \\
\hline 1448 & 0,7433 & 0,2830 & $-0,1391$ & 0,1221 & 0,2546 \\
\hline $14 \quad 49$ & 0,8340 & 0,3146 & 0,0274 & 0,1751 & 0,7288 \\
\hline 1450 & 0,4197 & 0,3304 & 0,3241 & 0,1089 & 0,7889 \\
\hline 1451 & 0,2274 & 0,0284 & 0,2036 & 0,3122 & 0,6213 \\
\hline 1452 & 0,8105 & 0,4949 & 0,4083 & 0,1397 & 0,2062 \\
\hline 1453 & 0,6679 & 0,2339 & $-0,0079$ & 0,3585 & 0,2787 \\
\hline $14 \quad 54$ & 0,8208 & 0,4715 & 0,3944 & 0,6418 & 0,2003 \\
\hline 1455 & 0,7572 & 0,1559 & 0,0956 & 0,0670 & 0,2359 \\
\hline 1456 & 0,7078 & 0,2472 & 0,2875 & 0,2247 & 0,3111 \\
\hline 1457 & 0,6981 & 0,2507 & $-0,0835$ & 0,1936 & 0,6399 \\
\hline 1458 & 0,1874 & $-0,1211$ & $-0,0947$ & 0,0138 & 0,6793 \\
\hline 1459 & 0,6411 & 0,3333 & 0,0233 & 0,0640 & 0,5716 \\
\hline 1460 & 0,7101 & 0,2192 & 0,4823 & 0,1746 & 0,1246 \\
\hline 1461 & 0,8020 & 0,4266 & $-0,1113$ & 0,7372 & 0,7754 \\
\hline 1462 & 0,3119 & 0,5264 & 0,5775 & 0,2842 & 0,3218 \\
\hline 1463 & 0,9704 & 0,5708 & 0,1570 & 0,0827 & 0,3111 \\
\hline $14 \quad 64$ & 0,7656 & 0,6263 & 0,1448 & 0,0079 & 0,3974 \\
\hline 1465 & 0,7780 & 0,3172 & 0,0301 & 0,0929 & 0,6558 \\
\hline 1466 & 0,7606 & 0,4301 & 0,2578 & 0,3181 & 0,7203 \\
\hline 1467 & 0,7461 & 0,2519 & $-0,0786$ & 0,0924 & 0,7081 \\
\hline 1468 & 0,7176 & 0,1848 & 0,3737 & 0,1207 & 0,3618 \\
\hline 1516 & 0,5047 & 0,0920 & $-0,1087$ & 0,0987 & 0,1682 \\
\hline 1517 & 0,4621 & 0,1836 & 0,1800 & 0,4060 & 0,0498 \\
\hline $15 \quad 18$ & 0,3025 & 0,1816 & $-0,1855$ & 0,0884 & 0,2341 \\
\hline 1519 & 0,5666 & 0,1943 & $-0,0144$ & 0,1606 & 0,2791 \\
\hline 1520 & 0,2765 & $-0,0411$ & $-0,4683$ & 0,0142 & 0,1244 \\
\hline
\end{tabular}




\begin{tabular}{|c|c|c|c|c|c|}
\hline $\begin{array}{c}\text { Pares de } \\
\text { Linhagens }\end{array}$ & local 1 & local 2 & local 3 & local 4 & média \\
\hline 1521 & 0,5308 & 0,5532 & $-0,2143$ & 0,1380 & 0,3513 \\
\hline 1522 & 0,3041 & $-0,0869$ & $-0,4231$ & 0,4842 & $-0,0426$ \\
\hline 1523 & 0,4356 & 0,0788 & $-0,0497$ & 0,3834 & 0,1365 \\
\hline 1524 & 0,6879 & 0,3873 & $-0,3482$ & 0,1779 & 0,0491 \\
\hline 1525 & 0,4597 & 0,1369 & $-0,1331$ & 0,1543 & 0,1946 \\
\hline 1526 & 0,4122 & 0,0316 & $-0,2238$ & 0,1594 & 0,1514 \\
\hline 1527 & 0,4399 & 0,2621 & $-0,1828$ & 0,1119 & $-0,0281$ \\
\hline 1528 & 0,5277 & 0,2507 & $-0,4211$ & 0,2955 & $-0,0466$ \\
\hline 1529 & 0,5501 & 0,1369 & $-0,4951$ & 0,3365 & 0,1456 \\
\hline 1530 & 0,4299 & 0,0115 & $-0,1631$ & 0,1398 & 0,1207 \\
\hline 1531 & 0,6267 & 0,1780 & $-0,2481$ & 0,3012 & 0,2423 \\
\hline 1532 & 0,4717 & 0,1157 & $-0,0011$ & 0,1805 & 0,1943 \\
\hline 1533 & 0,4766 & 0,0665 & $-0,0751$ & 0,1793 & $-0,1328$ \\
\hline 1534 & 0,4706 & 0,1509 & 0,2118 & 0,4703 & 0,0444 \\
\hline 1535 & 0,2660 & $-0,0392$ & 0,1071 & 0,2785 & 0,1235 \\
\hline 1536 & 0,5003 & 0,0803 & $-0,2178$ & 0,3187 & 0,1675 \\
\hline 1537 & 0,4977 & 0,0711 & 0,0758 & 0,1214 & 0,1899 \\
\hline 1538 & 0,4181 & 0,0705 & 0,2168 & 0,2757 & 0,2012 \\
\hline 1539 & 0,5789 & 0,2392 & 0,0131 & 0,3396 & 0,2666 \\
\hline 1540 & 0,4592 & 0,0783 & $-0,1668$ & 0,4593 & 0,1497 \\
\hline 1541 & 0,4702 & 0,1180 & $-0,1197$ & 0,0239 & $-0,1138$ \\
\hline 1542 & 0,4480 & 0,0138 & 0,2638 & 0,2772 & $-0,0599$ \\
\hline 1543 & 0,4613 & 0,0642 & 0,1516 & 0,2126 & 0,0152 \\
\hline 1544 & 0,5375 & 0,1405 & $-0,0958$ & 0,2893 & $-0,0281$ \\
\hline 1545 & 0,5191 & 0,4795 & $-0,2495$ & 0,0226 & 0,0643 \\
\hline 1546 & 0,5502 & 0,4761 & 0,2031 & 0,2658 & 0,3229 \\
\hline 1547 & 0,4676 & 0,4513 & 0,3507 & 0,4378 & 0,3920 \\
\hline 1548 & 0,4539 & 0,0338 & $-0,4580$ & 0,1601 & $-0,1767$ \\
\hline 1549 & 0,4786 & 0,1679 & $-0,1880$ & $-0,0138$ & 0,1907 \\
\hline 1550 & 0,3300 & 0,1759 & $-0,0248$ & 0,2484 & 0,2677 \\
\hline 1551 & 0,5108 & 0,1765 & $-0,0426$ & 0,2585 & 0,1715 \\
\hline 1552 & 0,5568 & 0,2091 & 0,1535 & 0,0830 & 0,2472 \\
\hline 1553 & 0,4137 & 0,0333 & $-0,0226$ & 0,2260 & $-0,1029$ \\
\hline 1554 & 0,5664 & 0,3180 & 0,1212 & 0,4382 & 0,2754 \\
\hline 1555 & 0,4530 & 0,0194 & $-0,2723$ & 0,1062 & $-0,1042$ \\
\hline 1556 & 0,4425 & 0,1462 & 0,0461 & 0,2345 & 0,0091 \\
\hline 1557 & 0,4401 & 0,0174 & $-0,1325$ & 0,2065 & 0,1382 \\
\hline 1558 & 0,5293 & 0,1242 & $-0,2644$ & 0,1640 & 0,2219 \\
\hline $15 \quad 59$ & 0,3982 & 0,1487 & $-0,2307$ & 0,0881 & 0,0739 \\
\hline 1560 & 0,4394 & 0,0316 & 0,3168 & 0,1855 & 0,2596 \\
\hline 1561 & 0,4955 & 0,3834 & $-0,3968$ & 0,5332 & 0,2718 \\
\hline 1562 & 0,6417 & 0,5784 & 0,5468 & 0,5335 & 0,4760 \\
\hline 1563 & 0,6513 & 0,4887 & 0,0834 & 0,1525 & 0,4677 \\
\hline 1564 & 0,5743 & 0,4693 & $-0,1135$ & 0,0637 & 0,0765 \\
\hline 1565 & 0,4760 & 0,0506 & $-0,2581$ & 0,1656 & 0,1245 \\
\hline
\end{tabular}




\begin{tabular}{|c|c|c|c|c|c|}
\hline $\begin{array}{l}\text { Pares de } \\
\text { Linhagens }\end{array}$ & local 1 & local 2 & lacal 3 & local 4 & média \\
\hline 1566 & 0,5260 & 0,2514 & 0,2673 & 0,3629 & 0,2476 \\
\hline 1567 & 0,4337 & 0,1378 & -0.2257 & 0,1317 & 0,1997 \\
\hline 1568 & 0,4155 & 0,0131 & 0,3087 & 0,2023 & 0,0004 \\
\hline 1617 & 0,0783 & 0,0253 & 0,1273 & 0,2649 & 0,2181 \\
\hline 1618 & 0,2758 & 0,1780 & 0,0567 & 0,1389 & 0,6105 \\
\hline 1619 & 0,7556 & 0,3850 & 0,1351 & 0,0956 & 0,6707 \\
\hline 1620 & 0,3175 & 0,0088 & $-0,0668$ & $-0,0666$ & $-0,1882$ \\
\hline 1621 & 0,1229 & 0,4878 & $-0,1316$ & 0,0184 & 0,0773 \\
\hline 1622 & 0,3157 & 0,0180 & $-0,1130$ & 0,4971 & 0,2658 \\
\hline 1623 & 0,0090 & $-0,0658$ & 0,1778 & 0,2779 & 0,5087 \\
\hline 1624 & 0,8834 & 0,4948 & $-0,2663$ & 0,2027 & 0,2902 \\
\hline 1625 & 0,1243 & $-0,0219$ & 0,0163 & $-0,0761$ & $-0,1304$ \\
\hline 1626 & $-0,0090$ & $-0,1658$ & $-0,0508$ & $-0,0683$ & $-0,1871$ \\
\hline 1627 & 0,0130 & 0,1562 & $-0,1437$ & 0,0798 & 0,1977 \\
\hline 1628 & 0,1842 & 0,1625 & $-0,1325$ & 0,2817 & 0,1634 \\
\hline 1629 & 0,1634 & $-0,0454$ & $-0,2469$ & 0,1090 & $-0,2332$ \\
\hline 1630 & $-0,0335$ & $-0,1743$ & $-0,0443$ & 0,0202 & $-0,2074$ \\
\hline 1631 & 0,8185 & 0,2513 & $-0,0356$ & 0,1180 & $-0,1644$ \\
\hline 1632 & 0,1481 & $-0,2168$ & 0,1961 & 0,0919 & 0,5466 \\
\hline 1633 & 0,0430 & $-0,0778$ & $-0,1404$ & 0,0729 & 0,0973 \\
\hline 1634 & 0,6773 & 0,4085 & 0,3717 & 0,3866 & 0,2986 \\
\hline 1635 & 0,2824 & $-0,0520$ & 0,1005 & 0,1337 & $-0,2803$ \\
\hline 1636 & 0,1004 & $-0,2184$ & 0,0789 & 0,2458 & 0,5334 \\
\hline 1637 & $-0,0262$ & $-0,2664$ & $-0,0532$ & $-0,0148$ & 0,5683 \\
\hline 1638 & 0,0373 & $-0,0532$ & 0,3166 & 0,1199 & 0,5760 \\
\hline 1639 & 0,7476 & 0,4020 & 0,2664 & 0,3022 & 0,6500 \\
\hline 1640 & 0,0268 & $-0,1136$ & $-0,1534$ & 0,3751 & $-0,2410$ \\
\hline 1641 & 0,0060 & $-0,0958$ & $-0,0638$ & $-0,1083$ & 0,0895 \\
\hline 1642 & 0,0386 & $-0,1546$ & 0,3545 & 0,2104 & 0,1512 \\
\hline 1643 & 0,0200 & $-0,0704$ & 0,2945 & 0,1618 & 0,2300 \\
\hline 1644 & 0,1299 & $-0,1249$ & 0,0409 & 0,2354 & 0,1754 \\
\hline 1645 & 0,1707 & 0,3562 & $-0,0419$ & $-0,0360$ & 0,2373 \\
\hline 1646 & 0,1318 & 0,3276 & 0,2008 & 0,2346 & 0,6653 \\
\hline 1647 & $-0,0477$ & 0,2424 & 0,3330 & 0,2684 & 0,0760 \\
\hline 1648 & 0,0517 & $-0,0787$ & $-0,1574$ & 0,1121 & 0,0799 \\
\hline 1649 & 0,0486 & 0,0786 & 0,0171 & $-0,0881$ & $-0,1483$ \\
\hline 1650 & 0,3045 & 0,2806 & 0,1608 & 0,1768 & $-0,0143$ \\
\hline 1651 & 0,7051 & 0,3466 & 0,1617 & 0,2628 & 0,1226 \\
\hline 1652 & 0,1787 & 0,1540 & 0,2645 & $-0,0649$ & 0,6289 \\
\hline 1653 & 0,0204 & $-0,1445$ & 0,0185 & 0,1881 & 0,1516 \\
\hline 1654 & 0,1528 & 0,1276 & 0,2771 & 0,3861 & 0,6326 \\
\hline 1655 & 0,0915 & $-0,1628$ & $-0,1072$ & $-0,0569$ & 0,0943 \\
\hline 1656 & 0,0848 & 0,0010 & 0,2592 & $-0,0270$ & 0,1895 \\
\hline 1657 & $-0,0043$ & $-0,0925$ & $-0,1371$ & 0,1256 & $-0,1714$ \\
\hline 1658 & 0,7359 & 0,2260 & $-0,1637$ & 0,0627 & $-0,0455$ \\
\hline
\end{tabular}




\begin{tabular}{|c|c|c|c|c|c|}
\hline $\begin{array}{c}\text { Pares de } \\
\text { Linhagens }\end{array}$ & local 1 & local 2 & local 3 & local 4 & média \\
\hline 1659 & $-0,0301$ & 0,0099 & $-0,0307$ & 0,0831 & $-0,2534$ \\
\hline 1660 & 0,0711 & $-0,1658$ & 0,4480 & 0,1536 & 0,6357 \\
\hline 1661 & 0,0663 & 0,2060 & $-0,2163$ & 0,4825 & $-0,0664$ \\
\hline 1662 & 0,8341 & 0,7221 & 0,5510 & 0,5860 & 0,8233 \\
\hline 1663 & 0,3751 & 0,3722 & 0,2162 & 0,1324 & 0,8303 \\
\hline 1664 & 0,2198 & 0,4011 & 0,0015 & $-0,0833$ & 0,2551 \\
\hline 1665 & 0,0741 & $-0,0382$ & 0,0661 & 0,0591 & $-0,2138$ \\
\hline 1666 & 0,1321 & 0,0480 & 0,2483 & 0,2489 & $-0,0318$ \\
\hline 1667 & $-0,0530$ & $-0,0433$ & $-0,1117$ & $-0,0308$ & $-0,1321$ \\
\hline 1668 & 0,0052 & $-0,2091$ & 0,4277 & 0,0830 & 0,1946 \\
\hline $17 \quad 18$ & 0,2282 & 0,1202 & 0,3205 & 0,4121 & 0,2353 \\
\hline 1719 & 0,6913 & 0,3469 & 0,3363 & 0,2319 & 0,2827 \\
\hline 1720 & 0,2613 & 0,0460 & 0,1767 & 0,1369 & 0,1133 \\
\hline 1721 & 0,1439 & 0,4762 & 0,2048 & 0,0566 & 0,3620 \\
\hline 1722 & 0,3039 & 0,0377 & 0,1152 & 0,5354 & 0,0058 \\
\hline 1723 & 0,0020 & $-0,0514$ & 0,4175 & 0,7078 & 0,1472 \\
\hline 1724 & 0,8376 & 0,5291 & 0,1149 & 0,3446 & 0,1334 \\
\hline 1725 & 0,0730 & 0,0162 & 0,3422 & 0,0275 & 0,1646 \\
\hline 1726 & $-0,1350$ & $-0,1334$ & 0,2701 & 0,0614 & 0,1166 \\
\hline 1727 & 0,0338 & 0,2037 & 0,2183 & 0,1756 & 0,0005 \\
\hline 1728 & 0,0617 & 0,0038 & 0.1954 & 0,6186 & $-0,1294$ \\
\hline 1729 & 0,1285 & 0,0026 & 0,0620 & 0,1714 & 0,1423 \\
\hline 1730 & $-0,0469$ & $-0,1399$ & 0,3024 & 0,0585 & 0,0885 \\
\hline 1731 & 0,7890 & 0,3988 & 0,2579 & 0,6374 & 0,2930 \\
\hline 1732 & 0,0128 & 0,0572 & 0,5031 & 0,0716 & 0,1864 \\
\hline 1733 & $-0,0418$ & 0,0484 & 0,1471 & 0,0832 & $-0,1285$ \\
\hline 1734 & 0,6007 & 0,4505 & 0,5060 & 0,3778 & 0,1106 \\
\hline 1735 & 0,2134 & 0,0558 & 0,3995 & 0,0029 & 0,1355 \\
\hline 1736 & 0,0691 & $-0,0308$ & 0,2797 & 0,0998 & 0,1604 \\
\hline 1737 & 0,0517 & 0,0064 & 0,3017 & 0,1105 & 0,2247 \\
\hline 1738 & $-0,0420$ & $-0,0607$ & 0,5039 & 0,0009 & 0,1923 \\
\hline 1739 & 0,7071 & 0,4646 & 0,4912 & 0,3197 & 0,2826 \\
\hline 1740 & 0,0576 & $-0,0802$ & 0,2015 & 0,2639 & 0,1826 \\
\hline 1741 & $-0,0129$ & 0,0233 & 0,2676 & 0,0258 & $-0,1447$ \\
\hline 1742 & 0,0215 & $-0,1175$ & 0,5941 & 0,4273 & $-0,0988$ \\
\hline 1743 & 0,0475 & $-0,0495$ & 0,3959 & 0,3398 & 0,0075 \\
\hline 1744 & 0,0930 & 0,0362 & 0,3403 & 0,5549 & $-0,0101$ \\
\hline 1745 & 0,0076 & 0,1121 & 0,1402 & 0,2731 & $-0,0948$ \\
\hline 1746 & 0,0882 & 0,1647 & 0,3908 & 0,2156 & 0,2418 \\
\hline 1747 & 0,0194 & 0,4001 & 0,4412 & 0,1818 & 0,3535 \\
\hline 1748 & $-0,0526$ & $-0,0306$ & 0,1377 & 0,2136 & $-0,1090$ \\
\hline 1749 & 0,0002 & 0,1188 & 0,3177 & 0,2396 & 0,2471 \\
\hline 1750 & 0,2538 & 0,2771 & 0,4387 & 0,2305 & 0,2947 \\
\hline 1751 & 0,6716 & 0,3888 & 0,2765 & 0,4766 & 0,2023 \\
\hline 1752 & 0,2108 & 0,2616 & 0,5376 & 0,0730 & 0,3165 \\
\hline
\end{tabular}




\begin{tabular}{|c|c|c|c|c|c|}
\hline $\begin{array}{c}\text { Pares de } \\
\text { Linhagens }\end{array}$ & local 1 & local 2 & local 3 & local 4 & média \\
\hline 1753 & $-0,0770$ & $-0,1088$ & 0,3576 & 0,4242 & $-0,0377$ \\
\hline 1754 & 0,1654 & 0,1555 & 0,5300 & 0,6340 & 0,2971 \\
\hline 1755 & 0,0143 & $-0,1068$ & 0,1849 & 0,0311 & $-0,1704$ \\
\hline 1756 & 0,0343 & 0,0314 & 0,3696 & 0,0322 & $-0,0926$ \\
\hline 1757 & $-0,0191$ & $-0,0446$ & 0,2409 & 0,0705 & 0,1290 \\
\hline 1758 & 0,6563 & 0,2774 & 0,1870 & 0,2507 & 0,2263 \\
\hline 1759 & $-0,1103$ & 0,0282 & 0,2719 & 0,0803 & 0,0569 \\
\hline 1760 & 0,0270 & $-0,1334$ & 0,5271 & 0,2351 & 0,2522 \\
\hline 1761 & 0,0409 & 0,3087 & 0,1228 & 0,6880 & 0,3111 \\
\hline 1762 & 0,7471 & 0,6095 & 0,6199 & 0,5027 & 0,3846 \\
\hline 1763 & 0,2359 & 0,3576 & 0,3297 & 0,1609 & 0,4461 \\
\hline 1764 & 0,1287 & 0,2746 & 0,2517 & 0,0444 & $-0,0019$ \\
\hline 1765 & 0,0063 & $-0,0148$ & 0,3514 & 0,0753 & 0,1514 \\
\hline 1766 & 0,0545 & $-0,0482$ & 0,4214 & 0,2215 & 0,2036 \\
\hline 1767 & $-0,0695$ & $-0,0082$ & 0,1762 & 0,0295 & 0,1832 \\
\hline 1768 & $-0,1022$ & $-0,1470$ & 0,5861 & 0,0669 & $-0,1120$ \\
\hline 1819 & 0,2933 & 0,1758 & 0,2483 & 0,1976 & $-0,0470$ \\
\hline 1820 & $-0,0661$ & 0,0494 & $-0,1124$ & 0,0194 & 0,5303 \\
\hline 1821 & 0,2577 & 0,3963 & 0,0922 & 0,1298 & 0,7243 \\
\hline 1822 & $-0,0528$ & 0,0431 & $-0,1228$ & 0,5529 & 0,0118 \\
\hline 1823 & 0,1056 & 0,0437 & $-0,1262$ & 0,4028 & $-0,1654$ \\
\hline 1824 & 0,4618 & 0,3150 & $-0,1846$ & 0,2808 & 0,2874 \\
\hline 1825 & 0,1804 & $-0,0966$ & 0,1377 & 0,2100 & 0,5782 \\
\hline 1826 & 0,1315 & 0,0823 & 0,0774 & 0,2091 & 0,5482 \\
\hline 1827 & 0,1306 & 0,2763 & $-0,0295$ & 0,0598 & 0,2413 \\
\hline 1828 & 0,2474 & 0,2464 & $-0,1083$ & 0,2313 & 0,1796 \\
\hline 1829 & 0,3098 & 0,1671 & $-0,1424$ & 0,4127 & 0,5621 \\
\hline $18 \quad 30$ & 0,0948 & $-0,0388$ & $-0,1600$ & 0,1317 & 0,5232 \\
\hline 1831 & 0,4296 & 0,2976 & $-0,3019$ & 0,3794 & 0,6840 \\
\hline 1832 & 0,2849 & 0,2290 & 0,2283 & 0,2250 & $-0,0791$ \\
\hline 1833 & 0,2052 & 0,2305 & 0,0650 & 0,1847 & 0,1515 \\
\hline 1834 & 0,2060 & 0,2988 & 0,3423 & 0,5617 & 0,3230 \\
\hline 1835 & $-0,0654$ & $-0,1815$ & 0,3487 & 0,3201 & 0,5493 \\
\hline 1836 & 0,1748 & 0,1425 & 0,0737 & 0,3596 & $-0,1104$ \\
\hline 1837 & 0,2649 & 0,0634 & 0,3190 & 0,2212 & $-0,0537$ \\
\hline 1838 & 0,0846 & 0,0517 & 0,2118 & 0,3065 & $-0,0387$ \\
\hline $18 \quad 39$ & 0,2681 & 0,3320 & 0,1563 & 0,3824 & 0,0135 \\
\hline 1840 & 0,1413 & 0,1251 & $-0,1743$ & 0,5204 & 0,5744 \\
\hline 1841 & 0,1269 & 0,2159 & 0,0203 & 0,0299 & 0,1480 \\
\hline 1842 & 0,1481 & $-0,0371$ & 0,5044 & 0,4040 & 0,1960 \\
\hline 1843 & 0,1388 & $-0,0770$ & 0,1665 & 0,2333 & 0,3041 \\
\hline 1844 & 0,3005 & 0,1277 & 0,1787 & 0,2791 & 0,2334 \\
\hline 1845 & 0,2401 & 0,3174 & $-0,0989$ & 0,0249 & 0,2142 \\
\hline 1846 & 0,2237 & 0,2523 & 0,2243 & 0,2677 & 0,0001 \\
\hline 1847 & 0,1413 & 0,3077 & 0,5871 & 0,4220 & 0,7695 \\
\hline
\end{tabular}




\begin{tabular}{|c|c|c|c|c|c|}
\hline $\begin{array}{c}\text { Pares de } \\
\text { Linhagens }\end{array}$ & local 1 & local 2 & local 3 & local 4 & média \\
\hline 1848 & 0,1683 & 0,1430 & $-0,1472$ & 0,1337 & 0,1298 \\
\hline 1849 & 0,3020 & $-0,0072$ & $-0,1928$ & 0,0490 & 0,6155 \\
\hline 1850 & $-0,1093$ & 0,1579 & 0.2310 & 0,2408 & 0,6820 \\
\hline 1851 & 0,2141 & 0,0014 & $-0,0581$ & 0,3310 & 0,5277 \\
\hline 1852 & 0,2958 & 0,3823 & 0,3863 & 0,1471 & 0,0452 \\
\hline 1853 & 0,1255 & 0,0851 & $-0,0317$ & 0,3808 & 0,2069 \\
\hline 1854 & 0,2398 & 0,1267 & 0,2358 & 0,4449 & $-0,0105$ \\
\hline 1855 & 0,2442 & $-0,1524$ & 0,0384 & 0,1401 & 0,1392 \\
\hline 1856 & 0,1550 & $-0,0819$ & 0,1862 & 0,2665 & 0,2126 \\
\hline 1857 & 0,1113 & 0,0243 & $-0,0927$ & 0,2858 & 0,5437 \\
\hline 1858 & 0,2579 & $-0,1262$ & $-0,2900$ & 0,1583 & 0,6019 \\
\hline 1859 & 0,0314 & 0,1085 & $-0,0839$ & 0,1363 & 0,4732 \\
\hline 1860 & 0,1394 & 0,0823 & 0,4467 & 0,3127 & 0,0382 \\
\hline 1861 & 0,2298 & 0,3041 & $-0,0875$ & 0,5231 & 0,6679 \\
\hline 1862 & 0,3210 & 0,4650 & 0,5770 & 0,5600 & 0,1790 \\
\hline 1863 & 0,4806 & 0,3576 & 0,2116 & 0,2143 & 0,1976 \\
\hline 1864 & 0,2243 & 0,2251 & 0,0265 & 0,0548 & 0,2412 \\
\hline 1865 & 0,2155 & 0,1782 & 0,0368 & 0,1709 & 0,5519 \\
\hline 1866 & 0,1679 & 0,2183 & 0,3153 & 0,4687 & 0,6375 \\
\hline 1867 & 0,1756 & 0,1097 & 0,0752 & 0,1653 & 0,6067 \\
\hline 1868 & 0,1287 & 0,0469 & 0,3329 & 0,1951 & 0,2545 \\
\hline 1920 & 0,3405 & 0,1232 & 0,0366 & $-0,1448$ & 0,5825 \\
\hline 1921 & 0,7633 & 0,7014 & 0,0173 & $-0,0323$ & 0,7941 \\
\hline 1922 & 0,3441 & 0,1163 & 0,0068 & 0,4195 & 0,0561 \\
\hline 1923 & 0,6500 & 0,3437 & 0,3576 & 0,5769 & $-0,0601$ \\
\hline 1924 & 0,2509 & 0,2847 & 0,0954 & 0,0364 & 0,3502 \\
\hline 1925 & 0,7056 & 0,3506 & 0,2689 & $-0,0225$ & 0,6498 \\
\hline 1926 & 0,6410 & 0,2972 & $-0,0232$ & $-0,0052$ & 0,6075 \\
\hline 1927 & 0,6545 & 0,4989 & 0,1357 & 0,0727 & 0,3217 \\
\hline 1928 & 0,7130 & 0,4201 & 0,0683 & 0,4971 & 0,2400 \\
\hline 1929 & 0,7742 & 0,3771 & 0,0081 & 0,1992 & 0,6224 \\
\hline 1930 & 0,6107 & 0,2647 & 0,2106 & $-0,0304$ & 0,5836 \\
\hline 1931 & 0,4705 & 0,2883 & 0,2136 & 0,4176 & 0,7360 \\
\hline 1932 & 0,7369 & 0,4355 & 0,3174 & 0,0509 & 0,0114 \\
\hline 1933 & 0,6984 & 0,3975 & 0,1618 & 0,0179 & 0,2114 \\
\hline 1934 & 0,1043 & 0,0796 & 0,5399 & 0,2315 & 0,3284 \\
\hline 1935 & 0,3329 & 0,1100 & 0,2110 & 0,0891 & 0,6097 \\
\hline 1936 & 0,6589 & 0,3545 & 0,1909 & 0,2053 & $-0,0136$ \\
\hline 1937 & 0,7540 & 0,3515 & 0,2228 & $-0,0283$ & 0,0384 \\
\hline 1938 & 0,6245 & 0,3478 & 0,5364 & 0,0723 & 0,0507 \\
\hline 1939 & 0,1528 & 0,2521 & 0,4208 & 0,1463 & 0,0502 \\
\hline 1940 & 0,6824 & 0,3382 & 0,2410 & 0,3714 & 0,6348 \\
\hline 1941 & 0,6419 & 0,4267 & 0,1640 & $-0,0997$ & 0,2175 \\
\hline 1942 & 0,6669 & 0,2689 & 0,4496 & 0,3159 & 0,2668 \\
\hline 1943 & 0,6582 & 0,3031 & 0,4079 & 0,2590 & 0,3497 \\
\hline
\end{tabular}




\begin{tabular}{|c|c|c|c|c|c|}
\hline $\begin{array}{c}\text { Pares de } \\
\text { Linhagens }\end{array}$ & local l & local 2 & local 3 & local $t$ & média \\
\hline 1944 & 0.7651 & 0.4015 & -0.0227 & 0.4610 & 0.3233 \\
\hline 1945 & 0.7279 & 0,5305 & 0.1495 & 0.1297 & 0.2738 \\
\hline 1946 & 0.7336 & 0.5478 & 0,4357 & 0,1823 & 0.0696 \\
\hline 1947 & 0.6672 & 0.6769 & 0.3233 & 0.3225 & 0.8376 \\
\hline 1948 & 0.6727 & 0,3123 & 0,0296 & 0.1217 & 0,1904 \\
\hline 1949 & 0,7476 & 0,3911 & 0.2122 & 0.0428 & 0,6797 \\
\hline 1950 & 0.3391 & 0.2093 & 0.2996 & 0.0181 & 0,7211 \\
\hline 1951 & 0.1378 & 0.1239 & 0.3047 & 0,2480 & 0,5608 \\
\hline 1952 & 0.7721 & 0.5018 & 0,3666 & -0.0771 & 0.0945 \\
\hline 1953 & 0.6078 & 0.3013 & 0,3294 & 0,2970 & 0,2778 \\
\hline 1954 & 0.7633 & 0.5010 & 0,4151 & 0,5874 & 0.0885 \\
\hline 1955 & 0.7182 & 0,2313 & -0.0030 & $-0,1114$ & 0,2104 \\
\hline 1956 & 0.6777 & 0.3674 & 0,3698 & 0.0130 & 0.2903 \\
\hline 1957 & 0.6341 & 0.2806 & 0.2776 & 0.0814 & 0.5976 \\
\hline 1958 & 0.1109 & 0.0615 & 0.1870 & $-0,0733$ & 0,6571 \\
\hline 1959 & 0,5685 & 0,3992 & 0,1479 & 0,0374 & 0,5337 \\
\hline 1960 & 0.6642 & 0,2972 & $0 .+123$ & 0.0895 & 0,0828 \\
\hline 1961 & 0.7294 & 0,6146 & 0.0559 & 0,7122 & 0.7505 \\
\hline 1962 & 0.2888 & 0,3071 & 0,6587 & 0,3655 & 0,1359 \\
\hline 1963 & 0.9292 & 0,6402 & 0,3298 & 0,0615 & 0.2907 \\
\hline 1964 & 0.7129 & 0.4944 & 0,1186 & -0.0780 & 0.2894 \\
\hline 1965 & 0.7164 & 0.3467 & 0.0910 & 0.0067 & 0.6039 \\
\hline 1966 & 0.7019 & 0.4396 & $0.52+3$ & 0.2475 & 0.6902 \\
\hline 1967 & 0.6657 & 0.3854 & 0.0393 & -0.0987 & 0.6706 \\
\hline 1968 & 0.6472 & 0.2631 & 0.4739 & 0,0096 & 0.2984 \\
\hline 2021 & $0.2+29$ & 0.5399 & -0.1648 & $-0,1485$ & 0.0209 \\
\hline 2022 & -0.0267 & -0.2357 & -0.3312 & 0,2727 & 0.2046 \\
\hline $20 \quad 23$ & 0.1393 & -0.0718 & -0.01112 & 0.4237 & 0,4369 \\
\hline $20 \quad 24$ & 0.4775 & 0,3288 & -0.3040 & -0.1107 & 0.2128 \\
\hline $20 \quad 25$ & 0,1345 & $-0,0075$ & $-0,1005$ & $-0,1848$ & $-0,2953$ \\
\hline 2026 & 0.1515 & $-0,1341$ & $-0,1877$ & $-0,2113$ & $-0,3689$ \\
\hline $20 \quad 27$ & 0.1630 & 0,1423 & $-0,1178$ & $-0,1767$ & 0.1230 \\
\hline 2028 & 0,2795 & 0,1553 & $-0,3551$ & 0,3168 & 0,0572 \\
\hline 2029 & 0,3397 & $-0,0596$ & $-0,4858$ & 0,0219 & -0.3219 \\
\hline 2030 & 0,1150 & $-0,1481$ & -0.1172 & -0.1467 & $-0,3857$ \\
\hline $20 \quad 31$ & 0.4436 & 0,1071 & -0.2131 & 0.2342 & -0.1228 \\
\hline $20 \quad 32$ & 0.2755 & 0,0512 & 0,0506 & $-0,0832$ & 0,4726 \\
\hline $20 \quad 33$ & 0.2247 & 0.0458 & $-0,0871$ & -0.1046 & 0,0040 \\
\hline 2034 & 0.2066 & 0.1612 & 0.2229 & 0.2170 & 0.1951 \\
\hline 2035 & $-0,0019$ & -0.1421 & 0,1050 & 0,0163 & -0.3201 \\
\hline $20 \quad 36$ & 0.1930 & -0.0713 & -0.1616 & 0,0910 & 0,4518 \\
\hline $20 \quad 37$ & 0.2959 & -0.0132 & 0.1263 & $-0,1128$ & 0.5118 \\
\hline $20 \quad 38$ & 0.0720 & $-0,0520$ & 0.2311 & $-0,0029$ & 0,4872 \\
\hline $20 \quad 39$ & 0.2878 & 0,1004 & 0,0696 & 0.0397 & 0.5520 \\
\hline 2040 & 0.1869 & -0.1182 & -0.1335 & 0.2610 & -0.2371 \\
\hline
\end{tabular}




\begin{tabular}{|c|c|c|c|c|c|}
\hline $\begin{array}{c}\text { Pares de } \\
\text { Linhagens }\end{array}$ & local 1 & local 2 & local 3 & local 1 & média \\
\hline $20+1$ & 0.1469 & 0.0046 & -0.0991 & $-0,3692$ & -0.0041 \\
\hline $20+2$ & 0.1354 & -0.1088 & 0.2785 & 0.2257 & 0.0444 \\
\hline $20+3$ & 0.1830 & -0.0544 & 0.2042 & 0.1386 & 0,1867 \\
\hline 2044 & 0.3012 & 0.0210 & -0.0753 & 0.3067 & 0.1150 \\
\hline 2045 & 0.2605 & 0.3475 & -0.2598 & -0.0652 & 0,1344 \\
\hline 2046 & 0.2447 & 0.3690 & 0,2533 & 0.0345 & 0.5841 \\
\hline 2047 & 0.1738 & 0.3395 & 0,3603 & 0,1171 & 0,0430 \\
\hline 2048 & 0.1999 & -0.0314 & -0.4625 & -0.1757 & 0,0050 \\
\hline 2049 & 0.3413 & 0.1055 & $-0,1412$ & -0.1061 & -0.1575 \\
\hline 2050 & -0.0687 & 0,2068 & -0.0036 & $-0,0346$ & $-0,0979$ \\
\hline 2051 & 0.2277 & 0,1141 & 0,0052 & 0.1582 & 0.0480 \\
\hline 2052 & 0.2789 & 0,2296 & 0.2128 & $-0,1804$ & 0,5818 \\
\hline 2053 & 0.1549 & $-0,0915$ & 0,0025 & 0,2223 & 0,0771 \\
\hline $20 \quad 54$ & 0,2968 & 0.2365 & 0,1713 & 0,4315 & 0,5931 \\
\hline $20 \quad 55$ & 0.2014 & $-0,1279$ & -0.1957 & $-0,1755$ & $-0,0135$ \\
\hline 2056 & 0,1087 & 0,0152 & 0.0668 & $-0,1089$ & 0.0832 \\
\hline $20 \quad 57$ & 0.1317 & -0.0508 & $-0,1160$ & $-0,0228$ & $-0,3366$ \\
\hline 2058 & 0.2775 & $-0,0195$ & -0.2304 & $-0,2499$ & $-0,2646$ \\
\hline 2059 & 0.0516 & $-0,0242$ & -0.2524 & $-0,1881$ & $-0,4342$ \\
\hline 2060 & 0.1075 & $-0,1341$ & 0.3555 & 0,0080 & 0,5641 \\
\hline 2061 & 0.2722 & 0.2750 & -0.3763 & 0,5497 & $-0,0591$ \\
\hline 2062 & 0.3108 & 0.4761 & 0.5529 & 0.3138 & 0.7194 \\
\hline 2063 & 0.4691 & 0.4473 & 0.1500 & -0.0836 & 0.7658 \\
\hline 2064 & 0.2710 & $0 .+161$ & -0.1306 & -0.3301 & 0,1529 \\
\hline 2065 & 0.2474 & -0.0134 & -0.2228 & -0.1126 & -0.2992 \\
\hline $20 \quad 66$ & 0.2040 & 0.1240 & 0.2559 & 0.1313 & $-0,1+43$ \\
\hline 2067 & 0.2074 & -0.0193 & -0.1775 & $-0,1488$ & -0.2151 \\
\hline 2068 & 0,1608 & $-0,1504$ & 0.3424 & -0.0791 & 0.1201 \\
\hline 2122 & 0.2948 & 0.5372 & -0.1027 & 0.2782 & 0,4314 \\
\hline 2123 & 0.0102 & 0,4413 & 0,2138 & 0,4988 & 0,6584 \\
\hline 2124 & 0,8834 & 0,8163 & $-0,0774$ & 0,0996 & 0,4095 \\
\hline 2125 & $-0,0056$ & 0.2959 & 0,0296 & $-0,1848$ & $-0,0023$ \\
\hline 2126 & 0.0336 & 0,4312 & $-0,1982$ & $-0,1858$ & 0,0216 \\
\hline 2127 & 0.0132 & 0,4687 & $-0,0601$ & $-0,1188$ & 0,3168 \\
\hline 2128 & 0.1912 & 0,4928 & $-0,1229$ & 0,3338 & 0,2815 \\
\hline 2129 & 0.2192 & 0,5249 & $-0,2431$ & 0.0682 & 0.0260 \\
\hline 2130 & -0.0593 & 0,3611 & $-0,0102$ & $-0,4785$ & 0,0206 \\
\hline 2131 & 0.8373 & 0,7905 & -0.0006 & 0.4278 & 0.1729 \\
\hline 2132 & 0.2020 & 0.5263 & 0,2135 & $-0,0740$ & 0.6982 \\
\hline 2133 & 0,1014 & 0.4531 & -0.0468 & $-0,3393$ & 0,2539 \\
\hline 2134 & 0.6768 & 0,7186 & 0.3569 & 0,2980 & 0.4261 \\
\hline 2135 & 0.3222 & 0.4209 & $-0,0163$ & $-0,1165$ & 0,0236 \\
\hline 2136 & 0,0935 & 0,4782 & -0.0251 & -0.0426 & 0.6792 \\
\hline 2137 & 0.1181 & 0,4179 & 0.0789 & -0.2084 & 0,7306 \\
\hline 2138 & -0.0344 & 0.4341 & 0.3523 & -0.1318 & 0,7255 \\
\hline
\end{tabular}




\begin{tabular}{|c|c|c|c|c|c|}
\hline $\begin{array}{l}\text { Pare s de } \\
\text { Linhagens }\end{array}$ & local I & local 2 & local 3 & local $t$ & média \\
\hline 2139 & 0.7425 & 0.8570 & 0.2517 & 0.2015 & 0.8029 \\
\hline 2140 & 0.0496 & 0.4729 & $-0,0020$ & 0.1863 & 0.0440 \\
\hline 2141 & $-0,0019$ & 0.5386 & 0,0182 & $-0,3543$ & 0,2650 \\
\hline 2142 & $-0,0563$ & 0,3773 & 0,2900 & 0,1433 & 0.3226 \\
\hline 2143 & 0.0408 & 0.3690 & 0.3305 & 0,0793 & 0,4221 \\
\hline 2144 & 0,1527 & 0.4003 & $-0,1029$ & 0,3277 & 0.3259 \\
\hline 2145 & 0,1069 & 0,6652 & 0.0331 & 0.0171 & 0.3492 \\
\hline 2146 & -0.0150 & 0,6224 & 0,3316 & $-0,1357$ & 0,7792 \\
\hline 2147 & $-0,0055$ & 0,5299 & 0,2470 & 0,1675 & 0.2014 \\
\hline 2148 & 0,1069 & 0,4065 & $-0,1489$ & $-0,0885$ & 0,2342 \\
\hline 2149 & 0.1986 & 0.2778 & 0,0524 & $-0,0817$ & $-0,0066$ \\
\hline 2150 & 0,2639 & 0.4916 & 0,0822 & $-0,1438$ & 0,0738 \\
\hline 2151 & 0,6916 & 0,5720 & 0,1979 & 0,3110 & 0.2547 \\
\hline 2152 & 0,1104 & 0.5251 & 0,1758 & -0.2173 & 0,7616 \\
\hline 2153 & 0,0674 & 0.4472 & 0,1570 & 0,1213 & 0,3338 \\
\hline 2154 & 0.1705 & 0.5193 & 0,2591 & 0,4595 & 0,7841 \\
\hline 2155 & 0,0097 & 0.3086 & -0.3131 & $-0,3985$ & 0.2667 \\
\hline 2156 & $-0,0579$ & 0,3116 & 0.2383 & $-0,1404$ & 0.3114 \\
\hline 2157 & -0.0293 & 0.3335 & 0.0857 & $-0,0798$ & $-0,0128$ \\
\hline 2158 & 0.7452 & 0.5354 & -0.0243 & $-0,0594$ & 0.0715 \\
\hline 2159 & -0.0509 & 0.5001 & -0.0714 & -0.1328 & -0.0444 \\
\hline 2160 & -0.0376 & $0 .+312$ & 0.4299 & -0.0438 & 0.7854 \\
\hline 2161 & 0.1609 & 0.5073 & -0.2149 & 0.5606 & 0.0775 \\
\hline 2162 & $0.77+6$ & 0.9520 & 0.6610 & 0.3261 & 0.9232 \\
\hline 2163 & 0.3748 & 0.3908 & 0.2870 & $-0,1445$ & 0.9147 \\
\hline 2164 & 0.1650 & $0 .+720$ & -0.0517 & -0.3325 & 0.3115 \\
\hline 2165 & 0.1354 & 0.4277 & -0.0086 & $-0,3686$ & -0.0187 \\
\hline 2166 & 0.1014 & 0,5450 & 0,3758 & 0,0912 & 0,1331 \\
\hline 2167 & 0,0332 & 0,3963 & $-0,1075$ & $-0,3608$ & 0,0512 \\
\hline 2168 & 0.0634 & 0.4090 & 0,4646 & $-0,2991$ & 0.3804 \\
\hline 2223 & 0,1599 & $-0,0716$ & 0,0086 & 0,8754 & $-0,1000$ \\
\hline 2224 & 0,4798 & 0,3099 & $-0,3762$ & 0.3038 & 0,0812 \\
\hline $22 \quad 25$ & 0.2138 & 0,0010 & $-0,0976$ & 0,3014 & 0.2621 \\
\hline 2226 & 0,1961 & $-0,1237$ & $-0,1214$ & 0,2280 & 0.2209 \\
\hline $22 \quad 27$ & 0,1652 & 0,1831 & $-0,1507$ & 0,3638 & $-0,0053$ \\
\hline 2228 & 0,2578 & 0,1725 & $-0,4055$ & 0,7538 & -0.0290 \\
\hline $22 \quad 29$ & 0,3269 & $-0,0101$ & -0.4304 & 0.3839 & 0,2220 \\
\hline 2230 & 0.1598 & -()$, 1383$ & -0.0616 & 0.2800 & 0,2071 \\
\hline 2231 & 0,4333 & 0.1074 & -0.1507 & 0,7510 & 0,3364 \\
\hline 2232 & 0,3002 & 0,0430 & $-0,0084$ & 0,4127 & -0.0082 \\
\hline $22 \quad 33$ & 0.2516 & 0.0369 & -0.0562 & 0.2965 & -0.0789 \\
\hline 2234 & 0.2427 & 0,1406 & 0,2278 & 0.5079 & 0.0453 \\
\hline $22 \quad 35$ & 0.0134 & -0.1514 & 0.1728 & 0,4340 & 0.2201 \\
\hline $22 \quad 36$ & 0,1689 & -0.0315 & -0.1363 & 0.4036 & -0.0415 \\
\hline $22 \quad 37$ & 0.3167 & -0.0043 & 0.0520 & 0.2994 & $0.00(06$ \\
\hline
\end{tabular}




\begin{tabular}{|c|c|c|c|c|c|}
\hline $\begin{array}{c}\text { Pares de } \\
\text { Linhagens }\end{array}$ & local I & local 2 & local 3 & local 4 & média \\
\hline 2238 & 0.1339 & -0.0806 & 0.2724 & 0.4364 & 0.0206 \\
\hline 2239 & 0.3150 & 0.1285 & 0,0879 & 0.4614 & 0.0800 \\
\hline 2240 & 0,1822 & -0.0744 & $-0,1306$ & 0,4830 & 0,2237 \\
\hline 2241 & 0,1739 & 0,0046 & $-0,1011$ & 0.1804 & $-0,0938$ \\
\hline 2242 & 0,1973 & $-0,1373$ & 0,3351 & 0,4705 & $-0,0381$ \\
\hline 2243 & 0,1407 & $-0,0767$ & 0,1416 & 0,5006 & $-0,0105$ \\
\hline 2244 & 0,3018 & 0,0303 & $-0,0169$ & 0,7703 & $-0,0141$ \\
\hline 2245 & 0,2854 & 0.3496 & $-0,2937$ & 0.5043 & 0,0404 \\
\hline 2246 & 0,3035 & 0,3713 & 0,1859 & 0,2849 & 0.1109 \\
\hline 2247 & 0,1945 & 0,3705 & 0,3546 & 0,5538 & 0,4533 \\
\hline 2248 & 0.2026 & $-0,0407$ & $-0,4682$ & 0,2557 & $-0,1376$ \\
\hline 2249 & 0,3407 & 0,0873 & $-0,0841$ & 0,4229 & 0,2809 \\
\hline 2250 & $-0,0203$ & 0.2010 & 0,0475 & 0,3064 & 0,3602 \\
\hline 2251 & 0,2381 & 0.0959 & $-0,0652$ & 0,5613 & 0,1098 \\
\hline 2252 & 0.2520 & 0,2312 & 0,2057 & 0,3364 & 0,0393 \\
\hline 2253 & 0.1247 & $-0,1238$ & 0,0012 & 0.4593 & $-0,0488$ \\
\hline 2254 & 0.2599 & 0,2385 & 0,1639 & 0,8447 & 0,0599 \\
\hline 2255 & 0.2771 & $-0,1191$ & $-0,1668$ & 0.2829 & $-0,0981$ \\
\hline 2256 & 0,1885 & 0,0093 & 0,0722 & 0,3427 & $-0,0290$ \\
\hline 2257 & 0.1766 & -0.0589 & $-0,1359$ & 0,3871 & 0,2205 \\
\hline 2258 & 0.3044 & -0.0111 & $-0,2275$ & 0.2567 & 0,2852 \\
\hline 2259 & 0.0963 & 0.0038 & -0.1395 & 0.3390 & 0.1537 \\
\hline 2260 & 0,1602 & -0.1237 & 0.2904 & 0.2991 & 0,0386 \\
\hline 2261 & 0.2519 & 0.2768 & -0.3731 & 0.9397 & 0,3580 \\
\hline 2262 & 0.3678 & 0.4953 & 0.4853 & 0.4508 & 0.2469 \\
\hline 2263 & 0.5160 & 0.4322 & $-0.01+4$ & 0.2469 & 0.2799 \\
\hline 2264 & 0.2498 & 0.4234 & -0.0330 & 0,2006 & 0,0607 \\
\hline 2265 & 0.2499 & $-0,0232$ & -0.1594 & 0,2881 & 0,2146 \\
\hline 2266 & 0.2309 & 0,1417 & 0,2669 & 0,3777 & 0,3338 \\
\hline 2267 & 0.2277 & -0.0097 & -0.2321 & 0,2981 & 0.2805 \\
\hline 2268 & 0,1811 & $-0,1402$ & 0,2898 & 0,3200 & $-0,0299$ \\
\hline $23 \quad 24$ & 0,7959 & 0,5163 & $-0,0662$ & 0,6382 & 0,2505 \\
\hline 2325 & $-0,1373$ & $-0,2023$ & 0,1276 & 0,4778 & 0,4842 \\
\hline 2326 & -0.1912 & $-0,2325$ & 0.2005 & 0,4851 & 0,4441 \\
\hline $23 \quad 27$ & $-0,2224$ & 0,0497 & 0,0158 & 0,4607 & 0,1384 \\
\hline $23 \quad 28$ & 0,0064 & 0,0633 & $-0,0603$ & 0.3704 & 0,0890 \\
\hline 2329 & 0.0229 & -0.1815 & $-0,0285$ & 0,6550 & 0,4579 \\
\hline 2330 & $-0,2112$ & $-0,3448$ & $-0,0095$ & 0,5006 & 0,4236 \\
\hline $23 \quad 31$ & 0,7102 & 0,2843 & $-0,1244$ & 0,3640 & 0,5884 \\
\hline $23 \quad 32$ & 0,0606 & $-0,0453$ & 0.2163 & 0.5071 & $-0,2454$ \\
\hline $23 \quad 33$ & -0.0972 & $-0,0565$ & 0.1663 & 0,5280 & 0,0385 \\
\hline $23 \quad 34$ & 0,5504 & 0.3580 & 0,3047 & 0,8449 & 0,2283 \\
\hline $23 \quad 35$ & 0.1473 & $-0,1451$ & 0,4527 & 0.6038 & 0,4496 \\
\hline $23 \quad 36$ & $-0,0845$ & -0.1632 & 0.1879 & 0,6953 & $-0,2840$ \\
\hline 2337 & -0.0290 & -0.1524 & 0.4237 & 0.5104 & -0.2106 \\
\hline
\end{tabular}




\begin{tabular}{|c|c|c|c|c|c|}
\hline $\begin{array}{c}\text { Pares de } \\
\text { Linhagens }\end{array}$ & local 1 & local 2 & local 3 & local $f$ & média \\
\hline 2338 & $-0,2388$ & $-0,2991$ & 0.3149 & 0.6052 & -0.1819 \\
\hline 2339 & 0,6061 & 0,3389 & 0,0877 & 0.7644 & $-0,0766$ \\
\hline 2340 & $-0,2541$ & $-0,2239$ & $-0,0248$ & 0,7656 & 0,4703 \\
\hline 2341 & $-0,1739$ & $-0,1441$ & 0,1385 & 0.4011 & 0,0305 \\
\hline $23 \quad 42$ & $-0,1753$ & $-0,3558$ & 0,4965 & 0,5214 & 0.0738 \\
\hline 2343 & $-0,1839$ & $-0,3281$ & 0,3001 & 0,4280 & 0,1842 \\
\hline 2344 & 0,0465 & $-0,0554$ & 0,2888 & 0,3606 & 0,1329 \\
\hline 2345 & 0,0115 & 0,2655 & 0,0067 & 0,2812 & 0,1578 \\
\hline 2346 & $-0,0019$ & 0,2456 & 0,3392 & 0,6589 & $-0,0382$ \\
\hline 2347 & $-0,1644$ & 0,2249 & 0,6888 & 0,7302 & 0,6905 \\
\hline $23 \quad 48$ & $-0,1350$ & $-0,1368$ & $-0,0301$ & 0,4876 & 0.0111 \\
\hline 2349 & 0,0621 & $-0,1032$ & $-0,0375$ & 0,2519 & 0,5250 \\
\hline 2350 & 0,1517 & 0,2462 & 0,2235 & 0,6114 & 0,5994 \\
\hline 2351 & 0,5663 & 0,2298 & 0,0869 & 0,6428 & 0,4532 \\
\hline 2352 & 0,0547 & 0,1337 & 0,3816 & 0,4131 & $-0,1253$ \\
\hline 2353 & $-0,1237$ & $-0,2369$ & 0,0941 & 0,5586 & 0,0895 \\
\hline $23 \quad 54$ & $-0,0349$ & 0.0439 & 0,2023 & 0,4982 & $-0,1169$ \\
\hline 2355 & $-0,0102$ & $-0,3450$ & 0,1641 & 0,4604 & 0,0213 \\
\hline 2356 & $-0,1480$ & -0.2012 & 0,2174 & 0,5361 & 0,1095 \\
\hline 2357 & -0.2279 & $-0,2342$ & $-0,0635$ & 0,5910 & 0,4392 \\
\hline 2358 & 0.5942 & 0,1264 & $-0,1302$ & 0,5684 & 0.5261 \\
\hline 2359 & -0.2747 & $-0,2925$ & 0,0394 & 0,4603 & 0,3735 \\
\hline 2360 & -0.1355 & -0.2325 & 0.4879 & 0,6135 & $-0,1099$ \\
\hline 2361 & $-0,0615$ & 0.1849 & 0,0395 & 0,5612 & 0,5912 \\
\hline 2362 & 0,6647 & 0,6400 & 0.6124 & 0,9411 & 0,1678 \\
\hline 2363 & 0,2793 & 0,3693 & 0,3379 & 0,5608 & 0.1788 \\
\hline 2364 & 0.0018 & 0.2994 & 0,1302 & 0,4255 & 0,1763 \\
\hline 2365 & $-0,1188$ & $-0,1225$ & 0,1588 & 0.5174 & 0,4500 \\
\hline 2366 & $-0,1325$ & 0,0280 & 0,4136 & 0,7465 & 0,5536 \\
\hline 2367 & $-0,1141$ & $-0,1018$ & 0,1959 & 0,4842 & 0,5185 \\
\hline 2368 & $-0,1879$ & $-0,2445$ & 0,4558 & 0,5560 & 0,1381 \\
\hline 2425 & 0.8346 & 0,4824 & $-0,1126$ & 0,0349 & 0,2734 \\
\hline 2426 & 0,7874 & 0,4809 & $-0,0819$ & $-0,0005$ & 0,2499 \\
\hline 2427 & 0,8005 & 0,6756 & $-0,2320$ & 0,1306 & 0,1192 \\
\hline 2428 & 0,8398 & 0,6451 & $-0,3768$ & 0,5652 & 0,0600 \\
\hline $24 \quad 29$ & 0,9013 & 0,5648 & $-0,4680$ & 0,1808 & 0,2603 \\
\hline 2430 & 0,7571 & 0,4471 & $-0,1642$ & 0,1015 & 0,2320 \\
\hline 2431 & 0,5664 & 0.3666 & $-0,2472$ & 0,3963 & 0,3503 \\
\hline $24 \quad 32$ & 0,8561 & 0.5289 & 0,0170 & 0,1838 & 0,2826 \\
\hline 2433 & 0,8259 & 0,5754 & $-0,1575$ & 0,1176 & 0,0255 \\
\hline 2434 & 0.2837 & 0.4322 & 0,2478 & 0.2445 & 0,1730 \\
\hline 2435 & 0,4837 & 0.2608 & 0,1874 & 0,2217 & 0,2404 \\
\hline 2436 & 0,7765 & 0.5068 & $-0,0743$ & 0,2737 & 0,2589 \\
\hline 2437 & 0.8819 & 0,4619 & $-0,0152$ & 0,0643 & 0,3005 \\
\hline 2438 & 0.7618 & 0.5095 & 0,1874 & 0,2252 & 0.3125 \\
\hline
\end{tabular}




\begin{tabular}{|c|c|c|c|c|c|}
\hline $\begin{array}{c}\text { Pares de } \\
\text { Linhagens }\end{array}$ & local 1 & local 2 & local 3 & local $t$ & média \\
\hline 2439 & 0.3035 & 0.3635 & 0.0592 & 0.1504 & 0.3425 \\
\hline 2440 & 0.8282 & 0.5214 & -0.2964 & 0.3960 & 0.2747 \\
\hline 2441 & 0,7693 & 0,5579 & $-0,1876$ & $-0,0608$ & 0,0130 \\
\hline 2442 & 0.8046 & 0.4527 & 0.3253 & 0,3490 & 0.0760 \\
\hline 2443 & 0,7948 & 0,4734 & 0.1473 & 0.3502 & 0.1891 \\
\hline 2444 & 0.8740 & 0.5012 & 0.0214 & 0.5558 & 0.0843 \\
\hline 2445 & 0.8560 & 0.7041 & $-0,3552$ & 0,2310 & 0,0936 \\
\hline 2446 & 0.8622 & 0,6790 & 0,0895 & 0.2220 & 0.3605 \\
\hline $24+7$ & 0.7950 & 0.6929 & 0,4190 & 0.3224 & 0.4622 \\
\hline $24 \quad 48$ & 0.8093 & 0,5436 & $-0,4307$ & 0,0974 & 0,0094 \\
\hline 2449 & 0.8939 & 0,5610 & $-0,1884$ & 0,1737 & 0.3116 \\
\hline 2450 & 0.4750 & 0.4832 & 0,0804 & 0,1592 & 0.3511 \\
\hline 2451 & 0,3175 & 0,3150 & $-0,0453$ & 0.2559 & 0.2662 \\
\hline 2452 & 0,8728 & 0,7212 & 0,2513 & 0,0531 & 0,3881 \\
\hline 2453 & 0.7441 & 0.4864 & $-0,1599$ & 0,3357 & 0,0652 \\
\hline 2454 & 0.8813 & 0.5917 & 0,1710 & 0.6630 & 0,3632 \\
\hline 2455 & 0.8475 & 0,4205 & -0.1159 & 0,0670 & 0,0312 \\
\hline 2456 & 0.8068 & 0.4946 & 0.0938 & 0,1377 & 0,0910 \\
\hline $2+57$ & 0.7804 & 0.5094 & $-0,3949$ & 0,1906 & 0,2471 \\
\hline 2458 & 0.2975 & 0.2080 & -0.4056 & $-0,0678$ & 0,2654 \\
\hline 2459 & 0.7141 & 0.5706 & -0.1662 & 0.0505 & 0.1755 \\
\hline $2+60$ & 0.7932 & 0.4809 & 0.3531 & 0.1720 & 0,3754 \\
\hline $2+61$ & 0.8567 & 0.6584 & -0.3567 & 0.7305 & 0.3623 \\
\hline $2+62$ & 0.4106 & 0.5771 & 0.4475 & 0.3571 & 0.5059 \\
\hline $2+63$ & 1.0492 & 0.7187 & 0.0399 & 0.1295 & 0.5276 \\
\hline 2464 & 0.8396 & 0.7517 & -0.0710 & -0.0112 & 0.1312 \\
\hline 2465 & 0.8532 & 0.5668 & -0.1226 & 0.1093 & 0.2501 \\
\hline $2+66$ & 0.8291 & 0.5760 & 0.1479 & 0.2656 & 0,3151 \\
\hline 2467 & 0,8125 & 0,5171 & $-0,1978$ & 0,0923 & 0,3070 \\
\hline 2468 & 0.7932 & 0,4578 & 0,3022 & 0,1630 & 0,1579 \\
\hline 2526 & -0.0964 & $-0,1527$ & 0.0634 & $-0,4404$ & $-0,3155$ \\
\hline 2527 & -0.0907 & 0.0768 & -0.0628 & $-0,0062$ & 0,1460 \\
\hline 2528 & 0.0768 & 0.1450 & $-0,3152$ & 0,4091 & 0,1063 \\
\hline 2529 & 0.1216 & $-0,0304$ & $-0,2201$ & $-0,1355$ & $-0,2700$ \\
\hline 2530 & $-0,1196$ & $-0,3180$ & 0,0928 & $-0,1831$ & $-0,3029$ \\
\hline 2531 & 0.7573 & 0,3308 & 0,0484 & 0.2857 & $-0,0424$ \\
\hline $25 \quad 32$ & 0.0879 & 0.0210 & $-0,0999$ & $-0,1335$ & 0.5208 \\
\hline $25 \quad 33$ & -0.0104 & 0.0179 & 0,1308 & -0.1267 & 0,0600 \\
\hline 2534 & 0.5892 & 0.3720 & 0.1101 & 0,1524 & 0.2671 \\
\hline 2535 & 0.2197 & $-0,2029$ & 0,3148 & $-0,1512$ & $-0,2443$ \\
\hline $25 \quad 36$ & $-0,0112$ & $-0,0668$ & 0,0654 & $-0,0203$ & 0,5004 \\
\hline 2537 & 0.0763 & -0.1595 & 0.2073 & $-0,2199$ & 0,5626 \\
\hline 2538 & -0.2234 & $-0,2119$ & 0,4211 & $-0,1664$ & 0,5380 \\
\hline 2539 & 0.6554 & 0,3893 & 0.0060 & 0,1146 & 0,6169 \\
\hline 2540 & -0.0670 & -0.1057 & 0.0222 & 0.1091 & -0.1873 \\
\hline
\end{tabular}




\begin{tabular}{|c|c|c|c|c|c|}
\hline $\begin{array}{c}\text { Pares de } \\
\text { Linhagens }\end{array}$ & local 1 & local 2 & local 3 & local $f$ & média \\
\hline $25+1$ & -0.0844 & 0.0072 & 0.0705 & $-0,3200$ & 0.0476 \\
\hline 2542 & $-0,1599$ & $-0,2687$ & 0.3096 & 0,1182 & 0.0908 \\
\hline 2543 & $-0,0426$ & $-0,3510$ & 0,3876 & 0,1511 & 0,2338 \\
\hline 2544 & 0.0914 & $-0,0989$ & 0.1735 & 0,3488 & 0.1403 \\
\hline 2545 & 0,0365 & 0,3209 & 0,0365 & 0,0397 & 0.1892 \\
\hline 2546 & 0,0220 & 0.2633 & 0,3754 & 0,0543 & 0.6327 \\
\hline 2547 & $-0,0488$ & 0.1068 & 0.5339 & 0,0216 & 0,0264 \\
\hline 2548 & -0.0257 & $-0,0581$ & -0.1546 & -0.0284 & 0,0567 \\
\hline 2549 & 0.1640 & -0.2637 & 0.1078 & -0.0845 & -0.1445 \\
\hline 2550 & 0,1930 & 0.2295 & $-0,0621$ & $-0,0565$ & $-0,0285$ \\
\hline 2551 & 0.6120 & 0,1264 & 0,2378 & 0.2386 & 0.1074 \\
\hline 2552 & 0,0702 & 0.2110 & 0.0927 & -0.1902 & 0.6255 \\
\hline 2553 & $-0,0339$ & $-0,1151$ & 0,1864 & 0.1601 & 0.1284 \\
\hline 2554 & 0,0835 & 0,0289 & 0.1336 & 0,4042 & 0,6390 \\
\hline 2555 & $-0,0479$ & $-0,4316$ & 0.0273 & $-0,2682$ & 0.0382 \\
\hline 2556 & $-0,2469$ & -0.4689 & 0,1425 & $-0,3153$ & 0.1055 \\
\hline 2557 & $-0,1257$ & -0.2044 & -0.0800 & -0.1153 & $-0,2875$ \\
\hline 2558 & 0.6433 & -0.0007 & -0.0222 & $-0,0877$ & -0.1844 \\
\hline 2559 & -0.1831 & -0.1205 & 0.0290 & -0.1359 & -0.3502 \\
\hline 2560 & -0.1581 & -0.1527 & 0.4668 & 0.0039 & 0.6122 \\
\hline 2561 & 0,0620 & 0.1111 & -0.1905 & 0.5359 & -0.0726 \\
\hline 2562 & 0.6797 & 0.6699 & 0.6370 & 0.3411 & 0.7805 \\
\hline 2563 & $0.28+7$ & 0.2782 & 0.2964 & -0.0760 & 0.7946 \\
\hline 2564 & 0.0713 & 0.2299 & 0.1785 & -0.2549 & 0,2000 \\
\hline 2565 & 0.0019 & -0.0389 & $0.0+10$ & -0.1416 & $-(1) .2371$ \\
\hline 2566 & $-0.0+34$ & 0.1161 & $0 .+009$ & -0.0038 & -0.0796 \\
\hline 2567 & -0.0071 & -0.1434 & -0.0377 & -0.2398 & -0.1993 \\
\hline 2568 & -0.0719 & -0.1710 & 0.5198 & $-0,1133$ & 0,1714 \\
\hline 2627 & -0.1407 & 0.0393 & $-0,0682$ & 0,0058 & 0,1243 \\
\hline 2628 & $-0,0212$ & 0,0218 & -0.1421 & 0,3687 & 0.0651 \\
\hline 2629 & 0,0125 & $-0,1863$ & $-0,2129$ & $-0,2296$ & $-0,3558$ \\
\hline 2630 & -0.2109 & $-0,3673$ & 0.0286 & $-0,1840$ & -0.3840 \\
\hline 2631 & 0,7181 & 0.2635 & -0.0167 & 0,2236 & $-0,1021$ \\
\hline 2632 & -0.0256 & $-0,1264$ & 0,1563 & $-0,1427$ & 0.4798 \\
\hline $26 \quad 33$ & $-0,1799$ & $-0,1449$ & 0,0001 & $-0,1305$ & 0,0162 \\
\hline 2634 & 0.5413 & 0.3222 & 0,4030 & 0,1188 & 0.2244 \\
\hline 2635 & 0.1343 & -0.0941 & 0,0031 & -0.1484 & -0.3170 \\
\hline 2636 & -0.0689 & -0.2469 & 0.0524 & -0.0275 & 0.4578 \\
\hline $26 \quad 37$ & $-0,0628$ & $-0,1743$ & 0.1194 & -0.1668 & 0.5202 \\
\hline 2638 & 0.2155 & -0.2437 & 0,4174 & $-0,1628$ & 0,4954 \\
\hline 2639 & 0.6195 & 0.3342 & 0.2738 & 0,0791 & 0.5770 \\
\hline 2640 & -0.1170 & $-0,3349$ & 0,0329 & 0.1380 & -0.2525 \\
\hline 2641 & -0.1734 & -0.1643 & 0.0129 & -0.3869 & 0,0016 \\
\hline $26+2$ & -0.1521 & -0.3005 & 0.2862 & 0,1001 & 0,0472 \\
\hline 2643 & -0.1061 & -0.2074 & 0.3101 & 0,1287 & 0.1845 \\
\hline
\end{tabular}




\begin{tabular}{|c|c|c|c|c|c|}
\hline $\begin{array}{c}\text { Pares de } \\
\text { Linhagens }\end{array}$ & local 1 & local 2 & local 3 & local t & média \\
\hline 2644 & 0,0053 & -0.1594 & -0.1907 & 0.3114 & 0.1142 \\
\hline 2645 & -0.0350 & 0.2446 & 0.0167 & 0,0514 & 0,1420 \\
\hline 2646 & $-0,0001$ & 0.2702 & 0.3645 & 0.0361 & 0,5905 \\
\hline 2647 & $-0,1311$ & 0.2574 & 0.2425 & 0.0328 & 0,0402 \\
\hline 2648 & $-0,1749$ & $-0,2294$ & $-0,1828$ & $-0,1005$ & 0,0105 \\
\hline 2649 & $-0,0169$ & $-0,0269$ & $-0,0126$ & $-0,1020$ & $-0,1550$ \\
\hline 2650 & 0,1670 & 0,2370 & 0,0527 & $-0,0632$ & $-0,0693$ \\
\hline 2651 & 0,5887 & 0.2620 & 0,1853 & 0,1985 & 0,0844 \\
\hline 2652 & 0.0929 & 0,1129 & 0,2359 & $-0,1516$ & 0,5880 \\
\hline 2653 & $-0,1629$ & $-0,3151$ & 0,1716 & 0,1344 & 0,0802 \\
\hline 2654 & 0,0388 & 0,1319 & 0,2340 & 0,3669 & 0,5991 \\
\hline 2655 & $-0,0779$ & $-0,2833$ & $-0,2033$ & $-0,2630$ & $-0,0108$ \\
\hline 2656 & $-0,1265$ & $-0,1290$ & 0.2231 & $-0,2999$ & 0,0822 \\
\hline 2657 & -0.2018 & $-0,2277$ & 0,0830 & $-0,1213$ & $-0,3405$ \\
\hline 2658 & 0.5872 & 0,1399 & -0.0394 & -0.2176 & $-0,1924$ \\
\hline 2659 & -0.2744 & -0.1382 & $-0,0534$ & $-0,1467$ & $-0,4225$ \\
\hline 2660 & $-0,1104$ & $-0,4679$ & 0,3658 & $-0,0173$ & 0,5737 \\
\hline 2661 & -0.0650 & 0,1642 & -0.1843 & 0.5213 & -0.0526 \\
\hline 2662 & 0.6775 & 0.6319 & 0.5781 & 0.3142 & 0,7376 \\
\hline 2663 & 0.2191 & 0.3290 & 0.2558 & -0.0847 & 0.7755 \\
\hline 2664 & 0.0280 & 0.3140 & -0.0473 & -0.3233 & 0.1571 \\
\hline 2665 & -0.1398 & -0.2208 & -0.1724 & -0.1445 & -0.3054 \\
\hline 2666 & -0.0929 & -0.0149 & 0.3900 & -0.0749 & -0.1425 \\
\hline 2667 & -0.1779 & -0.2210 & -0.0994 & $-0,2363$ & -0.2038 \\
\hline 2668 & -0.2357 & $-0,4111$ & 0.3836 & -0.1196 & 0.1196 \\
\hline 2728 & $-0,0163$ & 0.2134 & -0.2521 & 0.3354 & -0.1088 \\
\hline 2729 & 0.0263 & 0,0098 & -0.2183 & 0,2029 & 0,1337 \\
\hline $27 \quad 30$ & $-0,2092$ & 0,0216 & -0.0106 & $-0,1170$ & 0,1046 \\
\hline $27 \quad 31$ & 0.7269 & 0,4763 & $-0,0921$ & 0,4300 & 0,2712 \\
\hline $27 \quad 32$ & 0.0676 & 0,2087 & 0,0728 & $-0,0112$ & 0,1982 \\
\hline 2733 & $-0,0531$ & 0,1274 & $-0,0711$ & $-0,0780$ & $-0,1608$ \\
\hline $27 \quad 34$ & 0.5760 & 0,4776 & 0,2795 & 0,4172 & 0,0739 \\
\hline 2735 & 0,1899 & 0,1722 & 0,1345 & 0,0945 & 0,1357 \\
\hline 2736 & $-0,1102$ & 0,0470 & 0,0996 & 0,1393 & 0,1726 \\
\hline 2737 & $-0,0258$ & 0,1335 & 0,1328 & $-0,0044$ & 0,2234 \\
\hline 2738 & -0.1485 & 0.1169 & 0,3759 & 0,0929 & 0,2087 \\
\hline $27 \quad 39$ & 0,6106 & 0.5338 & 0,0776 & 0,2573 & 0,2946 \\
\hline 2740 & $-0,1735$ & 0.0244 & $-0,0720$ & 0,2823 & 0,1597 \\
\hline 2741 & -0.1276 & 0,1256 & 0,0473 & $-0,2234$ & $-0,1593$ \\
\hline 2742 & -0.1736 & 0,0214 & 0,1669 & 0,3096 & $-0,1131$ \\
\hline 2743 & $-0,1782$ & 0.0932 & 0.3049 & 0,1519 & 0,0373 \\
\hline 2744 & 0,0805 & 0,0679 & 0.0564 & 0,3631 & $-0,1347$ \\
\hline 2745 & 0.0175 & 0.4747 & -0.0652 & $-0,0020$ & 0.0686 \\
\hline 2746 & 0,0012 & 0,4967 & 0.3106 & 0,0237 & 0,3304 \\
\hline 2747 & -0.1156 & 0.2886 & 0.3929 & 0.2068 & 0,3584 \\
\hline
\end{tabular}




\begin{tabular}{|c|c|c|c|c|c|}
\hline $\begin{array}{c}\text { Pares de } \\
\text { Linhagens }\end{array}$ & local I & local 2 & local 3 & local $t$ & média \\
\hline 2748 & $-0,0550$ & 0,0230 & $-0,1805$ & $-0,1683$ & $-0,1850$ \\
\hline 2749 & 0,0655 & 0,0972 & $-0,0344$ & -0.0051 & 0,1921 \\
\hline 2750 & 0,1934 & 0,3944 & $-0,0451$ & 0.0612 & 0,2837 \\
\hline 2751 & 0,5817 & 0,4071 & 0,1067 & 0,3662 & 0,1893 \\
\hline 2752 & 0,0605 & 0,1942 & 0,1473 & $-0,1292$ & 0,2639 \\
\hline 2753 & $-0,1160$ & 0,0381 & 0,0904 & 0,2967 & $-0,0687$ \\
\hline 2754 & 0,0062 & 0,3635 & 0,0239 & 0,4962 & 0,3023 \\
\hline 2755 & $-0,0071$ & 0,0184 & $-0,1123$ & $-0,0890$ & $-0,1758$ \\
\hline 2756 & -0.1032 & 0.0918 & 0,1854 & 0,0469 & $-0,1127$ \\
\hline 2757 & $-0,2268$ & 0,0117 & $-0,1726$ & 0,0683 & 0,1220 \\
\hline 2758 & 0.6093 & 0,3342 & $-0,1717$ & 0,0332 & 0.2129 \\
\hline $27 \quad 59$ & $-0,1889$ & 0.0672 & 0,0030 & $-0,1439$ & 0,0708 \\
\hline 2760 & $-0,0646$ & 0.0393 & 0,3445 & 0,0987 & 0,2922 \\
\hline 2761 & 0.0132 & 0,2086 & $-0,1371$ & 0,5660 & 0,2580 \\
\hline 2762 & 0.6897 & 0.7825 & 0,4972 & 0,4239 & 0,4786 \\
\hline 2763 & 0,3251 & 0,3814 & 0,2569 & $-0,0270$ & 0,4669 \\
\hline 2764 & $-0,0200$ & 0.4794 & -0.0438 & $-0,1996$ & 0,0448 \\
\hline 2765 & $-0,0673$ & 0.0644 & 0.0286 & $-0,0936$ & 0,1311 \\
\hline 2766 & -0.0500 & 0.2561 & 0.3819 & 0,2702 & 0,2717 \\
\hline 2767 & -0.1117 & 0.0449 & 0,0090 & -0.0625 & 0,1825 \\
\hline 2768 & $-0,1012$ & -0.0001 & 0.4510 & $-0,0454$ & $-0,0283$ \\
\hline 2829 & 0.0707 & 0.0854 & -0.4563 & 0.5894 & 0.0910 \\
\hline $28 \quad 30$ & 0.0070 & 0.0068 & -0.0809 & 0,3357 & 0,0368 \\
\hline 2831 & 0,7924 & 0.5009 & $-0,1709$ & 0,4083 & 0.2427 \\
\hline $28 \quad 32$ & 0.0431 & 0.1964 & -0.1800 & 0,4058 & 0,1308 \\
\hline $28 \quad 33$ & -0.0014 & 0.1074 & $-0,0591$ & 0,3852 & $-0,2561$ \\
\hline 2834 & 0.6414 & 0.4855 & 0.1216 & 0,8034 & 0,0447 \\
\hline $28 \quad 35$ & 0.2669 & 0.1795 & 0,1552 & 0.4914 & 0,0843 \\
\hline 2836 & -0.1353 & 0,0841 & $-0,1181$ & 0,5385 & 0,1092 \\
\hline 2837 & 0,1418 & 0,1400 & 0,0621 & 0,4312 & 0,1695 \\
\hline 2838 & $-0,0138$ & 0,0839 & 0,2803 & 0,4782 & 0,1413 \\
\hline $28 \quad 39$ & 0.6911 & 0.5499 & $-0,0641$ & 0,6589 & 0,2274 \\
\hline 2840 & 0.0615 & 0.0383 & $-0,1508$ & 0,7155 & 0,1319 \\
\hline 2841 & -0.0119 & 0.1393 & $-0,1035$ & 0,2372 & $-0,2409$ \\
\hline $28 \quad 42$ & 0.0497 & 0,0271 & 0,2178 & 0,4640 & $-0,1812$ \\
\hline 2843 & $-0,0331$ & 0,0833 & 0,2191 & 0,3065 & 0,0362 \\
\hline $28 \quad 44$ & 0,0942 & 0,1749 & $-0,0203$ & 0,1100 & $-0,0854$ \\
\hline 2845 & -0.0296 & 0.2306 & $-0,2221$ & 0,1685 & $-0,1053$ \\
\hline $28 \quad 46$ & 0.1394 & 0.2776 & 0,2343 & 0,4682 & 0,2109 \\
\hline 2847 & 0,0710 & 0,4851 & 0,4018 & 0.6434 & 0,3489 \\
\hline $28 \quad 48$ & -0.0160 & 0,0272 & -0.4633 & 0,3437 & $-0,2141$ \\
\hline 2849 & 0,1761 & 0.1880 & $-0,1036$ & 0,1213 & 0,1772 \\
\hline 2850 & 0.2871 & 0.2845 & $-0,1305$ & 0,4770 & 0,2071 \\
\hline 2851 & 0.6836 & 0.4648 & 0.0232 & 0.5307 & 0,1854 \\
\hline 2852 & 0.1220 & 0.2313 & 0.0717 & 0.3717 & 0.2316 \\
\hline
\end{tabular}




\begin{tabular}{|c|c|c|c|c|c|}
\hline $\begin{array}{c}\text { Pares de } \\
\text { Linhagens }\end{array}$ & local 1 & local 2 & local 3 & local 4 & média \\
\hline 2853 & -0.1435 & 0.0433 & -0.0026 & 0.4405 & -0.1011 \\
\hline 2854 & 0,0690 & 0.2637 & 0.0244 & 0.3390 & $0.2+19$ \\
\hline 2855 & 0,1249 & 0.0251 & $-0,1691$ & 0.3276 & $-0,2447$ \\
\hline 2856 & 0,0615 & 0.1606 & 0.0361 & 0.4698 & $-0,1186$ \\
\hline 2857 & 0,0101 & 0.0167 & -0.2350 & 0.4617 & 0.0562 \\
\hline 2858 & 0.6593 & 0,3906 & -0.2483 & 0.4130 & 0.1716 \\
\hline 2859 & $-0,0564$ & 0,1115 & $-0,1607$ & 0.3358 & 0,0009 \\
\hline 2860 & 0.0737 & 0,0218 & 0,3154 & 0.4848 & 0.2357 \\
\hline 2861 & 0.0732 & 0.4139 & -0.3986 & 0.4534 & 0.2611 \\
\hline 2862 & 0,7312 & 0,6528 & 0.5026 & 0,8040 & 0,3677 \\
\hline 2863 & 0,3507 & 0,4255 & 0.1032 & 0,4126 & 0.4223 \\
\hline 2864 & $-0,1095$ & 0.2882 & $-0,0362$ & 0.2631 & $-0,1380$ \\
\hline 2865 & 0.0106 & 0.0415 & -0.1797 & 0.3725 & 0.0794 \\
\hline 2866 & 0.0018 & 0,0868 & 0,2859 & 0,6223 & 0,1772 \\
\hline 2867 & 0.0590 & 0.1352 & -0.1957 & 0,3516 & 0.1480 \\
\hline 2868 & $-0,0024$ & 0.0051 & 0,3541 & 0.3927 & $-0,0613$ \\
\hline 2930 & 0.0195 & $-0,1905$ & $-0,1598$ & 0.0700 & $-0,3369$ \\
\hline 2931 & 0.8447 & 0,3044 & -0.2405 & 0.4192 & $-(0.1425$ \\
\hline 2932 & 0.2130 & 0.0084 & -0.0214 & 0.0389 & 0.5033 \\
\hline 2933 & 0.0208 & -0.0012 & -0.1826 & 0.0996 & 0.0422 \\
\hline 2934 & 0.7153 & 0.3962 & 0.1554 & 0.1839 & 0.2346 \\
\hline 2935 & 0.3328 & -0.0048 & 0.0893 & $0.00+4$ & -0.3335 \\
\hline 2936 & 0.0408 & -0.2014 & -0.2521 & 0.0827 & 0.4803 \\
\hline 2937 & 0.1272 & -0.0613 & -0.0575 & 0.0193 & 0.5350 \\
\hline 29) 38 & 0.0591 & -0.0862 & 0.1761 & -0.0011 & 0.5179 \\
\hline 2939 & 0.7502 & 0.3685 & 0.0094 & $0.1+96$ & 0.5994 \\
\hline 2940 & 0.0633 & -0.2343 & $-0,2570$ & 0.2348 & -0.3184 \\
\hline 2941 & 0.0246 & $-0,1140$ & -0.2130 & $-0,0860$ & 0,0298 \\
\hline 2942 & 0.0603 & -0.1945 & 0.2511 & 0.3244 & 0.0734 \\
\hline 2943 & 0.0202 & -0.0970 & 0,1419 & 0.3619 & 0,1803 \\
\hline 2944 & 0,0980 & -0.0356 & $-0,0869$ & 0,5077 & 0,1254 \\
\hline 2945 & 0.1371 & 0.2991 & -0.3151 & 0,2718 & 0.1673 \\
\hline 2946 & 0.2045 & 0.3249 & 0,1218 & 0.2293 & 0,6139 \\
\hline 2947 & 0.0984 & 0.2632 & 0.3086 & 0.1811 & 0.0472 \\
\hline 2948 & 0.0286 & $-0,1074$ & $-0,5226$ & 0,1355 & 0,0196 \\
\hline 2949 & 0.1564 & 0.0567 & -0.1833 & 0.1769 & -0.1899 \\
\hline 2950 & 0.3682 & 0.3209 & -0.0268 & 0.2214 & $-0,0679$ \\
\hline 2951 & 0.7407 & 0.3352 & -0.0285 & 0.3532 & 0,0738 \\
\hline 2952 & 0.1817 & 0,1474 & 0.1506 & 0.0378 & 0.5933 \\
\hline 2953 & 0.0326 & -0.1932 & -0.0566 & 0,2769 & 0,0897 \\
\hline 2954 & 0.1836 & 0.1863 & 0.1445 & $0.58+1$ & 0.6044 \\
\hline 2955 & 0.1419 & -0.1734 & -0.2758 & $-0.00+9$ & 0,0156 \\
\hline 2956 & 0.1069 & -0.0152 & -0.0155 & $-0,0995$ & 0.1102 \\
\hline 2957 & 0.0173 & -0.1168 & $-0,2486$ & -0.0121 & $-0,2977$ \\
\hline 2958 & 0.7289 & 0.2234 & -0.3194 & 0.0357 & $-0,1581$ \\
\hline
\end{tabular}




\begin{tabular}{|c|c|c|c|c|c|}
\hline $\begin{array}{l}\text { Pares de } \\
\text { Linhagens }\end{array}$ & local I & local 2 & local 3 & local $t$ & média \\
\hline 2959 & 0.0167 & -0.1738 & -0.2363 & 0.0823 & -0.3765 \\
\hline 2960 & 0.1328 & -0.1863 & 0.3391 & 0.1297 & 0.5887 \\
\hline 2961 & 0.1004 & 0.2007 & -0.5241 & 0,6734 & $-0,0794$ \\
\hline 2962 & 0.8290 & 0.6613 & 0.4826 & 0.5130 & 0.7618 \\
\hline 2963 & 0.4307 & 0.4082 & 0,0487 & 0,1552 & 0,7905 \\
\hline 2964 & 0.1289 & 0.3983 & -0.1192 & -0.0667 & 0.1822 \\
\hline 2965 & $-0,0068$ & -0.0653 & -0.2496 & 0.0912 & -0.3043 \\
\hline 2966 & 0.0998 & 0,0492 & 0.1552 & $-0,0511$ & -0.1062 \\
\hline 2967 & 0.0421 & -0.0580 & -0.3255 & 0.0206 & -0.2035 \\
\hline 2968 & 0,0489 & -0.2315 & 0,3113 & 0,1308 & 0,1330 \\
\hline 3031 & 0.7104 & 0.2340 & -0.2848 & 0.4296 & $-(0.1169$ \\
\hline 3032 & 0.0593 & $-0,1337$ & 0.2444 & $-0,0722$ & 0,4558 \\
\hline $30 \quad 33$ & $-0,1183$ & -0.1465 & 0.0484 & $-0,3377$ & -0.0209 \\
\hline 3034 & 0,5325 & 0,2889 & 0,3342 & 0,2998 & 0.2144 \\
\hline $30 \quad 35$ & 0.1541 & -0.2303 & 0.2830 & $-0,1148$ & -0.3657 \\
\hline $30 \quad 36$ & $-0,1076$ & $-0,2416$ & 0,0894 & $-0,0408$ & 0,4373 \\
\hline $30 \quad 37$ & $-0,0648$ & -0.2663 & 0,2840 & $-0,2066$ & 0.4933 \\
\hline $30 \quad 38$ & -0.2120 & -0.3587 & 0.1962 & -0.1300 & 0.4646 \\
\hline $30 \quad 39$ & 0.5788 & 0.3021 & 0.2017 & 0.2033 & 0.5462 \\
\hline $30+0$ & -0.1396 & $-0.30+1$ & -0.2462 & 0.1881 & -0.2400 \\
\hline $30+1$ & -0.2413 & -0.1625 & -0.0511 & $-0,3526$ & $-0.02+7$ \\
\hline $30+2$ & -0.2602 & $-0 .+155$ & 0.5051 & 0.1451 & 0.0190 \\
\hline $30+3$ & $-0.1+65$ & -0.3908 & 0.1503 & 0.0811 & 0.1715 \\
\hline $30+4$ & 0.0156 & -0.1655 & 0.1200 & 0.3295 & 0.0966 \\
\hline 30) 45 & -0.0106 & 0.2172 & -0.0591 & 0.0191 & 0.1166 \\
\hline $30+6$ & -0.0956 & 0.1978 & 0.1831 & -0.1335 & 0.5708 \\
\hline 3047 & -0.1939 & $0.18+7$ & 0.5192 & 0.1693 & 0.0126 \\
\hline 3048 & -0.0931 & -0.2277 & -0.1053 & -0.0867 & $-0,0065$ \\
\hline 3049 & 0.0208 & -0.1696 & -0.2061 & $-0,0799$ & -0.1613 \\
\hline 3050 & 0.1414 & 0,1651 & 0,2295 & $-0,1419$ & -0.0664 \\
\hline 3051 & 0,5541 & 0,1608 & $-0,0147$ & 0,3128 & 0,0712 \\
\hline $30 \quad 52$ & 0.0431 & 0.0909 & 0,3594 & $-0,2155$ & 0.5719 \\
\hline 3053 & -0.1245 & $-0,3005$ & -0.0970 & 0,1231 & 0.0577 \\
\hline 3054 & 0.0410 & 0.0030 & 0.2953 & 0.4613 & 0.5785 \\
\hline $30 \quad 55$ & $-0,1015$ & $-0,4737$ & 0,0098 & $-0,3968$ & $-0,0391$ \\
\hline 3056 & -0.1678 & -0.2921 & 0,2137 & -0.1386 & 0.0703 \\
\hline 3057 & -0.3317 & $-0,3298$ & $-0,1097$ & $-0,0780$ & $-0.3+02$ \\
\hline 3058 & 0.5773 & 0.0363 & -0.2818 & $-0,0576$ & -0.1838 \\
\hline 3059 & -0.2891 & -0.2335 & -0.2031 & $-0,1311$ & -0.4521 \\
\hline 3060 & $-0,1305$ & -0.3673 & 0.4661 & $-0,0420$ & 0.5498 \\
\hline 3061 & -0.0046 & 0.1398 & -0.1269 & 0.5624 & -0.0884 \\
\hline 3062 & 0.6577 & 0.5962 & 0.6222 & 0.3281 & 0,7202 \\
\hline 3063 & 0.2891 & 0.3009 & 0.2365 & -0.1426 & 0.7487 \\
\hline 3064 & 0.0017 & 0,2088 & 0.0107 & $-0,3303$ & 0.1467 \\
\hline $30 \quad 65$ & -0.0706 & -0.2147 & 0.0288 & $-0,3670$ & -0.2984 \\
\hline
\end{tabular}




\begin{tabular}{|c|c|c|c|c|c|}
\hline $\begin{array}{c}\text { Pares de } \\
\text { Linhagens }\end{array}$ & local 1 & local 2 & local 3 & local $t$ & média \\
\hline 3066 & -0.0799 & -0.0276 & 0.2333 & 0.0931 & -0.1652 \\
\hline 3067 & -0.1974 & -0.2176 & -0.0250 & -0.3591 & -0.2547 \\
\hline 3068 & -0.1396 & -0.3733 & 0.2846 & $-0,2974$ & 0,0953 \\
\hline $31 \quad 32$ & 0.7800 & 0.2961 & 0.1917 & 0.4221 & 0.6272 \\
\hline 3133 & 0,7644 & 0.3526 & 0.0024 & 0.4620 & 0,1811 \\
\hline 3134 & 0.3664 & 0,3114 & 0.2797 & 0.6275 & 0,3509 \\
\hline 3135 & 0,4122 & 0,0598 & 0.2629 & 0,5033 & $-0,1586$ \\
\hline 3136 & 0.7296 & 0.2494 & 0.0442 & 0,6169 & 0.6118 \\
\hline 3137 & 0,8139 & 0.2245 & 0,2795 & 0,3988 & 0.6475 \\
\hline 3138 & 0,6839 & 0,3083 & 0,1875 & 0.5049 & 0,6508 \\
\hline 3139 & 0.4426 & 0.2062 & 0.1264 & 0,5620 & 0,7083 \\
\hline 3140 & 0,7355 & 0,2873 & $-0,2975$ & 0,7154 & -0.1325 \\
\hline 3141 & 0,7196 & 0,3098 & $-0,0423$ & 0,2447 & 0.1694 \\
\hline 3142 & 0.7474 & 0.2252 & 0,4418 & 0,4615 & 0,2264 \\
\hline 3143 & 0.7212 & 0.2693 & 0,1038 & 0,4229 & 0.3066 \\
\hline 3144 & 0,8247 & 0,3220 & 0,1160 & 0,3663 & 0,2490 \\
\hline 3145 & 0.8157 & 0,6442 & -0.1615 & 0.2573 & 0,3247 \\
\hline 3146 & 0,8339 & 0,6193 & 0,1956 & 0,6085 & 0,7446 \\
\hline 3147 & 0.7274 & 0.5481 & 0.5040 & 0,5803 & 0,1557 \\
\hline 3148 & 0.7309 & 0.3176 & -0.2098 & 0.3921 & 0.1686 \\
\hline 3149 & 0.8323 & 0,4001 & -0.3251 & 0.1863 & -0.0291 \\
\hline 3150 & 0.4413 & 0.3986 & $0.1+23$ & 0.5320 & 0.0582 \\
\hline 3151 & 0.3861 & 0.2648 & -0.1223 & 0.4047 & 0.1655 \\
\hline 3152 & 0.8187 & 0.4864 & 0.3481 & 0,3263 & 0.7075 \\
\hline 3153 & 0.6791 & 0.2539 & -0.0943 & 0.4750 & 0.2323 \\
\hline 3154 & 0.7967 & 0.4480 & 0.2035 & 0.4867 & 0.7111 \\
\hline 3155 & 0.7996 & 0.2076 & $-0.02+2$ & 0,3623 & 0.1696 \\
\hline 3156 & 0.7389 & 0.3422 & 0,1236 & 0,3825 & 0,2680 \\
\hline $\begin{array}{ll}31 \quad 57 \\
\end{array}$ & 0.7237 & 0,2878 & $-0,1935$ & 0,4906 & $-0,0659$ \\
\hline 3158 & 0.4080 & 0.1584 & -0.4308 & 0,2911 & $-0,0036$ \\
\hline 3159 & 0,6470 & 0,3267 & $-0,1955$ & 0,3625 & $-0,1377$ \\
\hline 3160 & 0,7180 & 0.2635 & 0.4123 & 0,5117 & 0.7185 \\
\hline 3161 & 0,7696 & 0.5266 & -0.1852 & 0,5678 & 0,0355 \\
\hline 3162 & 0.5258 & 0,6400 & 0,5391 & 0,8347 & 0.8806 \\
\hline 3163 & 0.9764 & 0.6870 & 0,1810 & 0,4872 & 0,9099 \\
\hline 3164 & 0.8035 & 0,6933 & $-0,0362$ & 0.2893 & 0,3391 \\
\hline 3165 & 0,7748 & 0.3526 & $-0,0564$ & 0.4499 & $-0,0949$ \\
\hline 3166 & 0,7594 & 0.4244 & 0,2211 & 0,5786 & 0,0711 \\
\hline 3167 & 0,7565 & 0.3562 & $-0,0168$ & 0,3857 & -0.0310 \\
\hline 3168 & 0.7061 & 0.2283 & 0,2703 & 0,4829 & 0,2698 \\
\hline 3233 & 0.0281 & -0.0549 & 0.2759 & $-0,0328$ & 0,0646 \\
\hline 3234 & 0.6088 & 0.4541 & 0.2991 & 0.2405 & 0.2815 \\
\hline 3235 & 0.2253 & 0.0001 & 0,4437 & -0.1676 & 0.4829 \\
\hline 3236 & 0.0204 & -0.1399 & 0.2129 & -0.0086 & $-0,2646$ \\
\hline $\begin{array}{ll}32 & 37\end{array}$ & 0.1152 & -0.1872 & 0.3074 & $-0,0248$ & -0.1955 \\
\hline
\end{tabular}




\begin{tabular}{|c|c|c|c|c|c|}
\hline $\begin{array}{c}\text { Pares de } \\
\text { Linhagens }\end{array}$ & local l & local 2 & local 3 & local 1 & média \\
\hline 3238 & -0.0182 & $-0.05+6$ & 0.5496 & -0.1613 & -0.1378 \\
\hline 3239 & 0.7249 & 0.4242 & 0.1465 & 0,1651 & -0.0720 \\
\hline 3240 & 0.1114 & -0.0735 & 0,1944 & 0.1372 & 0,5243 \\
\hline 3241 & 0.0477 & $-0,0940$ & 0.1610 & $-0,1750$ & 0.0590 \\
\hline 3242 & 0.0946 & $-0,1114$ & 0,4350 & 0.2161 & 0,1087 \\
\hline 3243 & 0.0669 & $-0,0444$ & 0.4806 & 0.1609 & 0.2561 \\
\hline 3244 & 0,1364 & $-0,0546$ & 0.2375 & 0.3114 & 0,1795 \\
\hline 3245 & 0.0678 & 0,3879 & 0.1555 & 0,0772 & 0,1928 \\
\hline 3246 & 0.1890 & 0,3586 & 0.4755 & 0.1505 & $-0,0133$ \\
\hline 3247 & 0,0562 & 0,2942 & 0,6484 & 0,2288 & 0.7176 \\
\hline 3248 & 0,0070 & $-0,0245$ & $-0,0443$ & $-0,0271$ & 0,0707 \\
\hline 3249 & 0.1377 & 0.1233 & 0.2106 & $-0,0892$ & 0,5780 \\
\hline 3250 & 0.2719 & 0.3319 & 0.0918 & 0.0494 & 0.6369 \\
\hline 3251 & 0.6846 & 0.3923 & 0,3539 & 0,3453 & 0,5119 \\
\hline 3252 & 0.1814 & 0.1980 & 0.2172 & $-0,1422$ & $-0,0270$ \\
\hline 3253 & $-0,1303$ & -0.1020 & 0.2943 & 0,2393 & 0.1453 \\
\hline 3254 & 0.1262 & 0.1541 & 0,2071 & 0.3572 & $-0,0630$ \\
\hline 3255 & 0.0918 & -0.1018 & 0.1843 & $-0,1520$ & 0,0613 \\
\hline 3256 & 0.0615 & 0,0362 & 0.2656 & $-0,0851$ & 0,1514 \\
\hline 3257 & 0.0754 & -0.0390 & 0.0812 & $-0,2066$ & 0.4722 \\
\hline 3258 & 0.6738 & 0.2810 & 0.1228 & 0.0492 & 0,5639 \\
\hline 3259 & -0.0516 & 0.0337 & 0.1683 & -10.2026 & 0.4070 \\
\hline 3260 & 0.0386 & -0.1264 & 0,4942 & 0.0390 & $-0,0406$ \\
\hline 3261 & 0.0671 & 0.2503 & $-0,0097$ & 0.5467 & 0.6329 \\
\hline 3262 & 0.7540 & 0.7590 & $0.655 t$ & 0.4099 & 0.2086 \\
\hline 3263 & 0.2362 & 0.4170 & 0.3516 & -0.0103 & 0.2237 \\
\hline 3264 & 0.1310 & 0.4563 & 0.2959 & -0.1501 & 0.2226 \\
\hline 3265 & 0.0809 & -0.0085 & 0.0789 & -0.0471 & 0,4936 \\
\hline 3266 & $0.085 \mathrm{I}$ & 0,0772 & 0,5324 & 0,0736 & 0,5773 \\
\hline 3267 & 0.0686 & $-0,0023$ & 0,0964 & -0.1251 & 0.5606 \\
\hline 3268 & -0.0379 & $-0,1403$ & 0,5426 & $-0,0070$ & 0,1897 \\
\hline $33 \quad 34$ & 0.6088 & 0.3749 & 0,3982 & 0,3237 & $-0,0001$ \\
\hline $33 \quad 35$ & 0.1994 & 0.0296 & 0,1397 & $-0,0837$ & 0,0197 \\
\hline $33 \quad 36$ & -0.0625 & -0.0931 & 0,0741 & 0,0093 & 0.0492 \\
\hline $33 \quad 37$ & -0.0134 & $-0,0824$ & 0,0918 & $-0,1548$ & 0,0984 \\
\hline $33 \quad 38$ & -0.1243 & -0.0662 & 0.3025 & -0.0876 & 0,0842 \\
\hline $33 \quad 39$ & 0.6723 & 0.4496 & 0,2790 & 0,2450 & 0,1688 \\
\hline 3340 & -0.0294 & $-0,0891$ & $-0,0416$ & 0.2130 & 0,0836 \\
\hline $33+1$ & $-0,1511$ & -0.0439 & 0.0172 & $-0,2987$ & $-0,3496$ \\
\hline 3342 & $-0,0608$ & $-0,1230$ & 0.3634 & 0,1588 & $-0,2395$ \\
\hline $33 \quad 43$ & -0.0553 & $-0,0495$ & 0.3499 & 0.1043 & $-0,0162$ \\
\hline 3344 & -0.0084 & -0.0145 & 0.0629 & 0.3751 & $-0,1598$ \\
\hline 3345 & 0.0156 & 0.3884 & $-0,0414$ & 0.0610 & $-0,0671$ \\
\hline $33+6$ & 0.0680 & 0.3860 & 0.2860 & $-0,0799$ & 0,2073 \\
\hline $33+7$ & -0.0799 & 0,3522 & 0.3962 & 0.2161 & 0.2848 \\
\hline
\end{tabular}




\begin{tabular}{|c|c|c|c|c|c|}
\hline $\begin{array}{c}\text { Pares de } \\
\text { Linhagens }\end{array}$ & local l & local 2 & local 3 & local $t$ & média \\
\hline 3348 & -0.1298 & -0.1638 & -0.1339 & -0.0710 & $-(0.2854$ \\
\hline 3349 & 0.0686 & 0,0579 & 0.0710 & -0.0261 & 0.1247 \\
\hline 3350 & 0,2317 & 0.2492 & 0.2027 & -0.0799 & 0,1852 \\
\hline 3351 & 0.6560 & 0.3585 & 0.1991 & 0,3634 & 0,1367 \\
\hline 3352 & 0,1080 & 0,0541 & 0,3223 & $-0,1996$ & 0,1812 \\
\hline 3353 & $-0,1117$ & $-0,1184$ & 0.0917 & 0.1626 & $-0,1654$ \\
\hline 3354 & 0.0636 & 0.2176 & 0.2882 & 0.5099 & 0.2086 \\
\hline 3355 & 0,0101 & -0.1064 & $-0,0755$ & $-0,3214$ & -0.3226 \\
\hline 3356 & -0.0395 & 0.0330 & 0.2642 & $-0,0884$ & -0.1701 \\
\hline $33 \quad 57$ & -0.1072 & -0.1500 & $-0,0088$ & $-0,0291$ & 0,0079 \\
\hline $33 \quad 58$ & 0.6447 & 0,2852 & -0.0762 & -0.0052 & 0,1233 \\
\hline 3359 & $-0,1817$ & 0,0262 & 0,0012 & $-0,1236$ & $-0,0565$ \\
\hline 3360 & -0.0272 & -0.1449 & 0,4528 & 0.0062 & 0.1843 \\
\hline 3361 & -0.0364 & 0,2806 & $-0,1184$ & 0,5934 & 0.1993 \\
\hline 3362 & 0.7351 & 0,7303 & 0,5694 & 0,3573 & 0,3736 \\
\hline 3363 & 0,2854 & 0,3888 & 0.2896 & $-0,0913$ & 0,3866 \\
\hline 3364 & 0.0561 & 0,3764 & -0.0832 & $-0,2873$ & $-0,0735$ \\
\hline 3365 & $-0,0970$ & $-0,1629$ & 0.1203 & $-0,3763$ & 0.0264 \\
\hline 3366 & -0.0624 & 0.1144 & 0.3164 & 0,1349 & 0,1420 \\
\hline $33 \quad 67$ & -0.0786 & -0.0132 & 0.0382 & $-0,2868$ & 0.0909 \\
\hline 3368 & -0.1327 & -0.1566 & 0.5003 & -0.2229 & $-0,1249$ \\
\hline 3435 & 0.1889 & 0.1352 & 0.6219 & 0.2346 & 0.2355 \\
\hline $3+36$ & 0.5785 & 0.3789 & 0.3122 & 0.3265 & 0.2613 \\
\hline $34 \quad 37$ & 0.6758 & 0.3743 & 0.5461 & 0.2573 & 0.3239 \\
\hline 3438 & 0.4952 & 0.3618 & 0.5394 & 0.2450 & 0.3160 \\
\hline $3+39$ & 0.1416 & 0.2766 & 0.2127 & 0.2081 & 0,3398 \\
\hline 3440 & 0.5829 & 0.3629 & 0.2714 & 0,4009 & 0.2492 \\
\hline $3+41$ & 0,5521 & 0,4411 & 0.3520 & 0,2036 & 0,0206 \\
\hline 3442 & 0.5800 & 0,2835 & 0,6177 & 0,5009 & 0,0493 \\
\hline 3443 & 0,5684 & 0,3163 & 0,5064 & 0,5329 & 0.1320 \\
\hline 3444 & 0,6767 & 0,4252 & 0.4869 & 0.7259 & 0,1146 \\
\hline 3445 & 0.6474 & 0.6912 & 0.2901 & 0,4900 & 0,1556 \\
\hline 3446 & 0,6643 & 0,7029 & 0.5331 & 0,4495 & 0,4070 \\
\hline 3447 & 0.5677 & 0.6920 & 0,7668 & 0,4485 & 0,4806 \\
\hline 3448 & 0.5615 & 0,2892 & 0,2083 & 0,3727 & $-0,0617$ \\
\hline $34 \quad 49$ & 0,6693 & 0.3660 & 0,3500 & 0,3846 & 0,2953 \\
\hline 3450 & 0,1973 & 0,2439 & 0,2988 & 0,3239 & 0,3183 \\
\hline 3451 & $-0,0105$ & 0.0838 & 0.3839 & 0,4221 & 0.2083 \\
\hline $34 \quad 52$ & 0.6750 & 0.4302 & 0.3926 & 0.2460 & 0,3293 \\
\hline 3453 & 0.4969 & 0.3164 & 0.4275 & 0,4930 & 0,0740 \\
\hline 3454 & 0,6614 & 0.5842 & 0,3792 & 0,7759 & 0,3854 \\
\hline 3455 & 0,6228 & 0,2538 & 0,3410 & 0,2265 & 0,0012 \\
\hline 3456 & 0.5612 & 0,3845 & 0.2607 & 0,1878 & 0,0668 \\
\hline 3457 & 0.5558 & 0.2581 & 0.2448 & 0.2326 & 0,1974 \\
\hline 3458 & 0.0359 & 0.0967 & 0.2543 & 0.1827 & 0,2643 \\
\hline
\end{tabular}




\begin{tabular}{|c|c|c|c|c|c|}
\hline $\begin{array}{c}\text { Pares de } \\
\text { Linhagens }\end{array}$ & local I & local 2 & local 3 & local 4 & média \\
\hline 3459 & 0.4477 & $0 .+129$ & 0.2945 & 0.2933 & 0.1619 \\
\hline 3460 & 0.5265 & 0,3222 & 0,6215 & 0.3414 & 0.3557 \\
\hline 3461 & 0,6183 & 0.6269 & 0.1819 & 0.8744 & 0,3951 \\
\hline $34 \quad 62$ & 0,1512 & 0.5180 & 0.7675 & 0.4959 & 0,4841 \\
\hline 3463 & 0,8016 & 0,6910 & 0.4848 & 0,3490 & 0,5703 \\
\hline 3464 & 0.6493 & 0,5873 & 0.4271 & 0.2270 & 0.1244 \\
\hline $34 \quad 65$ & 0,6267 & 0,3238 & 0,3764 & 0.3128 & 0,2139 \\
\hline 3466 & 0.5999 & 0.5401 & 0.5550 & 0.2678 & 0,3466 \\
\hline 3467 & 0.5877 & 0.4093 & 0,3001 & 0.2415 & 0.3054 \\
\hline $34 \quad 68$ & 0,5260 & 0,2883 & 0,6732 & 0,3399 & 0,0895 \\
\hline $35 \quad 36$ & 0,2045 & $-0,0629$ & 0.3145 & $-0,0808$ & 0.4682 \\
\hline $35 \quad 37$ & 0.2710 & $-0,1903$ & 0.3100 & -0.0617 & 0.5146 \\
\hline $\begin{array}{ll}35 & 38 \\
\end{array}$ & 0.1049 & -0.1341 & 0.6133 & -0.3080 & 0.5051 \\
\hline $35 \quad 39$ & 0,3184 & 0,1381 & 0,5260 & 0,2005 & 0,5830 \\
\hline 3540 & 0.1824 & $-0,0497$ & 0.2892 & 0.1446 & -0.2826 \\
\hline 3541 & 0,1583 & 0,0121 & 0,3186 & $-0,1390$ & 0.0159 \\
\hline 3542 & 0.2070 & -0.2309 & 0,3254 & 0.2309 & 0,0668 \\
\hline 3543 & 0.1787 & -0.2761 & 0.5977 & 0.2220 & 0.1819 \\
\hline 3544 & 0.2961 & -0.0068 & 0,0764 & 0.4001 & 0,1203 \\
\hline $35+5$ & 0.2759 & 0.3377 & 0.2774 & 0.1734 & 0.1526 \\
\hline $35+6$ & 0.3039 & 0.2598 & 0.6263 & 0.1265 & 0.6019 \\
\hline 3547 & 0.1646 & 0.2153 & 0.2889 & 0.2107 & 0.0189 \\
\hline $35+8$ & 0.1507 & -0.0308 & $0.10+0$ & $0.09+2$ & 0.0131 \\
\hline $35+9$ & 0.2910 & -0.1130 & 0.3262 & 0.0392 & -0.1911 \\
\hline $35 \quad 50$ & -0.0611 & $0.06+7$ & $0.22+2$ & 0.0641 & -0.0686 \\
\hline 3551 & 0.2549 & -0.1044 & $0.4+27$ & 0.3879 & 0,0777 \\
\hline $35 \quad 52$ & 0.3255 & 0.1954 & 0.3729 & -0.1045 & 0.5858 \\
\hline 3553 & 0.1107 & $-0,0926$ & 0.3878 & 0,2257 & 0,0831 \\
\hline 3554 & 0.2590 & 0,0003 & 0.3975 & 0,4778 & 0,5886 \\
\hline $35 \quad 55$ & 0.2668 & -0.3543 & 0,0106 & $-0,2026$ & 0.0091 \\
\hline $35 \quad 56$ & 0,1946 & $-0,1883$ & 0.5329 & $-0,1129$ & 0,1121 \\
\hline $35 \quad 57$ & 0,1710 & $-0,1628$ & 0.3295 & $-0,1807$ & $-0,2973$ \\
\hline $35 \quad 58$ & 0.2612 & $-0,2326$ & 0.2335 & 0,0916 & $-0,1442$ \\
\hline $35 \quad 59$ & 0.0517 & $-0,0732$ & 0.1967 & -0.0828 & $-0,4047$ \\
\hline 3560 & 0.1595 & -0.0941 & 0.5564 & 0.0772 & 0,5759 \\
\hline 3561 & 0.2041 & 0,2370 & 0,1003 & 0,5902 & $-0,1142$ \\
\hline 3562 & 0.3712 & 0.4765 & 0,7940 & 0,4282 & 0.7577 \\
\hline 3563 & 0.4451 & 0.3851 & 0.5424 & 0.0492 & 0,7743 \\
\hline 3564 & 0.2899 & 0.2456 & 0,0986 & -0.1175 & 0.1826 \\
\hline 3565 & 0.2185 & 0.0055 & 0.2561 & $-0,0954$ & $-0,3025$ \\
\hline 3566 & 0.1961 & 0.1243 & 0,6284 & 0,0361 & -0.1399 \\
\hline 3567 & 0.1987 & 0.0050 & 0,2344 & -0.1733 & $-0,2273$ \\
\hline 3568 & 0.1104 & -0.1308 & 0.6829 & $-0,0428$ & 0,1263 \\
\hline $36 \quad 37$ & 0.0678 & -0.2073 & 0.1617 & $-0,0004$ & $-0,2242$ \\
\hline $36 \times 38$ & -0.1159 & -0.1090 & 0.2553 & -0.1033 & -0.2343 \\
\hline
\end{tabular}




\begin{tabular}{|c|c|c|c|c|c|}
\hline $\begin{array}{c}\text { Pares de } \\
\text { Linhagens }\end{array}$ & local I & local 2 & local 3 & local $f$ & média \\
\hline 3639 & 0.6133 & 0.3604 & 0.1981 & 0.2172 & -0.0935 \\
\hline 3640 & $-0,0272$ & -0.2446 & 0,0326 & 0.1779 & 0,5014 \\
\hline 3641 & $-0,1547$ & $-0,1698$ & 0.0166 & $-0,0646$ & 0,0411 \\
\hline 3642 & $-0,0525$ & $-0,2193$ & 0,4934 & 0.3213 & 0,0797 \\
\hline 3643 & $-0,1484$ & $-0,1179$ & 0,3338 & 0.3217 & 0,2172 \\
\hline 3644 & 0,0179 & -0.1406 & 0.1168 & 0.4752 & 0,1577 \\
\hline .3645 & $-0,0080$ & 0.3004 & 0.0040 & 0,2482 & 0,1600 \\
\hline 3646 & 0,0618 & 0.2983 & 0.2904 & 0,0824 & $-0,0556$ \\
\hline 3647 & -0.0673 & 0.2182 & 0.5192 & 0.2417 & 0.7053 \\
\hline 3648 & -0.0626 & $-0,1459$ & $-0,1804$ & 0,1531 & 0,0437 \\
\hline 3649 & 0,1564 & 0,0370 & 0,1082 & 0,1538 & 0.5584 \\
\hline 3650 & 0,1999 & 0.2706 & 0.2366 & 0.1385 & 0.6229 \\
\hline 3651 & 0.6063 & 0,3181 & 0.2181 & 0,4183 & 0.4879 \\
\hline $36 \quad 52$ & $-0,0110$ & 0,1148 & 0,3005 & 0.0545 & -0.0407 \\
\hline 3653 & -0.2043 & $-0,2211$ & 0,1741 & 0.2520 & 0.0948 \\
\hline 3654 & -0.0263 & 0.1263 & 0,3521 & 0.5529 & $-0,0534$ \\
\hline 3655 & 0.0630 & $-0,2134$ & $-0,0737$ & $-0,0654$ & 0,0344 \\
\hline 3656 & -0.0384 & $-0,0435$ & 0.1650 & 0.0236 & 0.1275 \\
\hline 3657 & -0.0936 & -0.1515 & 0.1311 & $-0,1309$ & 0,4568 \\
\hline 3658 & 0.6057 & 0,1965 & 0.0211 & 0.1666 & 0.5410 \\
\hline 3659 & -0.1711 & $-0,1100$ & -0.0076 & 0.0235 & 0.3885 \\
\hline $36 \quad 60$ & -0.0339 & -0.2469 & 0.5164 & 0.0840 & -0.0939 \\
\hline $36 \quad 61$ & 0.0116 & 0.1700 & -0.2075 & 0,6532 & 0,6182 \\
\hline $36 \quad 62$ & 0.6755 & 0.6707 & 0.7069 & 0.4252 & 0.1839 \\
\hline 3663 & 0.3419 & 0.3619 & 0.2374 & 0,0604 & 0.1771 \\
\hline 3664 & -0.1333 & 0.3710 & 0.1091 & -0.0432 & 0.1937 \\
\hline 3665 & -0.0191 & $-0,1024$ & 0.0360 & $-0,0024$ & 0.4749 \\
\hline 3666 & $-0,0795$ & $-0,0017$ & 0,3583 & 0.0207 & 0,5509 \\
\hline $36 \quad 67$ & $-0,0027$ & -0.1060 & $-0,0368$ & $-0,0377$ & 0.5433 \\
\hline $36 \quad 68$ & $-0,0513$ & -0.2972 & 0.5125 & 0,0313 & 0,1673 \\
\hline 3738 & 0,0014 & $-0,1378$ & 0,4969 & -0.0801 & $-0,1532$ \\
\hline $37 \quad 39$ & 0.7300 & 0,3693 & 0,4340 & 0,1961 & $-0,0356$ \\
\hline 3740 & 0,0129 & -0.1246 & 0,1788 & 0,1829 & 0,5504 \\
\hline 3741 & -0.0237 & -0.0977 & 0.0952 & $-0,2399$ & 0,0927 \\
\hline 3742 & $-0,0074$ & -0.2449 & 0,5105 & 0,1134 & 0,1451 \\
\hline 3743 & 0.0223 & $-0,2149$ & 0.5012 & 0,1761 & 0.2580 \\
\hline 3744 & 0,1250 & $-0,1284$ & 0,1612 & 0,3942 & 0,1994 \\
\hline 3745 & 0.1357 & 0,3264 & 0,1800 & 0,0510 & 0.2301 \\
\hline 3746 & 0.1064 & 0.2554 & 0.3493 & -0.0164 & 0,0210 \\
\hline 3747 & -0.0529 & 0.1662 & 0.4597 & 0,1922 & 0,7466 \\
\hline 3748 & 0.0316 & -0.0925 & 0.0256 & 0.0488 & 0,1015 \\
\hline $37 \quad 49$ & 0.0721 & $-0,0508$ & 0.2834 & $-0,0474$ & 0,6017 \\
\hline $37 \quad 50$ & 0,3018 & 0.2084 & 0.3692 & $-0,0150$ & 0.6743 \\
\hline 3751 & 0.7056 & 0.2481 & 0.4366 & 0.2995 & 0.5320 \\
\hline 3752 & 0.1930 & 0.1326 & 0.3997 & -0.2133 & -0.0175 \\
\hline
\end{tabular}




\begin{tabular}{|c|c|c|c|c|c|}
\hline $\begin{array}{c}\text { Pares de } \\
\text { Linhagens }\end{array}$ & local 1 & local 2 & local 3 & local 4 & média \\
\hline 3753 & 0.0165 & $-0.15+6$ & 0.3060 & 0.0517 & $0.149 \mathrm{I}$ \\
\hline 3754 & 0.1415 & -0.0142 & 0.4847 & 0.5136 & $-0,0488$ \\
\hline 3755 & 0.0635 & $-0,3158$ & 0.0640 & $-0,3022$ & 0.0997 \\
\hline 3756 & 0.0482 & $-0,1357$ & 0,3866 & $-0,1392$ & 0.1978 \\
\hline $37 \quad 57$ & $-0,0536$ & $-0,1792$ & 0.1858 & $-0,0961$ & 0.5196 \\
\hline 3758 & 0.7182 & 0.1253 & 0,1743 & 0,0248 & 0.6059 \\
\hline 3759 & -0.0539 & $-0,0722$ & 0,2379 & $-0,0685$ & 0.4492 \\
\hline 3760 & 0,0673 & $-0,1743$ & 0.5870 & -0.1324 & $-0,0464$ \\
\hline 3761 & 0.0695 & 0,1822 & -0.0098 & 0,6186 & 0.6563 \\
\hline $37 \quad 62$ & 0.8175 & 0,6856 & 0,6705 & 0,3830 & 0,2605 \\
\hline 3763 & 0,3614 & 0,3444 & 0,3395 & $-0,1205$ & 0.2068 \\
\hline 3764 & 0,1828 & 0,2991 & 0,2391 & $-0,1997$ & 0,2663 \\
\hline 3765 & 0,0316 & $-0,0532$ & 0.1807 & $-0,1667$ & 0,5259 \\
\hline 3766 & 0.0842 & 0,0340 & 0,4358 & 0,0219 & 0,6079 \\
\hline 3767 & $-0,0609$ & $-0,0591$ & 0,0256 & $-0,2706$ & 0,5871 \\
\hline 3768 & $-0,0164$ & -0.2154 & 0,6119 & $-0,1290$ & 0,2125 \\
\hline $38 \quad 39$ & 0,5835 & 0,3525 & 0,4606 & 0,1808 & $-0,0749$ \\
\hline 3840 & -0.1643 & $-0,1878$ & 0.1433 & 0,1648 & 0,5446 \\
\hline $38+1$ & -0.2209 & $-0,1083$ & 0.2377 & $-0,1568$ & 0,0806 \\
\hline $38 \quad 42$ & -0.1901 & $-0,3214$ & 0.8070 & 0,2367 & 0.0994 \\
\hline 3843 & $-0,1533$ & -0.3405 & 0,4503 & 0.2330 & 0,2520 \\
\hline 3844 & -0.0044 & -0.0422 & 0,4585 & 0.3847 & 0,2007 \\
\hline $38 \quad 45$ & -0.0447 & 0.2780 & 0.2469 & 0.1547 & 0,1971 \\
\hline $38+6$ & $-0,0407$ & 0.2585 & 0,3604 & 0,1093 & 0,0109 \\
\hline $38+7$ & -0.1785 & 0.2729 & 0.8183 & 0.1941 & 0.7419 \\
\hline $38+8$ & -0.1782 & -0.1201 & 0.2146 & 0.1014 & 0,0979 \\
\hline 3849 & 0.0776 & $-0,0899$ & 0.2675 & 0.0252 & 0,5993 \\
\hline $38 \quad 50$ & 0.0841 & 0.2525 & 0,5793 & 0,0496 & 0,6695 \\
\hline $38 \quad 51$ & 0.5334 & 0,2341 & 0,3691 & 0,3743 & 0,5268 \\
\hline $38 \quad 52$ & 0,0005 & 0,1677 & 0.6357 & $-0,0851$ & 0,0483 \\
\hline $38 \quad 53$ & $-0,1806$ & $-0,2141$ & 0,2090 & 0,2238 & 0,1134 \\
\hline 3854 & $-0,0396$ & 0,0621 & 0,6031 & 0,4644 & 0,0452 \\
\hline $38 \quad 55$ & $-0,0764$ & $-0,3254$ & 0,3406 & -0.2182 & 0,0666 \\
\hline $38 \quad 56$ & $-0,2590$ & -0.2111 & 0,4346 & $-0,1329$ & 0.1745 \\
\hline 3857 & -0.2003 & $-0,2133$ & 0,2855 & $-0,2039$ & 0,4980 \\
\hline $38 \quad 58$ & 0.5606 & 0,1308 & 0.1677 & 0.0780 & 0.5842 \\
\hline $38 \quad 59$ & $-0,3871$ & $-0,1801$ & 0,1984 & $-0,0718$ & 0,4275 \\
\hline 3860 & -0.2805 & -0.2437 & 0.7268 & 0,0604 & $-0,0689$ \\
\hline 3861 & -0.0785 & 0,2159 & 0,1953 & 0,5950 & 0,6548 \\
\hline 3862 & 0.6035 & 0.6591 & 0,8416 & 0,4210 & 0,2369 \\
\hline 3863 & 0.1996 & 0,3757 & 0,4636 & 0,0319 & 0,1970 \\
\hline 3864 & $-0,0190$ & 0,3042 & 0,3361 & $-0,1389$ & 0,2480 \\
\hline 3865 & $-0,0946$ & -0.1327 & 0,4073 & $-0,0954$ & 0,5161 \\
\hline $38 \quad 66$ & $-0,1856$ & 0.0501 & 0.3846 & 0.0145 & 0,5808 \\
\hline 3867 & -0.0970 & -0.1114 & 0.3349 & -0.1889 & 0.5704 \\
\hline
\end{tabular}




\begin{tabular}{|c|c|c|c|c|c|}
\hline $\begin{array}{c}\text { Pares de } \\
\text { Linhagens }\end{array}$ & local 1 & local 2 & local 3 & local $f$ & média \\
\hline 3868 & -0.2312 & -0.2250 & 0.6278 & -0.0577 & 0.1992 \\
\hline 3940 & 0,6454 & 0.3429 & 0,1669 & 0,3966 & 0.6259 \\
\hline 3941 & 0,6052 & 0,3973 & 0.2527 & 0.0736 & 0.1653 \\
\hline 3942 & 0.6256 & 0,3186 & 0,4343 & 0.5107 & 0,1942 \\
\hline 3943 & 0.6306 & 0,3318 & 0.4615 & 0.4901 & 0,3526 \\
\hline 3944 & 0.7551 & 0,4400 & 0,3620 & 0.5992 & 0.2848 \\
\hline 3945 & 0,7241 & 0,6848 & 0,1559 & 0,3546 & 0,2973 \\
\hline 3946 & 0,7150 & 0.6799 & 0,4599 & 0,3242 & 0.1219 \\
\hline 3947 & 0,6328 & 0.6419 & 0,7334 & 0.3289 & 0,8158 \\
\hline 3948 & 0,6579 & 0,4099 & 0,0615 & 0,2482 & 0,1887 \\
\hline 3949 & 0.7679 & 0,4780 & 0,1799 & 0,2939 & 0.6805 \\
\hline 3950 & 0,3219 & 0,4609 & 0,1613 & 0,2630 & 0,7257 \\
\hline 3951 & 0,1055 & 0,2321 & 0,2999 & 0,3014 & 0,5720 \\
\hline 3952 & 0,7490 & 0,5812 & 0,2753 & 0,2058 & 0,1257 \\
\hline $39 \quad 53$ & 0,6019 & 0,3510 & 0,3070 & 0,4549 & 0,2297 \\
\hline 3954 & 0,7262 & 0,5380 & 0,1949 & 0,6767 & 0.1119 \\
\hline 3955 & 0.7059 & 0.2904 & 0,2020 & 0,1679 & 0,1587 \\
\hline 3956 & 0,6367 & 0,4014 & 0,2149 & 0,1613 & 0,2607 \\
\hline 3957 & 0.5927 & 0,3769 & 0,0692 & 0.1358 & 0,5743 \\
\hline 3958 & 0,0620 & 0.1251 & 0,1032 & 0,0424 & 0,6325 \\
\hline 3959 & 0.5367 & 0.3638 & 0.2028 & 0.1815 & 0,5091 \\
\hline 3960 & 0.6391 & 0.3342 & 0.5506 & 0,2729 & 0.0673 \\
\hline 3961 & 0.7167 & 0.6174 & 0.0982 & 0.7742 & 0.7322 \\
\hline 3962 & 0,2451 & 0.5470 & 0.7102 & 0.4351 & 0.2457 \\
\hline 3963 & 0.9358 & 0.7810 & 0.4379 & 0.2597 & 0,3203 \\
\hline 3964 & 0.6805 & 0,7528 & 0,2802 & 0.0935 & 0,3363 \\
\hline 3965 & 0.6924 & 0.4213 & 0.2313 & 0.2366 & 0.5974 \\
\hline 3966 & 0,6558 & 0,5028 & 0.5391 & 0,2159 & 0,6712 \\
\hline 3967 & 0,6606 & 0,4229 & 0,2338 & 0,1930 & 0,6519 \\
\hline 3968 & 0,6323 & 0,3231 & 0,6326 & 0,2639 & 0,2896 \\
\hline $40 \quad 41$ & $-0,1039$ & $-0,1589$ & $-0,1250$ & 0,1523 & 0,0720 \\
\hline $40 \quad 42$ & $-0,1009$ & $-0,2445$ & 0,4942 & 0,4009 & 0,1155 \\
\hline $\begin{array}{ll}40 & 43 \\
\end{array}$ & $-0,1747$ & $-0,1591$ & 0,1235 & 0,4367 & 0,1844 \\
\hline $40 \quad 44$ & 0,0850 & $-0,1060$ & 0,1440 & 0,6584 & 0,1517 \\
\hline $40 \quad 45$ & 0,0693 & 0,2675 & $-0,1414$ & 0,4155 & 0,1960 \\
\hline $40 \quad 46$ & 0,0568 & 0,2938 & 0,0945 & 0,3144 & 0.6344 \\
\hline $40 \quad 47$ & $-0,1195$ & 0,2608 & 0,5098 & 0,3756 & 0,0824 \\
\hline $40 \quad 48$ & -0.0927 & -0.1719 & $-0,1897$ & 0,2705 & 0,0346 \\
\hline $40 \quad 49$ & 0,0813 & 0,0181 & -0.2011 & 0,3142 & $-0,2114$ \\
\hline 4050 & 0,1867 & 0,2795 & 0,2036 & 0,2649 & $-0,0481$ \\
\hline 4051 & 0.5919 & 0.3023 & -0.0304 & 0,5802 & 0,0768 \\
\hline $40 \quad 52$ & 0.0742 & 0.1332 & 0,3517 & 0,1707 & 0,5971 \\
\hline $40 \quad 53$ & $-0,0855$ & -0.2505 & -0.1474 & 0,4315 & 0.1103 \\
\hline $40 \quad 54$ & $-0,0192$ & 0.1545 & 0.2689 & 0.6779 & 0,6081 \\
\hline $40 \quad 55$ & 0.0477 & -0.2346 & -0.0045 & 0.1565 & 0,0585 \\
\hline
\end{tabular}




\begin{tabular}{|c|c|c|c|c|c|}
\hline $\begin{array}{c}\text { Pares de } \\
\text { Linhagens }\end{array}$ & local I & local 2 & local 3 & local $t$ & média \\
\hline 4056 & -0.0795 & -0.0821 & 0.1333 & 0.1571 & 0.1468 \\
\hline 4057 & -0.1476 & -0.1750 & -0.2444 & 0.1455 & -0.2312 \\
\hline 4058 & 0.6333 & 0.1805 & -0.4104 & 0,3552 & -0.1067 \\
\hline 4059 & $-0,2030$ & -0.1660 & -0.1614 & 0.1887 & -0.3059 \\
\hline 4060 & $-0,0952$ & $-0,3349$ & 0,4576 & 0,2988 & 0,6010 \\
\hline 4061 & $-0,0462$ & 0.1855 & $-0,2291$ & 0,7717 & $-0,0810$ \\
\hline 4062 & 0,7035 & 0,6457 & 0,5357 & 0,5297 & 0,7849 \\
\hline 4063 & 0,3149 & 0,3720 & 0,1482 & 0.2394 & 0.8055 \\
\hline 4064 & 0,0562 & 0,3549 & 0,0210 & 0,1777 & 0.2107 \\
\hline 4065 & $-0,0737$ & $-0,1610$ & 0,0118 & 0,1986 & $-0,2771$ \\
\hline 4066 & $-0,0629$ & 0.0002 & 0.1201 & 0,2660 & $-0,0587$ \\
\hline 4067 & $-0,0723$ & -0.1626 & $-0,0713$ & 0,1824 & $-0,1543$ \\
\hline 4068 & $-0,1440$ & $-0,3319$ & 0,2984 & 0,2527 & 0.1587 \\
\hline 4142 & $-0,1574$ & $-0,1651$ & 0,5416 & 0,0887 & $-0,2635$ \\
\hline 4143 & -0.1494 & -0.0802 & 0,2228 & 0.0155 & $-0,0396$ \\
\hline 4144 & -0.0366 & $-0,0299$ & 0,0677 & 0,2290 & -0.1995 \\
\hline 4145 & -0.0063 & 0,3460 & -0.0525 & $-0,1067$ & $-0,0726$ \\
\hline 4146 & $-0,0368$ & 0,3443 & 0,1202 & -0.1377 & 0.1984 \\
\hline 4147 & -0.2060 & 0.2932 & 0.5008 & 0,0448 & 0.2759 \\
\hline+148 & -0.1324 & -0.0642 & -0.1639 & -0.2779 & -0.2714 \\
\hline 4149 & 0.0828 & 0.0967 & $-0,0438$ & -0.1990 & 0,1271 \\
\hline 4150 & 0.1453 & 0.3441 & 0.2758 & -0.1479 & 0.1970 \\
\hline+151 & $0.58+3$ & 0.3805 & 0.1592 & 0.1784 & 0.1369 \\
\hline+152 & 0.0071 & 0.1728 & 0.3624 & -0.2727 & 0.1929 \\
\hline+153 & -0.1504 & -0.1705 & 0.0015 & $0.08+4$ & -0.1824 \\
\hline+154 & -0.0096 & 0.1680 & 0.3662 & 0.3543 & 0.2012 \\
\hline 4155 & -0.0281 & -0.1179 & 0.0216 & -0.3660 & $-0,3553$ \\
\hline 4156 & $-0,1317$ & 0.0139 & 0.1658 & -0.2393 & -0.2063 \\
\hline 4157 & -0.2073 & $-0,0721$ & $-0,0365$ & -0.1459 & 0,0125 \\
\hline 4158 & 0.5977 & 0.2781 & $-0,1232$ & $-0,2528$ & 0,1119 \\
\hline 4159 & $-0,3048$ & $-0,0865$ & $-0,0933$ & $-(0,2828$ & $-0,0603$ \\
\hline 4160 & -0.1316 & $-0,1643$ & 0,4719 & $-0,1114$ & 0,1792 \\
\hline 4161 & -0.0500 & 0.2290 & $-0,2002$ & 0,4769 & 0,1959 \\
\hline 4162 & 0,6682 & 0.7239 & 0,5629 & 0,2688 & 0.3705 \\
\hline 4163 & 0.2912 & 0,4224 & 0.1532 & $-0,2259$ & 0,3923 \\
\hline 4164 & -0.0159 & 0.4530 & 0,0835 & $-0,5470$ & $-0,0531$ \\
\hline 4165 & -0.0725 & -0.0509 & $-0,0447$ & $-0,3110$ & 0,0271 \\
\hline 4166 & -0.1394 & 0.0501 & 0.1746 & $-0,0067$ & 0,1367 \\
\hline 4167 & -0.1097 & -0.0280 & -0.1503 & $-0,3360$ & 0.0853 \\
\hline 4168 & -0.1429 & $-0,1747$ & 0,3138 & $-0,2688$ & $-0,1503$ \\
\hline 4243 & -0.0899 & -0.3973 & 0.7785 & 0,2061 & $-0,0128$ \\
\hline 4244 & 0.0591 & -0.1453 & 0.3765 & 0,4161 & $-0,1134$ \\
\hline 4245 & 0.0188 & 0.2212 & 0,4251 & 0.2294 & -0.0475 \\
\hline+246 & -0.0544 & 0.2017 & 0,7999 & 0,3091 & 0.2434 \\
\hline 4247 & -0.1150 & 0.1871 & 0.5850 & 0,5333 & 0.3339 \\
\hline
\end{tabular}




\begin{tabular}{|c|c|c|c|c|c|}
\hline $\begin{array}{c}\text { Pares de } \\
\text { Linhagens }\end{array}$ & local 1 & local 2 & local 3 & local 4 & média \\
\hline $42+8$ & -0.0374 & -0.2333 & 0.2894 & 0.2592 & -0.2120 \\
\hline 4249 & 0,0885 & -0.1931 & 0.4872 & 0.0443 & 0.1810 \\
\hline 4250 & 0,1874 & 0,1678 & 0.1535 & 0.2226 & 0.2463 \\
\hline 4251 & 0.5969 & 0.1546 & 0.6043 & 0,4823 & 0,1852 \\
\hline 4252 & 0,0640 & 0,0755 & 0.3457 & 0.1229 & 0,2421 \\
\hline 4253 & -0.0578 & $-0,3476$ & 0.6069 & 0,1465 & -0.2017 \\
\hline 4254 & 0,0836 & 0.0053 & 0,3104 & 0,4873 & 0,2487 \\
\hline 4255 & $-0,0989$ & -0.4476 & 0.2539 & 0,0671 & $-0,3046$ \\
\hline 4256 & $-0,1956$ & -0.2679 & 0.5882 & 0.1938 & $-0,1550$ \\
\hline 4257 & $-0,2599$ & $-0,3398$ & 0,3832 & 0,2279 & 0,0506 \\
\hline 4258 & 0,6241 & 0,0510 & 0,4101 & 0,3063 & 0.1598 \\
\hline 4259 & $-0,2120$ & $-0,2368$ & 0.4610 & 0,1854 & $-0,0119$ \\
\hline 4260 & -0.1169 & -0.3005 & 0.6345 & 0,2065 & 0,2011 \\
\hline 4261 & 0,0504 & 0,1265 & 0.3392 & 0,6455 & 0.2459 \\
\hline 4262 & 0.6880 & 0.6023 & $0.8+59$ & 0.5770 & 0.4129 \\
\hline 4263 & 0.3088 & 0,2909 & 0.7255 & 0.1755 & 0,4306 \\
\hline 4264 & 0.0445 & 0.2236 & 0,3371 & 0.1224 & 0,0053 \\
\hline 4265 & -0.0311 & -0.1895 & 0.4357 & 0,1506 & 0.0837 \\
\hline 4266 & -0.0392 & -0.0067 & 0.8362 & 0.3274 & 0.1656 \\
\hline+267 & -0.1142 & -0.1682 & 0.4613 & 0.0935 & 0.1399 \\
\hline+268 & -0.0836 & -0.3471 & 0.8993 & 0.2087 & $-0,0954$ \\
\hline $43+4$ & 0.0129 & -0.0577 & 0.4057 & 0.3002 & 0.0225 \\
\hline 4345 & 0.0173 & 0.2566 & 0.1509 & 0.0780 & $0.08+6$ \\
\hline+346 & 0.0472 & 0.1952 & 0.2819 & $0.242 I$ & 0,3516 \\
\hline 4347 & -0.1238 & 0.1952 & $0.6+97$ & 0.4481 & 0.3995 \\
\hline $43 \quad 48$ & -0.1199 & -0.1266 & 0.1872 & 0.1216 & -0.0866 \\
\hline 4349 & 0.0716 & -0.2431 & 0.1021 & $-0,0161$ & 0.2530 \\
\hline 4350 & 0,1743 & 0.1748 & 0.5162 & 0,2047 & 0.3553 \\
\hline $43 \quad 51$ & 0,5823 & 0,1204 & 0.0661 & 0.4185 & 0.2024 \\
\hline $43 \quad 52$ & $-0,0307$ & 0.1403 & $0.6+10$ & 0,0708 & 0,3216 \\
\hline 4353 & $-0,1923$ & $-0,2068$ & 0.2688 & 0,2702 & $-0,0535$ \\
\hline $43 \quad 54$ & $-0,0676$ & -0.0575 & 0,5634 & 0,4258 & 0,3318 \\
\hline 4355 & 0,0379 & -0.5160 & 0,3149 & 0,0517 & $-0,0572$ \\
\hline $43 \quad 56$ & -0.0711 & -0.3559 & 0.2940 & 0,1821 & $-0,0019$ \\
\hline $43 \quad 57$ & -0.1343 & $-0,2899$ & 0.2242 & 0,2389 & 0,1969 \\
\hline 4358 & 0.6183 & 0.0165 & 0.0862 & 0.2370 & 0.2895 \\
\hline 4359 & -0.2100 & -0.2255 & 0.2106 & 0.1013 & 0,1290 \\
\hline 4360 & -0.1031 & -0.2074 & 0,5168 & 0.2252 & 0.2680 \\
\hline 4361 & -0.0729 & 0.1851 & 0.1770 & 0.5403 & 0,3290 \\
\hline 4362 & 0.6884 & 0,6182 & 0.6128 & 0,5519 & 0,5022 \\
\hline 4363 & 0.3125 & 0,3390 & 0.2079 & 0,1255 & 0,4960 \\
\hline 4364 & $-0,0359$ & 0,1887 & 0,3511 & 0.0404 & 0,1543 \\
\hline 4365 & -0.0802 & -0.1085 & 0.2340 & 0,0894 & 0.1850 \\
\hline 4366 & -0.0718 & 0.0531 & $0,3+40$ & 0,3920 & 0,2793 \\
\hline $43 \quad 67$ & -0.0792 & -0.0963 & 0.1717 & 0.0516 & 0.2331 \\
\hline
\end{tabular}




\begin{tabular}{|c|c|c|c|c|c|}
\hline $\begin{array}{c}\text { Pares de } \\
\text { Linhagens }\end{array}$ & local 1 & local 2 & local 3 & local $f$ & média \\
\hline 4368 & -0.1305 & -0.2247 & 0.2698 & 0.0922 & -0.0832 \\
\hline 4445 & 0.1016 & 0,3714 & 0.1074 & 0.1555 & 0.0593 \\
\hline 4446 & 0.1645 & 0,3686 & 0,4167 & 0.4913 & 0,3150 \\
\hline $44 \quad 47$ & 0,0336 & 0.1519 & 0.3188 & 0,6131 & 0.3350 \\
\hline 4448 & $-0,0231$ & $-0,0699$ & $-0,0745$ & 0,3677 & $-0,1630$ \\
\hline $44 \quad 49$ & 0,1525 & 0,0112 & 0,1225 & 0,0637 & 0.1946 \\
\hline 4450 & 0.3032 & 0,3218 & 0,1891 & 0,4710 & 0,2972 \\
\hline 4451 & 0,7218 & 0,3146 & 0,2987 & 0,4910 & 0.1948 \\
\hline $44 \quad 52$ & 0,0675 & 0,2021 & 0,2942 & 0,3348 & 0.2778 \\
\hline 4453 & $-0,0365$ & $-0,1374$ & 0,2352 & 0,3978 & $-(0,0808$ \\
\hline 4454 & 0,1452 & 0,2042 & 0.3354 & 0,2146 & 0.2857 \\
\hline 4455 & 0.0836 & -0.1508 & -0.0975 & 0,2908 & -0.1899 \\
\hline 4456 & 0.0489 & $-0,0749$ & 0,3272 & 0,4065 & -0.1258 \\
\hline $44 \quad 57$ & 0,0438 & $-0,0821$ & 0,1959 & 0.3679 & 0,1311 \\
\hline 4458 & 0.7278 & 0,1916 & 0.0912 & 0,4069 & 0.2050 \\
\hline $44 \quad 59$ & $-0,0478$ & 0,0217 & 0,0215 & 0,2955 & 0.0629 \\
\hline 4460 & 0,0238 & $-0,1594$ & 0,4314 & 0,4486 & 0.2871 \\
\hline 4461 & 0.0332 & 0,0503 & -0.0652 & 0,3980 & 0,2430 \\
\hline 4462 & 0.8006 & 0,7396 & 0.6556 & 0.7967 & 0,4803 \\
\hline 4463 & 0.3505 & 0.2576 & 0.3370 & 0.4046 & 0,4622 \\
\hline 4464 & 0,1449 & 0.4177 & 0.0104 & 0.2530 & 0.0722 \\
\hline $4+65$ & 0.0374 & -0.0289 & -0.0209 & 0.3644 & 0.1317 \\
\hline $4+66$ & 0.0732 & 0.1027 & 0.4578 & 0.5391 & 0.2557 \\
\hline 4467 & 0.0398 & -0.1877 & -0.0069 & 0.3150 & 0.1723 \\
\hline 4468 & 0.0058 & -0.2038 & 0.4608 & 0.3866 & -0.0486 \\
\hline+546 & 0.0403 & 0.1640 & 0.1883 & 0.1834 & $0.19+7$ \\
\hline $45+7$ & 0.0555 & 0.6380 & 0.4588 & 0.3053 & 0.4042 \\
\hline 4548 & 0,0025 & 0.3141 & -0.3158 & 0.0619 & $-0,0800$ \\
\hline 4549 & 0.1634 & 0,4024 & $-0,0846$ & $-0,1627$ & 0.2563 \\
\hline $45 \quad 50$ & 0.2597 & 0.4718 & 0.1770 & 0.1813 & 0.2819 \\
\hline 4551 & 0,6944 & 0,6254 & -0.0614 & 0.2903 & 0,2542 \\
\hline $45 \quad 52$ & 0.1370 & 0.5344 & 0,3588 & $-(0,0121$ & 0.3287 \\
\hline $45 \quad 53$ & -0.0717 & 0.2484 & $-0,0405$ & 0,2328 & $-0,0319$ \\
\hline $45 \quad 54$ & 0,1058 & 0,3323 & 0,2657 & 0.3225 & 0.2804 \\
\hline $45 \quad 55$ & 0,0591 & 0,2080 & $-0,0078$ & $-0,0121$ & $-0,0921$ \\
\hline $45 \quad 56$ & 0.0082 & 0.3318 & 0.1268 & 0.1039 & $-0,0041$ \\
\hline $45 \quad 57$ & 0.0035 & 0.2856 & -0.1672 & 0.1361 & 0.1396 \\
\hline $45 \quad 58$ & 0.6924 & 0.5244 & $-0,2482$ & 0,1399 & 0.2393 \\
\hline $45 \quad 59$ & -0.0741 & 0.3088 & $-0,1109$ & $-0,0192$ & 0.0639 \\
\hline 4560 & 0,0179 & 0,2446 & 0,3498 & 0,1441 & 0,2601 \\
\hline 4561 & 0.0931 & 0.5739 & -0.2178 & 0.4420 & 0.3253 \\
\hline 4562 & 0.7299 & 0.6695 & 0.4906 & 0.5341 & 0,3783 \\
\hline 4563 & 0.2944 & 0.5513 & 0.0700 & 0.0552 & 0,4370 \\
\hline 4564 & $-0,0209$ & 0,3699 & -0.0155 & $-0,0720$ & $-0.07+7$ \\
\hline 4565 & 0.0448 & 0.3353 & -0.0228 & 0.0528 & 0.1616 \\
\hline
\end{tabular}




\begin{tabular}{|c|c|c|c|c|c|}
\hline $\begin{array}{c}\text { Pares de } \\
\text { Linhagens }\end{array}$ & local 1 & local 2 & local 3 & local 4 & média \\
\hline 4566 & 0.0059 & 0.1925 & 0.2103 & 0.3199 & 0.1706 \\
\hline$\$ 567$ & 0.0382 & 0.3403 & -0.0859 & 0.0018 & 0.2224 \\
\hline 4568 & -0.0116 & 0,2236 & 0.3230 & 0.0591 & 0,0228 \\
\hline 4647 & -0.0159 & 0.5771 & 0.7160 & 0.2800 & 0.8235 \\
\hline 4648 & 0,0922 & 0,3381 & 0.2003 & 0.0485 & 0.2044 \\
\hline 4649 & 0.1998 & 0,3461 & 0.1874 & 0,1422 & 0,6879 \\
\hline 4650 & 0,2457 & 0.4261 & 0,5827 & 0,0692 & 0,7229 \\
\hline 4651 & 0,6861 & 0,5814 & 0.2825 & 0.4187 & 0,6092 \\
\hline+652 & 0.1661 & 0.5310 & 0,6287 & 0.0408 & 0.1533 \\
\hline 4653 & 0,0516 & 0,2744 & 0.2314 & 0,2390 & 0.2583 \\
\hline 4654 & 0.1503 & 0.1741 & 0,6128 & 0.6208 & 0.0609 \\
\hline 4655 & 0,0420 & 0,1483 & 0,3204 & $-0,0812$ & 0,1979 \\
\hline 4656 & -0.0232 & 0,2734 & 0,3402 & 0.0912 & 0.2739 \\
\hline 4657 & $-0,0651$ & 0.2666 & 0,1844 & 0,0963 & 0.5892 \\
\hline 4658 & 0,7177 & 0,4801 & 0.1205 & 0.1182 & 0.6727 \\
\hline 4659 & $-0,0842$ & 0.2891 & 0,2500 & 0,0513 & 0,5209 \\
\hline 4660 & 0.0082 & 0.2702 & $.0,6382$ & 0,0407 & 0,0688 \\
\hline 4661 & 0.1627 & 0.5702 & 0,1698 & 0,6943 & 0.7504 \\
\hline 4662 & 0,7464 & 0.6891 & 0,6569 & 0,3800 & 0.1562 \\
\hline $46 \quad 63$ & 0.3755 & 0.5492 & 0.2805 & $-0,0612$ & 0.2389 \\
\hline 4664 & 0.0895 & 0.2986 & 0.3693 & -0.1184 & 0.2401 \\
\hline+665 & 0.1215 & 0.3597 & 0.3077 & $-0,0922$ & 0,6039 \\
\hline 4666 & $0.0+2+$ & 0.1976 & 0.2671 & 0.1925 & 0.6456 \\
\hline+667 & 0.0219 & 0.3637 & 0.1625 & $-0,0693$ & 0.6663 \\
\hline+668 & 0.0492 & 0.2487 & 0.4459 & -0.0935 & 0.3006 \\
\hline+748 & -0.0808 & 0.3181 & 0.3643 & 0.2356 & 0,2913 \\
\hline $47+9$ & 0.0794 & 0.1946 & 0.5176 & 0.3215 & 0.0893 \\
\hline+750 & 0.1514 & 0,5670 & 0,4958 & 0,3221 & 0,2421 \\
\hline 4751 & 0.5931 & 0,4786 & 0,5597 & 0,4513 & 0,2523 \\
\hline $47 \quad 52$ & 0,0453 & 0.4754 & 0,6104 & 0.2049 & 0,8200 \\
\hline 4753 & -0.1064 & 0,2602 & 0,6367 & 0,5316 & 0,3547 \\
\hline $47 \quad 54$ & -0.0177 & 0,3519 & 0,6588 & 0,6707 & 0,8216 \\
\hline 4755 & 0.0071 & 0,1215 & 0.2674 & 0,1723 & 0,2777 \\
\hline 4756 & -0.0939 & 0,1218 & 0.6255 & 0,1065 & 0.3137 \\
\hline 4757 & $-0,1620$ & 0.2461 & 0,5533 & 0,2324 & 0,0650 \\
\hline 4758 & 0,6302 & 0,3665 & 0,4724 & 0.2326 & 0,1171 \\
\hline $47 \quad 59$ & -0.2574 & 0.2472 & 0.4638 & 0,1597 & $-0,0120$ \\
\hline 4760 & -0.1181 & 0.2574 & 0.6123 & 0.3515 & 0,7908 \\
\hline 4761 & $-0,0442$ & 0,1707 & 0.3409 & 0.6919 & 0,0626 \\
\hline $47 \quad 62$ & 0,7001 & 0,9456 & 0.8086 & 0,5428 & 0,9637 \\
\hline $47 \quad 63$ & 0.2966 & 0,4366 & 0.5989 & 0,2382 & 0,9381 \\
\hline 4764 & 0,0652 & 0.6373 & 0,3972 & 0.0952 & 0,4457 \\
\hline $47 \quad 65$ & -0.0220 & 0.3533 & 0.4146 & 0.2052 & 0,0630 \\
\hline+766 & $-0,0769$ & 0.4047 & 0.7318 & 0.3087 & 0.1515 \\
\hline+767 & -0.0967 & 0.2073 & 0.3346 & 0.1776 & -0.0070 \\
\hline
\end{tabular}




\begin{tabular}{|c|c|c|c|c|c|}
\hline $\begin{array}{c}\text { Pares de } \\
\text { Linhagens }\end{array}$ & local I & local 2 & loc:al 3 & local $t$ & médlia \\
\hline 4768 & -0.1297 & 0.2219 & 0.7267 & 0.1871 & 0.3415 \\
\hline 4849 & 0.0438 & -0.0385 & -0.1283 & -0.0081 & 0.0846 \\
\hline 4850 & 0,1841 & 0,1891 & -0.0155 & 0,0374 & $0,16+4$ \\
\hline 4851 & 0.6128 & 0,2749 & -0.0110 & 0,3605 & 0,0986 \\
\hline 4852 & 0,0648 & 0,0013 & 0,1820 & $-0,0833$ & 0,1441 \\
\hline 4853 & $-0,1913$ & $-0,2394$ & $-0,0664$ & 0.2948 & $-0,2067$ \\
\hline 4854 & $-0,0005$ & 0.2021 & 0,1301 & 0,4725 & 0,1792 \\
\hline 4855 & 0,0294 & $-0,2035$ & $-0,1969$ & $-0,0685$ & $-0,2886$ \\
\hline 4856 & $-0,0541$ & $-0,0431$ & 0,0652 & 0,0220 & $-0,1773$ \\
\hline 4857 & $-0,0796$ & $-0,2768$ & $-0,1936$ & 0,0809 & $-0,0025$ \\
\hline 4858 & 0,6152 & 0,2020 & -0.2894 & $-0,0624$ & 0.1097 \\
\hline 4859 & $-0,2364$ & $-0,0521$ & $-0,2383$ & $-0,1541$ & $-0,0627$ \\
\hline 4860 & -0.0994 & $-0,2294$ & 0,3269 & 0,1097 & 0,1658 \\
\hline 4861 & $-0,1525$ & 0.2206 & $-0,4826$ & 0,5797 & 0,1781 \\
\hline 4862 & 0.6948 & 0,6580 & 0.4999 & 0,3839 & 0.3686 \\
\hline 4863 & 0,2336 & 0,3285 & 0,0556 & -0.0281 & 0,3849 \\
\hline 4864 & 0.0369 & 0.2905 & $-0,1089$ & $-0,2592$ & $-0,0938$ \\
\hline 4865 & $-0,1361$ & $-0,2638$ & -0.2191 & $-0,0825$ & 0,0011 \\
\hline 4866 & -0.0967 & 0.0801 & 0.2224 & 0.2297 & 0.1409 \\
\hline+867 & -0.0708 & -0.0933 & -0.2235 & -0.0426 & 0.0931 \\
\hline 4868 & -0.2421 & -0.2776 & 0.3167 & $-0,0192$ & -0.1389 \\
\hline 4950 & 0.3438 & 0.2102 & 0.2097 & 0.0415 & -0.0198 \\
\hline 4951 & 0.7165 & 0.1499 & $-0.0+13$ & 0.2520 & 0.1061 \\
\hline 4952 & $0.2+13$ & 0.1688 & 0.4038 & -0.1166 & 0.6384 \\
\hline 49 53 & 0.0124 & -0.0425 & -0.0003 & 0.0888 & 0.1765 \\
\hline 4954 & 0.2373 & 0.1180 & 0.2746 & 0.1812 & 0,6652 \\
\hline +9 55 & 0.0835 & -0.2986 & 0.0299 & -0.1595 & 0.1243 \\
\hline 4956 & 0.1269 & -0.2687 & 0,1254 & $-0,0034$ & 0,1897 \\
\hline 4957 & 0.0484 & $-0,2016$ & $-0,1342$ & 0,0000 & $-0,1775$ \\
\hline 4958 & 0.7276 & 0,0919 & $-0,3157$ & 0,0406 & $-0,0631$ \\
\hline 4959 & 0,0126 & $-0,0260$ & $-0,0966$ & $-0,1054$ & $-0,2337$ \\
\hline 4960 & 0.1112 & $-0,0269$ & 0,4303 & 0,0309 & 0.6499 \\
\hline 4961 & 0.0918 & 0,1831 & $-0,1052$ & 0,4173 & $-0,0976$ \\
\hline 4962 & 0.8438 & 0,7149 & 0.5104 & 0,4623 & 0,8354 \\
\hline 4963 & 0,3438 & 0,2918 & 0,1975 & $-0,0339$ & 0,8262 \\
\hline 4964 & 0.2495 & 0.2289 & 0,0372 & $-0,1576$ & 0,2490 \\
\hline 4965 & 0,0663 & -0.0001 & $-0,1189$ & $-0,0402$ & $-0,2470$ \\
\hline 4966 & 0.1909 & 0,2165 & 0,2369 & 0,2048 & 0.0098 \\
\hline 4967 & -0.0605 & -0.0088 & -0.0220 & $-0,1326$ & $-0,1477$ \\
\hline 4968 & $-0,0027$ & $-0,0642$ & 0.2247 & $-0,0149$ & 0,2209 \\
\hline 5051 & 0.2345 & 0,2188 & 0,3299 & 0,3751 & 0,1923 \\
\hline $50 \quad 52$ & 0.2844 & 0.3030 & 0.1173 & -0.0271 & 0,6997 \\
\hline 5053 & 0.1328 & 0.2400 & 0.3448 & 0.2808 & 0.2664 \\
\hline $50 \quad 54$ & 0.2469 & 0.3215 & 0.0382 & 0,5448 & 0,7224 \\
\hline $50 \quad 55$ & 0.2587 & 0.1014 & 0.0572 & $-0,1592$ & 0.1990 \\
\hline
\end{tabular}




\begin{tabular}{|c|c|c|c|c|c|}
\hline $\begin{array}{l}\text { Pares de } \\
\text { Linhagens }\end{array}$ & local 1 & local 2 & local 3 & local 4 & média \\
\hline $50 \quad 56$ & 0.1591 & $0.2+56$ & 0.3023 & -0.0092 & 0.2779 \\
\hline 50) 57 & 0.1665 & 0.1123 & 0.1186 & 0.0916 & $-0,1324$ \\
\hline $50 \quad 58$ & 0,3009 & 0.2032 & 0.1152 & -0.0014 & -0.0009 \\
\hline 5059 & 0.0384 & 0,3072 & 0.1546 & 0.0390 & -0.1350 \\
\hline 5060 & 0.1141 & 0.2370 & 0,4563 & 0.1231 & 0,7244 \\
\hline 5061 & 0,2373 & 0,5499 & 0,0069 & 0.6999 & 0,1286 \\
\hline 5062 & 0,3142 & 0,5195 & 0.6879 & 0,2919 & 0.8484 \\
\hline 5063 & 0.4618 & 0.5149 & 0,4596 & $-0,0094$ & 0,9027 \\
\hline 5064 & 0.2645 & 0,2506 & 0,1741 & $-0,1240$ & 0,2417 \\
\hline 5065 & 0.2589 & 0,2256 & 0,1351 & -0.0966 & $-0,1212$ \\
\hline 5066 & 0,1838 & 0,3455 & 0,5939 & 0.2471 & 0,0466 \\
\hline 5067 & 0,2212 & 0,3299 & 0,1807 & $-0,1300$ & 0,0319 \\
\hline 5068 & 0,1446 & 0,2018 & 0.6306 & $-0,0621$ & 0,3136 \\
\hline 5152 & 0.6939 & 0,4560 & 0,5074 & 0,3144 & 0,5654 \\
\hline 5153 & 0.5525 & 0,2570 & 0.1237 & 0,4243 & 0.1848 \\
\hline 5154 & 0.6816 & 0,3998 & 0,3730 & 0,5916 & 0,5941 \\
\hline 5155 & 0,6640 & 0,0585 & 0,1646 & 0,2760 & 0,1277 \\
\hline 5156 & 0.5887 & 0,1372 & 0,2262 & 0,2980 & 0,1701 \\
\hline 5157 & 0.5727 & 0,1710 & 0,0252 & 0.3352 & 0.0817 \\
\hline 5158 & 0,0991 & $-0,2923$ & $-0,1326$ & 0.1636 & 0.0973 \\
\hline 5159 & 0.4906 & 0,2858 & 0.0478 & 0,3109 & 0,0264 \\
\hline 5160 & 0.5626 & 0.2620 & 0.4157 & 0.3466 & 0.5564 \\
\hline 5161 & 0.6627 & 0,4703 & 0.0259 & 0.6842 & 0.1826 \\
\hline 5162 & 0.1820 & 0.5098 & 0.5578 & 0.5437 & 0.7023 \\
\hline 5163 & 0.8709 & 0.5710 & 0.1668 & 0.3209 & 0.7303 \\
\hline 5164 & 0.6729 & 0,4750 & 0.1698 & 0.2167 & 0,2660 \\
\hline 5165 & 0.6625 & 0,3087 & 0.1431 & 0.3504 & 0.0662 \\
\hline 5166 & 0,6335 & 0.4777 & 0,3401 & 0,3953 & 0,2061 \\
\hline 5167 & 0,6222 & 0,2985 & 0,1016 & 0,2817 & 0,0985 \\
\hline 5168 & 0.5774 & 0,2283 & 0,2783 & 0,3330 & 0.1729 \\
\hline 5253 & $-0,0242$ & 0,0956 & 0.4675 & 0,1280 & 0.2472 \\
\hline 5254 & 0.1056 & 0,3729 & 0.2324 & 0,4651 & 0,0204 \\
\hline 5255 & 0,1236 & 0,0799 & 0,1607 & $-0,3090$ & 0,1948 \\
\hline 5256 & 0,0279 & 0.2207 & 0,4337 & $-0,1456$ & 0.2737 \\
\hline 5257 & 0.0701 & $-0,0043$ & 0,3149 & $-0,0771$ & 0,5686 \\
\hline 5258 & 0,7414 & 0,4273 & 0,3189 & $-0,0182$ & 0.6683 \\
\hline 5259 & $-0,0204$ & 0,1795 & 0,3028 & $-0,1847$ & 0,5208 \\
\hline 5260 & -0.0190 & 0.1129 & 0.5845 & $-0,0419$ & 0.0762 \\
\hline 5261 & 0,0985 & 0,4238 & 0,1670 & 0.5560 & 0.7184 \\
\hline 5262 & 0,7779 & 0,8093 & 0.8281 & 0,4068 & 0,3195 \\
\hline 5263 & 0.3999 & 0.4955 & 0.5683 & $-0,0770$ & 0,3105 \\
\hline 5264 & 0,1171 & 0,4428 & 0.3230 & $-0,2488$ & 0,2931 \\
\hline $52 \quad 65$ & 0,1224 & 0.0448 & 0,3413 & $-0,2169$ & 0.5722 \\
\hline 5266 & 0.1023 & 0,3062 & 0.6993 & 0,1212 & 0.6975 \\
\hline 5267 & 0.1107 & 0.2164 & 0.2848 & -0.2780 & 0.6556 \\
\hline
\end{tabular}




\begin{tabular}{|c|c|c|c|c|c|}
\hline $\begin{array}{c}\text { Pares de } \\
\text { Linhagens }\end{array}$ & local 1 & local 2 & local 3 & local $t$ & média \\
\hline 5268 & 0.0743 & 0,0751 & 0.7558 & $-0,1394$ & 0.2948 \\
\hline $53 \quad 54$ & -0.0592 & 0,1355 & 0,3865 & 0.5408 & 0.2536 \\
\hline $\begin{array}{ll}53 & 55 \\
\end{array}$ & $-0,0054$ & $-0,2641$ & 0,1598 & 0,0455 & $-0,2097$ \\
\hline 5356 & -0.0726 & -0.1091 & 0,3286 & 0.2153 & $-0,0850$ \\
\hline 5357 & -0.0973 & -0.2332 & $-0,0656$ & 0,1582 & 0,0876 \\
\hline $53 \quad 58$ & 0.5600 & 0,1541 & $-0,1841$ & 0.2821 & 0.1859 \\
\hline $53 \quad 59$ & $-0,2513$ & -0.1394 & $-0,0765$ & 0,2196 & 0,0153 \\
\hline 5360 & -0.1266 & -0.3151 & 0,5191 & 0,0690 & 0.1981 \\
\hline 5361 & -0.1163 & 0.1493 & $-0,0569$ & 0.6530 & 0.2470 \\
\hline $53 \quad 62$ & 0,6385 & 0,6380 & 0,6550 & 0,6069 & 0,4463 \\
\hline 5363 & 0,2033 & 0,3181 & 0,2446 & 0,1620 & 0,4256 \\
\hline 5364 & $-0,0801$ & 0,3284 & 0,1160 & 0,1100 & 0,0379 \\
\hline 5365 & -0.0905 & -0.1912 & 0.1667 & 0,1487 & 0,0945 \\
\hline 5366 & -0.0849 & 0,0074 & 0,2317 & 0,2135 & 0,1688 \\
\hline $53 \quad 67$ & -0.0937 & $-0,1624$ & 0,0918 & 0,0717 & 0,1615 \\
\hline 5368 & -0.2014 & $-0,3716$ & 0,3918 & 0,1863 & $-0,0649$ \\
\hline $54 \quad 55$ & 0,2029 & $-0,0957$ & 0,2060 & 0,4209 & 0,2013 \\
\hline 5456 & 0,0687 & 0,0357 & 0,3875 & 0,4828 & 0,2884 \\
\hline $54 \quad 57$ & 0,0440 & 0,0778 & 0,1810 & 0,4462 & 0,5928 \\
\hline 5458 & 0,7126 & 0,2974 & 0,1785 & 0,5280 & 0,6817 \\
\hline 5459 & $-0,0807$ & 0,0906 & 0,2709 & 0,3855 & 0,5298 \\
\hline 5460 & 0,0219 & 0.1319 & 0.5061 & 0,5750 & 0,0867 \\
\hline 5461 & 0.0111 & 0.4153 & 0,1799 & 0.4725 & 0,7213 \\
\hline 5462 & 0.7547 & 0.7216 & 0.7070 & 0.8390 & 0,2858 \\
\hline $5+63$ & 0.3752 & 0,4889 & 0.5282 & 0.5000 & 0,3050 \\
\hline 5464 & 0,0385 & 0.2904 & 0.2568 & 0,3899 & 0,3031 \\
\hline 5465 & 0,0625 & 0.2231 & 0,3020 & 0,4976 & 0,5989 \\
\hline 5466 & -0.0427 & 0.1568 & 0,6678 & 0,6159 & 0.6854 \\
\hline $54 \quad 67$ & 0,1086 & 0,2286 & 0,3455 & 0.4446 & 0,6671 \\
\hline 5468 & $-0,0143$ & 0,1112 & 0,6842 & 0.5166 & 0,3013 \\
\hline 5556 & $-0,1004$ & $-0,4046$ & 0,1989 & $-0,2269$ & $-0,2190$ \\
\hline $55 \quad 57$ & $-0,0715$ & $-0,3719$ & 0,0669 & $-0,1610$ & 0,0032 \\
\hline $55 \quad 58$ & 0,6847 & $-0,0673$ & $-0,0468$ & $-0,0913$ & 0,1029 \\
\hline $55 \quad 59$ & $-0,0928$ & $-0,2542$ & $-0,0474$ & $-0,1593$ & $-0,0696$ \\
\hline $55 \quad 60$ & $-0,0548$ & $-0,2833$ & 0,3977 & $-0,1229$ & 0,1763 \\
\hline $55 \quad 61$ & 0,1153 & 0.1243 & $-0,2184$ & 0.5504 & 0.1895 \\
\hline $55 \quad 62$ & 0,7508 & 0,5639 & 0,6223 & 0,3318 & 0,3615 \\
\hline $55 \quad 63$ & 0,2896 & 0.2775 & 0,2566 & $-0,1636$ & 0,3954 \\
\hline 5564 & 0,1622 & 0,1043 & $-0,0821$ & $-0,3428$ & $-0,0575$ \\
\hline $55 \quad 65$ & 0,0545 & $-0,1649$ & $-0,0326$ & $-0,3420$ & 0,0264 \\
\hline 5566 & 0,0951 & $-0,0048$ & 0,3913 & 0,0170 & 0,1318 \\
\hline 5567 & $-0,0605$ & $-0,1710$ & $-0,0838$ & $-0,4998$ & 0,0826 \\
\hline 5568 & -0.0158 & -0.3235 & 0,4669 & $-0,2950$ & $-0,1678$ \\
\hline $56 \quad 57$ & -0.1566 & -0.1907 & 0,1537 & $-0,0720$ & 0,0888 \\
\hline $56 \quad 58$ & 0,6246 & 0.0213 & 0,1030 & -0.0345 & 0,1680 \\
\hline
\end{tabular}




\begin{tabular}{|c|c|c|c|c|c|}
\hline $\begin{array}{c}\text { Pares de } \\
\text { Linhagens }\end{array}$ & local 1 & local 2 & local 3 & local $t$ & média \\
\hline 5659 & -0.2312 & -0.1166 & 0.1904 & -0.0292 & 0.0256 \\
\hline 5660 & -0.2171 & $-0,1290$ & 0,5081 & 0,0308 & 0,2374 \\
\hline 5661 & 0,0344 & 0.1181 & 0,0553 & 0.6145 & 0.2504 \\
\hline 5662 & 0.6610 & 0,6832 & 0.5839 & 0,3964 & 0,4260 \\
\hline $56 \quad 63$ & 0.2585 & 0.2872 & 0,2901 & $-0,0250$ & 0,4291 \\
\hline 5664 & 0,0558 & 0,2518 & 0,2959 & $-0,2197$ & 0,0293 \\
\hline $56 \quad 65$ & $-0,0112$ & $-0,0239$ & 0,1212 & $-0,1001$ & 0,1108 \\
\hline 5666 & -0.0564 & 0,1315 & 0,3878 & 0,0266 & 0.2139 \\
\hline $56 \quad 67$ & -0.0505 & $-0,1188$ & 0,1127 & $-0,2165$ & 0.1496 \\
\hline 5668 & $-0,1009$ & $-0,1474$ & 0,4706 & $-0,0986$ & $-0,0999$ \\
\hline 5758 & 0,5913 & 0,0999 & $-0,3550$ & 0,0832 & $-0,1787$ \\
\hline 5759 & $-0,2579$ & $-0,1406$ & $-0,0437$ & $-0,0968$ & -0.4273 \\
\hline 5760 & $-0,1021$ & $-0,2277$ & 0,4379 & $-0,0510$ & 0.5639 \\
\hline 5761 & 0,0099 & 0,1956 & $-0,1567$ & 0.5994 & $-0,0445$ \\
\hline 5762 & 0.6720 & 0,6227 & 0,4713 & 0,4130 & 0,7345 \\
\hline 5763 & 0.3056 & 0,3025 & 0,2007 & $-0,0203$ & 0,7674 \\
\hline 5764 & 0,0052 & 0,1780 & 0,0648 & $-0,1243$ & 0,1356 \\
\hline 5765 & -0.0763 & $-0,2260$ & 0,0399 & $-0,0405$ & $-0,3323$ \\
\hline 5766 & -0.0821 & 0,0623 & 0.2180 & $-0,0769$ & $-0,1388$ \\
\hline $57 \quad 67$ & -0.1637 & $-0,1040$ & $-0,0175$ & $-0,1332$ & $-0,1841$ \\
\hline 5768 & -0.1266 & -0.2714 & 0,3709 & $-0,0099$ & 0,1359 \\
\hline 5859 & 0.5138 & 0.1828 & -0.2037 & 0.0042 & -0.2525 \\
\hline 5860 & 0.6164 & 0.1399 & 0.3859 & 0.1098 & 0.6549 \\
\hline 5861 & 0.6790 & 0.3678 & -0.2638 & 0.6495 & 0.0131 \\
\hline $58 \quad 62$ & 0.2069 & 0,4484 & 0.4712 & 0.3159 & 0.7924 \\
\hline 5863 & 0.8813 & 0.5059 & 0.1074 & 0,0538 & 0,8373 \\
\hline 5864 & 0.6681 & 0.4245 & -0.0523 & $-0,2282$ & 0.2500 \\
\hline $58 \quad 65$ & 0.6600 & 0,2357 & $-0,0798$ & $-0,0189$ & $-0,1499$ \\
\hline 5866 & 0.6375 & 0,3667 & 0,1460 & 0,1584 & $-0,0076$ \\
\hline 5867 & 0,6393 & 0,1753 & $-0,0898$ & $-0,0658$ & $-0,0850$ \\
\hline 5868 & 0,5897 & 0,1060 & 0,2460 & 0,0048 & 0,2333 \\
\hline 5960 & -0.2737 & $-0,1382$ & 0,4292 & 0,0255 & 0,4987 \\
\hline 5961 & -0.1349 & 0.2297 & -0.2545 & 0,4937 & $-0,1300$ \\
\hline 5962 & 0.5737 & 0.6667 & 0.6305 & 0,3520 & 0,6773 \\
\hline 5963 & 0,1832 & 0,4304 & 0,2069 & $-0,0861$ & 0,7034 \\
\hline 5964 & -0.0618 & 0.3566 & $-0,0466$ & $-0,2258$ & 0,0903 \\
\hline 5965 & $-0,1341$ & $-0,0354$ & $-0,0409$ & $-0,1314$ & $-0,3843$ \\
\hline 5966 & -0.2225 & 0,0771 & 0.2373 & 0,1300 & $-0,2293$ \\
\hline 5967 & -0.1687 & $-0,0200$ & $-0,0832$ & $-0,1325$ & $-0,2782$ \\
\hline 5968 & $-0,2906$ & $-0,1537$ & 0,3168 & $-0,0629$ & 0.0637 \\
\hline 6061 & -0.0287 & 0.1642 & 0.3688 & 0,7225 & 0.7167 \\
\hline 6062 & 0,6423 & 0.6319 & 0,6622 & 0,4244 & 0,2733 \\
\hline 6063 & 0.2199 & 0,3290 & 0.4593 & $-0,1281$ & 0.1974 \\
\hline 6064 & 0,0672 & 0,3140 & 0,4206 & -0.0894 & 0,3241 \\
\hline 6065 & -0.0066 & -0.2208 & 0.4099 & -0.0050 & 0.5742 \\
\hline
\end{tabular}




\begin{tabular}{|c|c|c|c|c|c|}
\hline $\begin{array}{l}\text { Pares de } \\
\text { Linhagens }\end{array}$ & local I & local 2 & local 3 & local $t$ & média \\
\hline 6066 & -0.0635 & -0.0149 & 0.6755 & 0.0114 & 0.6399 \\
\hline 6067 & $-0,0422$ & $-0,2210$ & 0.3931 & -0.1253 & 0,6277 \\
\hline 6068 & $-0,1478$ & $-0,4111$ & 0.6023 & -0.0300 & 0,2397 \\
\hline 6162 & 0,7581 & 0,9088 & 0,5398 & 0,9489 & 0,9051 \\
\hline 6163 & 0,2875 & 0,3339 & 0,0580 & 0,6500 & 0,8708 \\
\hline 6164 & 0,1190 & 0,6381 & -0.0567 & 0,5125 & 0.3532 \\
\hline 6165 & -0.0478 & 0,2572 & $-0,1943$ & 0,5809 & $-0,0697$ \\
\hline 6166 & -0.0139 & 0.3554 & 0,1740 & 0,7448 & 0.0868 \\
\hline 6167 & 0,0016 & 0,0802 & -0.3014 & 0.5741 & -0.0903 \\
\hline 6168 & $-0,1474$ & 0,1272 & 0,3164 & 0,6179 & 0.2893 \\
\hline 6263 & 0,9281 & 0,8991 & 0,5875 & 0,3119 & 0,4360 \\
\hline 6264 & 0,7032 & 0,6878 & 0,6157 & 0,3018 & 0,3945 \\
\hline 6265 & 0,7505 & 0.6816 & 0.5410 & 0,3489 & 0,7509 \\
\hline 6266 & 0,6797 & 0,6700 & 0,6964 & 0,4900 & 0,8101 \\
\hline 6267 & 0.7387 & 0,7154 & 0,5455 & 0,3368 & 0.8105 \\
\hline $62 \quad 68$ & 0,6692 & 0,6082 & 0.6709 & 0,3456 & 0,4385 \\
\hline 6364 & 0.3995 & 0,5405 & 0,3399 & $-0,1846$ & 0,4801 \\
\hline $63 \quad 65$ & 0,3052 & 0,3647 & 0,1785 & $-0,1032$ & 0,7727 \\
\hline 6366 & 0,3104 & 0,4255 & 0,3426 & 0,1037 & 0,8262 \\
\hline 6367 & 0.2900 & 0.2751 & 0,0608 & $-0,1702$ & 0.8048 \\
\hline $63 \quad 68$ & 0.1906 & 0,2933 & 0,3520 & $-0,1438$ & 0,4616 \\
\hline 6465 & 0.0692 & 0.3251 & 0,0938 & -0.2941 & 0.1535 \\
\hline $6+66$ & -0.0300 & 0.3701 & 0,3991 & 0,0131 & 0.2380 \\
\hline $6+67$ & 0,1009 & 0.4017 & 0,0919 & $-0,3127$ & 0,2550 \\
\hline 6468 & 0.0425 & 0.2800 & 0,4786 & -0.2455 & 0.0913 \\
\hline 6566 & -0.0314 & 0.0974 & 0,3332 & 0.1265 & -0.1135 \\
\hline 6567 & $-0,0559$ & $-0,0788$ & $-0,1572$ & $-0,3066$ & -0.2048 \\
\hline $65 \quad 68$ & $-0,1345$ & $-0,2294$ & 0,2733 & $-0,2433$ & 0,1354 \\
\hline 6667 & 0,0275 & 0,1018 & 0,2125 & 0,0312 & $-0,0455$ \\
\hline $66 \quad 68$ & -0.1069 & -0.0308 & 0.4827 & 0,1331 & 0.2350 \\
\hline 6768 & $-0,1210$ & $-0,2307$ & 0.2704 & $-0,3190$ & 0,1698 \\
\hline
\end{tabular}




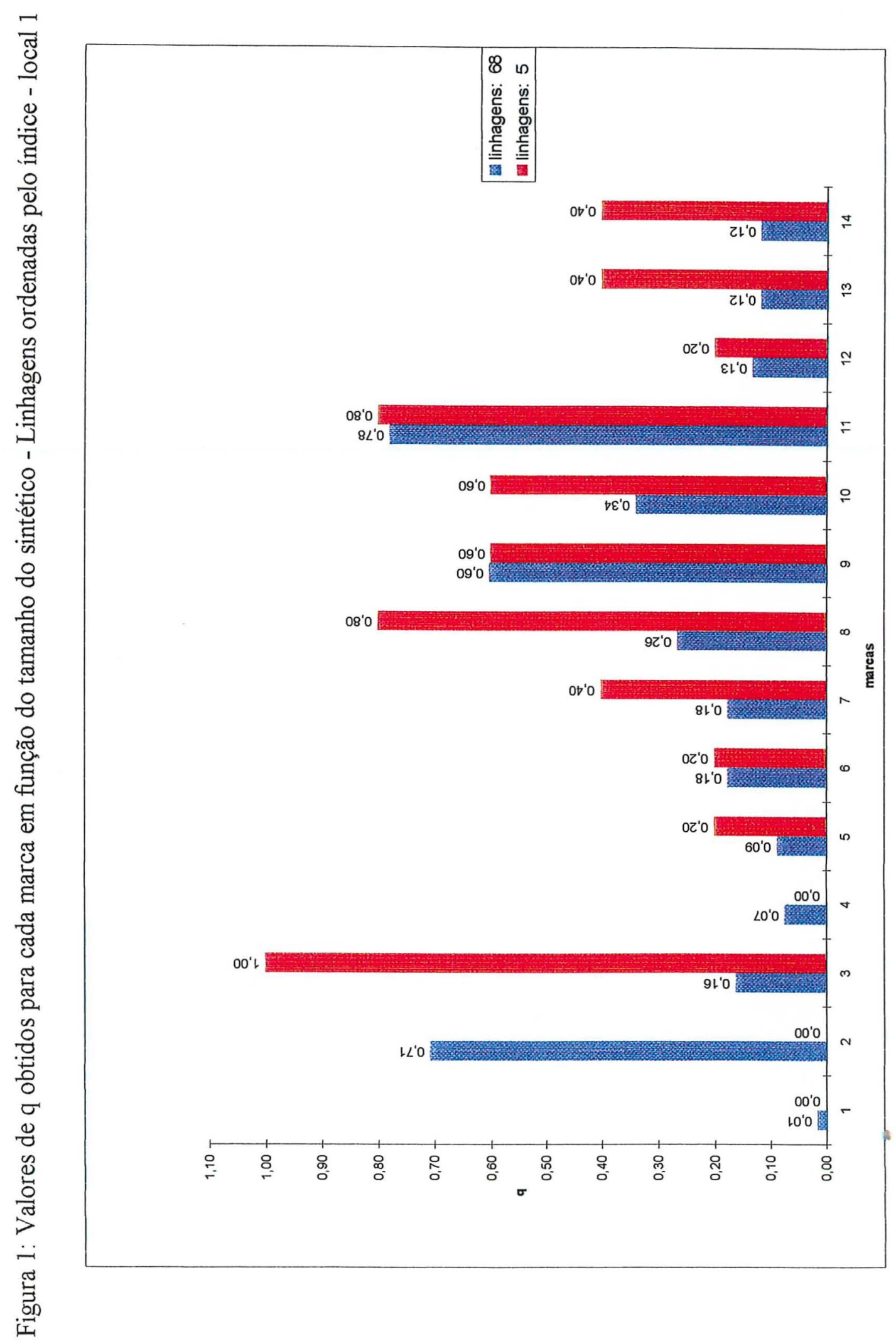




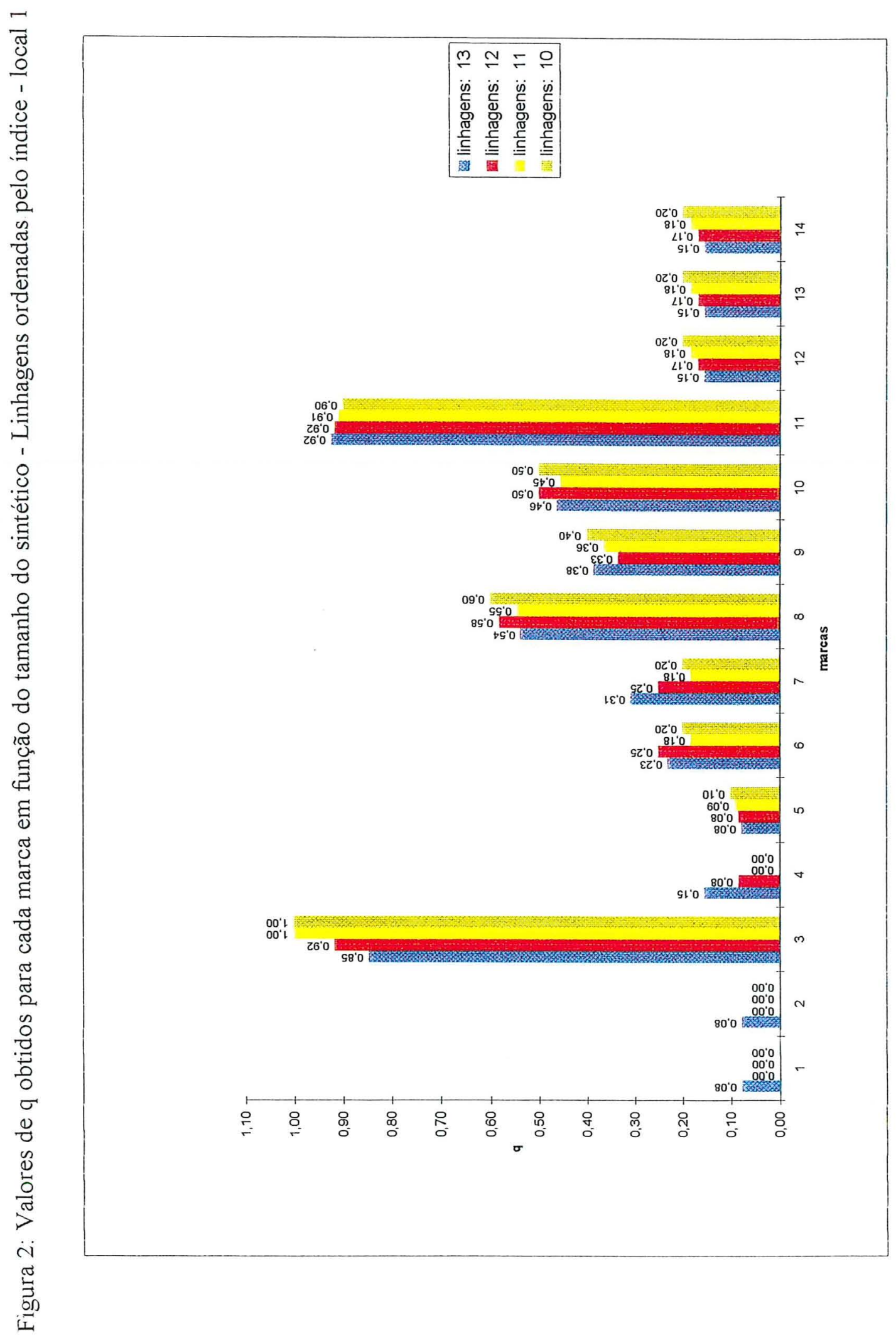




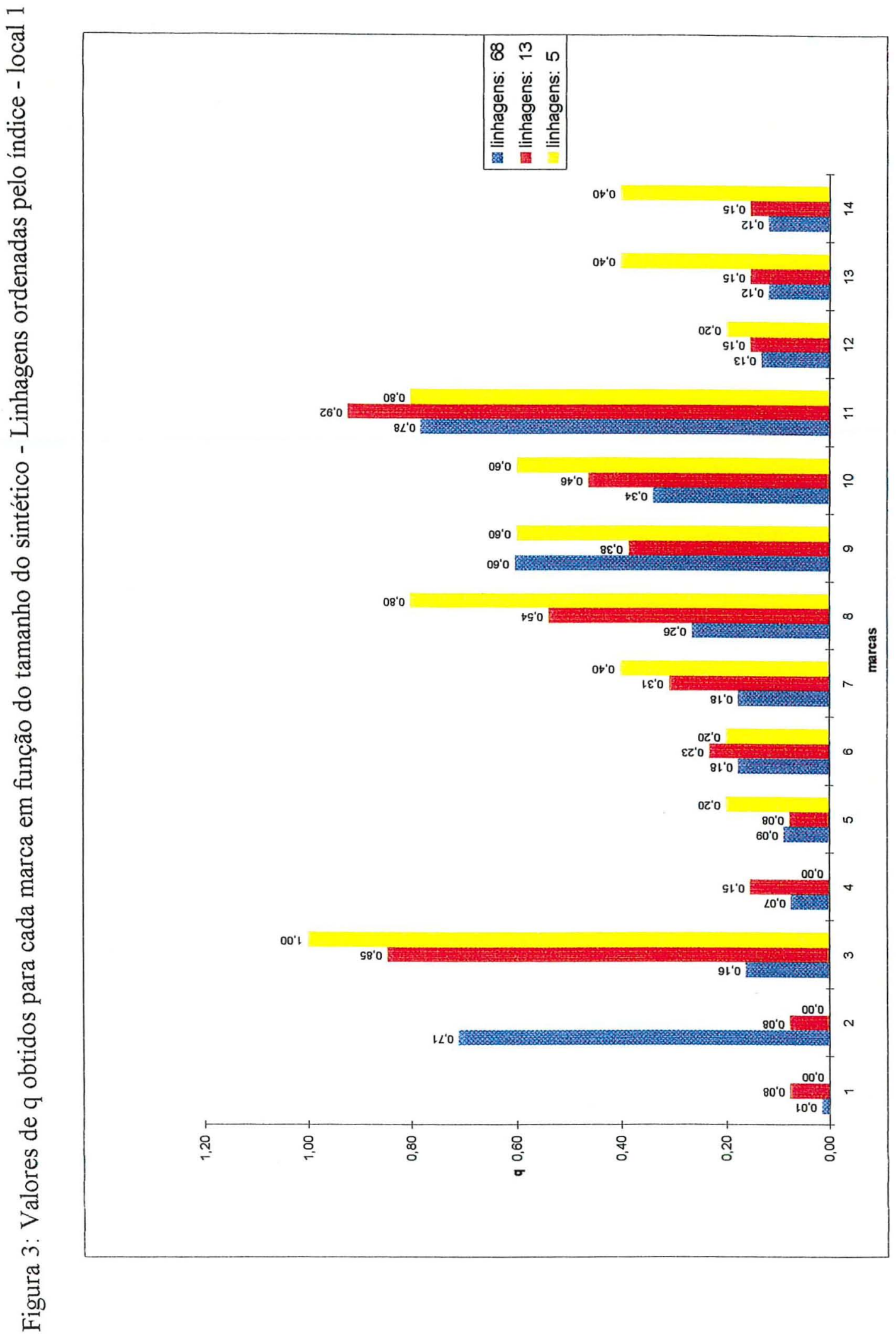




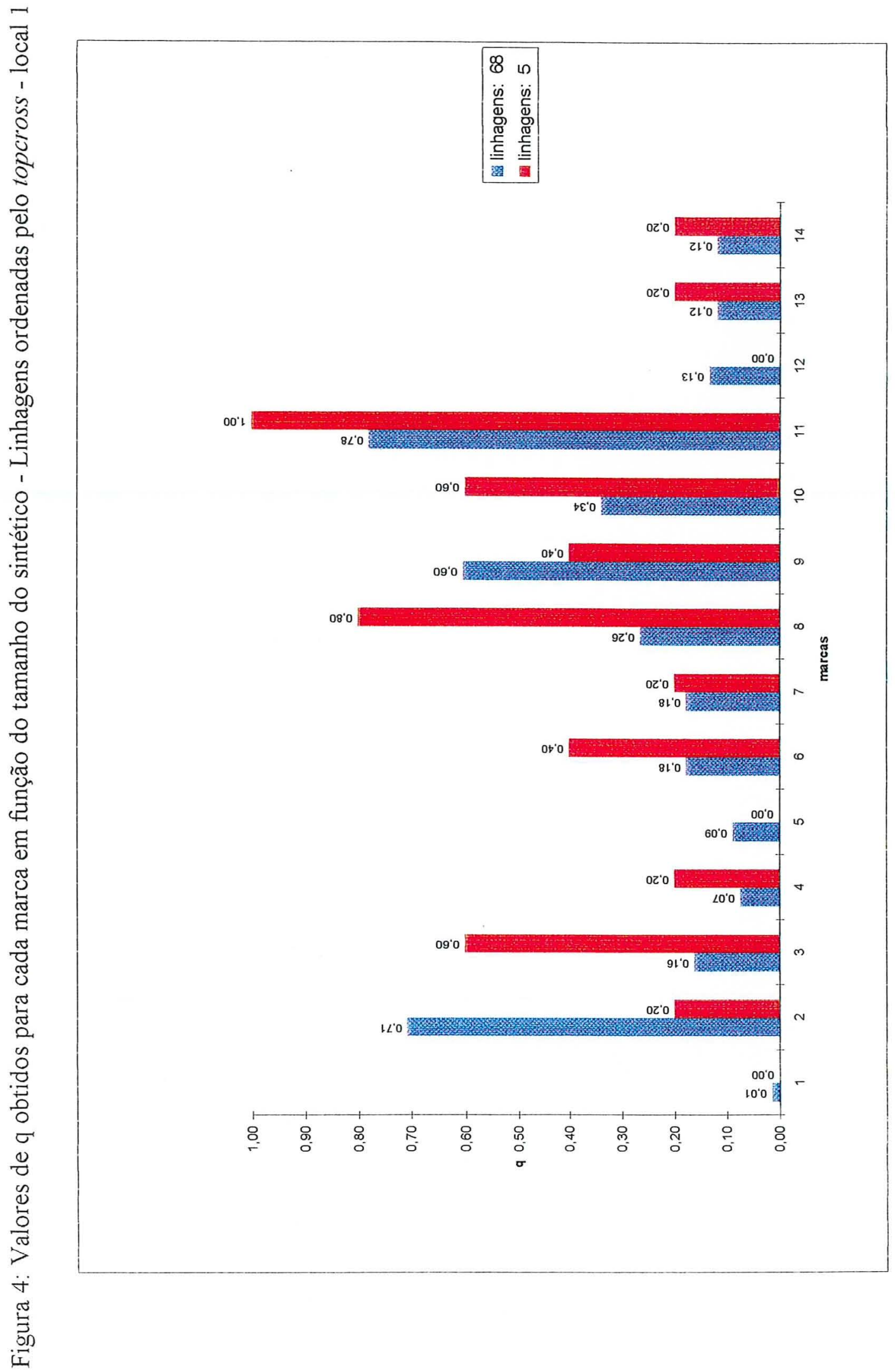




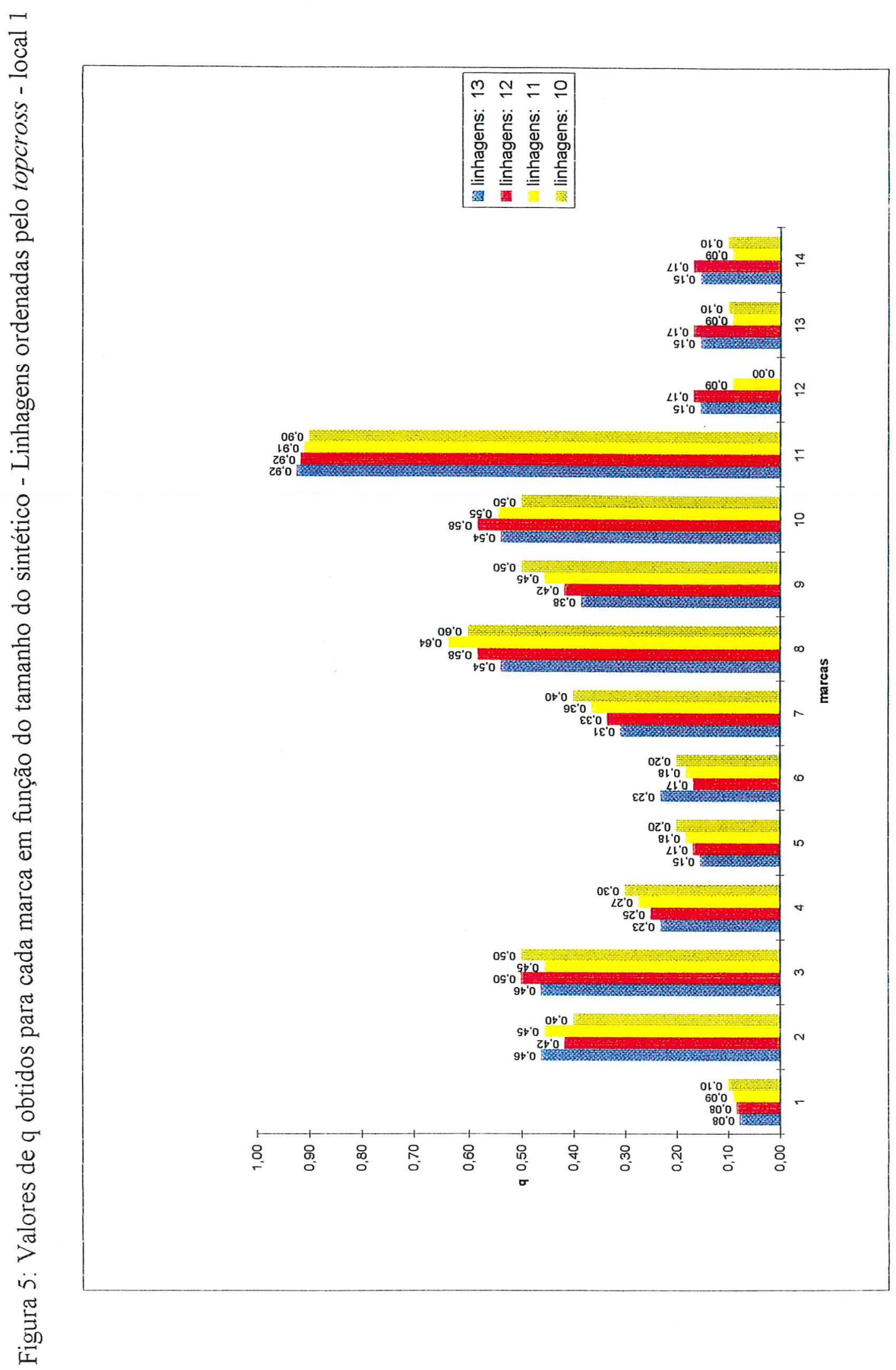




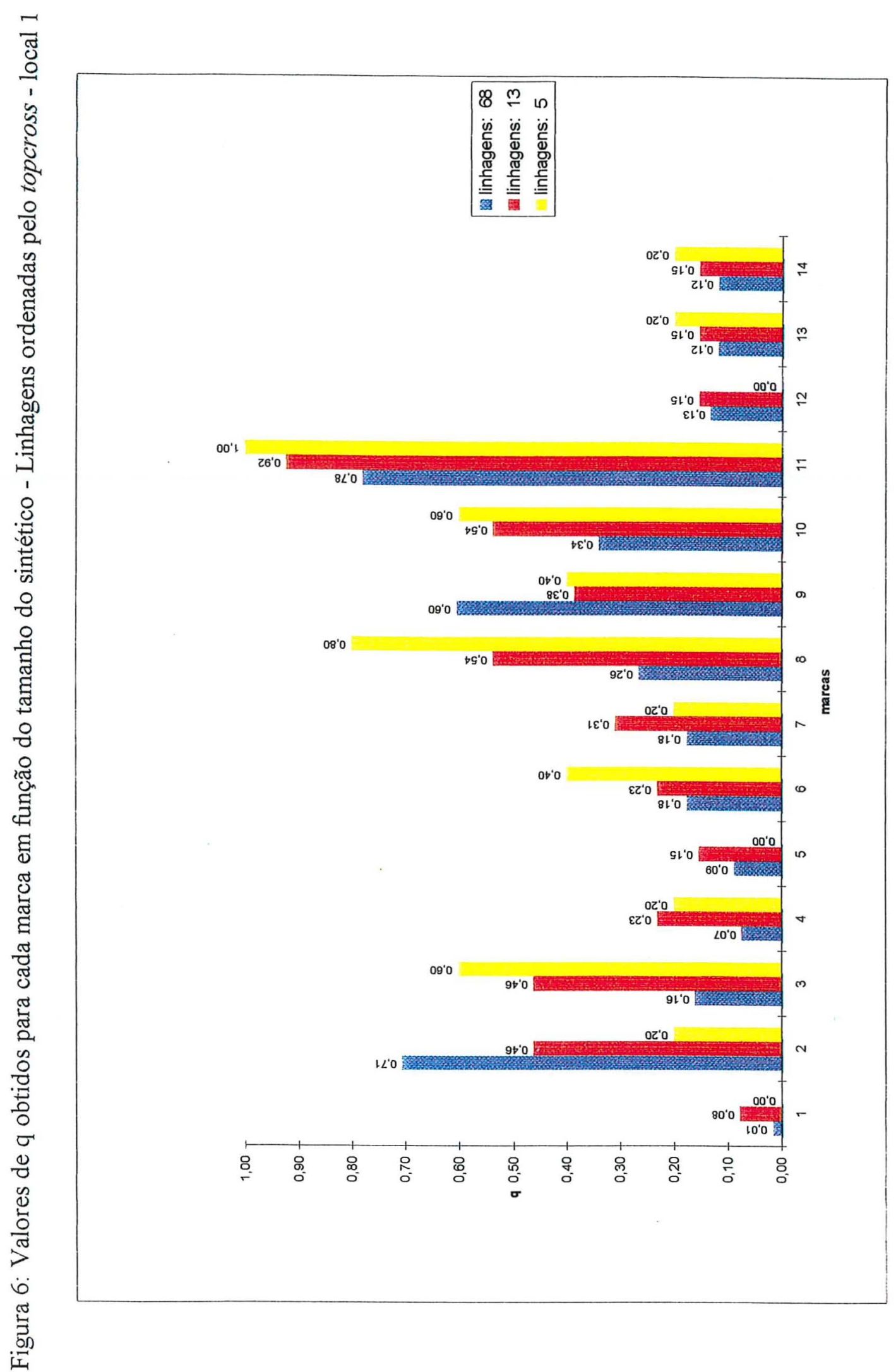




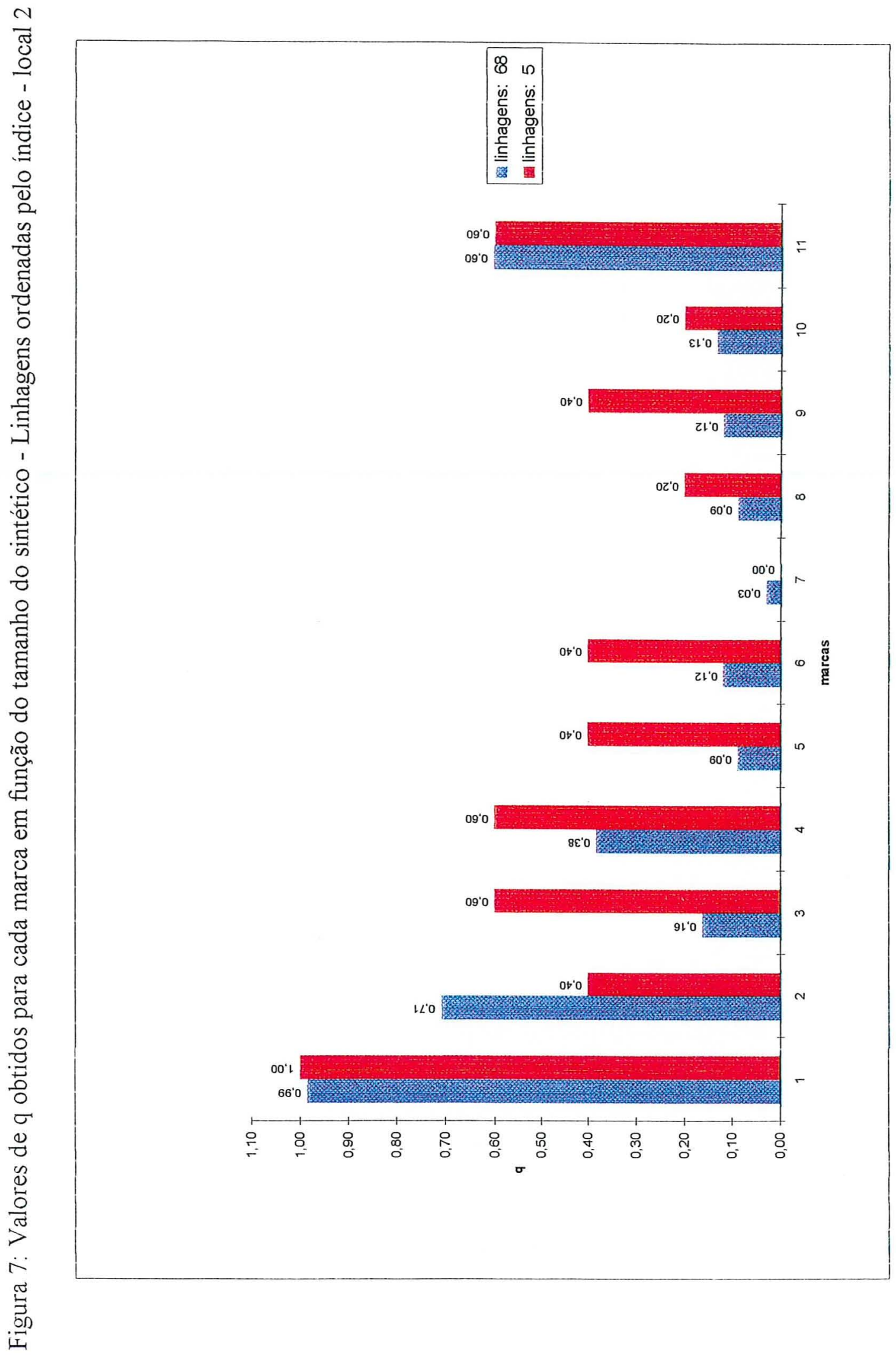




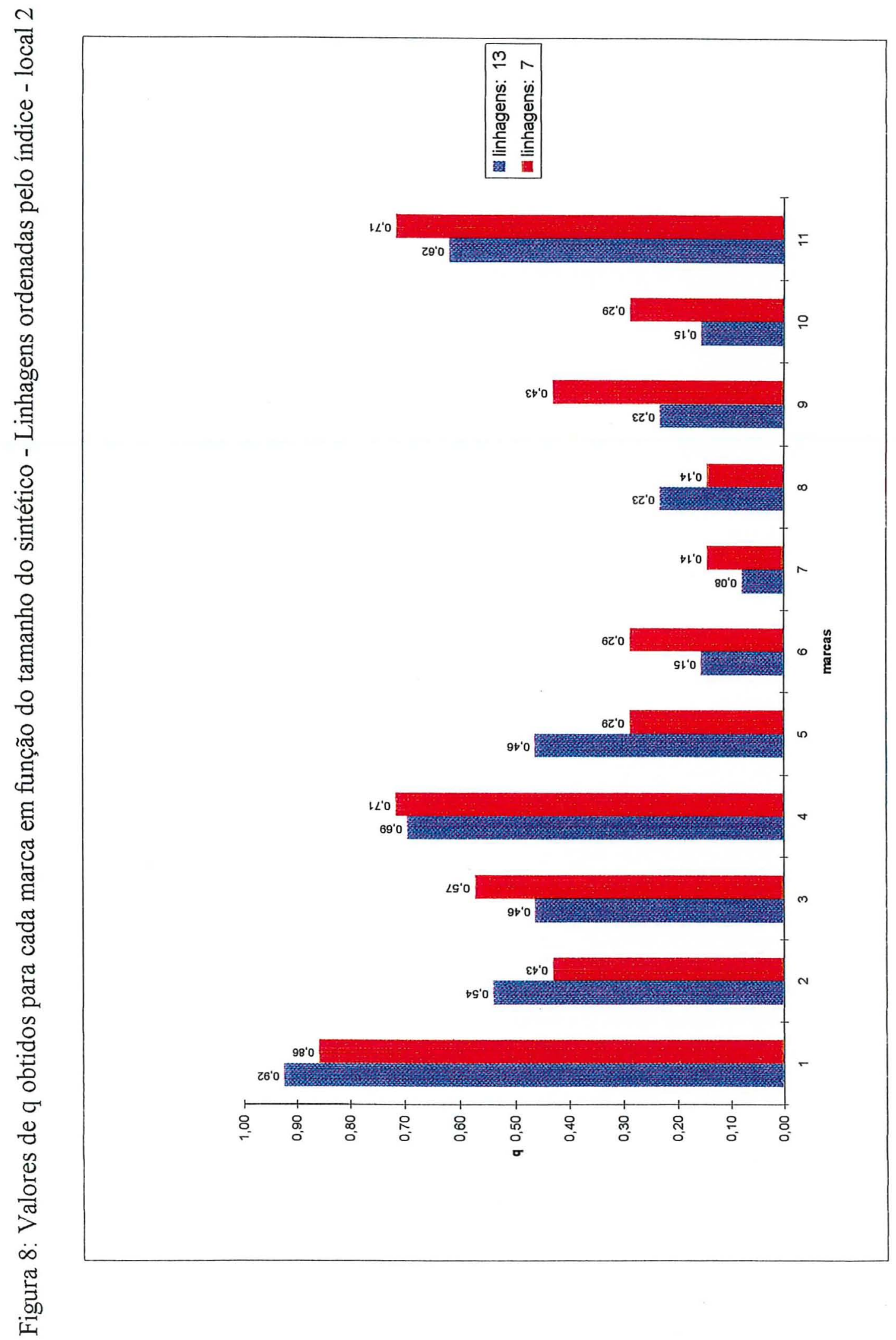




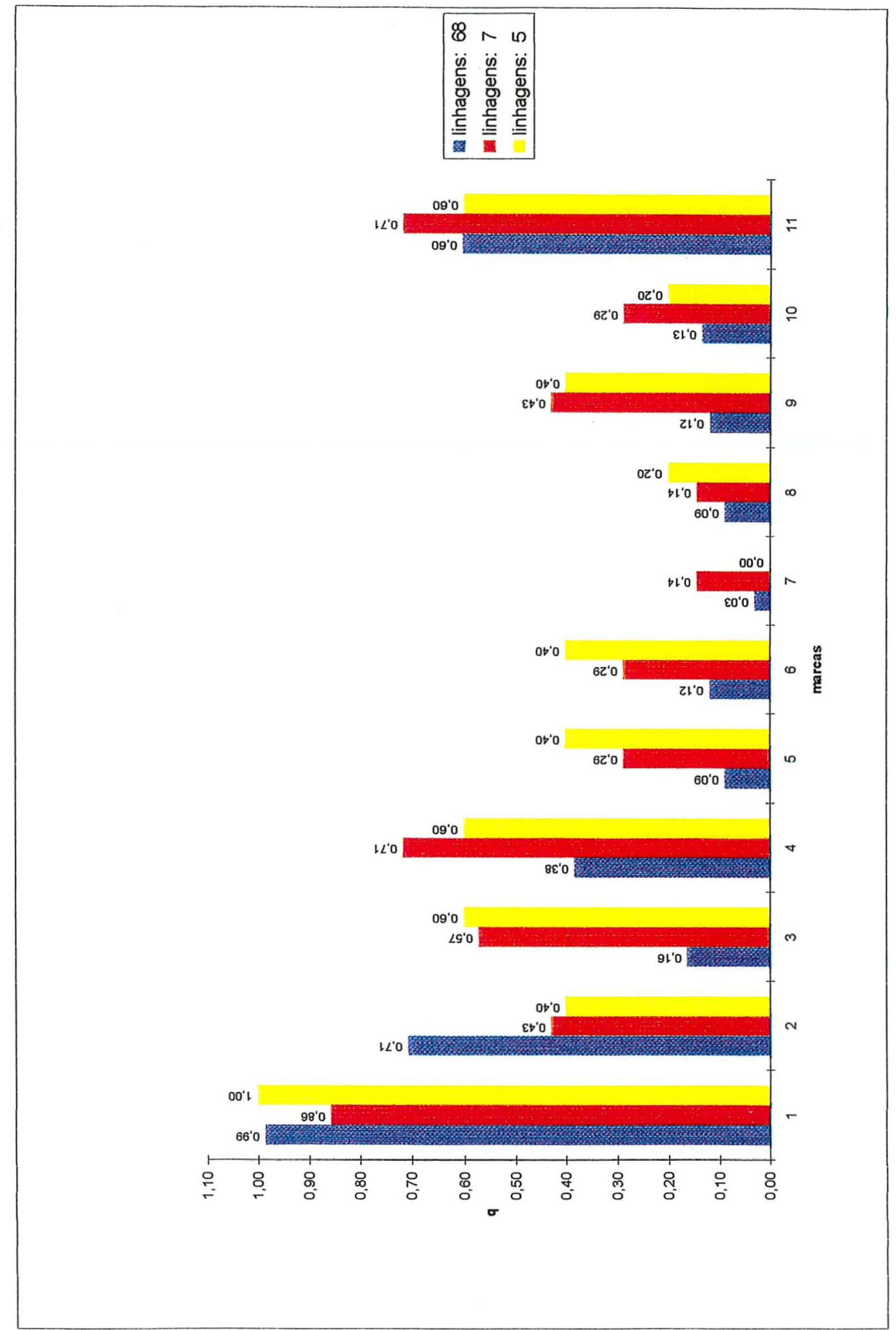

웜

茐 


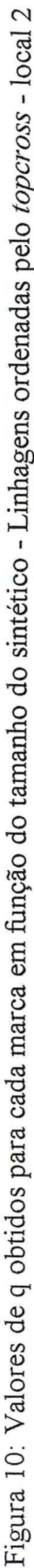
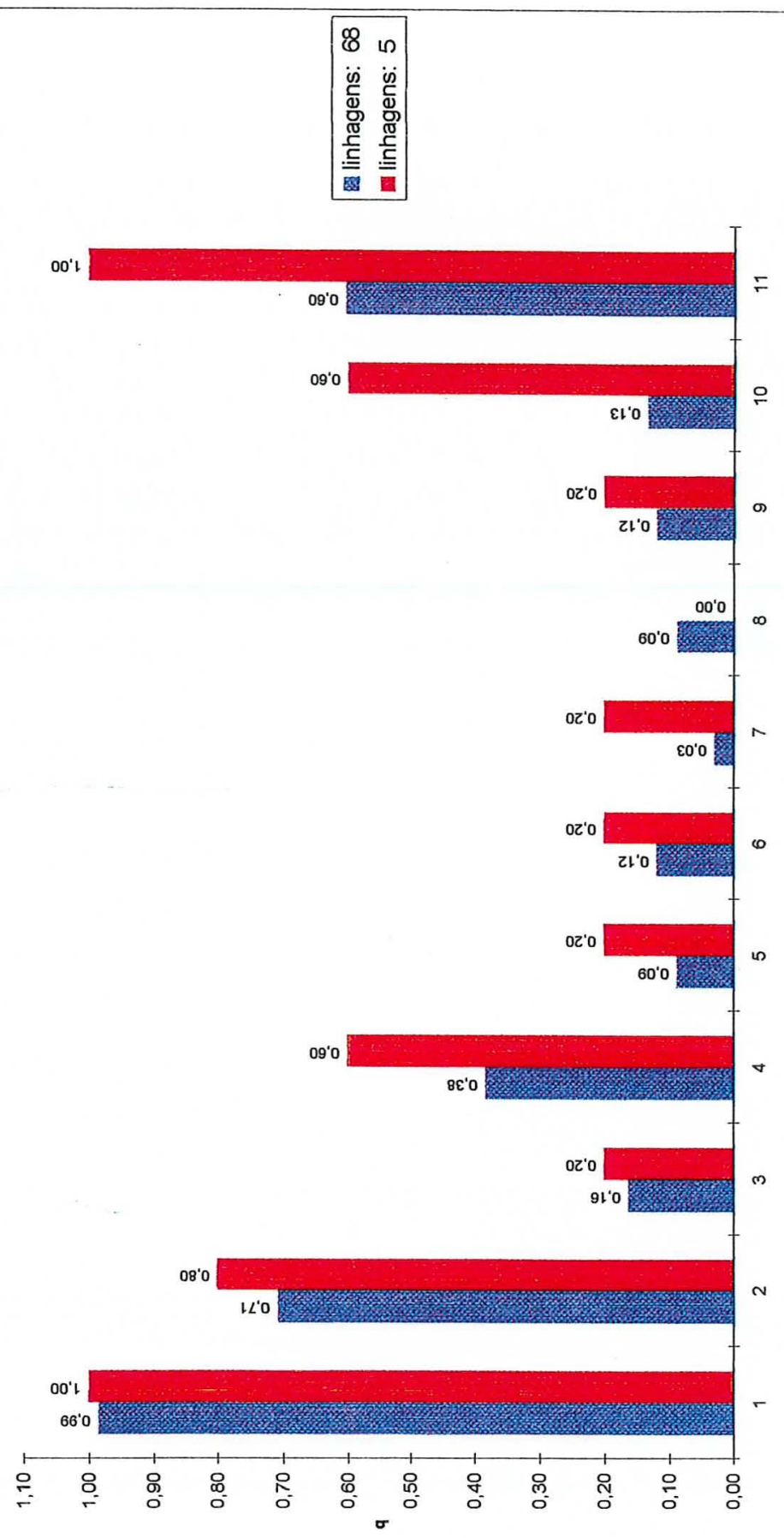


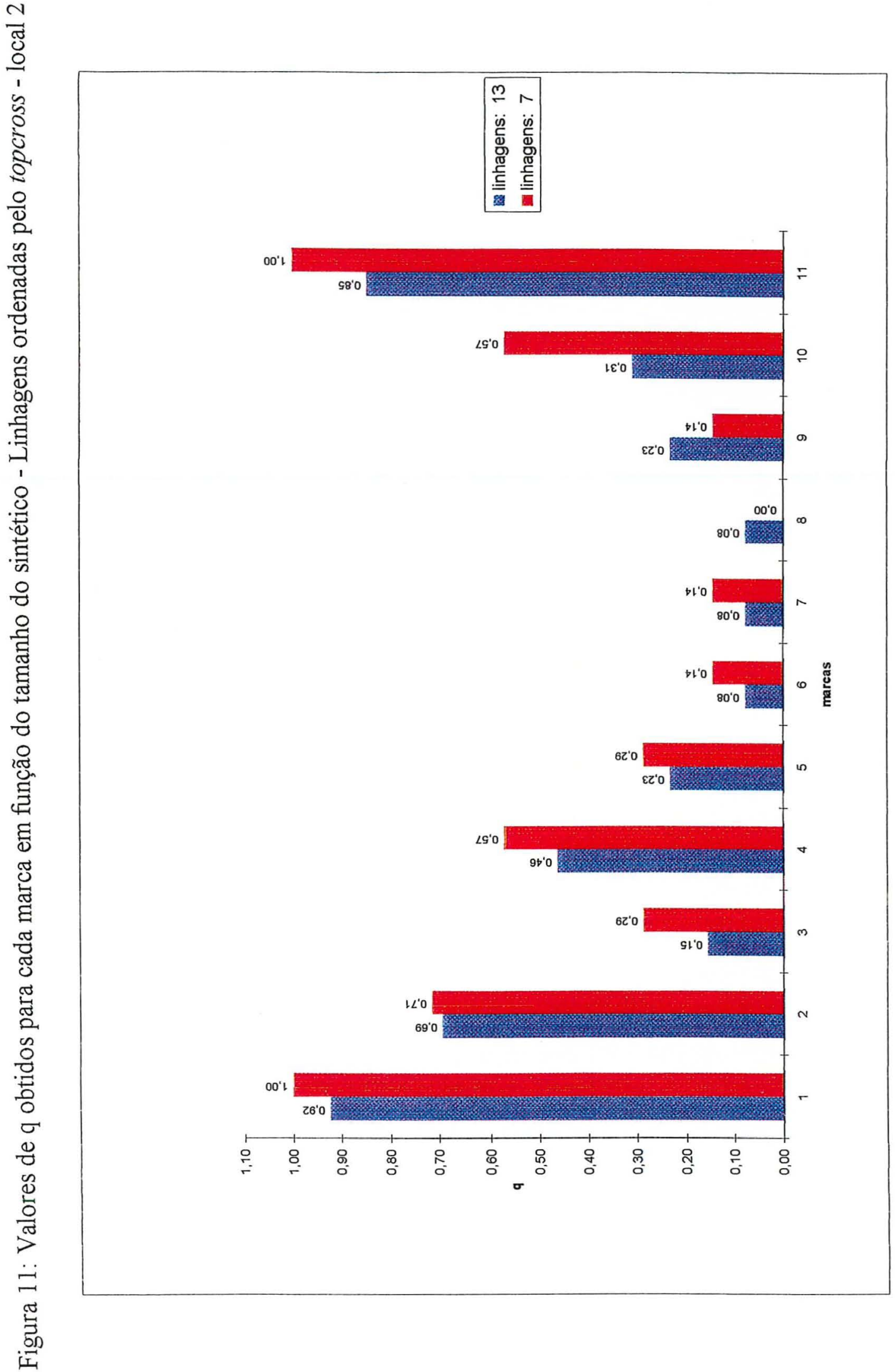




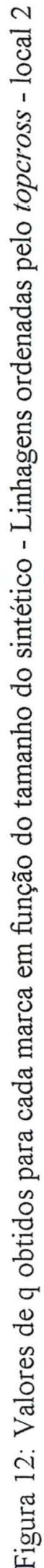




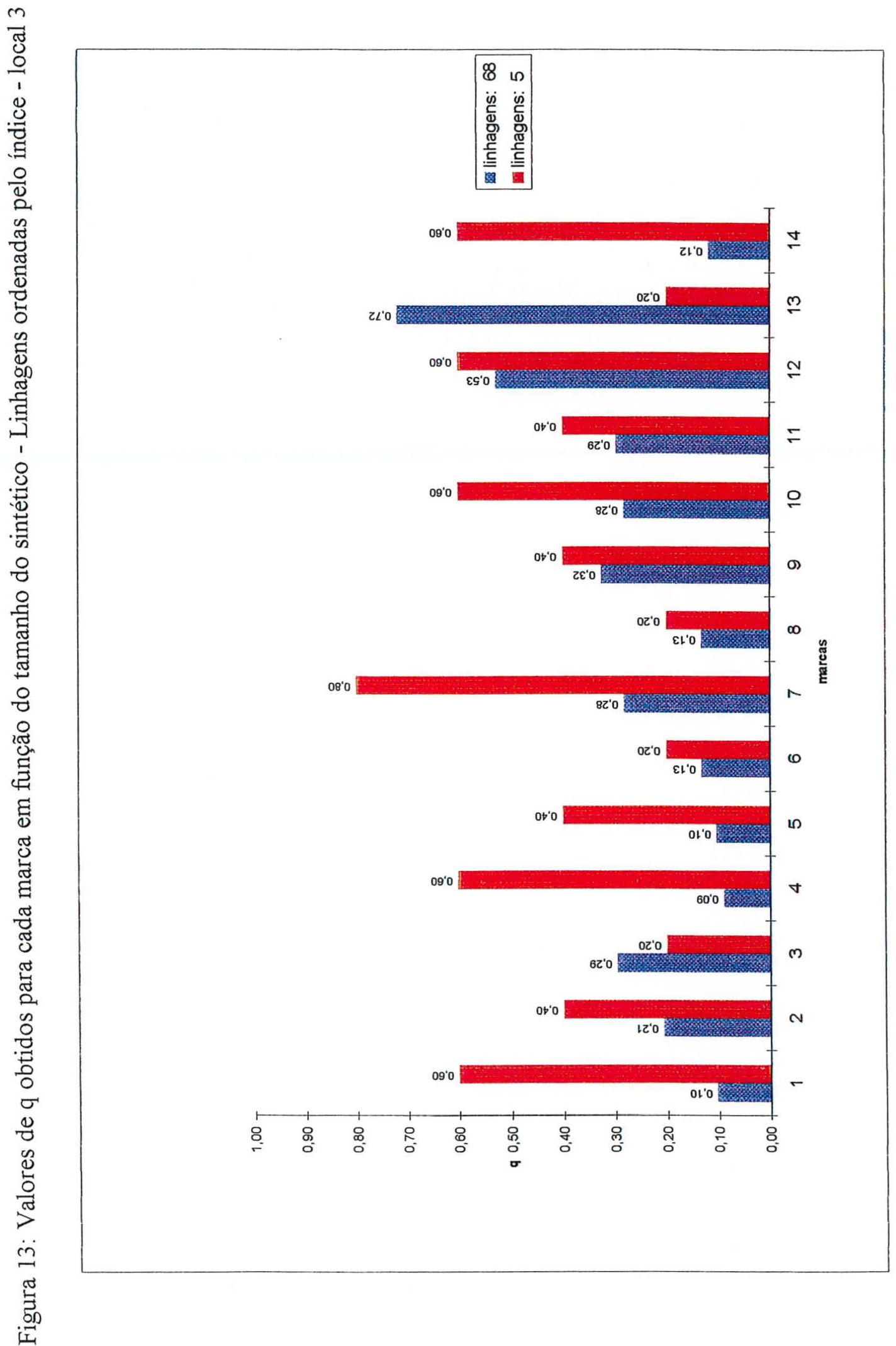




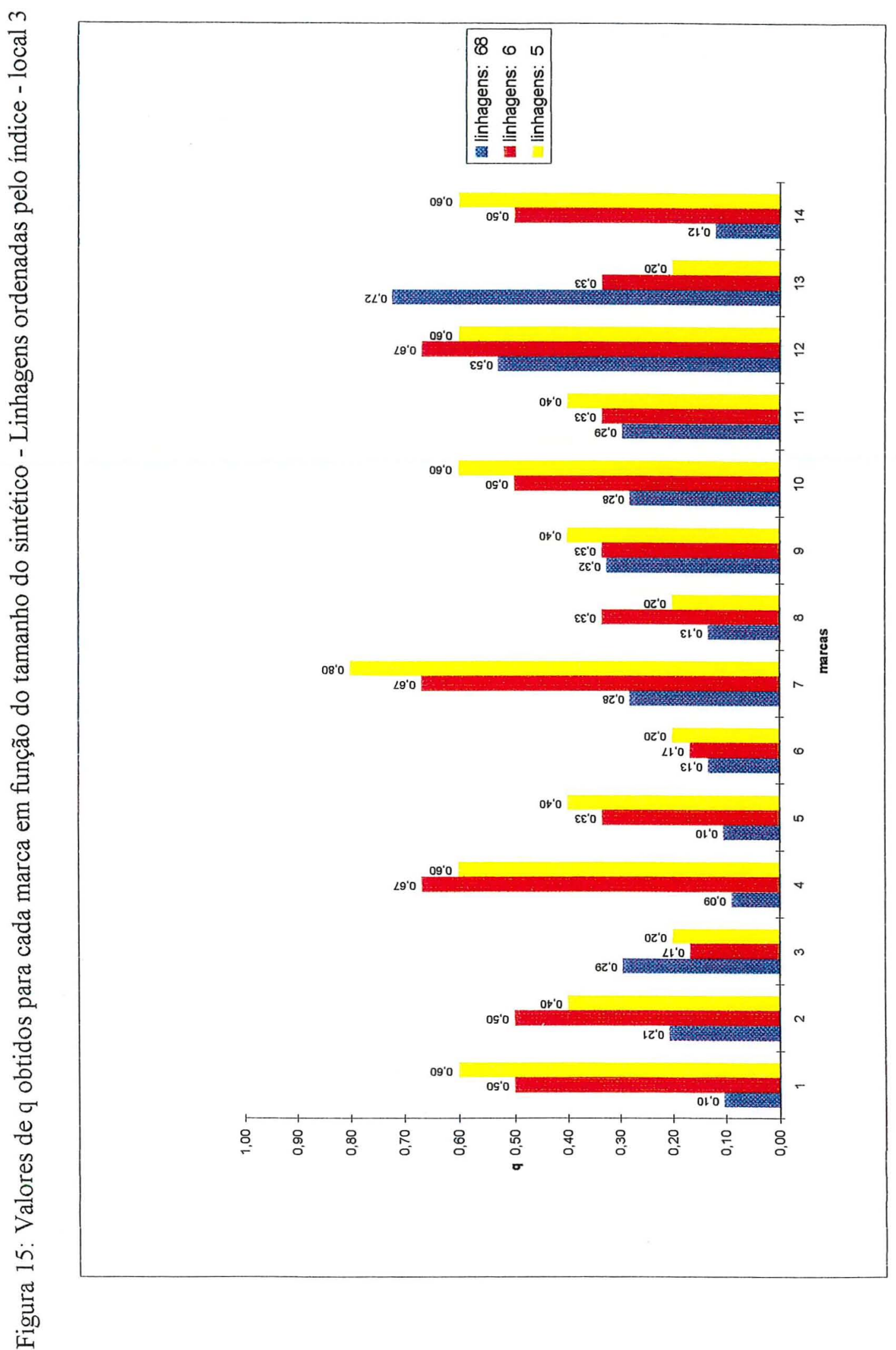




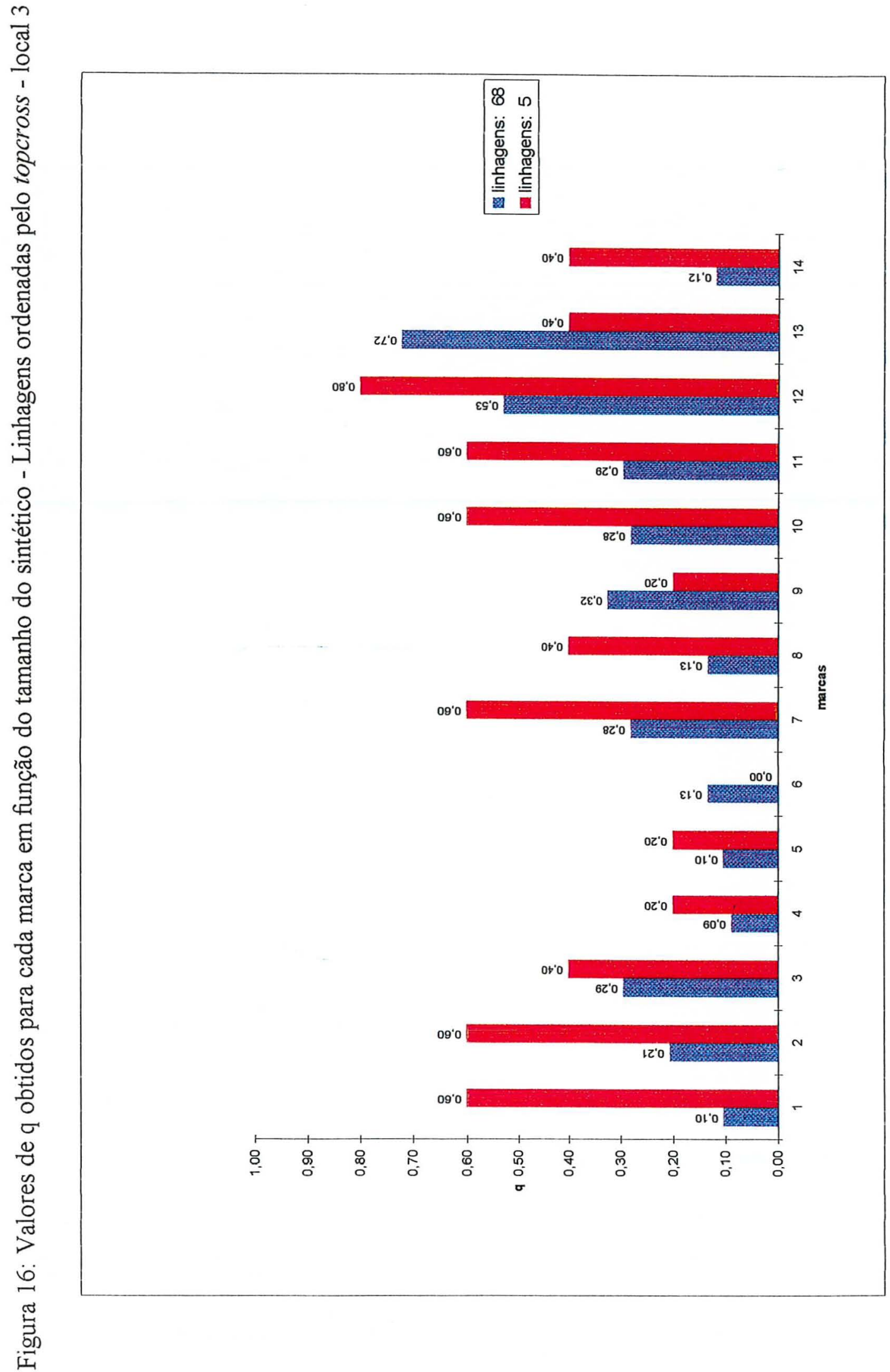




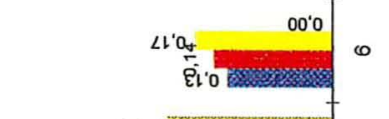




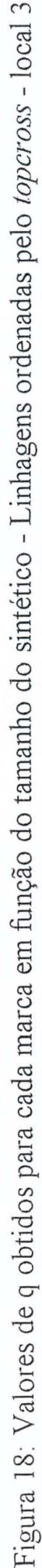
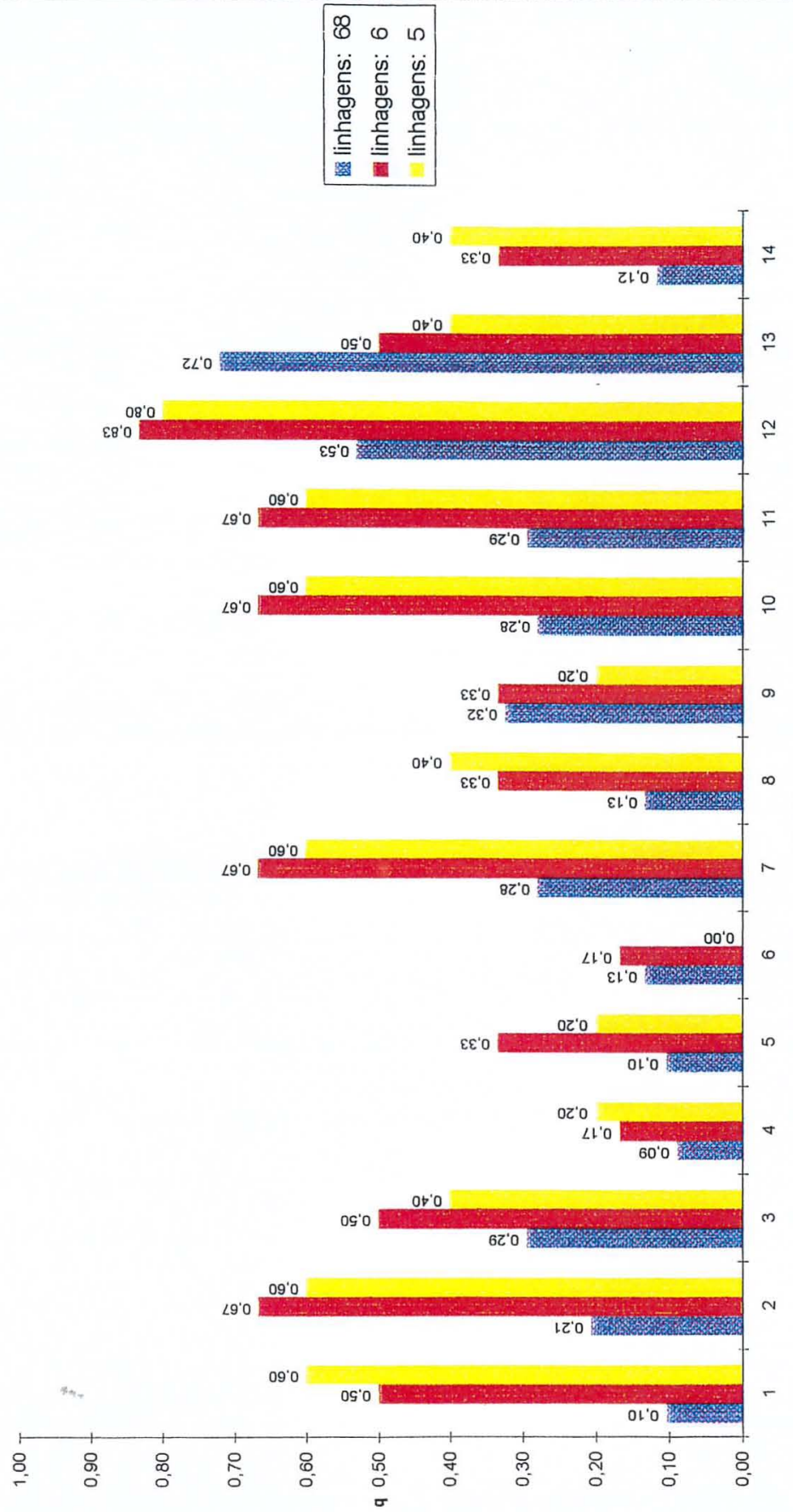


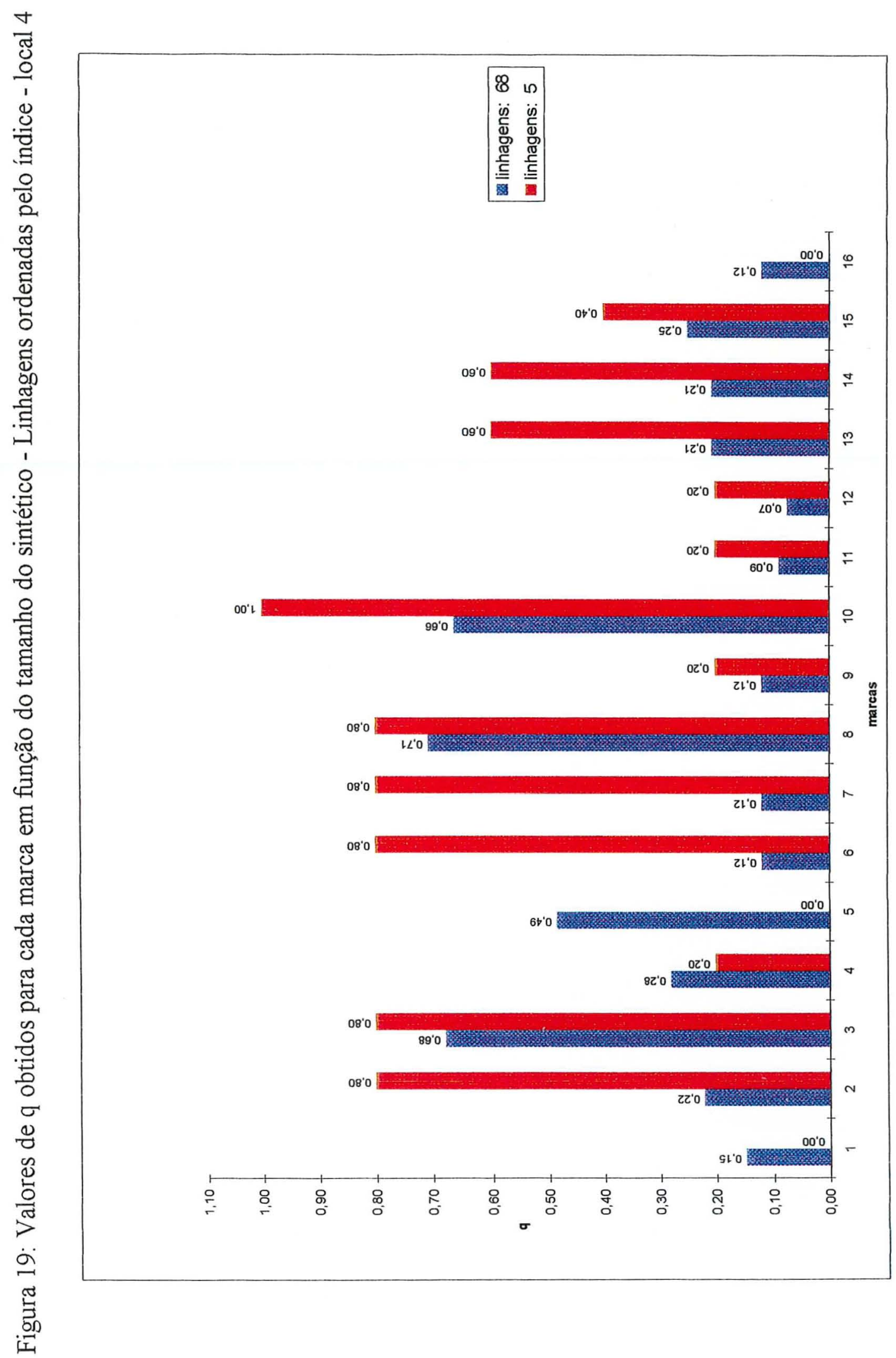




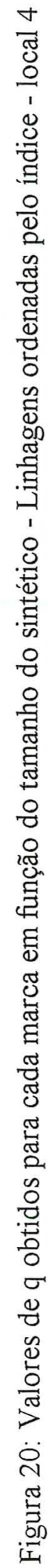

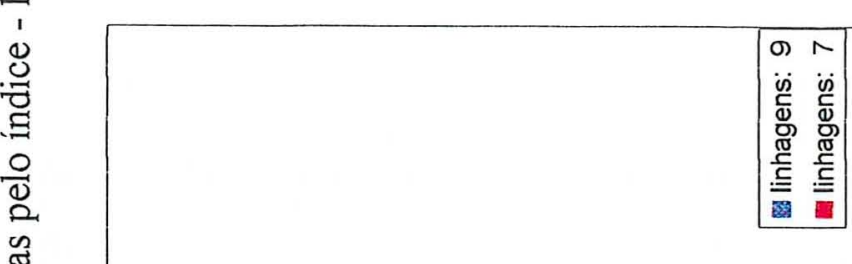

$99^{\prime} 0$ 


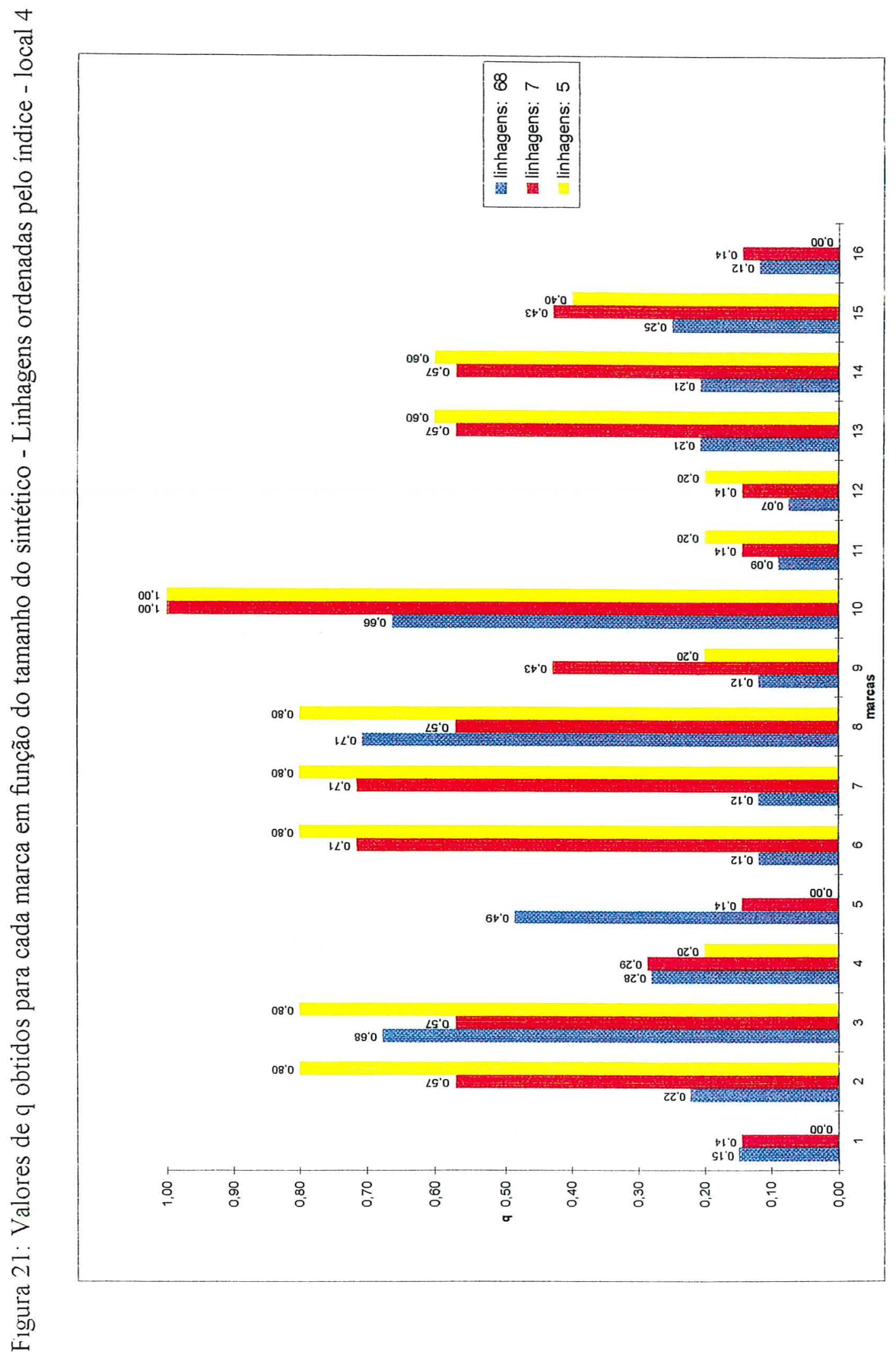




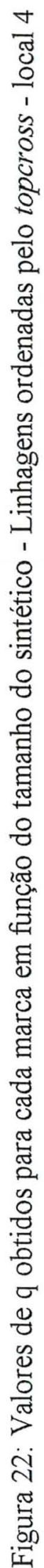
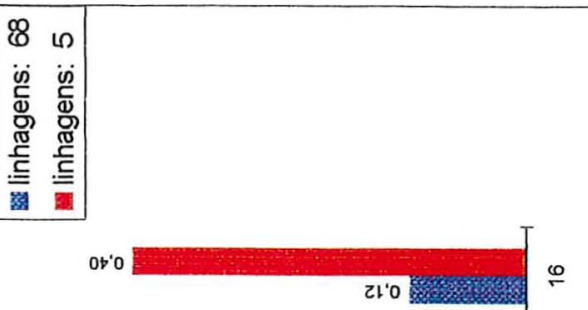
$00^{\circ}$

s乙'0
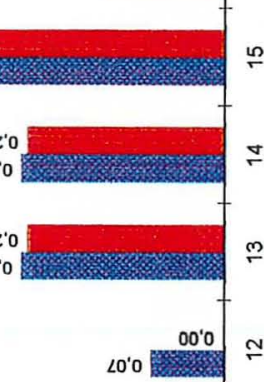

600 \%
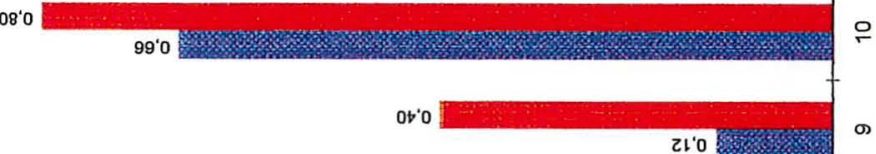

$08^{\circ}$
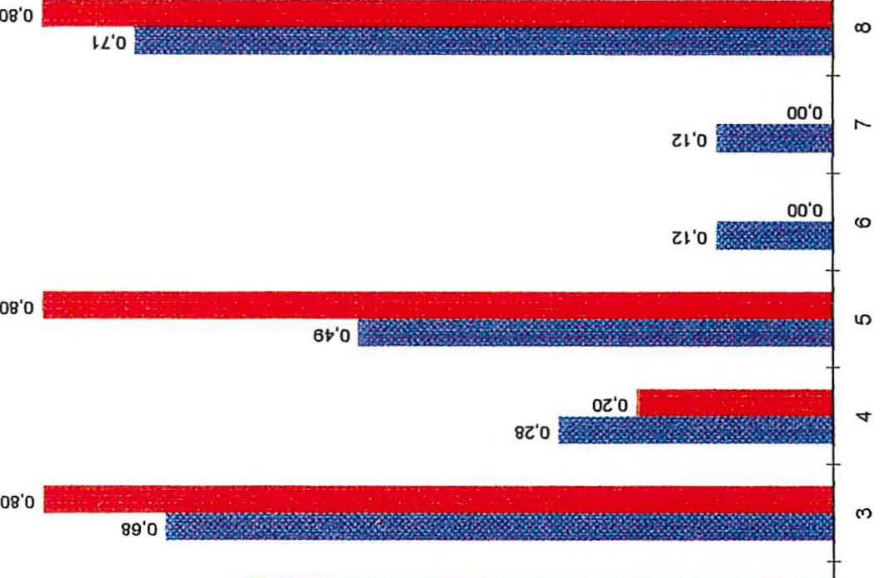

$09^{\circ} 0$

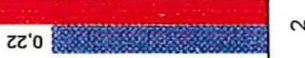

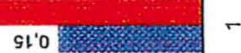

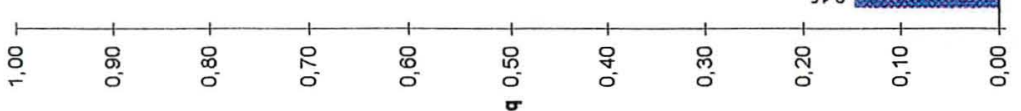




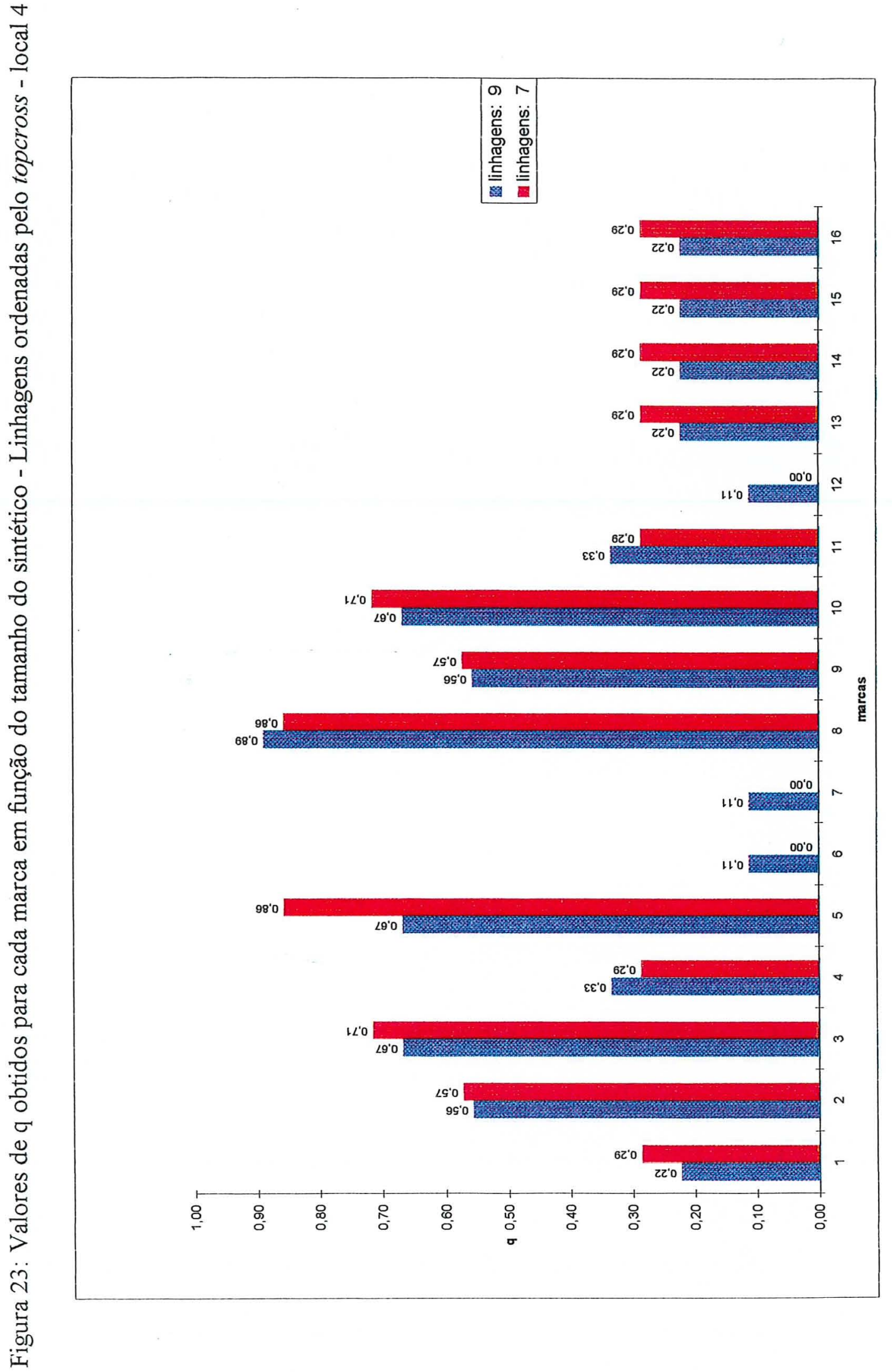




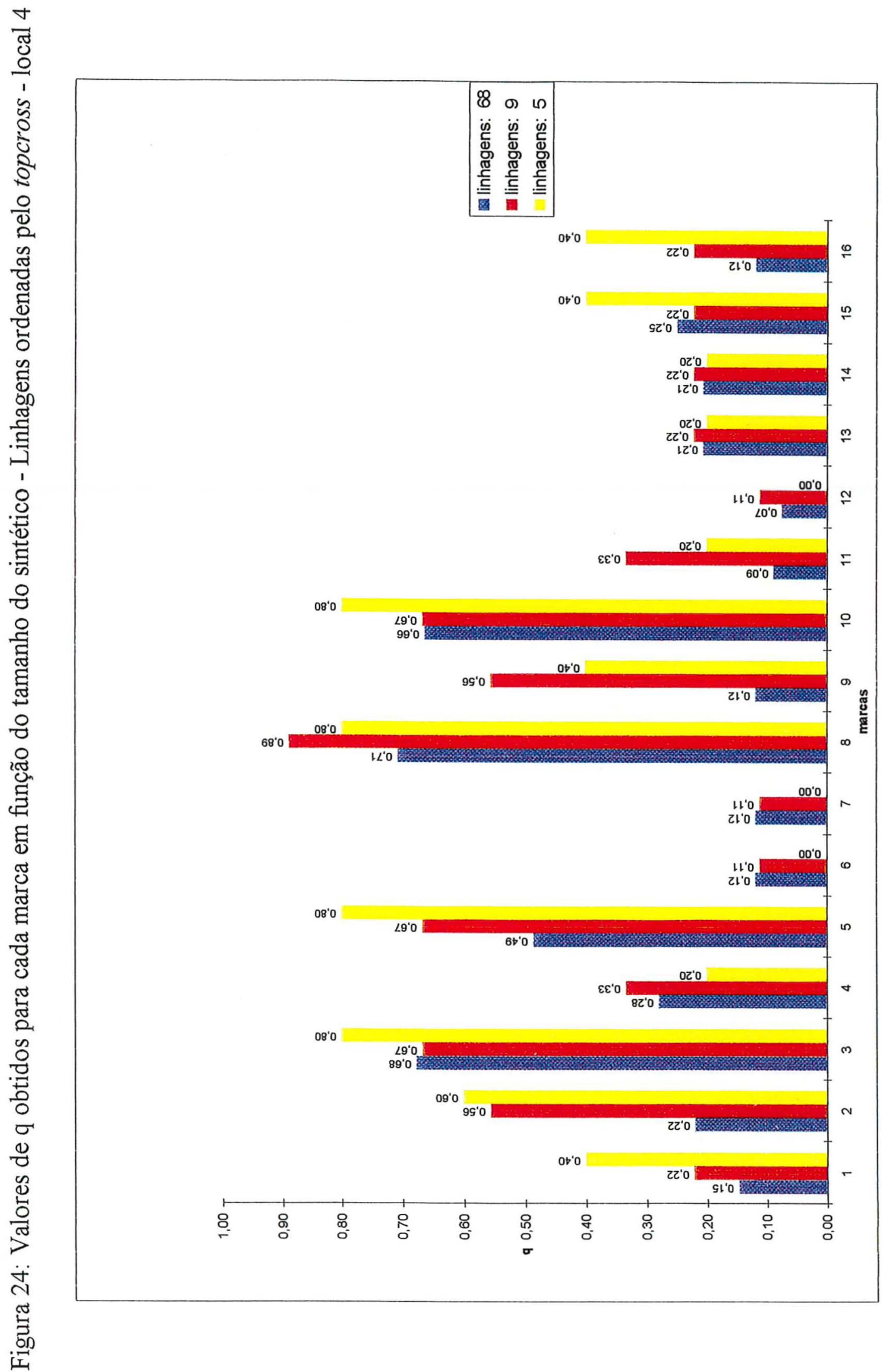

